\title{
Ecological and socio-economic effects of industrial oil palm plantations in Southwest Cameroon
}

\author{
Dissertation \\ for the award of the degree \\ "Doctor of Philosophy" Ph.D. Division of Mathematics and Natural Sciences \\ of the Georg-August-Universität Göttingen \\ within the doctoral program Biodiversity and Ecology \\ of the Georg-August University School of Science (GAUSS) \\ submitted by \\ Denis Kupsch
}

from Magdeburg, Germany

Göttingen, 2019 
Thesis Committee:

Prof. Dr. Matthias Waltert, Conservation Biology/Workgroup on Endangered Species, Johann-Friedrich-Blumenbach Institute of Zoology and Anthropology

Prof. i.R. Dr. Gerhard Gerold, Physical Geography, Institute of Geography

Prof. Dr. Eckhard W. Heymann, Sociobiology/Anthropology, Johann-Friedrich-Blumenbach Institute of Zoology and Anthropology

Member of the Examination Board:

Reviewer: Prof. Dr. Matthias Waltert, Conservation Biology/Workgroup on Endangered Species, Johann-Friedrich-Blumenbach Institute of Zoology and Anthropology

Second Reviewer: Prof. i.R. Dr. Gerhard Gerold, Physical Geography, Institute of Geography

Further Members of the Examination Board:

PD Dr. Sven Bradler, Animal Evolution and Biodiversity, Johann-Friedrich-Blumenbach Institute of Zoology and Anthropology

Prof. Dr. Eckhard W. Heymann, Sociobiology/Anthropology, Johann-Friedrich-Blumenbach Institute of Zoology and Anthropology

Prof. Dr. Teja Tscharntke, Agroecology, Department of Crop Sciences

Prof. Dr. Kerstin Wiegand, Ecosystem Modelling, Büsgen-Institut

Date of the oral examination: 30 September 2019 




\section{Table of contents}

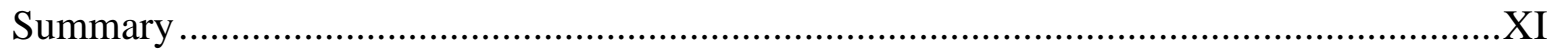

\section{PART I - GENERAL INTRODUCTION}

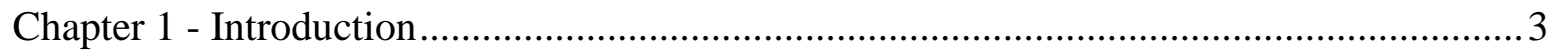

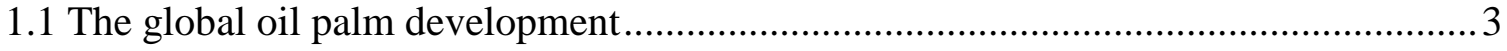

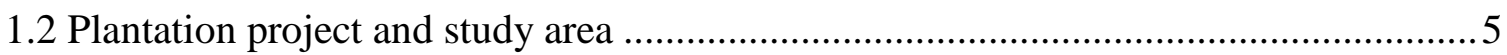

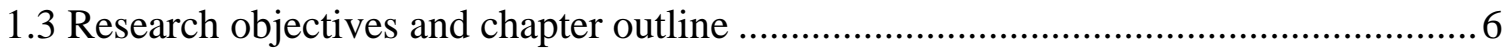

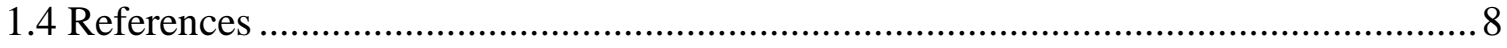

PART II - THE CONSERVATION STATUS OF WILDLIFE IN AGROFORESTRY LANDSCAPES IN SOUTHWEST CAMEROON

Chapter 2 - The status of large mammals in Southwest Cameroon: How threatened wildlife disappears from an Afrotropical forest biodiversity hotspot .......................................... 15

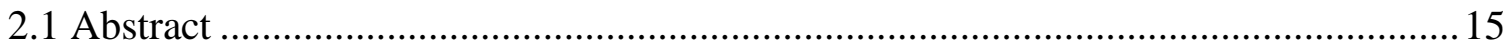

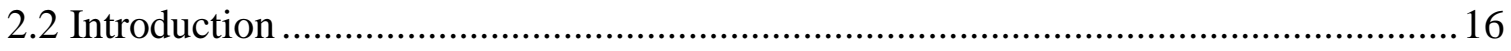

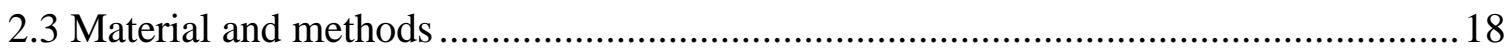

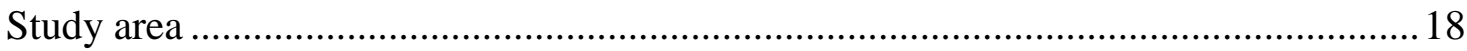

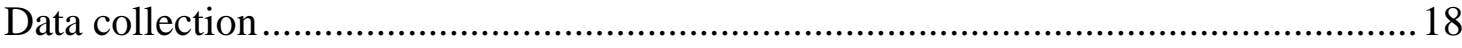

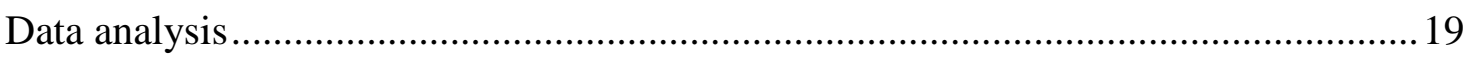

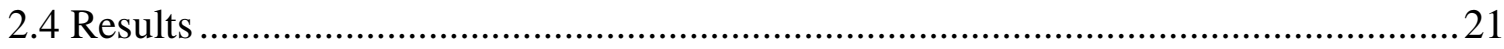

Relative mammal abundance trends from 2007 to 2014 in KNP and BMWS ..............21

Chimpanzee and elephant population estimates in 2007 and 2014 ............................ 23

Relative mammal abundances in 2014 in four survey sites........................................2 23

Parameters affecting species distribution ........................................................ 28

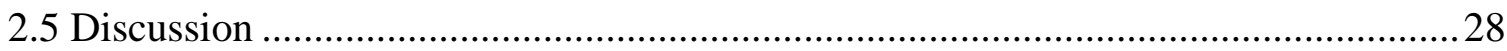

Recent large mammal abundance trends in BMWS and KNP .................................2 28

Patterns and factors of large mammal distribution in a multi-use landscape context ...29

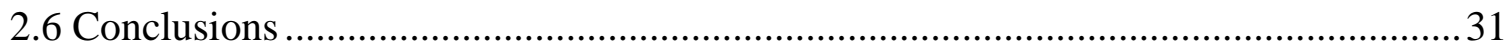

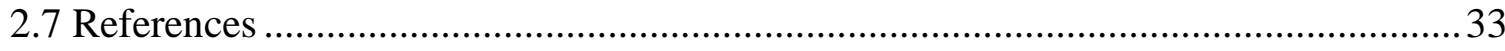

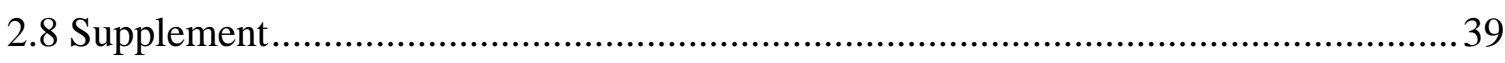




\section{PART III - EFFECTS OF AGRO-INDUSTRY AND OTHER LAND USES ON BIODIVERSITY IN}

\section{SOUTHWEST CAMEROON}

Chapter 3 - High critical forest habitat thresholds of native bird communities in

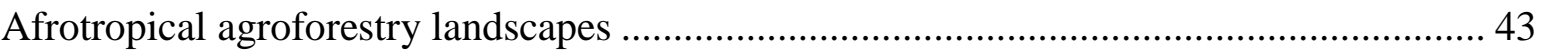

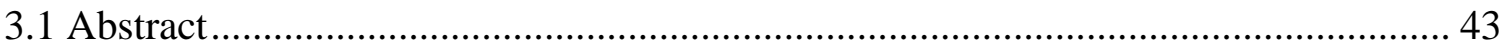

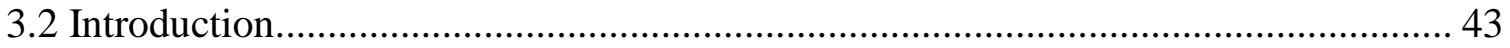

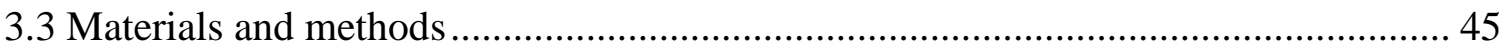

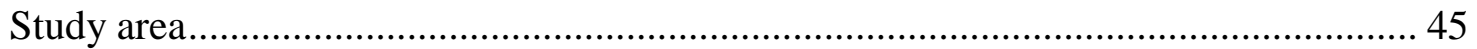

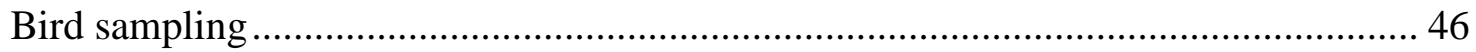

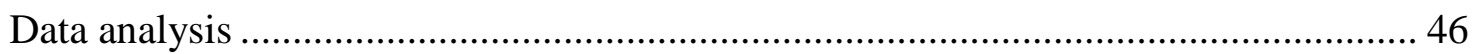

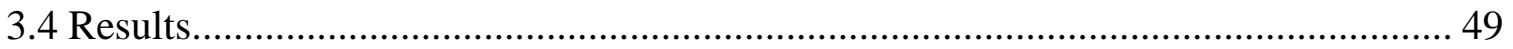

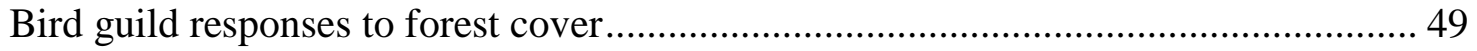

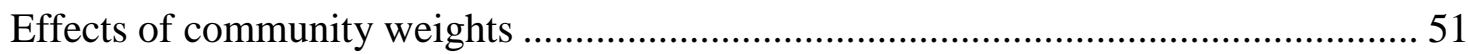

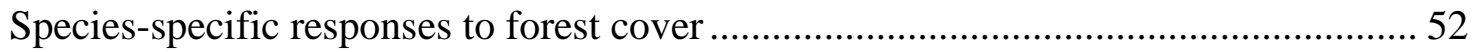

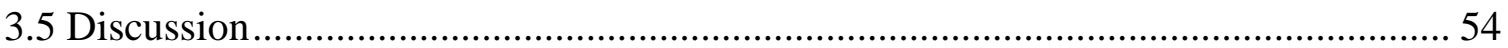

Differential responses to changes in forest cover .................................................... 54

Bird species composition at intermediate deforestation ........................................ 56

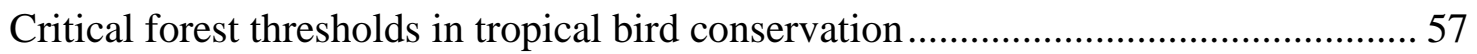

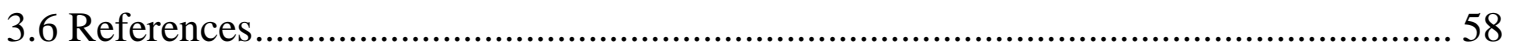

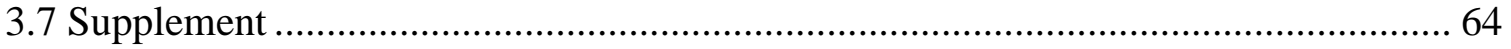

Chapter 4 - Extinction thresholds and negative responses of Afrotropical ant-following birds to forest cover loss in oil palm and agroforestry landscapes .................................... 83

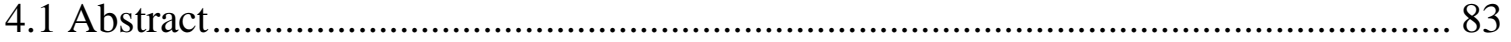

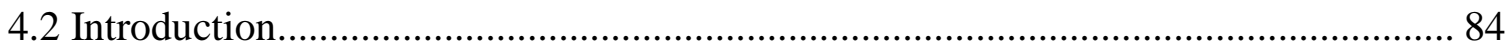

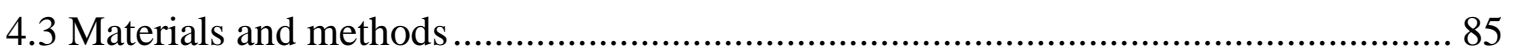

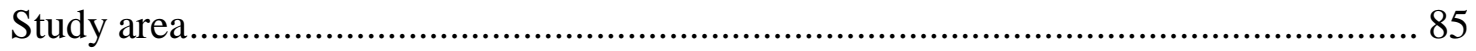

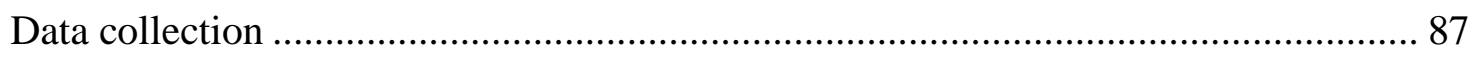

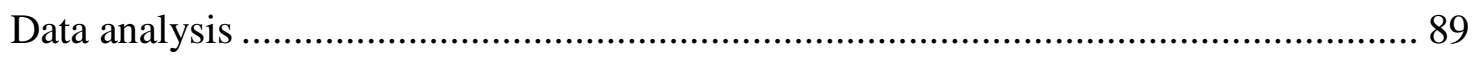

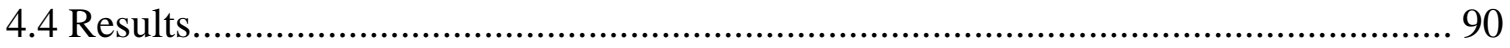

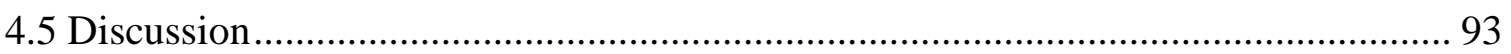




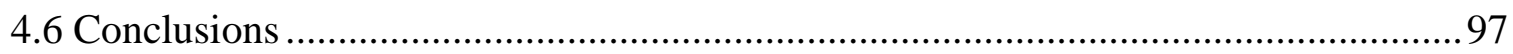

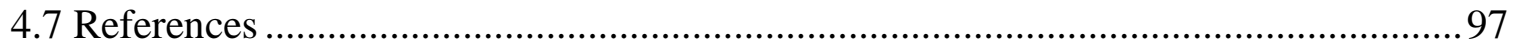

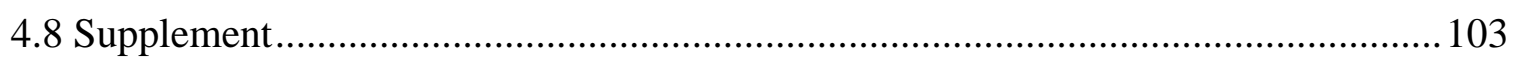

Chapter 5 - Congo Grey Parrot Psittacus erithacus densities in oil palm plantation, agroforestry mosaic and protected forest in SW Cameroon ........................................... 107

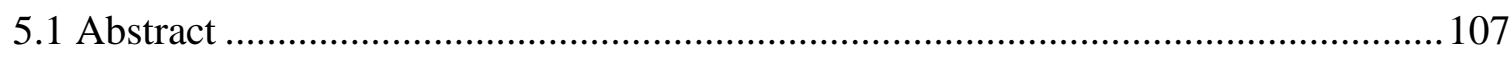

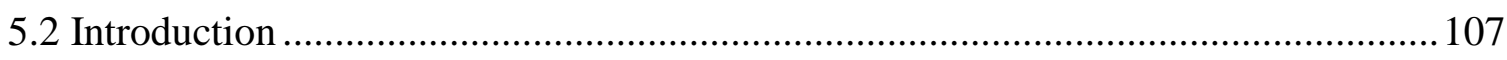

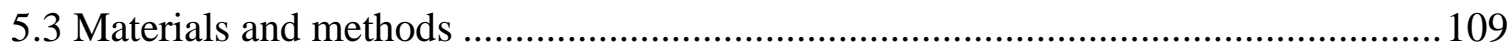

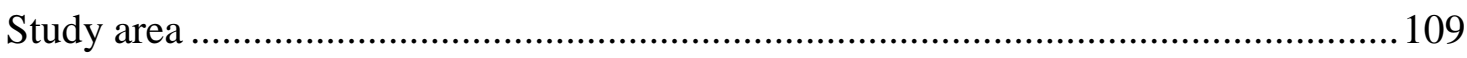

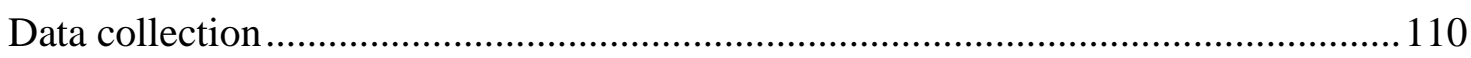

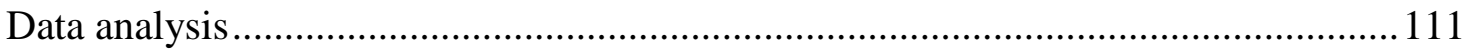

Field observations on feeding, breeding and roosting sites.................................... 112

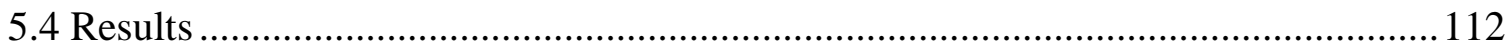

Parrot encounter metrics and density estimation ................................................. 112

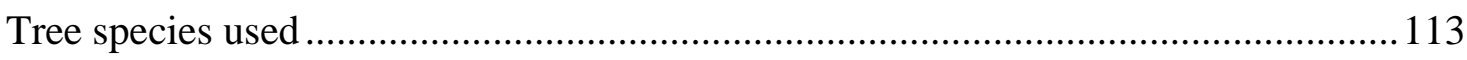

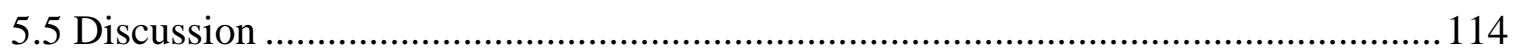

Spatial and temporal variation in parrot density estimates..................................... 114

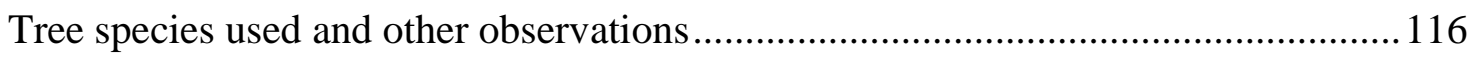

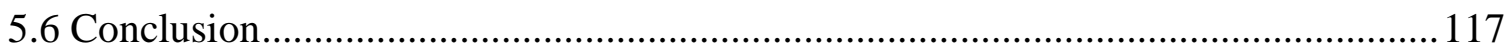

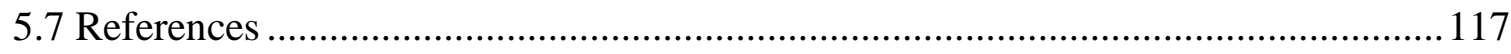

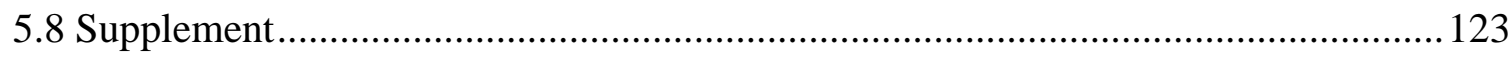

PART IV - DIRECT AND INDIRECT EFFECTS OF AGRICULTURAL INTENSIFICATION ON RURAL LIVELIHOODS IN SOUTHWEST CAMEROON

Chapter 6 - Income generation and expenditures of rural households in Afrotropical agroforestry systems and oil palm plantations .......................................................... 127

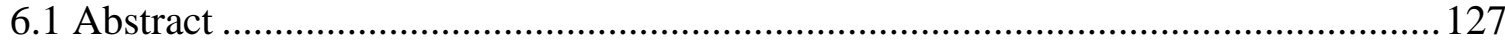

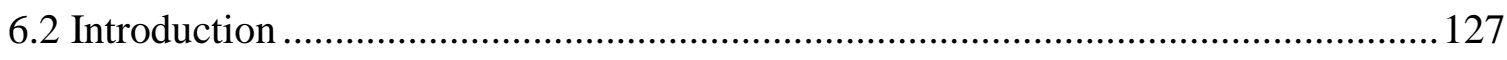

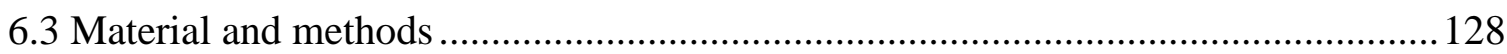

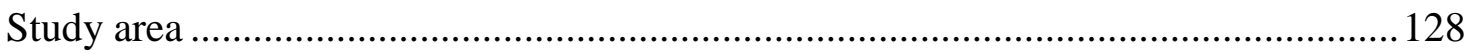

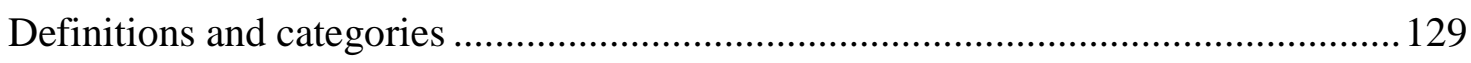




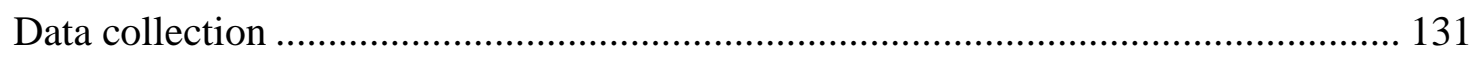

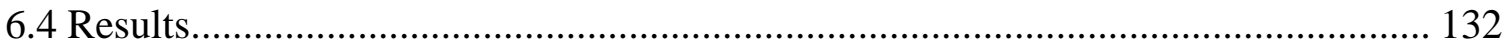

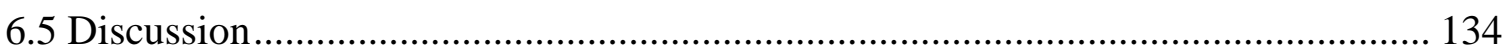

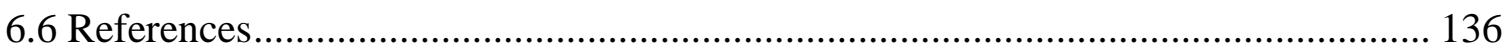

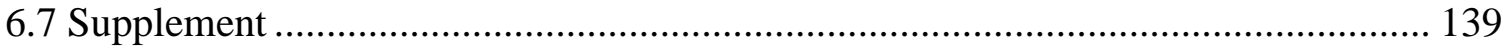

Chapter 7 - The effects of road access on income generation. Evidence from an integrated conservation and development project in Cameroon ....................................... 157

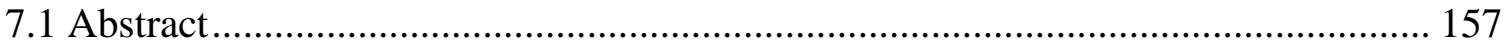

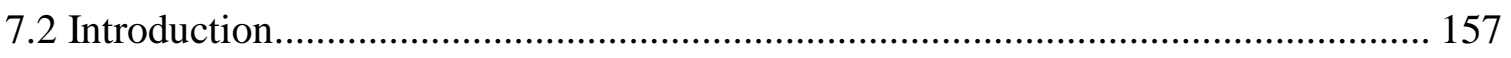

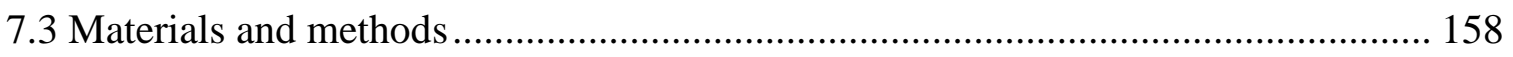

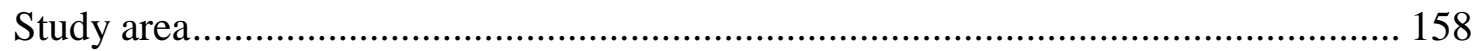

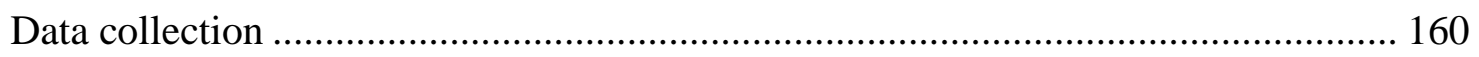

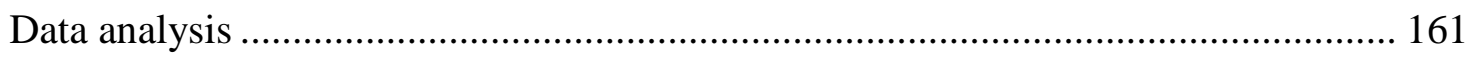

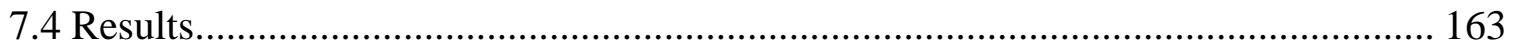

Descriptive analysis of household incomes ................................................................. 163

Impact analysis of road access on household incomes ............................................... 164

Perception of road impacts................................................................................... 165

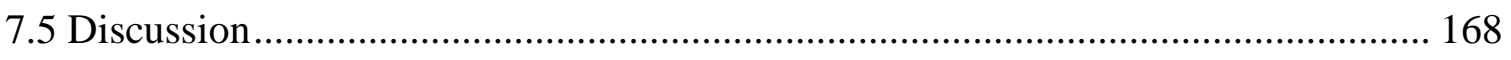

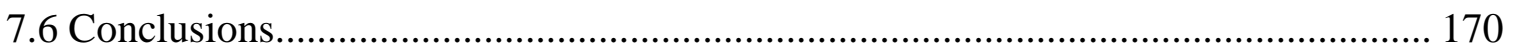

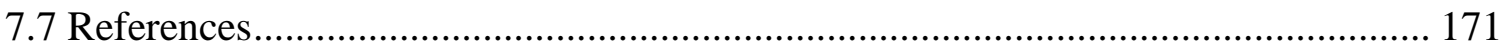

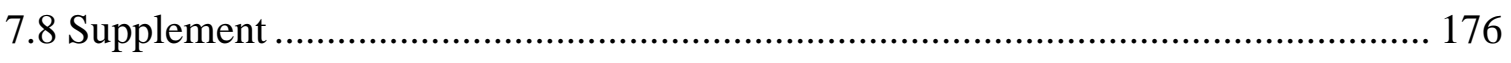

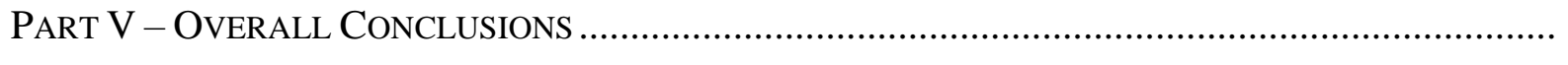

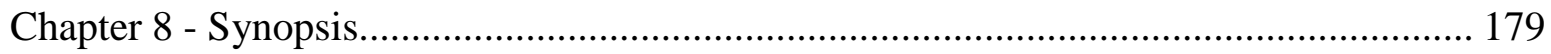

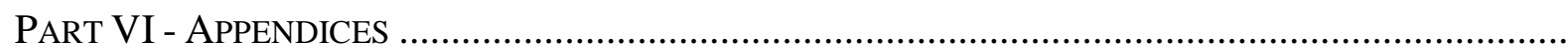

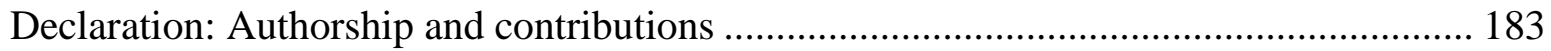

Acknowledgements ..................................................................................................... 184

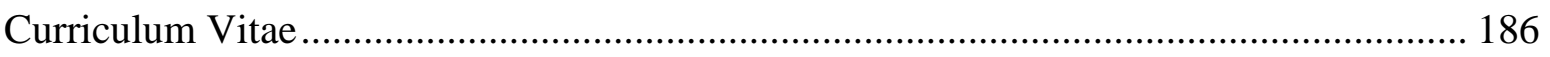




\section{Summary}

Rural agroforestry landscapes in West and Central Africa face a number of threats. Since decades, the ever escalating bushmeat crisis is pushing populations of threatened wildlife closer to extinction in many parts of West and Central Africa. In addition, population growth and economic needs are driving a slow but steady landscape transformation with protected areas being more and more isolated and surrounded by a mix of agricultural land, forestry and secondary forest patches. However, a recently emerged new wave of oil palm development might have the potential to outweigh experienced miseries. Since there is the risk that hundreds of thousands hectares of Afrotropical forest and agroforestry might be converted to homogeneous agro-industrial cultivations within only a few years.

Since West and Central African forested landscapes are characterized by social and economic complexities, site-specific, multi-faceted research approaches are needed to derive evidencebased conservation recommendations in the context of land use change. This doctoral thesis aimed to address some of the apparent knowledge gaps on land use and its effects on biodiversity and rural livelihood in an Afrotropical forest biodiversity hotspot, in Southwest Cameroon.

Our first study aimed to assess the status of large mammals and identify predictors of their distribution to inform conservation management in Southwest Cameroon. Based on line transect data from different sites and years as well as modelling of various predictor variables, we found that threatened wildlife in most abundant in protected areas but mainly due to their remoteness and high habitat quality, and less due to direct management interventions, such as patrolling. In addition, we estimated severe population declines between $29 \%$ and $94 \%$ from 2007 to 2014 of two conservation flagship species, the forest elephant and the chimpanzee.

Contrastingly, the second part of our research highlighted the high value of rural agroforestry systems also outside protected areas for native bird communities. Applying multivariate adaptive regression splines on bird count data from oil palm plantation and agroforestry in and outside Korup National Park as well as Landsat imagery, we identified high critical habitat thresholds at above $70 \%$ of forest cover for habitat and foraging specialists. In addition, generalists and wide-spread species mainly dominate in areas with low forest cover, such as oil palm plantations. Moreover, we modelled extinction thresholds for ant-following birds at $52 \%$ of forest cover for the most sensitive species. As result, we more than the half of resident antfollowers were absent from our data in oil palm plantations.

On the other hand, based on direct observations during transect walks and a distance sampling approach, we yielded higher density estimates of Congo Grey Parrots in oil palm plantations compared to Korup National Park. Whereas this is probably solely attributed to the abundant 
palm nut supply all year round, the agroforestry matrix provided a significantly higher variety of trees utilized and supported estimated densities thrice as high compared to the plantation. However, comparing our findings with previous density data from the same region suggests that parrots in the Korup region experienced severe population declines during the last decade. The third part of our research focused on income and expenditure structures of households in the Korup region. Based on quantitative household interviews in settlements in Korup National Park, its surrounding agroforestry landscape and the adjacent oil palm plantation, we found little differences in income between plantation, park and non-park settlements, though plantation household member had to work more for the same income and spent much more money on food items, mainly due to limited food farming. At the same time plantation households supported less members than park and non-park households. From a socioeconomic point, villagers that mainly depend on forest product seem to be better off than plantation workers depending on wage labour.

In a final study we analyzed the short-dated effects of motorbike road access on income activity choice in Korup National Park using a difference-in-difference approach. We found that road access led to a rise in total household income by $38 \%$ due to higher household participation in self-employment and wage labor, however, we did not study direct ecological effects of road construction. Any road construction should be carefully considered and accompanied by strict law-enforcement measures.

This thesis highlights the importance of using multi-taxa approaches. Whereas we may conclude from our research on large mammals that only protected areas seem to have the potential to halt population declines, the threshold analysis on bird assemblages also revealed high biodiversity values in agroforestry landscapes outside the park. Moreover, endangered Grey Parrots were often encountered feeding in the oil palm plantation adjacent to Korup National Park. These complex response patterns call for careful planning of task-specific conservation measures. Nevertheless, our results highlight that Afrotropical agroforestry can assure sustainable livelihoods for local inhabitants, while securing forest biodiversity if substantial proportions of forests are maintained. 


\section{PART I}

GENERAL INTRODUCTION 



\section{Chapter 1 \\ Introduction}

\subsection{The global oil palm development}

Rising global demand for edible oils and biofuels led to a rapidly growing market of palm oil in the last decades (Laurance et al. 2010). Due to the wide application possibilities of palm oil and high yield potentials, oil palms Elaeis guineensis are the most extensively cultivated oil crops in the world (e.g. Koh and Wilcove 2008, Koh et al. 2009). As a consequence of the expansion of palm oil cultivation in the tropics, rural agroforestry and natural forest ecosystems facing a substantial threat caused by land use change (Laurance et al. 2010, Dislich et al. 2016). Until today wide areas of Southeast Asia have been converted into palm oil plantations and for another large part concessions are already assigned (Wilcove and Koh 2010). In recent years, palm oil development started to emerge rapidly in the Amazon and tropical Africa (Butler and Laurance 2009, Wilcove and Koh 2010, Feintrenie 2014, Linder and Palkovitz 2016) conveying its associated impacts on socio-economic realities and environment.

The establishment of oil palm plantations has the potential for both stabilizing income in barely developed regions (Phalan 2009) and undermining land and labour rights, especially in the case of large projects (Rist et al. 2010). While traditional agroforestry systems can provide a variety of ecosystem services and products to local people, simplified land use systems, such as palm oil monocultures, are increasingly individualistic and profit driven (Pfund et al. 2011, Feintrenie 2014, Linder and Palkovitz 2016). As a result, employment in industrial plantations sometimes yield low and inconstantly paid labour wages (FEO 2008, Rist et al. 2009, Li 2014) and deprive local communities of a heterogeneous environment and the products therein, which may have constituted a substantial share of total household incomes before forest conversion (Sheil et al. 2006, Pfund et al. 2011). For Southeast Asia, several NGOs reported human rights violations, 'land grabbing' tactics, negative effects on human health and food insecurity related to palm oil industry (Colchester et al. 2007, Cotula et al. 2008, FOE 2008, Marti 2008). Moreover, Feintrenie (2014) describes similar problems in recent agro-industrial oil palm investment in Central Africa. Consequently, local communities suffer from losing autonomy, self-sufficiency and cultural heritage. As a reaction to this, oil palm companies and organizations drive aggressive campaigns to promote public acceptance (Koh and Wilcove 2009) while offering a minimum of transparency (Rist et al. 2010).

Often, social issues related to land use change are direct consequences of altered environmental conditions, such as human health effects of polluted rivers running through plantation areas (Sheil et al. 2009), or effects on forest biodiversity used by locals for livelihoods (Sheil et al. 2006). Whereas conservationists in the nineties often suggested a negative impact of poverty on environmental degradation as function of a downward spiral (Reardon and Vosti 1995), 
current research is focusing on approaches, such as 'pro-poor conservation' (Roe and Elliott 2006). It has been argued that biodiversity conservation may generate benefits for rural livelihoods if it is adapted to the demands of poor people living in the focal area (Belcher et al. 2005, Chazdon 2009). Therefore, land managers, scientists, politicians and indigenous people need to collaborate in research and co-design programs and policies to promote both development and conservation (Adams et al. 2004, Chazdon 2009).

The expansion of oil palm cultivation area and its associated infrastructure are key drivers of land use change and forest displacement in Southeast Asia (Laurance 2007, Turner et al. 2008, Wilcove and Koh 2010) and, thus, increases habitat fragmentation (DeFries et al 2005, Laurance 2007) and reduces ecosystem functioning (Dislich et al. 2016). The conversion of forest to oil palm plantations enhances the current tropical biodiversity crisis due to the limited conservation and biodiversity value of oil palm plantations (e.g. Donald 2004, Fitzherbert et al. 2008). The establishment of oil palm plantations often leads to a complete replacement of trees and lianas within the area under cultivation and plantation management usually allows only little under-growth, such as planted legumes (Peh et al. 2006, Danielsen et al. 2009). Homogeneous oil palm plantations do not serve as suitable habitats for large mammals, as shown in Southeast Asia (Maddox et al. 2007), and they contain lower numbers of bird species and abundance compared to primary forest (Aratrakorn et al. 2006) and rubber plantations (Peh et al. 2006). Moreover, also the conversion of degraded forest to oil palm cultivation habitats may eliminate more than $50 \%$ of bird species as shown for logged peat swamps (Azhar et al. 2011). The picture for invertebrate species groups is similar (Fitzherbert et al. 2008, Danielsen et al. 2009). Butterfly species richness in oil palm plantations is up to five times lower compared to primary or secondary forests (Koh and Wilcove 2008). In addition, community compositions of most species groups change severely, with a few species - often invasive species that are well adapted to agricultural conditions - becoming dominant in abundance (Donald et al. 2004, Turner and Foster 2008, Danielsen et al. 2009).

Some studies suggest retaining forest patches within the oil palm plantation area (Peh et al. 2006, Koh and Wilcove 2008) in order to maximize biodiversity. This strategy, which is also a common mitigation approach in management plans of oil palm plantations, since often not the entire plantation area is suitable for palm cultivation, seems to fail. Edwards et al. (2010) found that bird abundances are 200 and 60 times lower in oil palm plantations and embedded forest fragments, respectively, compared to contiguous forest. In addition, species composition of fragments was more similar to oil palm plantation than to contiguous forest (Edwards et al. 2010).

During the last ten years there has been a theoretical debate on how to reduce pressure on biodiversity under agricultural development. The land-sparing approach (e.g. see Phalan et al. 2011) assumes that agricultural activity affects most species rather negatively and suggests to 
intensify cultivation on farmland and concentrate conservation in protected area. Critics albeit argue that this strategy ignores social and ecological complexities (Fischer et al. 2011), such as the wide use of non-timber forest products in rural livelihoods (Belcher et al. 2005), which often occurs in agroforestry landscapes and, therefore, promote so-called land-sharing systems (Perfecto and Vandermeer 2010). Today, many conservation biologists favour a rather combined approach with large continuous intact protected areas surrounded by a wildlifefriendly farming matrix (see e.g. Kremen 2015). However, since there is a risk of overinterpreting simple theoretical models, validation through holistic field studies are indispensable (Godfray 2011).

\subsection{Plantation project and study area}

The background and motivation of this doctoral project was an incident related to an oil palm plantation project in Cameroon, West Africa. In 2009, the government of Cameroon has proclaimed the Cameroon Vision 2035, which shall address pressing challenges of the country, such as stagnating economic growth, increasing population growth, rapid urbanization and poor governance (MINEPAT 2009). As part of the strategy, the government has also embarked on initiatives to expand the agricultural sector, including its palm oil industry. Although production increased during the last years, the country is still a net importer of palm oil (Hoyle and Levang 2012).

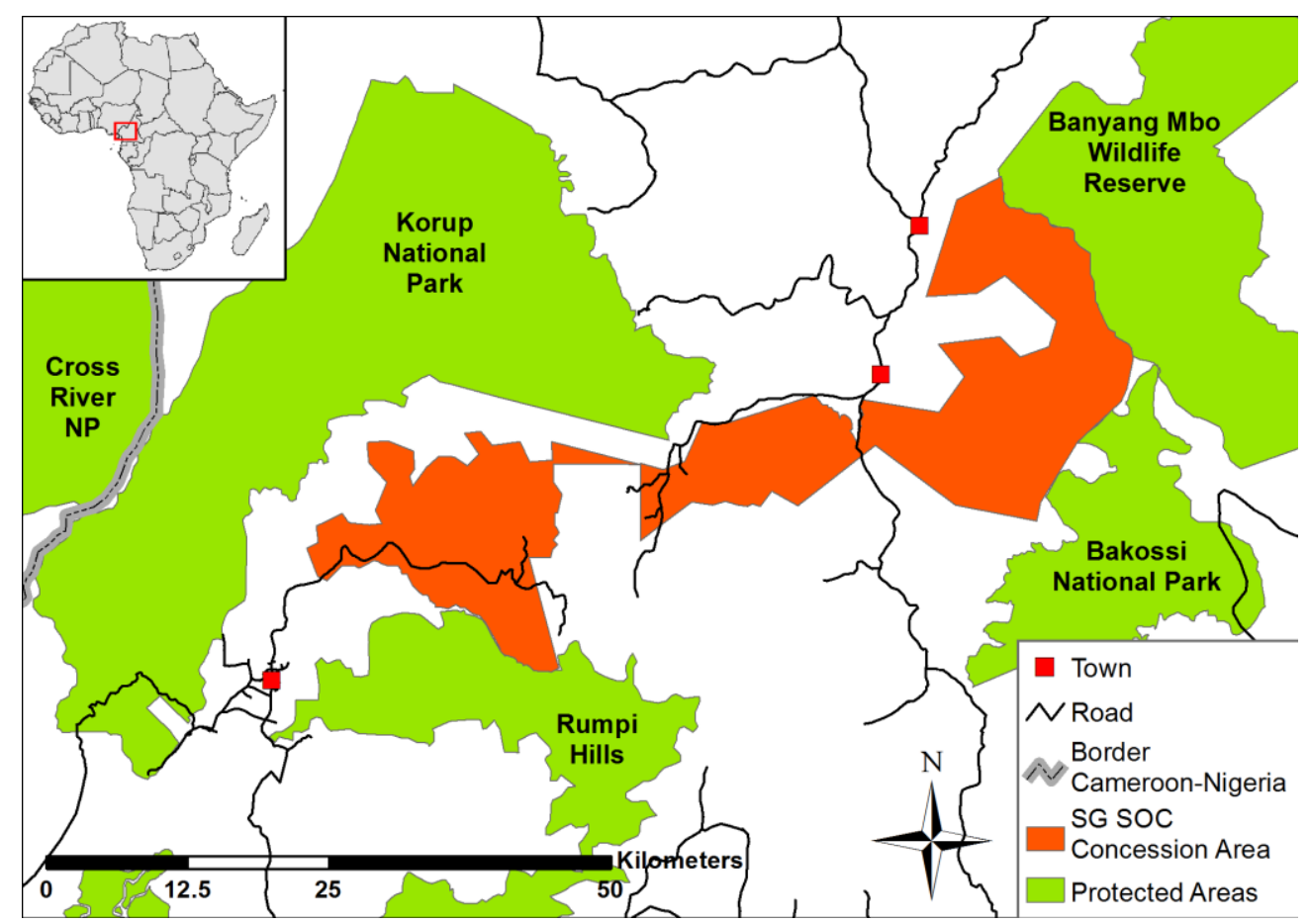

Figure 1.1 - Location of the Herakles Farms/SG SOC oil palm concession. 
In the same year Cameroonian government started its Vision 2035 campaign, 2009, the American agribusiness company Herakles Farms signed a 99-years concession lease for the establishment of an industrial oil palm plantation in the Southwest Region of Cameroon. In 2011, its Cameroonian affiliate SG Sustainable Oils Cameroon (SGSOC) started to rise infrastructure and nurseries for oil palms. The proposed concession covered more than 70,000 ha (H\&B Consulting 2011) and was located in the midst of a number of protected areas, namely Korup and Bakossi Mountains National Parks, Banyang Mbo Wildlife Sanctuary as well as Rumpi Hills Forest Reserve (Fig. 1.1). Thus, the project area intersected the CrossSanaga forests, a continuous forest block between the Cross-River National Park in Nigeria and the Sanaga-River in Cameroon. This region belongs to the important biodiversity hotspot of the Gulf of Guinea forests (Mittermeier 2004), which is known to harbour exceptional diverse species pool (Oates et al. 2004), including endangered flagship species, such as the African forest elephant, Nigeria-Cameroon chimpanzee and mainland drill (Okon and Ekobo 2007). The area contains mainly small villages, whose inhabitants are small-holders relying on cashcrop and subsidence agriculture, which is embedded into the forested region (MINFOF 2017). Additionally, hunting, fishing and the exploitation of wood and NTFPs are used to ensure local livelihoods (MINFOF 2017). Between 1987 and 2003 the area has been subject to one of the largest integrated conservation and development projects of the wet tropics, the multilateral Korup Project, which aimed at the conservation of biodiversity in the protected areas as well as at sustainable land use development in their vicinity through socially acceptable development. Its main objectives have been taken further by a program which started in 2006, the Programme for the Sustainable Management of Natural Resources in Southwest Region, Cameroon (PSMNR-SWR), a bilateral cooperation between the Governments of Cameroon and Germany.

The planned oil palm project raised much public attention, mainly stemming from a resistance against the project by leading conservation scientists (Linder et al. 2012) and several NGOs (e.g. see Ntumwel and Kupsch 2014), who were apprehensive of irreparable negative social and ecological consequences due to plantation establishment.

\subsection{Research objectives and chapter outline}

Although there is a growing body of studies on oil palm plantations and their ecological effects at the level of biotic communities, those mainly focus on Southeast Asia (e.g. Prabowo et al. 2016, Barnes et al. 2017, Paoletti et al. 2018). Detailed knowledge on species-specific responses to conversion from forest to oil palm cultivation in tropical Africa is still poor but much needed in to evaluate environmental impacts and inform development and conservation policy makers. In addition, there is an urgent need to address the social and ecological complexities of Afrotropical landscapes (Norris et al. 2010) and, therefore, use systematic approaches for broad-scale assessments across multiple disciplines to fill knowledge gaps (Turner et al. 2008, 
Sheil et al. 2009, Koh and Sodhi 2010, Dislich et al. 2016). In addition, we have the opportunity to document de facto effects during land use change since rural conditions still exist in many regions.

The core structure of this doctoral thesis consists of six research manuscripts, which are grouped in three parts addressing each one overarching question:

(1) What is the conservation value of the agroforestry landscapes in Southwest Cameroon?

(2) What are the ecological effects of industrial oil palm plantations and other land uses on biodiversity in Southwest Cameroon?

(3) How is rural livelihood effected by agro-industry and land use change in Southwest Cameroon?

The first part contains one manuscript on the status of wildlife across the Southwest Region of Cameroon (chapter 2). It is based on large mammal line transect surveys in two protected areas (Korup National Parka and Banyang Mbo Wildlife Reserve), one production forest (Forest Management Unit 11-005) and unprotected agroforestry landscapes (the former Herakles Farms oil palm concession area). In this chapter, I identify wildlife trends between 2007 and 2014 in Korup and Banyang Mbo, as well as differences between survey sites in 2014. To identify factors behind distribution patterns, I ran GLMs using set of landscape, environmental and anthropogenic predictors.

The next part compromises three manuscripts all using birds as indicators for land use effects. Chapter 3 and 4 are based on bird point sampling in Korup National Park, its surrounding agroforestry as well as the Ndian estate of the oil palm plantations PAMOL Plc. Whereas chapter 3 uses the entire bird data set and works with $\alpha$-, $\beta$ - and $\gamma$-richness of guilds, chapter 4 focuses on ant-following birds only. Both studies use multivariate adaptive regression splines to model birds in relation to forest cover and identify critical habitat thresholds.

Chapter 5 provides densities of Congo grey parrots based on transect walks in oil palm, agroforestry and protected land uses of the Korup region.

Finally, the last part contains two research chapters, which are both based on quantitative interview surveys. Chapter 6 provides a detailed overview on differences in income generation and expenditure structures of households in Korup National Park, its surrounding agroforestry matrix and the PAMOL oil palm plantation. Chapter 7, on the other hand, represents two case studies illustrating how income generation composition in rural households alters after the establishment of motorbike roads into formerly isolated rural communities. 


\subsection{References}

Adams, W.M., Aveling, R., Brockington, D., Dickson, B., et al., (2004). Biodiversity conservation and the eradication of poverty. Science 306: 1146-1149.

Aratrakorn, S., Thunhikorn, S., and Donald, P.F., (2006). Changes in bird communities following conversion of lowland forest to oil palm and rubber plantations in southern Thailand. Bird Conservation International 16: 71-82.

Azhar, B., Lindenmayer, D.B., Wood, J., Fischer, J., et al., (2011). The conservation value of oil palm plantation estates, smallholding and logged peat swamp forest for birds. Forest Ecology and Management 262: 2306-2315.

Barnes, A.D., Allen, K., Kreft, H., Corre, M.D., Jochum, M., et al., (2017). Direct and cascading impacts of tropical land-use change on multi-trophic biodiversity. Ecology and Evolution 1: 1511-1519.

Belcher, B., Ruíz-Pérez, M., and Achdiawan, R., (2005). Global patterns and trends in the use and management of commercial NTFPs: Implications for livelihoods and conservation. World Development 33: 1435-1452.

Butler, R.A., and Laurance, W., (2009). Is oil palm the next emerging threat to the Amazon? Trop Conservation Science 2:1-10.

Chazdon, R.L., Harvey, C.A., Komar, O., Griffith, D.M., et al., (2009). Beyond reserves: A research agenda for conserving biodiversity in tropical landscapes. Biotropica 41: 142153.

Colchester, M., Aik Pang, W., Chuo, W.M., and Jalong, T., (2007). Land is life: Land rights and oil palm development in Sarawak. Forest Peoples Programme and Perkumpulan Sawit Watch, Indonesia.

Cotula, L., Dyer, N., and Vermeulen, S., (2008). Fuelling exclusion? The biofuels boom and poor people's access to land. IIED.

Danielsen, F., Beukema, H., Burgess, N.D., Parish, F., et al., (2009). Biofuel Plantations on Forested Lands: Double Jeopardy for Biodiversity and Climate. Conservation Biology 23: 348-358.

DeFries, R., Hansen, A., Newton, A.C., and Hansen, M.C., (2005). Increasing isolation of protected areas in tropical forests over the past twenty years. Ecological Applications 15: 19-26. 
Dislich, C. Keyel, A.C., Salecker, J., Kisel, Y., Meyer, K.M., et al., (2016). A review of the ecosystem functions in oil palm plantations, using forests as a reference system. Biological Reviews 92: 1539-1569.

Donald, P.F., (2004). Biodiversity Impacts of Some Agricultural Commodity Production Systems. Conservation Biology 18: 17-37.

Edwards, D.P., Hodgson, J.A., Hamer, K.C., Mitchell, S.L., et al., (2010). Wildlife-friendly oil palm plantations fail to protect biodiversity effectively. Conservation Letters 3: 236-242.

Fargione, J., Hill, J., Tilman, D., Polasky, S., and Hawthorne, P., (2008). Land clearing and the biofuel carbon debt. Science 319: 1235-1238.

Feintrenie, L., (2014). Agro-industrial plantations in Central Africa, risks and opportunities. Biodiversity and Conservation 23:1577-1589.

Fischer, J., Batary, P., Bawa, K.S., Brussaard, L., et al., (2011). Conservation: Limits of land sparing. Science 334: 593.

Fitzherbert, E.B., Struebig, M.J., Morel, A., Danielsen, F., et al., (2008). How will oil palm expansion affect biodiversity? Trends in Ecology and Evolution 23: 538-545.

FOE (2008). Losing ground - The human rights impacts of oil palm plantation expansion in Indonesia. Friends of the Earth, UK.

Godfray, H.C.J., (2011). Food and biodiversity. Science 333: 1231-1232.

H\&B Consulting (2011). Environmental and Social Impact Assessment. Prepared for SG Sustainable Oils Cameroon Ltd. Yaoundé, Cameroon.

Hoyle, D., and Levang, P., (2012). Oil Palm Development in Cameroon. WWF Carpo, Yaoundé, Cameroon.

Koh, L.P., and Wilcove, D.S., (2008). Is oil palm agriculture really destroying tropical biodiversity? Conservation Letters 1:60-64.

Koh, L.P., and Wilcove, D.S., (2009). Oil palm: disinformation enables deforestation. Trends in Ecology and Evolution 24: 67-68.

Koh, L.P., and Sodhi, N.S., (2010). Conserving Southeast Asia's imperiled biodiversity scientific, management, and policy challenges. Biodiversity and Conservation 19: 913917.

Koh, L.P., Levang, P., and Ghazoul, J., (2009). Designer landscapes for sustainable biofuels. Trends in Ecology and Evolution 24: 431-438.

Kremen, C., (2015). Reframing the land-sparing/land-sharing debate for biodiversity conservation. Annals of the New York Academy of Sciences 1355: 52-76. 
Laurance, W.F., (2007). Forest destruction in tropical Asia. Current Science 93: 1544-1550.

Laurance, W.F., Koh, L.P., Butler, R., Sodhi, N.S., et al., (2010). Improving the Performance of the Roundtable on Sustainable Palm Oil for Nature Conservation. Conservation Biology 24: 377-381.

Li, T., (2014). The gendered dynamics of Indonesia's oil palm regime. ARI working paper 225. Asia Research Institute, National University of Singapore.

Linder, J.M., Laurance, W.F., Struhsaker, T., Lovejoy, T.E., Ehrlich, P.R., Raven, P.H., Fredriksson, G., Bradshaw, C.J.A., Brook, B.W., Koh, L.P., and Waltert, M., (2012). An Open Letter about the Environmental and Social Impacts of a Massive Oil Palm Development in Cameroon.

Linder, J.M., and Palkovitz, R.E., (2016). The threat of industrial oil palm expansion to primates and their habitats. In: Waller, M.T., (Ed.), Ethnoprimatology: Primate Conservation in the 21st Century. Springer, Berlin, Germany, pp. 21-45.

Maddox, T.M., Gemita, E., Wijamukti, S., and Salampessy, A., (2007). The conservation of tigers and other wildlife in oil palm plantations, Jambi Province, Sumatra, Indonesia. Zoological Society of London, London.

Marti, S., (2008). Losing ground: the human rights impacts of oil palm plantation expansion in Indonesia. LifeMosaic, Sawit Watch Indonesia and Friends of the Earth.

MINEPAT (2009). Cameroon Vision 2035. Work Document. Ministry of Economy, Planning and Regional Development. Yaoundé, Cameroon.

MINFOF (2017). The Management Plan for Korup National Park and its peripheral zone 20172021. Buea, Cameroon: Regional Delegation of the Ministry of Forestry and Wildlife.

Mittermeier, R.A., Robles-Gil, P., Hoffmann, M., Pilgrim, J.D., Brooks, T.B., Mittermeier, C.G., Lamoreux, J.L., and Fonseca, G.A.B., (2004). Hotspots Revisited: Earth's Biologically Richest and Most Endangered Ecoregions. CEMEX, Mexico City, Mexico.

Norris, K., Asase, A., Collen, B., Gockowski, J., Mason, J., Phalan, B., and Wade, A., (2010). Biodiversity in a forest-agriculture mosaic - The changing face of West African rainforests. Biological Conservation 143: 2341-2350.

Ntumwel, B.C., and Kupsch, D., (2014). Endangered species pay the price of palm oil's expansion. Greenpeace Blog. http://www.greenpeace.org/eastasia/news/blog/endangered-species-pay-the-price-ofpalm-oils/blog/50967 
Oates, J.F., Bergl, R.A., and Linder J.M., (2004). Africa's Gulf of Guinea Forests: Biodiversity Patterns and Conservation Priorities. Advances in Applied Biodiversity Science, number 6. Conservation International, Washington D.C.

Okon, D., and Ekobo, A., (2007). Monitoring Large Mammals and Human Activities in Korup National Park. WWF Cameroon.

Peh, K.S.-H., Sodhi, N.S., de Jong, J., Sekercioglu, C.H., et al., (2006). Conservation value of degraded habitats for forest birds in southern Peninsular Malaysia. Diversity and Distributions 12: 572-581.

Perfecto, I., and Vandermeer, J., (2010). The agroecological matrix as alternative to the landsparing/agriculture intensification model. PNAS 107: 5786-5791.

Pfund, J.-L., Watts, J.D., Boissiere, M., Boucard, A., et al., (2011). Understanding and Integrating Local Perceptions of Trees and Forests into Incentives for Sustainable Landscape Management. Environmental Management 48: 334-349.

Phalan, B., (2009). The social and environmental impacts of biofuels in Asia: An overview. Applied Energy 86: 21-29.

Phalan, B., Onial, M., Balmford, A., and Green, R.E., (2011). Reconciling food production and biodiversity conservation: Land sharing and land sparing compared. Science 333: 12891291.

Prabowo, W.E., Darras, K., Clough, Y., Toledo-Hernandez, M., Arlettaz, R., et al., (2016). Bird Responses to Lowland Rainforest Conversion in Sumatran Smallholder Landscapes, Indonesia. PLOS ONE 11: e0154876

Reardon, T., and Vosti, S.A., (1995). Links between rural poverty and the environment in developing countries: Asset categories and investment poverty. World Development 23: 1495-1506.

Rist, L., Lee, J.S.H., and Koh, L.P., (2009). Biofuels: social benefits. Science 326:1344.

Rist, L., Feintrenie, L., and Levang, P., (2010). The livelihood impacts of oil palm: smallholders in Indonesia. Biodiversity and Conservation 19: 1009-1024.

Roe, D., and Elliott, J., (2006). Pro-poor conservation: the elusive win-win for conservation and poverty reduction? Policy Matters 14: 53-63.

Sheil, D., Puri, R., Wan, M., Basuki, I., et al., (2006). Recognizing local people's priorities for tropical forest biodiversity. Ambio 35: 17-24. 
Sheil, D., Casson, A., Meijaard, E., van Nordwijk, M., et al., (2009). The impacts and opportunities of oil palm in Southeast Asia: what do we know and what do we need to know? Occasional paper no. 51, Center for International Forestry Research (CIFOR), Bogor.

Turner, E.C., and Foster, W.A., (2008). The impact of forest conversion to oil palm on arthropod abundance and biomass in Sabah, Malaysia. Journal of Tropical Ecology 25: 23-30.

Turner, E.C., Snaddon, J.L., Fayle, T.M., and Foster, W.A., (2008). Oil Palm Research in Context: Identifying the Need for Biodiversity Assessment. PLoS ONE 3: e1572.

Wilcove DS and Koh, L.P., (2010). Addressing the threats to biodiversity from oil-palm agriculture. Biodiversity Conservation 19: 999-1007. 


\section{PART II}

THE CONSERVATION STAtus OF WILDLIFE IN AGROFORESTRY

LANDSCAPES IN SOUTHWEST CAMEROON 



\section{Chapter 2}

\section{The status of large mammals in Southwest Cameroon: How threatened wildlife disappears from an Afrotropical forest biodiversity hotspot}

\subsection{Abstract}

Populations of large mammals are under pressure in most West and Central African forests. Though there is consent that poaching is the main driver of wildlife declines, we lack a deeper understanding on the factors behind population patterns in Afrotropical landscape mosaics. We assessed the status of large mammals and identified predictors of their distribution to inform conservation management in Southwest Cameroon. We surveyed line transects $(n=321$, $L=638.5 \mathrm{~km}$ ) in four sites of different protection status in 2013 and 2014, namely Korup National Park (KNP), Banyang Mbo Wildlife Reserve (BMWS), the Forest Management Unit 11-005 (FMU) and an unprotected agroforestry matrix (AFM), and compared encounter rates between sites. For KNP and BMWS, we used data from 2007 for trend analysis and calculated chimpanzee and elephant population estimates based on indirect Distance sampling approaches. Finally, we used GLMs to identify best predictors for mammal distribution based on a set of landscape, anthropogenic and environmental variables. Nearly all mammal species occurred in all four sites, however, in different compositions. Whereas rare primate species showed low encounter rates in all sites, most duiker and guenon species were more abundant in the PAs compared to AFM. Chimpanzees and elephants were mainly restricted to the PAs, however, compared to 2007 their estimated populations in 2014 declined severely between $29 \%$ and $94 \%$. Except of red-eared monkey, all recorded species declined in abundance in BMWS since 2007, while hunting track density increased. In KNP, only red duiker decreased, but guenons showed higher abundances in 2014. Although landscape type (KNP, BMWS, FMU) affected the distribution of most mammal species, anthropogenic or environmental variables were stronger predictors, except for red and blue duikers. Estimates of chimpanzee, elephant, drill and mangabey abundances were higher at larger distance to settlements. Vegetation density positively affected a number of species, including red colobus, red-eared monkeys, sitatunga and civet. For some rare species, such as chimpanzee and drill, roughness of terrain was an important parameter, probably as a result of reduced hunting activity in those areas. Our results suggest that PAs in Southwest Cameroon did have a mitigating effect on mammal population declines, mainly due to their remoteness and high habitat quality, but less due to direct management interventions, such as patrolling. 


\subsection{Introduction}

While wildlife outside African protected areas (PAs) has declined since decades, also populations in high level conservation sites, such as national parks, are increasingly under pressure and collapse locally (Caro and Scholte 2007). In West and Central Africa, a great share of PAs are not managed efficiently and face severe poaching (Tranquilli et al. 2014). As one result, large mammal abundance declined by $85 \%$ in West African forest reserves since 1970 (Craigie et al. 2010). Consequently, there are numerous reports of steep species population declines or even local extinctions: The survey results of Jimoh et al. (2013) suggest the local depletion of the large-bodied yellow-back (Cephalophus sylvicultor) and Bay duikers (C. dorsalis) in Cross River National Park, Oban Hills, Nigeria. Already in 2000, Oates et al. (2000) suggested that Miss Waldron's red colobus monkey (Procolobus badius waldroni), which was endemic to the forests of Ghana and Côte d'Ivoire, became extinct. Total relative monkey abundances dropped by nearly $70 \%$ in the Dzanga-Sangha Dense Forest Reserve in the Central African Republic (Remis and Jost Robinson 2012). The percentage of local extinction of large carnivores in PAs in West and Central Africa is estimated at $85 \%$ and $64 \%$, respectively, compared to their historical occurrence (Brugière et al. 2015). Forest elephants (Loxodonta africana cyclotis) are at risk in the entire Congo Basin (Blake et al. 2007) showing both a critical population and a geographical range decline of approximately $62 \%$ and $30 \%$ between 2002 and 2011 in Central Africa (Maisels et al. 2013). Also great apes are threatened and experience dramatic population declines in many PAs, such as Grauer's gorilla (Gorilla beringei graueri) in the Biega National Park, DRC (87\% from 1994/1995 to 2011-2015, Plumptre et al. 2016), and the western chimpanzee (Pan troglodytes verus) in Taï National Park, Côte d'Ivoire, (90\% from 1989 to 2007, Campbell et al. 2008) and across 20 PAs in West Africa ( $80 \%$ from 1990 to 2014, Kühl et al. 2017). Reviewing their ecological performance on a global scale, Geldmann et al. (2013) resumed that PAs have been mainly effective in conserving forest habitats but results are inconclusive regarding wildlife populations. Whereas there are indications that protected areas seemed to at least mitigate overall population declines to a certain extent (Stoner et al. 2007, Western et al. 2009, Kühl et al. 2017), we often lack information on population's status in sites of different management levels, including their surroundings (Gaston et al. 2008, Craigie et al. 2010, Norris et al. 2010). This is especially true for forested regions in West and Central Africa, where few efforts has been made to assess mammal populations (Caro and Scholte 2007), since systematic large mammal surveys cannot be realized via airplane but still rely on resource-intensive ground methods (Maisels et al. 2013). However, there are some exceptions, such as for species of high conservation concern. It has been confirmed that populations of forest elephants and great apes in Central Africa depend on protected areas (Blake et al. 2007, Stokes et al. 2010). Furthermore, during the last two decades there has been some research on mammal status and distribution in the conservation landscapes Ndouki-Likoukoula in northern Congo and the adjacent Dzanga-Sangha region in the southern 
Central African Republic, which suggest that there is a complex interaction between protection status and management of the landscape, infrastructure, as well as human presence and activity, such as logging and hunting (Blom et al. 2005, Stokes et al. 2010, Poulsen et al. 2011, Remis and Jost Robinson 2012). In fact, there is no dissent around the fact that in West and Central Africa, the main driver of large mammal decline is bushmeat hunting, which during the last decades has increasingly turned from a subsistence activity to commercial poaching for African and international urban markets (e.g. Macdonald et al. 2012, Tranquilli et al. 2014). There is also an increasing pressure on West African mammal populations from forest conversion through agricultural expansion of both smallholders (Tranquilli et al. 2014, Caro and Scholte 2007) and industrial plantations (Linder and Palkovitz 2016, Strona et al. 2018). Both poaching and habitat conversion lead to cascading effects on ecosystem functioning, while land use change is even intensifying hunting pressure (Abernethy et al. 2013). Furthermore, Maisels et al. (2013) found that in Central African countries with high levels of corruption elephant populations tend to be under higher pressure than elsewhere. However, beyond these overall trends, species-specific responses to anthropogenic and environmental patterns often remain unstudied, which, in turn, affects our understanding of their successful or unsuccessful maintenances in protected areas (Abernethy et al. 2013). There is growing evidence that roads, which serve as gateways for poachers, but also settlements negatively influences occurrence of several large mammal species, such as chimpanzee (Stokes et al. 2010, Junker et al. 2012), forest elephant (Blom et al. 2005, Laurance et al. 2006, Blake et al. 2007, Stokes et al. 2010), monkeys (Blom et al. 2005, Remis and Jost Robinson 2012) and medium-sized duiker species (Blom et al. 2005, Laurance et al. 2006, Clark et al. 2009). Few studies on large mammal distribution or occurrence in West and Central Africa included environmental predictors in a multi-factor analysis. Habitat type as predictor in a forest-dominated landscape and study design yielded only very weak responses for chimpanzee, elephant and monkeys compared to anthropogenic factors (Clark et al. 2009). In a more detailed approach using a set of variables describing vegetation and habitat quality besides hunting sign rates, Linder and Lawler (2012) found that primate abundance in Korup National Park, Cameroon, was best predicted by and positively correlated with stem density and basal area. On Bioko Island, primate abundance was negatively affected by elevation presumably due to reduced habitat productivity even though hunting mainly occurred in lower altitudes (Cronin et al. 2011). However, apart from those findings, our knowledge on the interplay between anthropogenic and environmental factors in Afrotropical forest mosaics of varying protection levels remains very limited (Norris et al. 2010). Facing changing conditions in West and Central African landscapes with an ongoing replacement of rainforest for agricultural and forestry land uses urgently call for a deeper understanding of wildlife population patterns in the heterogeneous landscape mosaics and the factors behind to address conservation management issues (Abernethy et al. 2013). Focusing on the highly biodiverse lowland rainforests in Southwest Cameroon, we therefore aimed 
(1) to describe recent population trends of large mammals in two important protected areas, (2) to assess the current status of large mammal populations across various landscape types and (3) to assess the effect of landscape type as well as anthropogenic or environmental parameters on species distribution.

\subsection{Material and methods}

\section{Study area}

The study area, the central part of the Southwest Region in Cameroon, is located in the tropical moist lowland forest zone. The altitude varies between 30 and $1750 \mathrm{~m}$ a.s.l. The yearly rainfall averages at 5,272 mm (Chimpanzee Camp, Korup National Park, Chuyong et al. 2004). The area is part of the large continuous forest block between the rivers Cross in Nigeria and Sanaga in Cameroon in the southeastern section of the biodiversity hotspot of the Gulf of Guinea forests (Oates et al. 2004). As part of a strategy to protect the regions exceptional diverse species pool, including endangered mammal species such as the African elephant, the Nigeria-Cameroon chimpanzee, the mainland drill and Preuss's red colobus, a number of protected areas, namely the national parks Mt. Cameroon, Korup, Bakossi Mountains and Takamanda, the wildlife sanctuary Banyang Mbo as well as several forest reserves have been established in Southwest Cameroon (Fig. 2.1). In addition, Cameroons forest policies also prescribe a forest management plan for all types of production forests, such as forest management units (FMU) or community forests in the Southwest region, which ensures that the production of timber and other forest goods does not endanger future production as well as intrinsic values of the physical and social environment (MINEF 1994). The study area contains few small towns and numerous villages, whose inhabitants are mainly smallholders relying on cash-crop and subsidence agriculture, which is embedded into the forested landscape (Kupsch et al. 2019). Additionally, hunting, fishing and the exploitation of wood and NTFP are used to ensure local livelihoods (Spey et al. 2019, MINFOF 2017, Willcox and Nambu 2007). The area has been subject to one of the largest integrated conservation and development projects of the wet tropics, the multilateral Korup Project (1987-2003), which aimed at the conservation of biodiversity in the protected areas as well as at sustainable land use development in their vicinity. Since 2006, its main objectives have been taken further by the Program of Sustainable Management of Natural Resources South-West Region (PSMNR-SWR), a bilateral cooperation between the Governments of Cameroon and Germany.

\section{Data collection}

We sampled large mammals and hunting signs along line transects (Buckland et al. 2001) in four survey sites, namely Korup National Park (KNP), Banyang Mbo Wildlife Sanctuary 
(BMWS), Forest Management Unit 11-005 (FMU) and an unprotected agroforestry matrix (AFM) in Ndian and Koupé-Manengouba divisions (a former proposed oil palm concession of Herakles Farms), between April 2013 and March 2014 (Fig. 2.1). We overlaid grids of $4 \mathrm{~km} * 4 \mathrm{~km}$ cell size at KNP and AFM and $3 \mathrm{~km} * 3 \mathrm{~km}$ cell size at BMWS and FMU. We randomly placed one transect of $2 \mathrm{~km}$ and $1.5 \mathrm{~km}$ length in each $4 \mathrm{~km} 2$ and $3 \mathrm{~km} 2$ grid cell, respectively. Transects were cut with a minimum of disturbance, and survey teams followed the transect cutters earliest one day later. In KNP, BMWS and FMU all transects were surveyed once, whereas in AFM we repeated walks at all transects (except of one in the western part of the site). The total survey amounted up to $L_{\text {total }}=638.5 \mathrm{~km}$ (transects $\left.n_{\text {total }}=321\right)$ with $L_{K N P}=176 \mathrm{~km}\left(\mathrm{n}_{\mathrm{KNP}}=88\right), L_{B M W S}=124.5 \mathrm{~km}\left(n_{B M W S}=83\right), \mathrm{L}_{\mathrm{FMU}}=156 \mathrm{~km}\left(n_{F M U}=104\right)$ and $L_{A F M}=182 \mathrm{~km}\left(n_{A F M}=46\right)$. Type and location of all signs (direct and indirect) on large mammals and hunting signs were recorded and the perpendicular distance to the transect line measured for elephant dung and chimpanzee nest. In addition, large mammal records were obtained from discrete movements in between the systematic transects, in the form of recce walks. However, this data was not used for statistical analysis. No attempt could be made to distinguish indirect signs of the two red duiker species Cephalophus ogilbyi and C. dorsalis as well as the two pangolin species Phataginus tetradactyla and Ph. tricuspis. Mammal data from line transect surveys in 2007 in KNP and BMWS were taken from Okon and Ekobo (2007) and Greengrass and Maisels (2007), respectively.

\section{Data analysis}

Comparisons of relative abundances between survey sites and years

We tested for differences in all sign encounter rates of large mammal species and hunting signs from line transects between survey sites using the Kruskal-Wallis test with multiple Dunn test as post hoc with the dunn.test package (Dinno 2017) in R version 3.5.3 (R Core Team 2019). Differences between survey years 2007 and 2014 in BMWS and KNP were tested using the Mann Whitney test focusing on sign types from line transects, which were available from 2007 data (direct, nest, dung, hunting trail, see Greengrass and Maisels 2007 and Table 2.1). Significance level was set at $\alpha=0.05$ and Bonferroni-corrected for multiple tests.

Chimpanzee and elephant population estimation

We estimated densities and population sizes of chimpanzees and elephants in BMWS and KNP following the distance sampling approach (Buckland et al. 2001) using the package Distance (Miller 2017) in R. For this, we used chimpanzee nest and elephant dung from line transects from all survey sites in 2013/14 as well as from Okon and Ekobo (2007). To model detection probability, we ran combinations of key functions (half-normal, hazard-rate and uniform), 
adjustment terms (cosine, simple polynomial and hermite polynomial) and covariates (survey ID and lead observer ID). Data was truncated to $w_{\text {Eleph }}=5 \mathrm{~m}$ and $w_{\text {Chimp }}=27 \mathrm{~m}$ for elephant dung and chimpanzee nest models, respectively. All models without covariates were controlled for monotonicity. We evaluated model fit based on goodness of fit (Q-Q plot and Cramér-von Mises test comparing the cumulative distribution function of the fitted detection function and the distribution of the data), the AIC and, finally visual examination of best fitting models within $\triangle A I C<2$ (Miller et al. 2016). To convert yielded nest and dung densities to individual level, we applied multipliers (Buckland et al. 2001), which are available from literature for chimpanzees: proportion of nest builders ( $p=0.83$, Plumptre and Cox 2006), nest production rate $(r=1.09 \pm 0.05$ nests/day) and disappearance time $(t=91.5 \pm 1.67$ days, Morgan et al. 2006, Rainey et al. 2009). For elephants, we calculated a dung defecation rate of $r=20.24 \pm 1.09$ per day using the rainfall model for the dry season proposed by Theuerkauf and Gula (2010). The only parameter required for the model, annual rainfall, was averaged over the entire study region using data from the WorldClim database (Hijmans et al. 2005) with ArcGIS 10.3. The mean dung disappearance time was calculated for each survey period respectively $\left(t_{K N P O 7}=104.90 \pm 0.10, t_{K N P 14}=117.70 \pm 0.07, t_{B M W S 07}=113.14 \pm 0.08\right.$, $t_{B M W S 14}=117.37 \pm 0.08$ days) based on data provided by Nchanji and Plumptre (2001).

\section{Modeling parameters of large mammal distribution}

We fitted generalized linear models (GLMs) using the stats package in R version 3.5.3 (R Core Team 2019) to examine the influence of landscape (FMU, BMWS, KNP), anthropogenic (distance to settlement, distance to road) and environmental (vegetation density, altitude, relief roughness) predictor variables on large mammal and hunting signs encounter rates at transect level in 2013 and 2014. Landscape variables were dummy coded. To obtain values for environmental variables, we created polygon shapefiles in ArcGIS 10.3 by buffering the transect lines by $1 \mathrm{~km}$, which we then intersected with environmental data. We averaged $10 \mathrm{~m}$ contour line data to obtain the mean altitude and used the coefficient of variance as a measure for relief roughness. Distance to human settlements and roads where taken from the mid points of each transect. We used the enhanced vegetation index (EVI) based on $250 \mathrm{~m}$ resolution MODIS Terra imagery as a proxy for vegetation density, due to its superior sensitivity at higher biomass levels (Jiang et al. 2008). The entire 16-day interval EVI time series for the study period in 2013 and 2014 was downloaded from the USGS data base and averaged. We compared GLMs using all possible sets of predictor variables and selected best fitting GLMs based on the Akaike information criterion (AIC). 


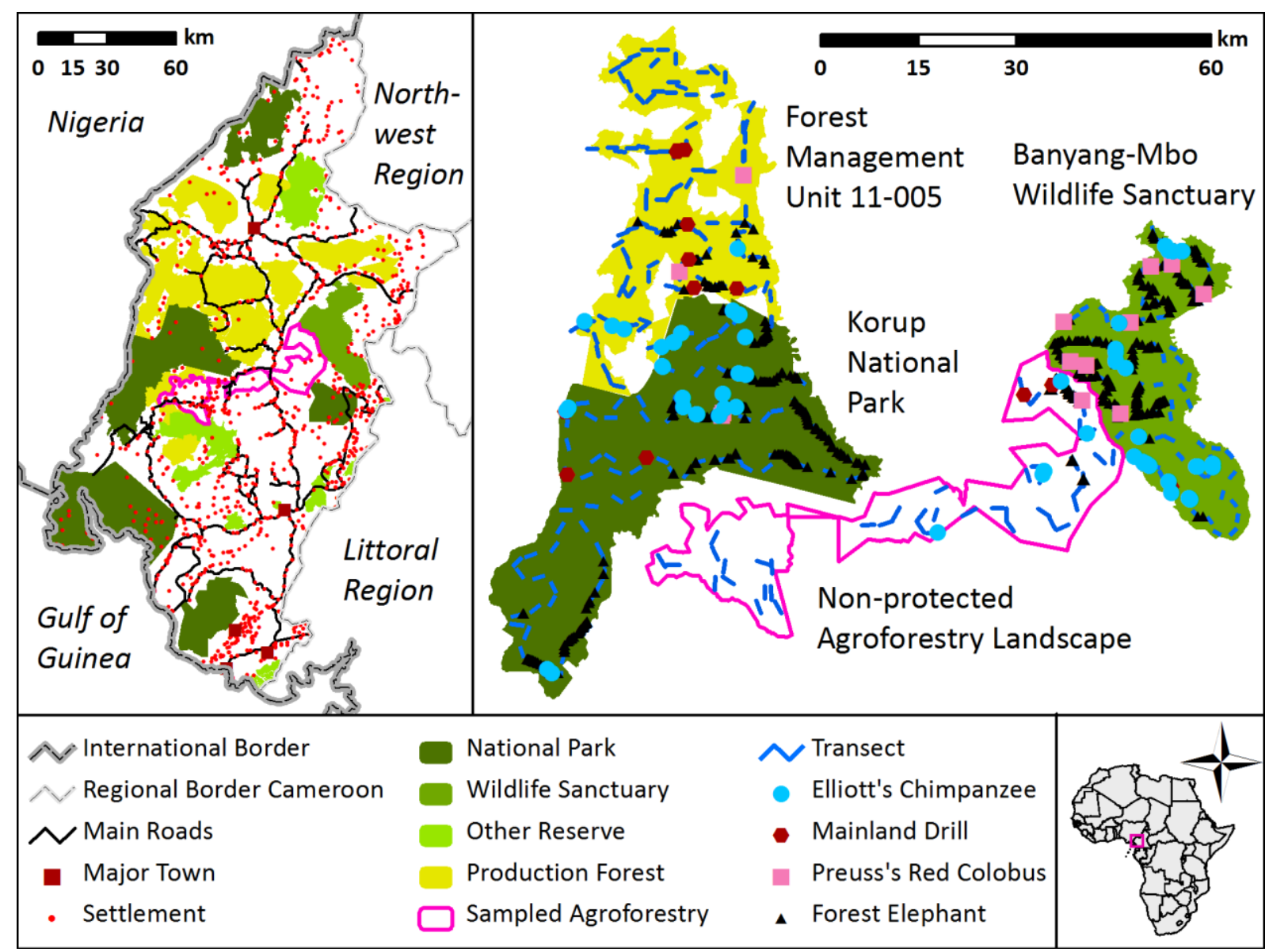

Figure 2.1 - Study area in Southwest Cameroon with protected areas, production forests and agroforestry landscapes as well as sampled transects and encounter locations of mammal species most relevant to conservation in 2013 and 2014.

\subsection{Results}

Relative mammal abundance trends from 2007 to 2014 in KNP and BMWS

We found substantial changes in encounter rates for many mammal species in BMWS and KNP from 2007 to 2014 (Table 2.1, comparing with results from Greengrass and Maisels 2007, Okon and Ekobo 2007). In BMWS, relative abundances of all species recorded in 2007 where lower in 2014 with chimpanzee and elephant showing significant declines down to less than a tenth and quarter of the initial figures, respectively. Also red and blue duikers showed strong (though not significant) declines. In the same time, hunting trail density in BMWS significantly increased. In KNP, chimpanzee and elephant encounter rates also declined from 2007 to 2014, however, on a lower and not significant level. Except for crowned monkeys, all forest guenon encounter rates increased significantly. While encounter rates of blue duikers remained on a low level, the higher red duiker rates in 2007 dropped significantly in 2014. Hunting trail rates in KNP declined slightly, however, remaining on a high level. 
Table 2.1 - Mean encounter rates (with standard errors) of large mammal species and hunting signs in Banyang Mbo Wildlife Sanctuary and Korup National Park in 2007 and 2014 as well as the results of Mann-Whitney tests on differences between sample years. Data from BMWS and KNP 2007 was taken from Greengrass and Maisels (2007) and Okon and Ekobo (2007), respectively.

\begin{tabular}{|c|c|c|c|c|c|c|c|c|c|}
\hline \multirow[t]{3}{*}{ Species \& signs } & \multirow{3}{*}{$\begin{array}{l}\text { Sign } \\
\text { type }\end{array}$} & \multicolumn{2}{|c|}{ Banyang Mbo Wildlife Sanctuary } & \multirow{2}{*}{\multicolumn{2}{|c|}{$\begin{array}{l}\text { Mann- } \\
\text { Whitney test }\end{array}$}} & \multicolumn{2}{|c|}{ Korup National Park } & \multirow{2}{*}{\multicolumn{2}{|c|}{$\begin{array}{l}\text { Mann-Whitney } \\
\text { test }\end{array}$}} \\
\hline & & \multirow{3}{*}{$\begin{array}{l}2007 \\
n=17 ; L=30,5 \mathrm{~km} \\
\quad \text { Mean encounter } r\end{array}$} & \multirow{2}{*}{$\begin{array}{l}2014 \\
n=83 ; L=124,5 \mathrm{~km} \\
\text { ate }[\text { enc. } / \mathrm{km}] \pm S E\end{array}$} & & & \multirow{2}{*}{\multicolumn{2}{|c|}{$\begin{array}{cc}2007 & 2014 \\
n=85 ; & L=154,7 \mathrm{~km} \quad n=88 ; L=176 \mathrm{~km} \\
& \text { Mean encounter rate }[\mathrm{enc} . / \mathrm{km}] \pm S E\end{array}$}} & & \\
\hline & & & & $w$ & $p$ & & & $w$ & $p$ \\
\hline \multicolumn{9}{|l|}{ Primates } & \\
\hline Pan troglodytes ellioti & nest & $1.793 \pm 0.422 * *$ & $0.129 \pm 0.052$ & 1400 & $<0.001$ & $0.121 \pm 0.040$ & $0.085 \pm 0.026$ & 3778 & 0.844 \\
\hline Mandr. leucophaeus leucophaeus & dung & $*$ & $0.008 \pm 0.008$ & NA & & $*$ & $0.006 \pm 0.006$ & NA & \\
\hline Piliocolobus preussi & direct & - & $0.024 \pm 0.014$ & NA & & $0.036 \pm 0.017$ & $0.006 \pm 0.006$ & 3918.5 & 0.088 \\
\hline Cercocebus torquatus & direct & $0.076 \pm 0.052$ & $*$ & NA & & $0.024 \pm 0.014$ & $0.051 \pm 0.021$ & 3576 & 0.220 \\
\hline Cercopithecus pogonias pogonias & direct & $0.076 \pm 0.052$ & - & NA & & $0.073 \pm 0.023$ & $0.057 \pm 0.019$ & 3809.5 & 0.699 \\
\hline Cercop. erythrotis camerunensis & direct & $*$ & $0.161 \pm 0.044$ & NA & & $0.006 \pm 0.006$ & $0.239 \pm 0.038$ & 2419.5 & $<0.001$ \\
\hline Cercopithecus nictitans martinii & direct & $0.338 \pm 0.134$ & $0.225 \pm 0.048$ & 779.5 & 0.393 & $0.205 \pm 0.044$ & $0.449 \pm 0.049$ & 2489.5 & $<0.001$ \\
\hline Cercopithecus mona & direct & $0.304 \pm 0.107$ & $0.225 \pm 0.048$ & 780.5 & 0.380 & $0.109 \pm 0.035$ & $0.295 \pm 0.039$ & 2584.5 & $<0.001$ \\
\hline \multicolumn{10}{|l|}{ Proboscidea } \\
\hline Loxodonta africana (cyclotis) & dung & $1.867 \pm 0.626$ & $0.450 \pm 0.116$ & 947 & 0.008 & $0.565 \pm 0.133$ & $0.369 \pm 0.093$ & 3810 & 0.784 \\
\hline \multicolumn{10}{|l|}{ Bovidae } \\
\hline $\begin{array}{l}\text { Cephalophus ogilbyi ogilbyi, } \\
\text { Cephalophus dorsalis castaneus }\end{array}$ & dung & $3.883 \pm 1.672$ & $1.149 \pm 0.148$ & 890 & 0.083 & $2.224 \pm 0.332$ & $0.710 \pm 0.108$ & 4784.5 & 0.001 \\
\hline Philantomba monticola & dung & $2.269 \pm 0.878$ & $0.723 \pm 0.104$ & 816.5 & 0.284 & $0.801 \pm 0.170$ & $0.813 \pm 0.128$ & 3181 & 0.061 \\
\hline Cephalophus silvicultor & dung & $*$ & $0.040 \pm 0.021$ & NA & & $*$ & $0.136 \pm 0.048$ & NA & \\
\hline Hunting & trail & $1.962 \pm 0.364$ & $2.867 \pm 0.172$ & 425.5 & 0.010 & $3.694 \pm 1.011 * * *$ & $2.443 \pm 0.146$ & 718.5 & 0.318 \\
\hline
\end{tabular}

*presence confirmed during survey

**For chimpanzees, a slightly higher survey effort was realized at BMWS in 2007 with $n=20$ and $L=36.5 \mathrm{~km}$.

***A part of the raw data on human signs from the KNP 2007 survey was lost. Hunting trail encounter rate in KNP 2007 is based on $n=14$ and $L=23.6 \mathrm{~km}$. 
Chimpanzee and elephant population estimates in 2007 and 2014

The best fitting model for chimpanzee nest was the uniform key function with cosine adjustment term of order 1 and the hazard-rate key function with lead observer ID as covariate for elephant dung. Expected chimpanzee nest cluster size was estimated to $E(s)_{B M W S}=2.15 \pm 0.63$, $E(s)_{K N P 07}=2.79 \pm 0.58$ and $E(s)_{K N P 14}=1.80 \pm 0.19$ for BMWS 2014, KNP 2007 and KNP 2014 surveys, respectively. Both estimated elephant and chimpanzee densities strongly decreased in KNP between 2007 and 2014, leading to estimated population sizes of around 70 individuals for both species in KNP in 2014 (Table 2.2). Using figures provided in Greengrass and Maisels (2007), we recalculated the chimpanzee density and population estimate with multipliers used in this study and found that estimates dropped by $94 \%$ since 2007 , whereas elephant density and population estimates in 2014 seem to range on a relatively high level compared to KNP.

Table 2.2 - Density (ind*km-2) and population estimates of chimpanzee and elephants in Banyang Mbo Wildlife Sanctuary and Korup National Park in 2007 and 2014 derived from Distance sampling analysis. Data from BMWS and KNP 2007 was taken from Greengrass and Maisels (2007) and Okon and Ekobo (2007), respectively.

\begin{tabular}{|c|c|c|c|c|}
\hline \multirow{2}{*}{$\begin{array}{l}\text { Species } \\
\text { Year }\end{array}$} & \multicolumn{2}{|c|}{ Banyang Mbo Wildlife Sanctuary } & \multicolumn{2}{|l|}{ Korup National Park } \\
\hline & Density $D(95 \% C l)$ & Population N (95\% Cl) & Density $D(95 \% \mathrm{Cl})$ & Population N (95\% Cl) \\
\hline \multicolumn{5}{|c|}{ Pan troglodytes ellioti } \\
\hline 2007 & $1.45(0.81-2.57)^{*}$ & $905(504-1606)^{*}$ & $0.15(0.08-0.29)$ & $188(96-369)$ \\
\hline 2014 & $0.08(0.03-0.25)$ & $50(16-153)$ & $0.06(0.03-0.11)$ & $69(36-132)$ \\
\hline \multicolumn{5}{|c|}{ Loxodonta africana (cyclotis) } \\
\hline 2007 & NA & NA & $0.08(0.05-0.14)$ & $101(59-172)$ \\
\hline 2014 & $0.50(0.20-1.23)$ & $311(126-768)$ & $0.06(0.03-0.10)$ & $71(38-130)$ \\
\hline
\end{tabular}

*recalculated with multipliers used in this study (production rate, disappearance rate and survey area size as well as proportion of nest builders) based on reported densities from 2007 (Greengrass \& Maisels 2007)

\section{Relative mammal abundances in 2014 in four survey sites}

With some few exceptions, we could record nearly all large mammal species in each of the survey sites (Table 2.3). However, there were significant differences in all sign encounter rates between survey sites in all species of conservation importance, apart from of red colobus and drill. Except of the white-nosed monkey, all primates but also elephants showed highest relative abundances in the protected areas. Encounter rates of all duiker species, porcupines and water chevrotains in FMU were comparable between KNP and BMWS, whereas they were significantly lower in the unprotected AFM. Buffalos were more often recorded in KNP and the red river hog in BMWS than in the other sites, respectively. We recorded significantly lower encounter rates of pangolins in the protected areas compared to FMU and AFM. Encounter rates of porcupines are significantly higher in BMWS and significantly lower in AFM compared to KNP and FMU. 
Table 2.3 - Mean encounter rates (with standard errors; all signs) of large mammal species and hunting signs in four sampled landscapes in 2013 and 2014 as well as the results of Kruskal-Wallis tests on differences between landscape types. Significance levels as derived from Dunn post hoc tests are indicated as superscripts.

\begin{tabular}{|c|c|c|c|c|c|c|c|}
\hline \multirow[t]{2}{*}{ Species \& signs } & \multirow[t]{2}{*}{ IUCN status } & $\begin{array}{l}\text { Korup NP } \\
n=88 ; L=176 \mathrm{~km}\end{array}$ & $\begin{array}{l}\text { Banyang Mbo WS } \\
n=83 ; L=124.5 \mathrm{~km}\end{array}$ & $\begin{array}{l}\text { FMU 11-005 } \\
n=104 ; L=156 \mathrm{~km}\end{array}$ & $\begin{array}{l}\text { Non-protected AFM } \\
n=46 ; L=182 \mathrm{~km}\end{array}$ & \multicolumn{2}{|c|}{ Kruskal-Wallis test } \\
\hline & & \multicolumn{4}{|c|}{ Mean encounter rate $[$ enc. $/ \mathrm{km}] \pm$ standard error } & $x^{2}$ & $p$ \\
\hline \multicolumn{8}{|l|}{ Primates } \\
\hline Pan troglodytes ellioti & EN decr & $0.107 \pm 0.029^{a}$ & $0.176 \pm 0.059^{a}$ & $0.025 \pm 0.012^{\mathrm{a}}$ & $0.027 \pm 0.013^{a}$ & 8.006 & 0.046 \\
\hline Mandrillus leucophaeus leucophaeus & EN decr & $0.022 \pm 0.013$ & $0.056 \pm 0.032$ & $0.038 \pm 0.017$ & $0.016 \pm 0.012$ & 0.290 & 0.962 \\
\hline Piliocolobus preussi & CR decr & $0.005 \pm 0.005$ & $0.024 \pm 0.013$ & $0.012 \pm 0.009$ & $*$ & 2.537 & 0.469 \\
\hline Cercocebus torquatus & VU decr & $0.051 \pm 0.021^{\mathrm{a}}$ & $*$ & $0.006 \pm 0.006^{b}$ & $0.010 \pm 0.010^{\mathrm{ab}}$ & 12.214 & 0.007 \\
\hline Cercopithecus pogonias pogonias & VU decr & $0.056 \pm 0.018^{a}$ & - & $0.038 \pm 0.017^{a}$ & $0.021 \pm 0.013^{\mathrm{a}}$ & 8.877 & 0.030 \\
\hline Cercopithecus erythrotis camerunensis & VU decr & $0.238 \pm 0.037^{a}$ & $0.176 \pm 0.044^{\mathrm{ab}}$ & $0.064 \pm 0.019^{b}$ & $0.016 \pm 0.009^{b}$ & 25.690 & $<0.001$ \\
\hline Cercopithecus nictitans martinii & LC decr & $0.448 \pm 0.049^{a}$ & $0.273 \pm 0.053^{b}$ & $0.307 \pm 0.048^{\mathrm{ab}}$ & $0.157 \pm 0.029^{b}$ & 13.548 & 0.004 \\
\hline Cercopithecus mona & LC unkn & $0.295 \pm 0.039^{a}$ & $0.248 \pm 0.048^{\mathrm{ab}}$ & $0.134 \pm 0.032^{b}$ & $0.086 \pm 0.022^{b}$ & 15.572 & 0.001 \\
\hline \multicolumn{8}{|l|}{ Proboscidea } \\
\hline Loxodonta africana (cyclotis) & EN decr & $1.375 \pm 0.245^{\mathrm{a}}$ & $1.799 \pm 0.282^{\mathrm{a}}$ & $0.250 \pm 0.081^{b}$ & $0.092 \pm 0.044^{b}$ & 48.110 & $<0.001$ \\
\hline \multicolumn{8}{|l|}{ Bovidae } \\
\hline $\begin{array}{l}\text { Cephalophus ogilbyi ogilbyi, } \\
\text { Cephalophus dorsalis castaneus }\end{array}$ & $\begin{array}{l}\text { VU decr. } \\
\text { NT decr }\end{array}$ & $3.090 \pm 0.194^{b}$ & $5.453 \pm 0.468^{\mathrm{a}}$ & $3.416 \pm 0.203^{b}$ & $2.190 \pm 0.272^{c}$ & 32.522 & $<0.001$ \\
\hline Philantomba monticola & LC decr & $3.000 \pm 0.229^{a}$ & $2.538 \pm 0.239^{a}$ & $2.820 \pm 0.229^{a}$ & $1.010 \pm 0.148^{b}$ & 38.584 & $<0.001$ \\
\hline Cephalophus silvicultor & NT decr & $0.250 \pm 0.061^{\mathrm{a}}$ & $0.112 \pm 0.040^{b c}$ & $0.121 \pm 0.035^{a b}$ & $0.016 \pm 0.009^{b c}$ & 11.943 & 0.008 \\
\hline Syncerus caffer nanus & LC decr & $0.079 \pm 0.026^{a}$ & $0.008 \pm 0.008^{b}$ & $0.019 \pm 0.014^{b}$ & $0.027 \pm 0.013^{\mathrm{ab}}$ & 12.423 & 0.006 \\
\hline Tragelaphus spekii & LC decr & $0.107 \pm 0.033^{\mathrm{a}}$ & - & $0.019 \pm 0.010^{b}$ & $0.010 \pm 0.010^{b}$ & 19.915 & $<0.001$ \\
\hline Tragelaphus scriptus & LC stab & $0.011 \pm 0.007$ & $0.024 \pm 0.017$ & - & - & 3.551 & 0.314 \\
\hline \multicolumn{8}{|l|}{ Tragulidae } \\
\hline Hyemoschus aquaticus & LC decr & $0.318 \pm 0.051^{\mathrm{a}}$ & $0.120 \pm 0.048^{b}$ & $0.397 \pm 0.073^{\mathrm{a}}$ & $0.092 \pm 0.027^{b}$ & 20.524 & $<0.001$ \\
\hline \multicolumn{8}{|l|}{ Cetartiodactyla } \\
\hline Potamochoerus porcus & LC decr & $1.193 \pm 0.119^{b}$ & $2.401 \pm 0.272^{\mathrm{a}}$ & $1.096 \pm 0.110^{b}$ & $1.065 \pm 0.145^{b}$ & 20.305 & $<0.001$ \\
\hline
\end{tabular}




\begin{tabular}{|c|c|c|c|c|c|c|c|}
\hline \multicolumn{8}{|l|}{ Carnivora } \\
\hline Civettictis civetta & LC unkn & $0.062 \pm 0.017$ & $0.064 \pm 0.035$ & $0.070 \pm 0.020$ & $0.016 \pm 0.009$ & 2.561 & 0.464 \\
\hline \multicolumn{8}{|l|}{ Pholidota } \\
\hline $\begin{array}{l}\text { Phataginus tetradactyla, } \\
\text { Phataginus tricuspis }\end{array}$ & $\begin{array}{l}\text { VU decr. } \\
\text { VU decr }\end{array}$ & $0.289 \pm 0.039^{a}$ & $0.152 \pm 0.043^{b}$ & $0.500 \pm 0.079^{a}$ & $0.402 \pm 0.060^{\mathrm{a}}$ & 26.045 & $<0.001$ \\
\hline \multicolumn{8}{|l|}{ Rodentia } \\
\hline Atherurus africanus & LC unkn & $2.477 \pm 0.141^{c}$ & $7.188 \pm 0.429^{a}$ & $4.801 \pm 0.330^{b}$ & $1.875 \pm 0.181^{\mathrm{c}}$ & 104.521 & $<0.001$ \\
\hline Hunting signs & & $2.443 \pm 0.146^{b}$ & $3.333 \pm 0.208^{a}$ & $2.294 \pm 0.215^{b}$ & $0.907 \pm 0.136^{c}$ & 67.231 & $<0.001$ \\
\hline
\end{tabular}


Table 2.4 - Effects of landscape, anthropogenic and environmental predictor variables on large mammal species and hunting signs in 2013/2014. The GLM analysis is based on encounter rates and mean values of distances, EVI and altitude at transect level $(\mathrm{n}=321)$. Only best fitting models are presented with predictor variables. All models were fit to a gamma distribution and log-linked. If to be transformed to encounter rate estimates, intercepts and coefficients are to be exponentiated, with coefficients representing multipliers (not slopes). Predictor variables, which influenced the response significantly, are indicated in bold and p-values are given in parentheses.

\begin{tabular}{|c|c|c|c|c|c|c|c|c|c|}
\hline Species \& signs & Intercept & FMU & BMWS & KNP & $\begin{array}{l}\text { Distance to } \\
\text { settlement }\end{array}$ & $\begin{array}{l}\text { Distance to } \\
\text { main road }\end{array}$ & $\begin{array}{l}\text { Vegetation } \\
\text { density }\end{array}$ & Altitude & $\begin{array}{l}\text { Relief } \\
\text { roughness }\end{array}$ \\
\hline \multicolumn{10}{|l|}{ Primates } \\
\hline Pan troglodytes & $-31.40(<0.01)$ & $1.35(0.26)$ & $0.86(0.45)$ & $0.74(0.55)$ & $35.09(0.02)$ & $1.95(<0.01)$ & $50.11(<0.01)$ & $6.46(<0.01)$ & $14.00(<0.01)$ \\
\hline Mandrillus leucophaeus & $-8.35(<0.01)$ & & $-2.31(<0.01)$ & $-3.09(<0.01)$ & $46.35(<0.01)$ & & & $2.00(0.19)$ & $17.51(<0.01)$ \\
\hline Piliocolobus preussi & $-24.26(<0.01)$ & $5.16(<0.01)$ & $4.62(<0.01)$ & $3.66(<0.01)$ & & & $42.24(<0.01)$ & & $-4.69(0.31)$ \\
\hline Cercocebus torquatus & $-12.23(<0.01)$ & $-1.16(0.19)$ & $-3.54(<0.01)$ & $1.41(0.13)$ & $57.24(<0.01)$ & $0.43(0.25)$ & & $3.89(<0.01)$ & $12.03(<0.01)$ \\
\hline Cercopithecus pogonias & $-8.32(<0.01)$ & $0.78(0.29)$ & $-5.20(<0.01)$ & $1.43(0.06)$ & & $0.57(0.08)$ & $9.72(0.19)$ & & \\
\hline Cercopithecus erythrotis & $-15.75(<0.01)$ & $3.41(<0.01)$ & $2.33(<0.01)$ & $4.12(<0.01)$ & & $1.50(<0.01)$ & $20.51(<0.01)$ & $4.62(<0.01)$ & $-3.22(0.23)$ \\
\hline Cercopithecus nictitans & $-1.99(<0.01)$ & $0.54(0.02)$ & & $0.89(<0.01)$ & & & & $1.03(0.02)$ & \\
\hline Cercopithecus mona & $-2.46(<0.01)$ & & $0.59(0.04)$ & $0.79(<0.01)$ & & $0.36(0.03)$ & & & \\
\hline \multicolumn{10}{|l|}{ Proboscidea } \\
\hline Loxodonta africana & $-9.81(<0.01)$ & $1.49(0.03)$ & $3.66(<0.01)$ & $3.31(<0.01)$ & $41.68(<0.01)$ & & $15.54(0.02)$ & $-4.45(<0.01)$ & \\
\hline \multicolumn{10}{|l|}{ Bovidae } \\
\hline $\begin{array}{l}\text { Cephalophus ogilbyi, } \\
\text { Cephalophus dorsalis }\end{array}$ & $0.78(<0.01)$ & $0.44(<0.01)$ & $0.91(<0.01)$ & $0.34(<0.01)$ & & & & & \\
\hline Philantomba monticola & $0.09(0.49)$ & $1.09(<0.01)$ & $1.02(<0.01)$ & $1.21(<0.01)$ & & $-0.16(0.02)$ & & & \\
\hline Cephalophus silvicultor & $-10.51(<0.01)$ & $2.41(<0.01)$ & $1.56(0.03)$ & $2.93(<0.01)$ & $13.80(0.13)$ & & $16.61(0.02)$ & $-1.95(0.07)$ & \\
\hline Tragelaphus spekii & $-17.36(<0.01)$ & $4.43(<0.01)$ & & $7.20(<0.01)$ & $15.13(0.19)$ & $-1.83(<0.01)$ & $25.56(<0.01)$ & $4.40(<0.01)$ & $-7.60(0.03)$ \\
\hline \multicolumn{10}{|l|}{ Tragulidae } \\
\hline Hyemoschus aquaticus & $-5.82(<0.01)$ & $1.18(<0.01)$ & & $0.98(0.01)$ & & $0.53(0.02)$ & $8.28(0.10)$ & & \\
\hline \multicolumn{10}{|l|}{ Cetartiodactyla } \\
\hline Potamochoerus porcus & $0.36(<0.01)$ & & $0.88(<0.01)$ & & & & & $-0.85(<0.01)$ & \\
\hline
\end{tabular}




\begin{tabular}{|c|c|c|c|c|c|c|c|c|c|}
\hline \multicolumn{10}{|l|}{ Carnivora } \\
\hline Civettictis civetta & $-34.17(<0.01)$ & $1.67(<0.01)$ & $-1.59(<0.01)$ & & & $2.27(<0.01)$ & $70.79(<0.01)$ & $0.98(0.36)$ & $9.82(<0.01)$ \\
\hline \multicolumn{10}{|l|}{ Pholidota } \\
\hline $\begin{array}{l}\text { Phataginus tetradactyla, } \\
\text { Phataginus tricuspis }\end{array}$ & $-0.44(0.06)$ & & $-0.78(<0.01)$ & & $-11.42(<0.01)$ & & & & \\
\hline \multicolumn{10}{|l|}{ Rodentia } \\
\hline Atherurus africanus & $0.68(<0.01)$ & $0.68(<0.01)$ & $1.18(<0.01)$ & & $-3.73(0.01)$ & & & & $1.84(<0.01)$ \\
\hline Hunting signs & $0.13(0.26)$ & $1.10(<0.01)$ & $1.50(<0.01)$ & $1.24(<0.01)$ & & $-0.18(<0.01)$ & & & $-1.31(<0.01)$ \\
\hline
\end{tabular}




\section{Parameters affecting species distribution}

The landscape variables were significant predictors for most species modelled; however, at least one other parameter, either anthropogenic or environmental, had a much stronger effect in all models, except for blue and red duikers (Table 2.4). Distance to settlement had a very strong positive effects on chimpanzee, drill, mangabey and elephant encounter rates, but was negative for pangolins. Encounter rates of most species were positively correlated with vegetation density, but most strongly so in chimpanzee, red colobus, red-eared monkey, yellow-backed duiker, sitatunga, water chevrotain and civet. Altitude and relief roughness were significant in most models, however, only relief roughness had a considerable positive effect in the models for chimpanzee, drill and mangabey. On the other hand, the rate of hunting signs was positively influenced by landscape variables (FMU, BMWS, KNP) but strongly negatively influenced by rough terrain.

\subsection{Discussion}

This study represents the first attempt to assess the status and distribution patterns of large mammals across several landscapes representing a considerably large portion of the forests in Southwest Cameroon which is in the midst of the Gulf of Guinea biodiversity hotspot (Oates et al. 2004).

\section{Recent large mammal abundance trends in BMWS and KNP}

Our results highlight that mammal populations in protected areas are under considerable pressure and many species experienced severe declines within only a few years. For some rare primate species, for which detection mainly based on direct sightings or calls, such as drill, red colobus, crowned monkey and red-capped mangabey, populations in BMWS and KNP (but also their surroundings as found by Waltert et al. 2002) were already severely reduced in 2007, so that their presence as well as abundance trends could only be recorded with increasing survey effort, making an evaluation of the impact of threats or management interactions hardly possible (Barnes et al. 2002). On the other hand, encounter rates of the remaining small monkeys (mona, putty-nose and red-eared guenons) in KNP and BMWS increased from 2007 to 2014 or remained stable on a relatively high level. However, this change in primate community composition gives reason for concern as this might also be a result of competitive release due to declining abundances of threatened species sharing a comparable niche (Cronin et al. 2016, Linder and Oates 2011, Waltert et al. 2002).

Besides the endemic and critically endangered Preuss's red colobus and endangered drill, the region also harbours two other flagship species, forest elephants and Nigeria-Cameroon chimpanzees (Oates et al. 2004). Nevertheless, population estimates for chimpanzee fell below 
100 individuals in KNP and BMWS, representing alarming declines of $63 \%$ and $94 \%$ from 2007 to 2014, respectively. A similar decline of $80 \%$ have been recorded for western chimpanzees by Kühl et al. (2017) across 20 West African protected areas during the last two decades. However, contrary to western chimpanzees, the suitable habitat of the endemic Nigeria-Cameroon chimpanzee did not significantly decrease during the last two decades (Junker et al. 2012), which suggests that our findings result from either poaching or disease spread. Also elephant populations are under pressure in both PAs. Coming from estimated 425 individuals in the early 90ies (Powell 1993, as cited in Blanc et al. 2007), the estimated elephant population in KNP remain declining at an alarmingly low level from 101 individuals in 2007 to 71 in 2014. For BMWS, there are no reliable population estimates of elephants for 2007, whereas we yielded an estimate of 311 in 2014. However, we assume that the population has been larger in the past, since all sign encounter rates of elephants in BMWS dropped by $76 \%$ between 2007 and 2014. Such a decline would be in line with Poulsen et al. (2017), who estimated an elephant population decline of more than 80\% in Gabon between 2004 and 2014. If the negative population trends cannot be stopped and reversed in the near future, the elephant populations in KNP and BWMS might be prone to local extinction within a few decades as it has been shown for most of West African elephant populations smaller than 200 individuals (e.g. Barnes 2002, Blake et al. 2008).

In contrast to the 2007 surveys, we succeeded to record the uncommon yellow-backed duiker during transect walks in both BMWS and KNP, nevertheless, at a low level. At the same time encounter rates of red duikers declined by more than $70 \%$ in both PAs since 2007 . As we could not reliably distinguish between the two resident red duiker species, Bay and Ogilby's duiker, we cannot attribute declines to the respective species. However, Viquerat et al. (2012) and Jimoh et al. (2013) already suggested the local depletion of yellow-backed and Bay duikers in southern KNP and the Oban Hills region of the adjacent Cross River National Park, probably due to the fact that these larger-bodied duikers are more vulnerable to hunting. In light of this, we might assume that encounters of Ogilby's duiker made up for most of the red duiker encounters from 2007 and 2014, and therefore, also their declines. On the other hand, this might also imply that Bay duiker are at risk to extinct locally. Also alarming are the severe declines of $61 \%$ in encounter rates of the small-bodied blue duiker in BMWS between 2007 and 2014, supporting the general finding of high poaching pressure particularly in BMWS during this period. Accordingly, the encounter rate of hunting trails significantly increased in BMWS and remained on a high level in KNP.

\section{Patterns and factors of large mammal distribution in a multi-use landscape context}

In accordance with the majority of studies from West and Central African forests (e.g. Laurance et al. 2006, Linder and Oates 2011, Poulsen 2011), we ascribe wildlife declines in BMWS and 
KNP mainly to unsustainable and illegal hunting. From bioacoustic monitoring conducted in the southern sector of the park, Astaras et al. (2017) extrapolated that more than 39,000 animals were poached per year by guns alone in Korup National Park between 2013 and 2015. Even though most hunters mainly target abundant fast producing species, such as smaller duiker species or porcupines (Nasi et al. 2011), large and rare species are usually killed as opportunistic by catch (Bennett et al. 2007). Nevertheless, despite our finding that most mammal groups experienced severe declines in KNP and BMWS during the last years, we found that populations of conservation relevant mammals were mainly concentrated to protected areas. Therefore, our results are in line with findings from other parts of West and Central Africa (e.g. Blake et al. 2007, Stokes et al. 2010, Remis and Jost Robinson 2012), highlighting the importance of PAs for large mammal conservation, though their performance seems to be mainly reduced to mitigate but not halt overall wildlife declines (Stoner et al. 2007, Western et al. 2009, Kühl et al. 2017). Those findings are particularly true for flagship species, such as chimpanzee and elephant, which only showed a few encounters outside but close to protected areas (Fig. 2.1). On the other hand, we could not detect significant differences between sites for encounter rates of the threatened primate species red colobus and drill, and only slight differences for crowned monkey and red-capped mangabey. Again, we attribute this to their rarity nowadays and associated difficulties to detect differences in abundances (Barnes et al. 2002). Nevertheless, there has been previous research on the effects of land use, particularly logging, on large mammal assemblages suggesting species-specific responses. In the southern part of the FMU 11-005, which was also part of our study, Waltert et al. (2002) already recorded declines in encounter rates of chimpanzee, red-capped mangabey, mona and red-eared monkey after logging events between 1999 and 2001. Also abundances of apes, primates, duikers and elephants in the northern Republic of Congo showed negative but complex response patterns several decades after logging events, but they were additionally related to distances to human infrastructure (Clark et al. 2009).

Very little is known about the conservation value of heterogeneous matrices dominated by smallholder agroforestry for large mammals. The fact that we recorded nearly all mammal species also outside protected areas, suggests that habitat quality requirements for large mammals can be met in rural agroforestry systems in Southwest Cameroon; also for species, which seem to depend on mature forest, such as chimpanzee, red colobus, red-ear monkey and civet, Kupsch et al. (2019) demonstrated that the landscapes of KNP and its surrounding AFM may reach similar forest cover rates and can harbour similar forest bird assemblages. The fact that mammal assemblages, on the other hand, significantly differ between the studied landscapes types with unlike grades of protection, suggests that hunting had a strong confounding effect. Also surveys in the multi-use conservation landscape of the DzangaSangha region in the Central African Republic showed that most large mammal species were most strongly affected by hunting and less so by other land uses (Blom et al. 2005). This was 
also found for selective logging, to which western chimpanzees in Southeast Cameroon (Arnhem et al. 2008) and ungulates at Borneo (Brodie et al. 2015) seem to be resilient to a certain extent, when hunting is absent or at least limited.

In contrast to several other studies from West and Central African forests (e.g. Blake et al. 2007, Blom et al. 2005, Junker et al. 2012, Laurance et al. 2006), roads seem play a minor role in the distribution of mammal assemblages in our study area. On the other hand, we found strong, and with the exception of pangolins, negative effects of settlements on the detection of several species. Also the configuration of the landform, mainly its level of roughness, was more important than roads. This is probably attributed to the fact that most settlements around KNP and BMWS are not linked to main roads and still depend on forest foot paths. Short or overnight hunting trips and trapping may, therefore, accumulate closer to settlements, whereas a rough terrain seems to halt also more professional poaching (see also Table 2.4) to the benefit of some wildlife species.

\subsection{Conclusions}

This study reveals an alarming status of wildlife in the Southwest Region of Cameroon and drastic declines of most conservation relevant mammal species. Our results also suggest that the performance of protected areas is limited and pre-eminently achieved through remoteness and quality of embedded habitats. To counteract this trend, the Southwest Region of Cameroon is in urgent need for a landscape wide protection concept. Such a wildlife conservation concept needs to implement a multifaceted but focused tool set and meet both biological and socioeconomic needs (Bennett et al. 2007). There are already many good recommendations on wildlife conservation management for various settings in African forest landscapes made in the literature. In the following, we attempt to group the main topics, which apply best to our study area, according to different management levels or fields.

First of all, law enforcement inside KNP and BMWS has to be improved ideally through the (1) recruitment of more patrolling staff. However, (2) limited personnel resources can also be deployed by using less predictable patrolling schemes (Astaras et al. 2017) and create enlarged strict core zones of increased patrol presence in areas of excellent habitat quality and high abundance of endangered wildlife. (3) Though there has been a long history of attempts, there is no regular and transparent documentation of monitoring efforts and illegal activities using SMART or cyber trackers implemented in KNP and BMWS up to date.

On a regional administrational level, (1) landscape planning efforts to maintain habitat networks and migration corridors including transboundary cooperation with Cross River National Park in Nigeria have to be increased. (2) There is the need to promote community-based organizations (Western et al. 2009), which may help to facilitate conservation communication 
and increase credibility, as well as corruption resistant networks (Maisels et al. 2013). (3) Since the transport of animals hunted in Southwest Cameroon to bushmeat markets in Nigeria is increasingly facilitated by an expanding road network (Fa et al. 2014, Spey et al. 2019), controls along roads outside have to be adequately carried out across Southwest Cameroon and Southeast Nigeria (Macdonald et al. 2012).

We also need to increase efforts to manage agroforestry landscapes outside protected areas for conservation, if we want to stop a development towards an isolation of parks of considerable mammal diversity but reduced populations in West African forests (Caro and Scholte 2007). A broader reach is also needed because protected area management mainly addresses rare species conservation. Surrounding landscapes could be managed for more common species to reduce sink effects and prevent profound changes in natural assemblages and, in turn, ecosystem functioning (Gaston and Fuller 2007). There are probably three main activity fields to cover coincidently and in cooperation with the local population in agroforestry landscapes: (1) conservation education and community outreach programs (Struhsaker et al. 2005), (2) support of local smallholder farming and the promotion of alternative income and protein sources (Bennett et al. 2007, Spey et al. 2019, Willcox and Nambu 2007), but also (3) local hunting management of non-endangered mammal species (Bennett et al. 2007), because even if locals would only hunt for subsistence, offtake levels would probably still remain unsustainable (Willcox and Nambu 2007).

Another partner for successful wildlife management on a landscape scale should be the private forestry sector (Poulsen et al. 2009). In Cameroon, forest management plans frequently permit hunting in the agroforestry and production areas of FMUs, and often in the protection zones, but if so, hunting regulations are usually not enforced (Lescuyer et al. 2012). As an effect, logging concessions are an important source of bushmeat for urban markets (Nasi et al. 2011). Additionally, concessions cause immigration since often only a limited number of locals are hired in Cameroon (Lescuyer et al. 2012), which puts wildlife within the concession and its surroundings under additional hunting pressure (Poulsen et al. 2009). This might be either direct through trapping by the rather unskilled immigrants or indirect through salaries creating markets for gun-hunted bushmeat by locals (Willcox and Nambu 2007, Poulsen et al. 2009). Therefore, forest management plans of logging concessions should (1) consequently ban hunting from their protection zones, (2) permit hunting only for small-bodied, fast reproducing species, such as blue duiker and rodents and (3) enforce those regulations strictly. In addition, companies with logging concession in proximity to protected areas could be obliged to pay a contribution for additional patrolling staff, which might be linked to the proportion of immigrant workers hired.

Furthermore, we should not disregard international dependencies: (1) The performance of forestry and agro-certification schemes, such as FSC and RSPO, is poor and has to be enhanced 
(Cerutti et al. 2011, Strona et al. 2018). (2) The global demand for bushmeat and other wildlife products has to be internationally condemned and the trade regulated. And finally, even though West African PAs face severe pressure from bushmeat hunting and attract less mitigating activities, such as tourism and research (Tranquilli et al. 2014), their available financial and personnel resources are extremely limited compared to East and Southern African PAs (Craigie et al. 2010). Therefore, (3) there has to rise a global understanding and consent that wildlife conservation activities as described above cannot be successfully implemented in developing regions, such as West Africa, without sufficient and long-term financial commitment from abroad (Struhsaker et al. 2005, Tranquilli et al. 2012).

\subsection{References}

Abernethy, K.A., Coad, L., Taylor, G., Lee, M.E., and Maisels, F., (2013). Extent and ecological consequences of hunting in Central African rainforests in the twenty-first century. Philosophical Transactions of the Royal Society B 368: 2012002.

Arnheim, E., Dupain, J., Vercauteren Drubbel, R., Devos, C., and Vercauteren, M., (2008). Selective logging, habitat quality and home range use by sympatric gorillas and chimpanzee: a case study from an active logging concession in Southeast Cameroon. Folia Primatologica 79: 1-14.

Astaras, C., Linder, J.M., Wrege, P., Orume, R.D., and Macdonald, D.W., (2017). Passive acoustic monitoring as a law enforcement tool for Afrotropical rainforests. Frontiers in Ecology and the Environment: 15, 233-234.

Barnes, R.F.W., (2002). The problem of precision and trend detection posed by small elephant populations in West Africa. African Journal of Ecology 40: 179-185.

Bennett, E.L., Blencowe, E., Brandon, K., Brown, D., Burn, R.W., et al., (2007). Hunting for consensus: reconciling bushmeat harvest, conservation, and development policy in West and Central Africa. Conservation Biology 21: 884-887.

Blake, S., Strindberg, S., Boudjan, P., Makombo, C., Bila-Isia, I., et al., (2007). Forest elephant crisis in the Congo Basin. PloS Biology 5: e111.

Blake, S., Deem, S.L., Strindberg, S., Maisels, F., Momont, L., et al., (2008). Roadless Wilderness Area Determines Forest Elephant Movements in the Congo Basin. PLoS ONE 3: e3546.

Blanc, J.J., Barnes, R.F.W., Craig, G.C., Dublin, H.T., Thouless, C.R., Douglas-Hamilton, I., Hart, J.A., (2007). African Elephant Status Report 2007: An Update from the African Elephant Database. pp 31-35. 
Blom, A., van Zalinga, R., Heitkönig, I.M.A., and Prins, H.H.T., (2005). Factors influencing the distribution of large mammals within a protected central African forest. Oryx 39: $1-8$.

Brodie, J.F., Giordano, A.J., and Ambu, L., (2015). Differential responses of large mammals to logging and edge effects. Mammalian Biology 80: 7-13.

Brugière, D., Chardonnet, B., and Scholte, P., (2015). Large-scale extinction of large carnivores, (lion Panthera leo, cheetah Acinonyx jubatus and wild dog Lycaon pictus) in protected areas of West and Central Africa. Tropical Conservation Science Vol: 8: 513-527.

Buckland, S.T., Anderson, D.R, Burnham, K.P., Laake, J.L., Borchers, D.L., and Thomas, L., (2001). Introduction to distance sampling: estimating abundance of biological populations. Oxford University Press, Oxford.

Campbell, G., Kühl, H., Kouame, P.N., and Boesch, B., (2008). Alarming decline of West African chimpanzees in Côte d'Ivoire. Current Biology 18: R903-R904.

Caro, T., and Scholte, P., (2007). When protection falters. African Journal of Ecology 45: 233-235.

Cerutti, P.O., Tacconi, L., Nasi, R., and Lescuyer, G., (2011). Legal vs. certified timber: Preliminary impacts of forest certification in Cameroon. Forest Policy and Economics 13: 184-190.

Chuyong, G.B., Condit, R., Kenfack, D., Losos, E.C., Moses, S.N., Songwe, N.C., and Thomas, D.W., (2004). Korup forest dynamics plot, Cameroon. In: Losos, E.C., Leigh Jr.E.G., (Eds.), Tropical Forest Diversity and Dynamism: Findings From a Large-Scale Plot Network. University of Chicago Press, Illinois, pp. 506-516.

Clark, C.J., Poulsen, J.R., Malonga, R., and Elkan, P.W., (2009). Logging concessions can extend the conservation estate for Central African tropical forests. Conservation Biology 23: 1281-1293.

Craigie, I.D., Baillie, J.E.M., Balmford, A., Carbone, C., Collen, B., Green, R.E., and Hutton, J.M., (2010). Large mammal population declines in Africa's protected areas. Biological Conservation 143: 2221-2228.

Cronin, D.T., Riaco, C., Linder, J.M., Bergl, R.A., Gonder, M.K., O’Conner, M.P., and Hearn, G.W., (2016). Impact of gun-hunting on monkey species and implications for primate conservation on Bioko Island, Equatorial Guinea. Biological Conservation 197: 180-189.

Dinno, A., (2017). Package 'dunn.test'. Dunn's Test of Multiple Comparisons Using Rank Sums, (version 1.3.5). https://cran.r-project.org/package=dunn.test/. Assessed 17 March 2019. 
Fa, J.E., Farfán, M.A., Marquez, A.L., Duarte, J., Nackoney, J., et al., (2014). Mapping Hotspots of Threatened Species Traded in Bushmeat Markets in the Cross-Sanaga Rivers Region. Conservation Biology 28: 224-33

Gaston, K.J., and Fuller, R.A., (2007). Commonness, population depletion and conservation biology. TRENDS in Ecology and Evolution 23: 14-19.

Gaston, K.J., Jackson, S.F., Cantú-Salazar, L., and Cruz-Piñón, G., (2008). The ecological performance of protected areas. The Annual Review of Ecology, Evolution, and Systematics 39: 93-113.

Greengrass, E.J., and Maisels, F., (2007). Conservation of the Nigerian-Cameroon Chimpanzee P. t. vellerosus, (and other mammals) in and around Banyang-Mbo Wildlife Sanctuary, Southwest province, Cameroon. Report, WCS Cameroon programme, Wildlife Conservation Society, New York.

Hijmans, R.J., Cameron, S.E., Parra, J.L., Jones, P.G., and Jarvis, A., (2005). Very high resolution interpolated climate surfaces for global land areas. International Journal of Climatology 25: 1965-1978.

Jiang, Z., Heute, A.R., Didan, K., and Miura, T., (2008). Development of a two-band enhanced vegetation index without a blue band. Remote Sensing of Environment 112: 3833-3845.

Jimoh, S.O., Ikyaagba, E.T., Alarape, A.A:, Adeyemi, A.A., and Waltert, M., (2013). Local depletion of two larger duikers in the Oban Hills Region, Nigeria. African Journal of Ecology 51: 228-234.

Junker, J., Blake, S., Boesch, C., Campbell, G., Toit, L. d., et al., (2012). Recent decline in suitable environmental conditions for African great apes. Diversity and Distributions 18: 1077-1091.

Kühl, H.S., Sop, T., Williamson, E.A., Mundry, R., Brugière, D., et al., (2017). The Critically Endangered western chimpanzee declines by $80 \%$. American Journal of Primatology 79 : e22681.

Kupsch, D., Vendras, E., Ocampo-Ariza, C., Batáry, P., Motombi, F. N., Bobo, K. S., and Waltert, M., (2019). High critical forest habitat thresholds of native bird communities in Afrotropical agroforestry landscapes. Biological Conservation 230: 20-28.

Laurance, W.F., Croes, B.M., Tchignoumba, L., Lahm, S.A., Alonso, A., et al., (2006). Impacts of roads and hunting on Central African rainforest mammals. Conservation Biology 20: 1251-1261.

Lescuyer, G., Mvondo, S.A., Essoungou, J.N., Toison, V., Trébuchon, J.-F., and Fauvet, N., (2012). Logging concessions and local livelihoods in Cameroon: from indifference to alliance? Ecology and Society 17: 7. 
Linder, J.M., and Oates, J.F., (2011). Differential impact of bushmeat hunting on monkey species and implications for primate conservation in Korup National Park, Cameroon. Biological Conservation 144: 738-745.

Linder, J.M., and Lawler, R.R., (2012). Model selection, zero-inflated models, and predictors of primate abundance in Korup National Park, Cameroon. American Journal of Physical Anthropology 149: 417-425.

Linder, J.M., and Palkovitz, R.E., (2016). The threat of industrial oil palm expansion to primates and their habitats. In: Waller, M.T., (Ed.), Ethnoprimatology: Primate Conservation in the 21st Century. Springer, Berlin, Germany, pp. 21-45.

Macdonald, D.W., Johnson, P.J., Albrechtsen, L., Seymour, S., Dupain, J., Hall, A., and Fa, J.E., (2012). Bushmeat trade in the Cross-Sanaga rivers region: Evidence for the importance of protected areas. Biological Conservation 147: 107-114.

Maisels, F., Strindberg, S., Blake, S., Wittemyer, G., Hart, J., et al., (2013). Devastating decline of forest elephants in Central Africa. PLoS ONE 8: e59469.

MINEF (1994). Loi No 94/01 du 20 janvier 1994 portant régime des forêts, de la faune et de la pêche. Republic of Cameroon, Yaoundé, Cameroon.

Miller, D. L., (2017). Package 'Distance'. Distance Sampling Detection Function and Abundance Estimation, (version 0.9.7). https://cran.r-project.org/package=Distance/. Assessed 09 April 2019.

Miller D.L., Rexstad E., Thomas. L., Marshall, L., and Laake. J., (2016). Distance sampling in R. bioRxiv 1: 063891.

MINFOF (2017). The Management Plan for Korup National Park and its peripheral zone 20172021. Buea, Cameroon: Regional Delegation of the Ministry of Forestry and Wildlife.

Morgan, D., Sanz, C., Onononga, J.R., and Strindberg, S., (2006). Ape Abundance and Habitat Use in the Goualougo Triangle, Republic of Congo. International Journal of Primatology 27: 147-179.

Nasi, R., Taber, A., and Van Vliet, N., (2011). Empty forests, empty stomachs? Bushmeat and livelihoods in the Congo and Amazon Basins. International Forestry Review 13: 355-368.

Nchanji, A.C., and Plumptre, A., (2001). Seasonality in elephant dung decay and implications for censusing and population monitoring in south-western Cameroon. African Journal of Ecology 39: 24-32.

Norris, K., Asase, A., Collen, B., Gockowski, J., Mason, J., Phalan, B., and Wade, A., (2010). Biodiversity in a forest-agriculture mosaic - The changing face of West African rainforests. Biological Conservation 143: 2341-2350. 
Oates, J.F., Abedi-Lartey, M., McGraw, W.S., Struhsaker, T.T., and Whitesides, G.H., (2000). Extinction of a West African red colobus monkey. Conservation Biology 14: 1526-1532.

Oates, J.F., Bergl, R.A., and Linder, J.M., (2004). Africa's Gulf of Guinea Forests: Biodiversity Patterns and Conservation Priorities. Center for Applied Biodiversity Science, Conservation International.

Okon, D., and Ekobo, A., (2007). Monitoring Large Mammals and Human Activities in Korup National Park. Report to WWF - Coastal Forests, (SAWA) Program. Buea, Cameroon.

Poulsen, J.R., Clark, C.J., Mavah, G., and Elkan, P.W., (2009). Bushmeat supply and consumption in a tropical logging concession in northern Congo. Conservation Biology 23: $1597-1608$.

Poulsen, J.R., Clark, C.J., and Bolker, B.M., (2011). Decoupling the effects of logging and hunting on an Afrotropical animal community. Ecological Applications 21: 1819-1836.

Poulsen, J.R., Koerner, S.E., Moore, S., Medjibe, V.P., Blake, S., et al., (2017). Poaching empties critical Central African wilderness of forest elephants. Current Biology 27: R134-R135.

Plumptre, A.J., and Cox, D., (2006). Counting primates for conservation: primate surveys in Uganda. Primates 47:65-73.

Plumptre, A.J., Nixon, S., Kujirakwinja, D.K., Vieilledent, G., Critchlow, R., et al., (2016). Catastrophic decline of world's largest primate: $80 \%$ loss of Grauer's gorilla, (Gorilla beringei graueri) population justifies Critically Endangered status. PLoS ONE 11: e0162697.

R Core Team (2019). R: A Language and Environment for Statistical Computing, (version 3.5.3). R Foundation for Statistical Computing, Vienna, Austria. https://www.Rproject.org/. Accessed 17 March 2019.

Rainey, H.J., Iyenguet, F.C, Malanda, G.-A.F., Madzoke, B., Dos Santos, D., Stokes, E.J., Maisels, F., and Strindberg, S., (2009). Survey of Raphia swamp forest, Republic of Congo, indicates high densities of Critically Endangered western lowland gorillas Gorilla gorilla gorilla. Oryx 44(1): 124-132.

Remis, M.J., and Jost Robinson, C.A., (2012). Reductions in primate abundance and diversity in a multiuse protected area: synergistic impacts of hunting and logging in a Congo Basin forest. American Journal of Primatology 74: 02-612.

Spey, I.-K., Kupsch, D., Bobo, K.S., Waltert, M., and Schwarze, S., (2019). The Effects of Road Access on Income Generation. Evidence from an integrated conservation and development project in Cameroon. Sustainability 11: 3368 . 
Stokes, E.J., Strindberg, S., Bakabana, P.C., Elkan, P.W., Iyenguet, F.C., et al., (2010). Monitoring great ape and elephant abundance at large spatial scales: Measuring effectiveness of a conservation landscape. PLoS ONE 5: e10294.

Stoner, C., Caro, T., Mduma, S., Mlingwa, C., Sabuni, G., and Borner, M., (2007). Assessmentof effectiveness of protection strategies in Tanzania based on a decade of surveydata for large herbivores. Conservation Biology 21: 635-646.

Strona, G., Stringer, S.D., Vieilledenta, G., Szantoi, Z., Garcia-Ulloaf, J., and Wich, S.A., (2018). Small room for compromise between oil palm cultivation and primate conservation in Africa.

Struhsaker, T.T., Struhsaker, P.J., and Siex, K.S., (2005). Conserving Africa's rain forests: problems in protected areas and solutions. Biological Conservation 123: 45-54.

Theuerkauf, J., and Gula, R., (2010). Towards standardisation of population estimates: defecation rates of elephants should be assessed using a rainfall model. Annales Zoologici Fennici 47: 398-402.

Tranquilli, S., Abedi-Lartey, M., Amsini, F., Arranz, L., Asamoah, A., et al., (2012). Lack of conservation effort rapidly increases African great ape extinction risk. Conservation Letters 5: 48-55.

Tranquilli, S., Abedi-Lartey, M., Abernethy, K., Amsini, F., Asamoah, A., et al., (2014). Protected Areas in Tropical Africa: Assessing Threats and Conservation Activities. PLoS ONE 9: e114154.

Viquerat, S.M.A., Bobo, K.S., Müller, M., Kiffner, C., and Waltert, M., (2012). Estimating forest duiker, (Cephalophinae) density in Korup National Park: a case study on the performance of three line transect methods. South African Journal of Wildlife Research 42: $1-10$.

Waltert, M., Lien, Faber, K., and Mühlenberg, M., (2002). Further declines of threatened primates in the Korup Project Area, south-west Cameroon. Oryx 36: 257-265.

Western, D., Russell, S., and Cuthill, I., (2009). The status of wildlife in protected areas compared to non-protected areas of Kenya. PLoS ONE 4: e6140.

Willcox, A.S., and Nambu, D.M., (2007). Wildlife hunting practices and bushmeat dynamics of the Banyangi and Mbo people of Southwestern Cameroon. Biological Conservation 134: 251-261. 


\subsection{Supplement}

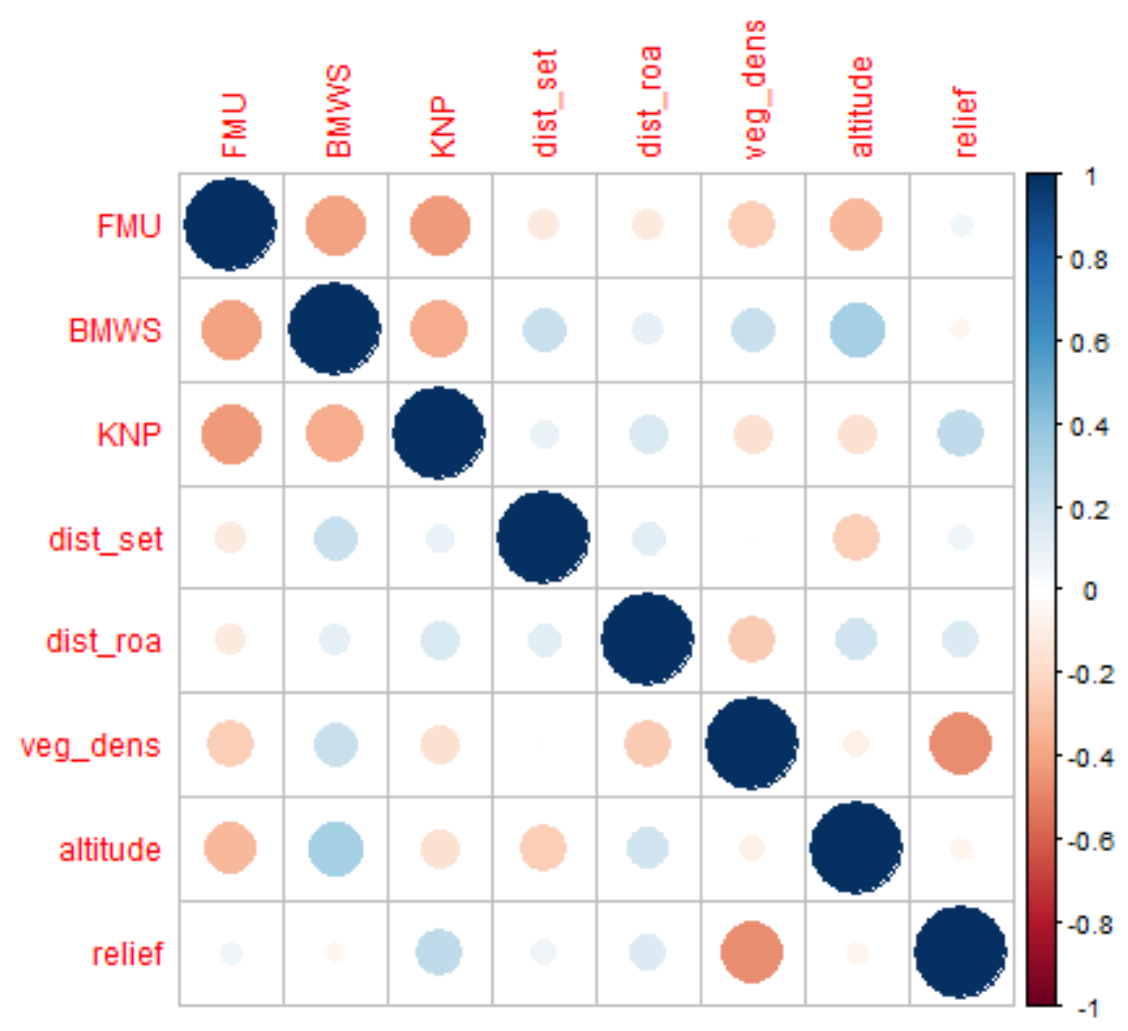

Figure S2.1 - Correlation matrix plot of predictor variables used for GLM analyses 
CHAPTER 2 


\section{PART III}

EFFECTS OF AGRO-INDUSTRY AND OTHER LAND USES ON BIODIVERSITY IN SOUTHWEST CAMEROON 



\section{Chapter 3 \\ High critical forest habitat thresholds of native bird communities in Afrotropical agroforestry landscapes}

\section{Publication}

Denis Kupsch, Elleni Vendras, Carolina Ocampo-Ariza, Peter Batáry, Francis Njie Motombi, Kadiri Serge Bobo and Matthias Waltert, 2019, Biological Conservation 230:20-28. https://doi.org/10.1016/j.biocon.2018.12.001

\subsection{Abstract}

Our knowledge on the relationship between tropical forest cover and biotic communities is still limited. Understanding the relationship between forest cover and bird functional guilds may serve as a valuable tool to assess how much forest is necessary to conserve significant portions of typical forest assemblages. We sampled birds (198 species, 6,883 encounters) along a full gradient of deforestation across $4,000 \mathrm{~km}^{2}$ of forest-dominated landscapes in Southwest Cameroon and applied multivariate adaptive regression splines to model $\alpha$-, $\beta$ - and $\gamma$-richness of guilds in relation to forest cover. Overall, $\beta$ - and $\gamma$-richness remained constant above $42 \%$ forest cover. However, total $\alpha$-richness as well as all richness partitions of Guinea-Congo biome-restricted, large-bodied arboreal foliage gleaning, tree nesting, and frugivorous species declined when forest cover was below 74\%. Moreover, ant-followers and terrestrial insectivores showed their highest diversity at zero deforestation. In contrast, open-land, granivorous, opportunistic insectivorous and widespread species strongly increased below $42 \%$ forest cover. High $\beta$-diversity at intermediate deforestation conditions indicate that the sharp decline of original forest bird diversity may only be compensated by habitat and foraging generalists, which benefit from high habitat heterogeneity. Our study implies that Afrotropical forest bird diversity decreases non-linearly with forest loss. Critical habitat thresholds estimated by us at above $70 \%$ are much higher than those previously reported and highlight the need to integrate substantial proportions of natural vegetation within wildlife friendly farming schemes.

\subsection{Introduction}

For more than two decades, there has been a debate on how much forest is needed to maintain diversity in a landscape context. In his pioneering review on the effects of woodland cover on bird and mammal species, Andrén (1994) argued for a minimum of 10\% to 30\% forest cover needed to preserve a substantial portion of original species diversity. In the following years, numerous field studies on various taxa have found support for a critical threshold hypothesis. 
Whereas several bird (e.g. Cushman and McGarigal 2003, Radford et al. 2005), invertebrate (e.g. Bergman et al. 2004), and multi-taxa studies (Banks-Leite et al. 2014, Ochoa-Quintero et al. 2015) are in line with Andrén's proposed threshold range, others suggest a minimum forest cover level of $40 \%$ to $50 \%$ for amphibians (e.g. Gibbs 1998), invertebrates (Schmidt and Roland 2006), birds (e.g. Martensen et al. 2012, Morante-Filho et al. 2015), and mammals (Reunanen et al. 2004). Moreover, some authors have failed to find evidence of non-linear relations between forest cover and species richness or occurrence in birds (e.g. Villard et al. 1999) as well as lizards and birds (Lindenmayer et al. 2005). Besides an undeniable effect of landscape configuration (Fahrig 2003, Villard et al. 1999), these contradicting results suggest that species' responses to deforestation are determined by their ecological characteristics (Andrén 1994, Luck and Daily 2003, Maas et al. 2009). Although many of the before-mentioned studies focused on birds, our knowledge on the response patterns of functional guilds of complete bird communities remains limited. Respective studies are needed to predict ecological consequences related to land-use change and deforestation (Lewis 2009), which can influence conservation management efforts in forested landscapes (Metzger and Décamps 1997).

Conversion of forests to simplified land-use systems usually leads to changes in bird species composition with altered proportions of functional groups and less specialized bird communities (Harvey and Villalobos 2007, Maas et al. 2009, Şekercioğlu 2012). Some groups have been found to persist at high levels of species richness or even increase at intermediate disturbance or forest cover levels, i.e. as nectarivores or frugivores. This is presumably due to high primary productivity and food availability in systems such as agroforests (Gomes et al. 2008, Waltert et al., 2005). Large-bodied and insectivorous species tend to decrease with increasing deforestation rates and get replaced by small-sized and granivorous or omnivorous species that become highly abundant in open agricultural areas (Newbold et al. 2012, Senior et al. 2013).

Until today, very little is known about the effects of deforestation and land-use intensification on functional bird diversity in the Guineo-Congolian forest belt. Our study area lies within the heart of the Gulf of Guinea forest, which represents the largest continuous forest block in the biodiversity hotspot West African forests (Oates et al. 2004). In this region, land-use change from a growing human population and from industrial oil palm expansion is imminent (Linder and Palkovitz 2016). In this study, we aimed to identify potential critical habitat thresholds for various guilds. We applied multivariate adaptive regression splines on bird data collected along a deforestation gradient from $0 \%$ to $100 \%$ at a local scale. The diversity measures used are based on diversity partitioning (alpha, beta, and gamma richness) as well as a series of diversity indices with increasing community weights. We expected that relationships between diversity in bird guilds and forest cover are non-linear. We further expected that critical habitat thresholds would be guild-specific and appear at intermediate deforestation levels for habitat, feeding and foraging generalists and at lower deforestation levels for more specialized forest bird species. 


\subsection{Materials and methods}

\section{Study area}

The study was conducted inside the Korup region in the Ndian Division of Southwest Cameroon $\left(4^{\circ} 54^{\prime} \mathrm{N}\right.$ to $5^{\circ} 23^{\prime} \mathrm{N}$ and $8^{\circ} 44^{\prime} \mathrm{E}$ to $\left.9^{\circ} 7^{\prime} \mathrm{E}\right)$. The altitude varies between 50 and $800 \mathrm{~m}$ a.s.l. The average yearly rainfall is $5272 \mathrm{~mm}$ and the average daily temperature ranges from a minimum of 22.7 to a maximum of $30.6{ }^{\circ} \mathrm{C}$ (Chuyong et al. 2004). The study area (Fig. 3.1) is part of the largest continuous rainforest block in Western Africa, the Cross-Sanaga-Bioko coastal forests, located within the Gulf of Guinea Biodiversity Hotspot (Oates et al. 2004). The area is sparsely populated, with small villages and agroforests both inside and around the Korup National Park (KNP). For birds, Rodewald et al. (1994) listed 390 species in Korup National Park and its surroundings, of which twelve were considered as endemic montane forest species for the Cross-Sanaga region. One of the few intensified land-use systems in the region, an oil palm plantation estate of PAMOL Plantations Plc., is located at the southern end of KNP, separated from the park by the Mana River. This plantation (5,804 ha) was set up with oil palms (Elaeis guineensis) in 1928.

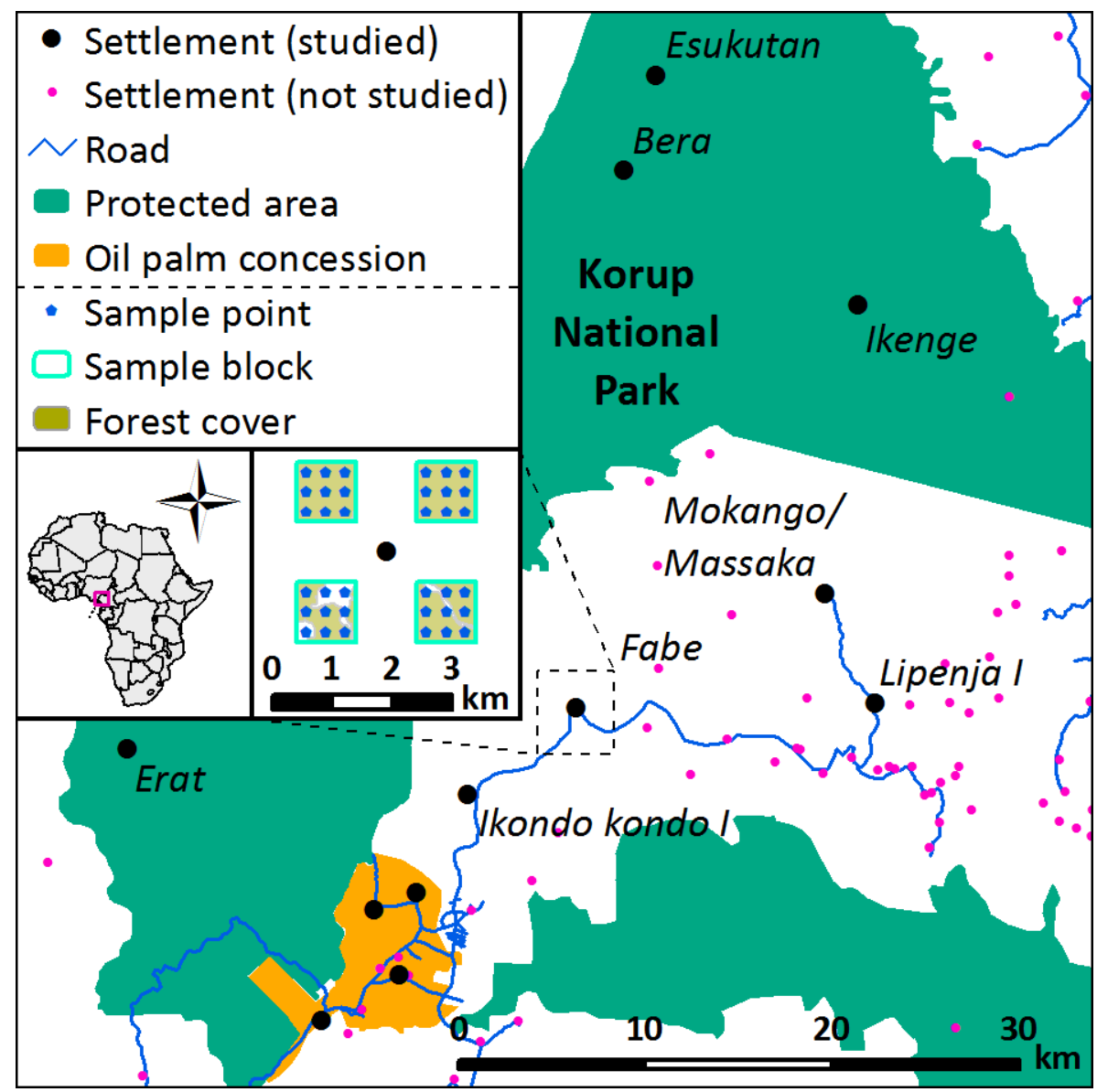

Figure 3.2 - Map of the study area in Southwest Cameroon and an illustration of the study design at settlement level (here: Fabe village). 


\section{Bird sampling}

We systematically sampled bird communities around twelve villages, equitably distributed in three different landscapes, namely 1) inside evergreen rainforest in KNP, 2) in the agroforestry landscapes outside the park and 3) in PAMOL. We used the center of each settlement to define the midpoint of a grid consisting of nine $1 \mathrm{~km} \times 1 \mathrm{~km}$ blocks (Fig. 3.1). Of these nine blocks, the four extreme corner blocks were sampled, resulting in 48 sampled blocks in twelve sample sites. Since we know from own bird surveys in the region (e.g. Waltert et al. 2005) that nine repeats are sufficient to saturate species accumulation curves and derive reliable richness estimates (Colwell 2016), we placed nine sample points within each sample block, spaced 333 $\mathrm{m}$ each (Fig. 3.1). Hence, we also complied with the recommended minimum distance between sample points to avoid multiple counting ( $250 \mathrm{~m}$; Ralph et al. 1995). Therefore, we surveyed a total of 432 sample points across the whole study area.

We began bird point count sampling (Ralph et al. 1995) in June and July 2013, and finalized the survey from May to June 2014. In both years, the survey team consisted of one expert ornithologist (FNM) and one assistant (mainly EV and DK). At each sample point we once recorded all seen or heard bird species for a period of ten minutes in the morning (6-11 h) or afternoon (15-18 h). Bird species identification followed Borrow and Demey (2001). To reduce disturbance caused by noises and movements of the survey team, we opened paths to the sample points at least one day before data collection and waited for at least two minutes after the arrival at each point before starting the sample protocol. Only presence-absence data were taken and flyovers, i.e. birds not interacting with the surveyed area, were discarded before analyses.

\section{Data analysis}

Following Fotso et al. (2001), Fry et al. (2004), and Waltert et al. (2005), we classified the recorded bird species by feeding guild (carnivorous, frugivorous, granivorous, insectivorous, nectarivorous, and omnivorous), foraging guild (arboreal foliage gleaner, sallyier foliage gleaner, bark gleaner, sallyier, terrestrial and opportunistic miscellaneous insectivore), habitat preference (forest specialists, generalists, and open-land species), nest site affiliation (ground, bush, shrub, and tree breeders), and range size (Guineo-Congolian biome-restricted and nonbiome-restricted species). Additionally, we categorized large canopy frugivores (turacos, parrots, and hornbills), ant-followers, which track the raids of army or driver ants of the genus Dorylus to prey on animals flashed by the ants (including occasional ant-followers; Peters and Okalo 2009, Willis 1985), and size classes of arboreal foliage gleaners (small, medium, and large)

We combined satellite imagery interpretation and ground-truthing to assess forest cover. For this, we searched the NASA archive for the most recent LANDSAT images prior to the field 
survey in 2013. Given that from 2003 on, all images contain stripes, several cloud-free scenes per year were needed to cover the entire study area. Barely cloud contaminated LANDSAT ETM+ images (30 m pixel size) were found for January 2013/December 2012 and December 2012/November 2012 for the southern/central and most northern part of our study area, respectively. We created forest cover maps for each sample grid and printed them for ground truthing, which we performed with locals from the closest settlements. At every sample site we spent at least four days walking a minimum of $5 \mathrm{~km}$ pathways through each $1 \mathrm{~km}^{2}$ sampling block to increase the accuracy of forest cover estimates and detect most recent changes due to farm opening. We used GPS devices for field work and processed all maps in ESRI ArcGIS 10.3 .

We did not estimate detection probably, since neither a distance sampling nor an occupancy modelling approach was followed. Previous work in the region showed that $>90 \%$ of bird observations were of acoustic nature so that results are highly likely unbiased by habitat except from the smaller canopy dwelling nectarivores who seemingly are underrecorded in high forest compared to secondary habitats (Waltert et al. 2005). However, we standardized observer and sampling efforts (see also Methods 2.2) to limit sources of heterogeneity. Therefore, our count statistics were referred to as indices (Yoccoz et al. 2001) and focused our analysis and discussion solely on relative diversity changes. We used two different approaches to dissect the structure of bird communities. First, since previous research pointed out that beta diversity is more consistent between taxa and, therefore, provides a higher indicator value than alpha (or gamma) diversity (Kessler et al. 2009, Schulze et al. 2004), we analyzed the response of withinmicrohabitat (at sampling points; referring to alpha richness, $\alpha$ ), between-microhabitat (beta, $\beta$ ) and within-sampling block $\left(1 \mathrm{~km}^{2}\right.$; gamma, $\left.\gamma\right)$ species richness. We followed the additive partitioning method (equation 3.1; Veech 2002), which allows straightforward comparison of species assemblage partitions.

Eq. (3.1) $\quad \gamma=\alpha+\beta$

Since alpha is calculated as mean species richness per sample point (Veech 2002), it also serves as an equivalent to the relative abundance of the sample block and can, therefore, be interpreted as the niche breadth of a focus guild or group. In addition, richness estimates for $\gamma$-richness were done using the classical formula of the first-order Jackknife estimator in EstimateS 9.1 (Colwell 2016). 
Second, to assess the effect of community weights and their implication on diversity values within analysed bird groups, we used Shannon (equation 3.2) and Rényi's entropy (equation 3.3) to calculate a series of diversity indices from order one to four (Tóthmérész 1995):

Eq. (3.2)

Eq. (3.3)

$$
\begin{aligned}
& x_{s h}=-\sum_{i=1}^{S} p_{i} \ln p_{i} \\
& x_{r e}=\left(-\ln \sum_{i=1}^{S} p_{i}^{q}\right) /(1-q)
\end{aligned}
$$

where $p$ is the frequency of species $i$, derived from its relative abundance, and $q$ is the order of the diversity index value $x$.

Since we compared responses of different diversity measures, we converted the index values into effective numbers $(D)$ of species following Jost (2006; equation 3.4).

Eq. (3.4)

$$
D=\exp (x)
$$

We examined the change of bird diversity along the gradient of forest cover using multivariate adaptive regression splines (MARS) based on linear models (Friedman, 1991) through the earth package in $\mathrm{R}$ version 3.4.1 (Milborrow 2016, R Core Team 2017). We allowed a maximum number of six terms before pruning. We used cross-validation (with 30 cross-validations and five cross-validation folds) as well as classical backward pruning and selected the better fitting model by comparison of the generalized $\mathrm{R}^{2}$ value. We also tested the performance of elevation (mean elevation of sampling points per block) and landscape (KNP, unprotected agroforestry, oil palm plantation) as single as well as interacting covariates to forest cover. However, both elevation and landscape were of less importance compared to forest cover, since model fitting decreased after inclusion of the variables (Table S3.2). In most cases, earth did even remove the terms from the models due to non-significance. Therefore, we removed both covariates from our analysis and focused on the main predictor variable forest cover.

Finally, we analyzed the response of all recorded bird species to forest cover using redundancy analysis (RDA) through the vegan package in $\mathrm{R}$ (Oksanen et al. 2016). The species matrix was constrained using forest cover and Hellinger transformed prior to the analyses, which allows a RDA with species data tables that contain many zeros (Legendre and Gallagher 2001). F-values and p-values were obtained by permutation tests based on 999 permutations.

We tested for spatial autocorrelation in model residuals using a spatial correlogram and global Morans' I test for spatial autocorrelation in the ade4 (Dray et al. 2007) and ncf packages (Bjørnstad and Cai 2018) for R. These packages assesses p-values using randomization. Neither Moran's $I$ test $\left(I_{\text {Total community }}=-0.101, p=0.999\right)$ nor the correlogram (Fig. S3.1) of the total community model on observed $\gamma$-diversity indicated spatial autocorrelation. At the level of bird guilds and groups, we focused our discussion on the non-autocorrelated models (two out of thirty models showed spatial autocorrelation; Table S3.1). 


\subsection{Results}

We recorded a total of 6,883 bird encounters and 198 bird species along 432 sampling points (Table S3.3). They belonged to 43 families, with Pycnonotidae (22 species) being the most species-rich family in the study area followed by Sylviidae (13) and Ploceidae (11). All encountered birds could be identified to species level. At sampleblock level $\left(1 \mathrm{~km}^{2}\right)$, we recorded slightly more species in agroforestry matrices outside the national park than inside, whereas species richness in the oil palm plantation was the lowest (Table 3.1).

Table 3.3 - Summary of forest cover and species richness figures as well as sampling effort at sampling block level $\left(1 \mathrm{~km}^{2}\right)$ in the three survey landscapes; means are presented with SD; richness estimates are based on the classical first-order Jackknife estimator; KNP - Korup National Park, UAF - unprotected agroforestry matrix; OPP - oil palm plantation.

\begin{tabular}{|c|c|c|c|c|c|c|c|c|c|}
\hline & \multicolumn{3}{|c|}{ Forest cover } & \multirow{2}{*}{$\begin{array}{l}\text { Sampling } \\
\text { effort (min) }\end{array}$} & \multicolumn{5}{|c|}{ p-diversity at $1 \mathbf{k m}^{2}(\mathrm{n})$} \\
\hline & mean & $\min$ & $\max$ & & total & $\begin{array}{c}\text { mean } \\
\text { observed }\end{array}$ & $\begin{array}{c}\text { mean } \\
\text { expected }\end{array}$ & $\min$ & $\max$ \\
\hline KNP & $\begin{array}{c}0.88 \\
( \pm 0.14)\end{array}$ & 0.52 & 1.00 & 1440 & 140 & $\begin{array}{c}58.31 \\
( \pm 9.26)\end{array}$ & $\begin{array}{c}78.09 \\
( \pm 13.60)\end{array}$ & 44 & 78 \\
\hline UAF & $\begin{array}{c}0.87 \\
( \pm 0.11)\end{array}$ & 0.64 & 1.00 & 1440 & 145 & $\begin{array}{c}60.38 \\
( \pm 11.14)\end{array}$ & $\begin{array}{c}82.60 \\
( \pm 15.93)\end{array}$ & 38 & 82 \\
\hline OPP & $\begin{array}{c}0.10 \\
( \pm 0.13)\end{array}$ & 0.00 & 0.42 & 1440 & 123 & $\begin{array}{c}37.50 \\
( \pm 11.54)\end{array}$ & $\begin{array}{c}53.72 \\
( \pm 17.90)\end{array}$ & 23 & 62 \\
\hline
\end{tabular}

\section{Bird guild responses to forest cover}

With the exception of some groups (ground and bush nest builders, carnivorous and omnivorous feeders, sallier foragers, and bark gleaners), our MARS models obtained high $\mathrm{R}^{2}$ values above 0.30 (Figs. 3.2, 3.3). Observed and estimated total gamma richness of the total community reached their maxima at $42 \%$ of forest cover, remaining stable above. Whereas beta richness, which accounted for almost $70 \%$ of the observed species richness across the gradient of forest cover, showed the same pattern, alpha richness only peaked at $74 \%$ of forest cover (Fig. 3.2).

Only few bird guilds showed similar responses to that of the entire community (insectivorous feeders, sallier-foliage gleaners, and medium-sized arboreal foliage gleaners). Frugivorous, forest specialists, biome-restricted, and large canopy bird richness indicators, however, reached their maximum at $74 \%$ of forest cover. Alpha and gamma richness of large-sized arboreal foliage gleaners increased until $81 \%$ of forest cover, whereas its beta component and the estimated gamma richness peaked at $92 \%$. The highly specialized group of ant-following birds did not show any threshold response to forest cover. This guild showed the highest values for all diversity components at $100 \%$ forest cover. For terrestrial insectivorous, tree-nesting, and arboreal foliage gleaning birds the alpha richness peaked at high forest cover rates, whereas 
their beta components already formed brinks at $42 \%$. However, the observed gamma richness of these groups also peaked at $74 \%$ of forest cover (Fig. 3.2).

At intermediate forest cover, habitat generalists, nectarivores and shrub-nesters showed highest beta and gamma richness at intermediate forest cover rates of $15 \%$ to $42 \%$. However, the alpha richness in nectarivorous and shrub-nesting birds peaked at higher forest cover rates, whereas it remained nearly unchanged across the entire gradient in granivores (Fig. 3.2).
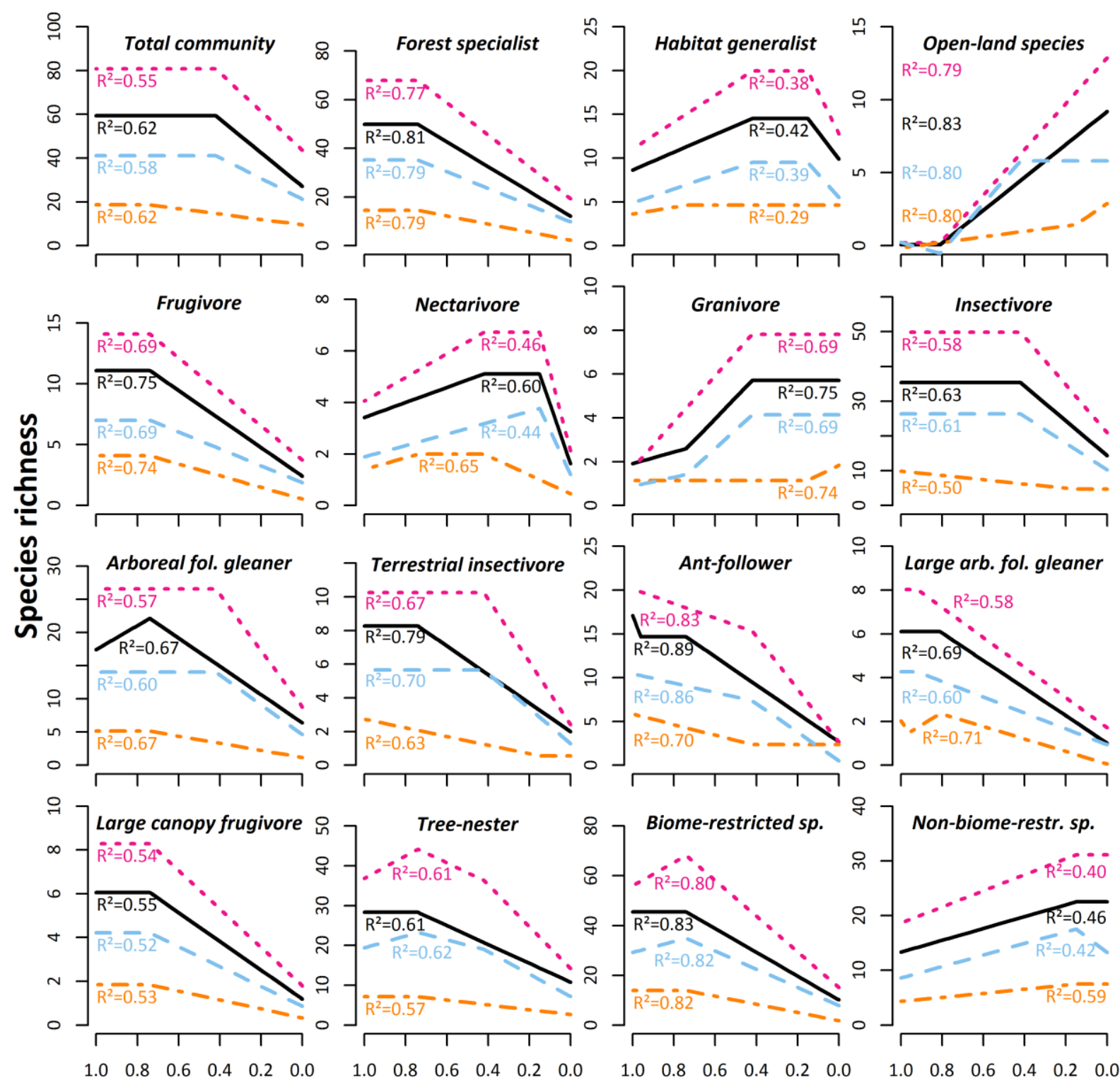

Forest cover

Figure 3.3 - Response patterns of within-microhabitat (alpha; orange dot-dashed line), betweenmicrohabitat (beta; skyblue dashed line), observed (black solid line) and estimated within-block (gamma; pink dotted line) species richness to changes in forest cover in most studied bird groups (see Fig. S3.1 for the remaining groups) corresponding to the best-fitting MARS models; richness estimates are based on the classical first-order Jackknife estimator. 
Among the different feeding guilds, only granivores were found in high species numbers at low forest cover. Their beta and gamma richness was highest between $0 \%$ and $42 \%$ forest cover and lower above, whereas their alpha diversity remained low across the entire gradient with a small peak at $0 \%$ forest cover (Fig. 3.2). The response of open-habitat specialists was even more pronounced: all species richness components dropped down to zero at $81 \%$ and were highest at $0 \%$ forest cover. Only beta richness remained stable at a high level below $42 \%$ forest cover. The group of non-biome-restricted species showed a threshold at $15 \%$ forest cover, above which all diversity components decreased. The response of miscellaneous insectivorous foragers was more complex. Whereas within- and beta richness decreased across the gradient with thresholds at $42 \%$ and $74 \%$ of forest cover, observed and estimated gamma richness were lowest at $74 \%$ and highest between $0 \%$ and $42 \%$ of forest cover (Fig. S3.2).

\section{Effects of community weights}

The general pattern of most guild responses to forest did not differ when adding weight to frequent species (Figs. 3.3 and S3.3). Generally, effective numbers decreased with increasing order of the diversity index and, therefore, increases and declines appeared to be less steep. For some groups, such as insectivorous, biome-restricted and non-biome-restricted species, we observed dissimilarities of more than $50 \%$ in effective numbers across the gradient between order zero (species richness) and Rényi's fourth-order entropy. In contrast, some groups did not differ greatly, such as nectarivorous, terrestrial insectivorous, and medium-sized arboreal foliage gleaners. Effective numbers of forest specialist, frugivorous, large canopy, and antfollowing species only decreased strongly in highly forested blocks when adding community weights, but remained on a generally low level in open areas (Fig. 3.3).

However, in some groups the thresholds at which species numbers remain stable changed with higher orders of diversity indices. This was the case for the total bird community, the arboreal foliage gleaners and the non-biome-restricted species, where the threshold shifted from lower ( $15 \%$ and $42 \%$ ) to higher forest cover rates ( $42 \%$ and $74 \%$ ). When adding community weights, habitat generalists reached a single peak at $42 \%$ forest cover and decreased below, while openland species remained stable below the same threshold instead of showing an increase of species numbers. The more weight we added to frequent species, the more pronounced became the decline and increase of miscellaneous and terrestrial insectivorous bird guilds, respectively, along the gradient of forest cover. Shrub-breeding species numbers peaked at intermediate forest cover in first order but not second to fourth order diversity indices. 

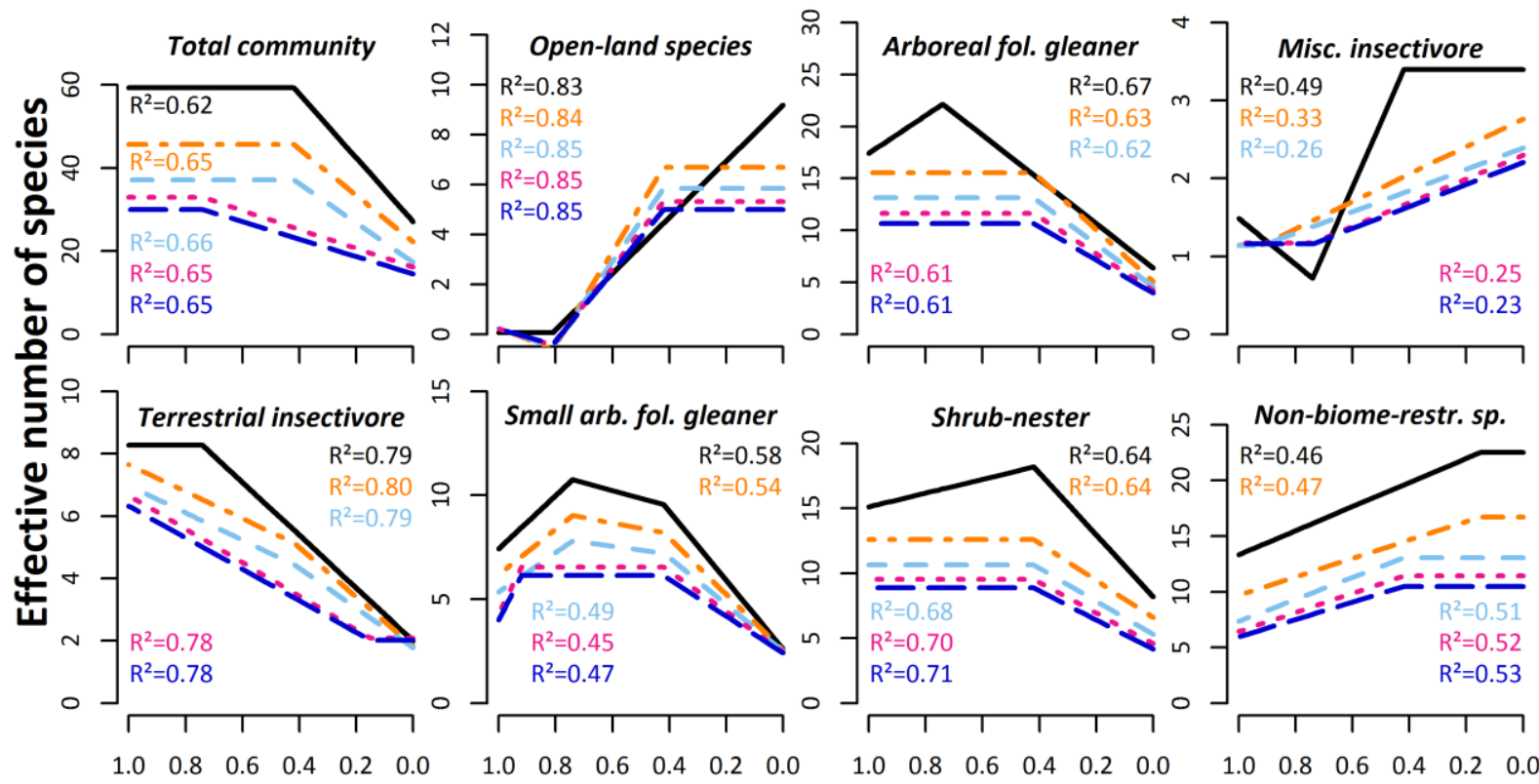

Forest cover

Figure 3.4 - Response patterns of observed within-block (gamma) species richness (black solid line), Shannon (orange dot-dashed line) as well as Rényi's second-order (skyblue dashed line), third-order (pink dotted line) and fourth-order entropy (blue coarse-dashed line) species richness to changes in forest cover in some studied bird groups (see Fig. S3.3 for the remaining groups) corresponding to the best-fitting MARS models; all diversity indices are expressed in effective numbers (see Jost 2006).

\section{Species-specific responses to forest cover}

Forest cover explained a significant part of the variance in bird species composition (proportion of constrained inertia $=31.54 \% ;$ Pseudo $\left.-F_{1,46}=21.19, \mathrm{p}=0.001\right)$ within the redundancy analyses. Bird communities related to high forest cover were dominated by biome-restricted species, which are mainly either arborial foliage gleaners or terrestrial insectivores (Table 3.2, Figs. S3.4-S3.11). We also observed a significant share of ant-following birds in highly forested areas with only a few common species, such as African thrush (Turdus pelios) and common bulbul (Pycnonotus barbatus), remaining in open areas. Widespread, open-land, granivorous, and miscellaneous insectivorous species were mainly negatively associated with forest cover. Species that showed a weak response to forest cover were mainly insectivores with various foraging strategies (Table 3.2). 
Table 3.4 - Bird species with strongest (positive and negative) and weakest association with forest cover in the RDA; RDA axis 1 is fully associated with forest cover (see Fig S3.1). Habitat preference: F - forest species, G - generalist, O - open-land species; Feeding guild: F - frugivore, G - granivore, I - insectivore, O - omnivore; Insectivore foraging guild: AFG - arboreal foliage gleaner, MISC - opportunistic miscellaneous insectivore, SA - sallyier, SFG - sallyier foliage gleaner, T - terrestrial insectivore; AFG size group: L - large, M - medium, S - small; Nest site: B - bush, G - ground, S - shrub, T - tree; Geographical range: A - Africa, BR - biome-restricted (Guineo-Congolian endemic), SUB - sub-Saharan Africa, TRA tropical Africa; Others: Ant - Ant-follower, LCB - large canopy bird.

\begin{tabular}{|c|c|c|c|c|c|c|c|c|}
\hline Scientific Name & $\begin{array}{l}\text { RDA1 } \\
\text { Score }\end{array}$ & Habitat & Feeding & Foraging & $\begin{array}{l}\text { AFG } \\
\text { Size }\end{array}$ & Nesting & Range & Others \\
\hline \multicolumn{9}{|c|}{ Positive association with forest cover } \\
\hline Criniger chloronotus & -0.29 & $\mathrm{~F}$ & I & AFG & $\mathrm{L}$ & $\mathrm{S}$ & BR & Ant \\
\hline Deleornis fraseri & -0.29 & $\mathrm{~F}$ & 1 & AFG & $\mathrm{S}$ & $\mathrm{T}$ & $\mathrm{BR}$ & - \\
\hline Bleda syndactyla & -0.29 & $\mathrm{~F}$ & 1 & $\mathrm{~T}$ & - & B & $\mathrm{BR}$ & Ant \\
\hline Illadopsis rufipennis & -0.27 & $\mathrm{~F}$ & I & $\mathrm{T}$ & - & $\mathrm{B}$ & $\mathrm{BR}$ & Ant \\
\hline Neocossyphus poensis & -0.27 & $\mathrm{~F}$ & I & $\mathrm{T}$ & - & - & $\mathrm{BR}$ & Ant \\
\hline Bleda notata & -0.27 & $\mathrm{~F}$ & 1 & $\mathrm{~T}$ & - & $\mathrm{S}$ & $\mathrm{BR}$ & Ant \\
\hline Turtur afer & -0.27 & $\mathrm{~F}$ & G & - & - & B & TRA & - \\
\hline Ceuthmochares aereus & -0.26 & $\mathrm{~F}$ & 1 & AFG & $\mathrm{L}$ & $\mathrm{S}$ & TRA & - \\
\hline Sarothrura pulchra & -0.26 & $\mathrm{~F}$ & I & - & - & G & $\mathrm{BR}$ & - \\
\hline Tricholaema hirsuta & -0.26 & $\mathrm{~F}$ & I & AFG & $\mathrm{S}$ & $\mathrm{B}$ & $\mathrm{BR}$ & - \\
\hline \multicolumn{9}{|c|}{ Negative association with forest cover } \\
\hline Cisticola anonymus & 0.35 & $\mathrm{O}$ & 1 & MISC & - & G & $\mathrm{BR}$ & - \\
\hline Lonchura bicolor & 0.34 & $\mathrm{O}$ & G & - & - & $\mathrm{T}$ & TRA & - \\
\hline Camaroptera brachyura & 0.34 & G & 1 & MISC & - & B & SUB & - \\
\hline Platysteira cyanea & 0.33 & $\mathrm{O}$ & I & SA & - & $\mathrm{T}$ & TRA & - \\
\hline Streptop. semitorquata & 0.33 & $\mathrm{~F}$ & G & - & - & $\mathrm{T}$ & SUB & - \\
\hline Turdus pelios & 0.31 & G & 1 & $\mathrm{~T}$ & - & $\mathrm{T}$ & TRA & Ant \\
\hline Estrilda melpoda & 0.30 & $\mathrm{O}$ & G & - & - & G & TRA & - \\
\hline Pycnonotus barbatus & 0.30 & G & $\mathrm{O}$ & - & - & $\mathrm{S}$ & A & Ant \\
\hline Cinnyris chloropygius & 0.28 & G & $\mathrm{N}$ & - & - & $\mathrm{S}$ & TRA & - \\
\hline Ploceus ocularis & 0.28 & G & 1 & AFG & M & $\mathrm{S}$ & TRA & - \\
\hline \multicolumn{9}{|c|}{ Weak association with forest cover } \\
\hline Chrysococcyx cupreus & 0.01 & G & 1 & AFG & M & $\mathrm{S}$ & TRA & - \\
\hline Camaroptera chloronota & -0.01 & $\mathrm{~F}$ & I & AFG & $\mathrm{S}$ & G & $\mathrm{BR}$ & - \\
\hline Malimbus scutatus & -0.02 & $\mathrm{~F}$ & । & SFG & - & $\mathrm{T}$ & $\mathrm{BR}$ & - \\
\hline Ceyx picta & -0.02 & G & 1 & MISC & - & $\mathrm{O}$ & TRA & - \\
\hline Gymnobucco calvus & -0.03 & G & $\mathrm{F}$ & - & - & $\mathrm{T}$ & $\mathrm{BR}$ & - \\
\hline Camaroptera superciliaris & -0.03 & $\mathrm{~F}$ & I & AFG & $\mathrm{S}$ & $\mathrm{S}$ & $\mathrm{BR}$ & - \\
\hline Halcyon malimbica & -0.03 & $\mathrm{~F}$ & 1 & MISC & - & $\mathrm{S}$ & TRA & - \\
\hline Tockus fasciatus & -0.04 & $\mathrm{~F}$ & $\mathrm{O}$ & - & - & $\mathrm{T}$ & $\mathrm{BR}$ & $\mathrm{LCB}$ \\
\hline Nigrita fusconota & -0.04 & $\mathrm{~F}$ & 1 & AFG & $\mathrm{S}$ & $\mathrm{S}$ & $\mathrm{BR}$ & - \\
\hline Andropadus virens & 0.05 & G & I & MISC & - & G & TRA & Ant \\
\hline
\end{tabular}




\subsection{Discussion}

\section{Differential responses to changes in forest cover}

Our results support previous findings of low species numbers in bird assemblages of highly deforested landscapes (e.g. Andrén, 1994, Martensen et al. 2012, Waltert et al. 2005). Above $42 \%$ forest cover, overall gamma richness remained stable, but species composition changed strongly along the gradient of forest cover.

The response pattern to deforestation of insectivore gamma richness was congruent with that of the entire bird community, though showing a more pronounced decline below $42 \%$ forest coverage. Low tree, bush, and liana density and diversity under intensified land-use have presumably reduced bark and foliage gleaners' richness; instead, opportunistic miscellaneous insectivores were more prominent. Though small- and medium-sized foliage gleaners also showed diversity declines below 74\% remaining forest cover, large foliage gleaners were affected the most, already decreasing at $81 \%$. This might be attributed to greater energy requirements that might not be met due to bottom-up effects of reduced or changed resource availability (Senior et al. 2013). Among the group of insectivorous birds, terrestrial foragers were most sensitive to deforestation. While beta richness started declining below $74 \%$ forest cover, alpha species diversity as well as diversity indices under community weight even indicates a steady decline without any threshold. Warmer microclimate due to lower canopy cover as well as lacking leaf litter might change the ground arthropod fauna and, therefore, negatively affect the foraging opportunities of terrestrial insectivores (Waltert et al. 2005).

Ant-following birds also showed a severe and steady decline in alpha, beta as well as gamma richness along the entire gradient of deforestation. Only few of the recorded 26 ant-following bird species are omnivorous (Andropadus latirostris, Baeopogon indicator, Pycnonotus barbatus, Thescelocichla leucopleura), whereas most are highly specialized and depend on the occurrence of army ant raids. Those specialists are believed to be among the first to disappear in altered tropical rainforest environments (Peters et al. 2008). Various studies documented the higher-order effects of fragmented forests associated with the rapid loss of specialized antfollowing birds (e.g. Peters and Okalo 2009, Turner 1996). In small forest fragments in Western Kenya, the decline of highly specialized ant-followers was associated with changes in army ant composition. Although overall army ant abundances remained stable, the forest-dependent army ant species, Dorylus wilverthii, declined along with forest fragment size, whereas Dorylus molestus increased (Peters and Okalo 2009). The latter is a generalist found in various habitats from forest to dry bushland (Gotwald 1995). However, its diurnal activity strongly depends on humidity, ceasing when conditions are too dry (Willis 1985), which has in turn a negative effect on the foraging success of ant-following birds. Although the ecological mechanisms behind the decline of ant-followers under deforestation regimes in West Africa are not yet studied, Peters 
and Okalo's (2009) findings underline the importance of high forest cover for the conservation of this highly sensitive bird guild.

Thirteen granivorous bird species were recorded throughout the study area with increasing richness from forested to open areas. Whereas the granivorous blue-headed wood dove (Turtur brehmeri) seemed to be a characteristic species for natural forests, six other species were recorded exclusively in deforested areas. In line with previous studies (Clough et al. 2009, Şekercioğlu 2012, Waltert et al. 2005), diversity in granivores was highest at low forest coverage attributed to higher food availability due to the increased abundance and diversity of herbs and grasses under open conditions (Waltert et al. 2005).

Also, nectar-feeding birds seem to thrive with some deforestation. In previous studies, nectarivores often showed highest species richness in moderately human-modified landscapes (e.g. Schulze et al. 2004, Şekercioğlu 2012), but low diversity in highly deforested and homogeneous land-use systems, such as oil palm plantations (Clough et al. 2009, Tscharntke et al. 2008). In addition, higher species richness in nectarivores was found not to be related to their abundance, which seems to decrease more pronouncedly with increasing habitat modification (Newbold et al. 2013, Waltert et al. 2004). This is in line with our results, which show highest gamma richness between 15 and 42\%, whereas relative abundance was highest above $42 \%$. On the one hand, hump-shaped richness patterns of nectarivores might be explained by higher productivity and greater food resources in agroforestry matrices (Şekercioğlu 2012, Tscharntke et al. 2008). On the other hand, it might also be attributed to sampling limitations: canopy nectarivores are very difficult to detect in natural forests due to small sizes and thin vocalizations. Presence-absence data of nectarivores might therefore be biased towards humanmodified landscapes and conclusions on conservation management implications should be drawn with caution (Waltert et al. 2005).

In accordance with previous studies (e.g. Gomes et al. 2008, Martensen et al. 2012), diversity values of frugivorous birds showed a pronounced response to deforestation, with a sharp decrease below $74 \%$ of forest cover. Compared to forests, structurally diverse agroforestry systems may retain a similar frugivore species richness and up to $75 \%$ of their abundance (Harvey and Villalobos 2007). However, the composition of frugivorous assemblages also depends on floristic characteristics (Luck and Daily 2003) as well as on the proximity of natural rainforest (Moran and Catterall 2014). Presumably due to low resource availability, frugivores may not sustain in highly deforested areas (Senior et al. 2013). This particularly accounts for large canopy frugivores, which are known to depend on large forest remnants (Galetti et al. 2013). Apart from the semi-granivorous grey parrot (Psittacus erithacus), which used to regularly feed on oil palm nuts in plantation areas, this group was nearly absent in sample blocks with less than $42 \%$ of remaining forest cover. Yet, large canopy frugivores are of special 
conservation concern, since they are important long-distance dispersers of large seeds, while being prone to poaching (Galetti et al. 2013).

Ground-nesting birds seem to benefit marginally from the open nature of industrial agricultural systems, which might be due to the limited presence of mammal predators (unpubl. data, DK). Bush-breeders, on the other hand, show an opposite, albeit weak, response, with slightly higher alpha and gamma richness above $42 \%$ and $74 \%$ of forest cover, respectively. Presumably due to more heterogeneous and abundant nesting sites, some infrequent shrub-breeding species profited from half-open habitats, whereas tree-nesting bird richness naturally depends on high forest cover. Also the proportion of species with unknown breeding ecology was higher in forested areas, which reflects the need for more research on the ecology of forest-dependent birds.

The most distinct differences we observed between forested and open areas were in regard to biogeographic distribution of the recorded bird species. Whereas Guineo-Congolian biomerestricted species clearly dominated the bird assemblages in highly forested blocks, their alpha and gamma richness strongly declined below $74 \%$ forest cover. On the contrary, widespread species, such as Senegal coucal (Centropus senegalensis), barn swallow (Hirundo rustica) or black kite (Milvus migrans), showed highest richness in deforested landscapes below 15\% forest cover. In addition, also within the non-biome-restricted species group, we found differential responses to forest cover related to distribution; whereas beta and gamma richness of species bound to the African tropics dropped below 15\% forest cover. The rest of the group (cosmopolitans and species distributed in Africa, sub-Saharan Africa as well as the Old World) showed highest abundance and diversity in fully deforested blocks (Fig. S3.3). This highlights that landscapes under high land-use intensity and environmental homogenization are not only prone to biotic simplification (Maas et al., 2009), but also to alienation of species assemblages, even if closely bordered by natural habitat.

For some studied bird groups we could not detect clear response patterns: Whereas omnivores might have indeed the ability to adapt to habitat changes due to feeding plasticity, the graphs of aerial feeders and carnivores are presumably artifacts. Due to their prolonged foraging flights, they are more likely to be recorded in open sampling conditions, independently from their abundance or richness.

\section{Bird species composition at intermediate deforestation}

According to the intermediate disturbance hypothesis, which predicts maximum local species richness at intermediate disturbance levels (Gomes et al. 2008, Horn 1975), we expected to find highest diversity values in areas with intermediate forest coverage. However, we only observed this pattern in a few bird guilds, such as the small-sized arboreal foliage gleaners and the shrub- 
nesting species, for which gamma richness peaked around $42 \%$ to $74 \%$ of forest cover. In addition, in many groups the proportion of beta richness tended to be higher at intermediate levels of forest cover as e.g. in arboreal foliage gleaners, terrestrial insectivores and biomerestricted species, indicating higher species turnover rates due to greater habitat heterogeneity, even if the landscape is human-modified (Andrén, 1994, Tscharntke et al. 2012). Presumably, for the same reason alpha and gamma richness of most guilds including the total bird community already showed a threshold at $42 \%$ of forest cover, albeit not forming any peak at this level. It seems instead that the landscape mosaic at intermediate forest cover provides a wider range of different habitat types, whereas highly forested areas maintain the capacity to harbor a large species pool due to manifold niche diversification (Martensen et al. 2012). Species richness in forest specialists remained high above a level of $74 \%$ but dropped by one third already at $42 \%$ of forest cover. This loss could only be compensated by an increase of generalists and open-land specialists, which benefit from non-forest habitat structures. Another contribution to constantly high total species richness at intermediate forest levels could be caused by an edge effect. As the study took place within the large continuous forest block in and around KNP, most sample blocks of intermediate forest cover were located in the immediate vicinity of (near-)primary forest. Spill-over of birds and/or their prey from the surrounding mature forest might have contributed to the high species richness in the agroforestry matrices (Lucey and Hill 2012, Pardini et al. 2010).

\section{Critical forest thresholds in tropical bird conservation}

Although several studies already documented changes in bird diversity along a gradient of habitat modification (e.g. Maas et al. 2009, Şekercioğlu 2012) or forest cover (e.g. Martensen et al. 2012, Radford et al. 2005) in various settings, our study is the first to illustrate how the rate of forest cover affects functional bird diversity in an African forest-dominated landscape. In general, the response pattern to deforestation found for gamma richness is in line with previous references of minimum habitat requirements of $40-50 \%$ cover to preserve bird diversity (Banks-Leite et al. 2014, Martensen et al. 2012, Morante-Filho et al. 2015, OchoaQuintero et al. 2015), though still being higher than the 10-30\% initially proposed by Andrén (1994). However, it might be misleading to solely base conservation management strategies on diversity values of the overall bird community, since that might mask important changes in species composition, and might therefore not address conservation needs of ecological bird groups of particular conservation concern (Batáry et al. 2011, Maas et al. 2009, Morante-Filho et al. 2015). If a fully forested sampling block would be cleared down to a minimum habitat threshold of about $40 \%$ as indicated by the response of the bird community as a whole, the bird assemblage would lose more than $30 \%$ of the frugivorous, large canopy, and biome-restricted species as well as $40 \%$ of the terrestrial insectivores, large foliage gleaners and ant-followers. 
In addition, granivorous, opportunistic miscellaneous insectivorous, and wide-spread species would immigrate, leading to richness increases of more than $250 \%, 150 \%$ and $200 \%$, respectively. Such a dramatic deviation from a natural bird species composition might have profound and cascading effects on ecosystem processes and services (Banks-Leite et al. 2014). For instance, highly specialized native insectivores may hardly be replaceable by other more generalist taxa in regard to natural pest-control (Şekercioğlu et al. 2004). Also, the decline of nectarivores and frugivores, including large canopy species, which serve as important pollinators and (long-distance) seed dispersers (Luck and Daily 2003, Moran and Catterall, 2014, Şekercioğlu, 2012), may have severe impacts on the reproduction of some plants species and, therefore, on the floral species richness and composition (Clough et al. 2009, Galetti et al. 2013). Consequently, in order to maintain a bird community functionally similar to the original one, the preservation of a minimum of $70 \%$ of forest cover may be needed. Such a critical habitat threshold reflects those of the most specialized forest bird groups and allows for higherorder diversity indices of the overall bird community. Additionally, this would also preserve a substantial proportion of the highly sensitive groups of terrestrial insectivores and antfollowers.

Overall bird species richness may serve as a comparably good indicator for overall species richness (Gardner et al. 2008), but since there is knowledge on bird functional ecology, analyses at the guild level may indicate functional characteristics of the larger ecological system. Diversity changes in bird guilds should therefore be taken into account when planning wildlife friendly landscape conservation. We provide the first analysis of bird diversity responses to forest cover loss based on data from a landscape with largely continuous mature forest only interrupted by loosely scattered settlements and their associated productive land. Such productive land can already hold forest cover rates above 70\% (see also Table 3.1) because it consists of a heterogeneous matrix of primary and secondary forests as well as compartmentalized farmland with shade trees. On the one hand, the Korup region can, therefore, serve as a model to illustrate responses of an original Afrotropical forest bird assemblage to changes in forest cover. On the other hand, these circumstances form the basis to align forest conservation with sustainable development efforts in the West African forest region. While sustaining the well-established network of protected areas (Harvey and Villalobos 2007, Marsden et al. 2006), conservation and development schemes are well-advised to strengthen smallholder farming (Uezo et al. 2008) instead of industrial plantation agriculture to meet nutritional and economic needs (Linder and Palkovitz 2016).

\subsection{References}

Andrén, H., (1994). Effects of habitat fragmentation on birds and mammals in landscapes with different proportions of suitable habitat: a review. Oikos 71: 355-366. 
Banks-Leite, C., Pardini, R., Tambosi, L.R., Pearse, W.D., Bueno, A.A., et al., (2014). Using ecological thresholds to evaluate the costs and benefits of set-asides in a biodiversity hotspot. Science 345: 1041-1045.

Batáry, P., Fischer, J., Báldi, A., Crist, T.O., and Tscharntke, T., (2011). Does habitat heterogeneity increase farmland biodiversity? Frontiers in Ecology and the Environment 9: $152-153$.

Bergman, K.-O., Askling, J., Ekberg, O., Ignell, H., Wahlman, H., and Milberg, P., (2004). Landscape effects on butterfly assemblages in an agricultural region. Ecography 27: 619628.

Bjørnstad, O.N., and Cai, J., (2018). ncf: Spatial Covariance Functions. version 1.2-5. https://cran.r-project.org/web/packages/ncf (assessed 09.07.2018).

Borrow, N., and Demey, R., (2001). The birds of Western Africa. Christopher Helm, London, UK.

Chuyong, G.B., Condit, R., Kenfack, D., Losos, E.C., Moses, S.N., Songwe, N.C., and Thomas, D.W., (2004). Korup Forest Dynamics Plot, Cameroon. In: Losos, E.C., and Leigh Jr., E.G. (Eds.) Tropical forest diversity and dynamism: Findings from a large-scale plot network. University of Chicago Press, Illinois. pp. 506-516.

Clough, Y., Dwi Putra, D., Pitopang, R., and Tscharntke, T., (2009). Local and landscape factors determine functional bird diversity in Indonesian cacao agroforestry. Biological Conservation 142: 1032-1041.

Colwell, R.K., (2016). EstimateS: Statistical estimation of species richness and shared species from samples. Version 9.1. http://purl.oclc.org/estimates (assessed 02.02.2017).

Cushman, S.A., and McGarigal, K., (2003). Landscape-level patterns of avian diversity in the Oregon coast range. Ecological Monograph 73: 259-281.

Dray, S., and Dufour, A.B., (2007). The ade4 package: implementing the duality diagram for ecologists. Journal of Statistical Software 22: 1-20.

Fahrig, L., (2003). Effects of Habitat Fragmentation on Biodiversity. Annual Review of Ecology, Evolution, and Systematics 34: 487-515.

Fotso, R., Dowsett-Lemaire, F., Dowsett, R.J., Club, C.O., Scholte, P., Languy, M., and Bowden, C., (2001). Cameroon. In Fishpool, L.D.C, and Evans, M.I., (Eds.) Important Bird Areas in Africa and associated islands: Priority sites for conservation. Pisces Publications and BirdLife International, Cambridge. pp. 133-160.

Friedman, J.H., (1991). Multivariate adaptive regression splines. Annals of Statistics 19: 1-67. 
Fry, C., Keith, S., Newman, K., Urban, E., 2004. The Birds of Africa. London Academic Press, London, UK.

Galetti, M., Guevara, R., Côrtes, M.C., Fadini, R., Von Matter, S., et al., (2013). Functional Extinction of Birds Drives Rapid Evolutionary Changes in Seed Size. Science 340: 10861089.

Gardner, T.A., Barlow, J., Araujo, I.S., Avila-Pires, T.C.S. et al., (2008). The cost-effectiveness of biodiversity surveys in tropical forests. Ecological Letters 11: 139-150.

Gibbs, J.P., (1998). Distribution of woodland amphibians along a forest fragmentation gradient. Landscape Ecology 13: 263-268.

Gomes, L.G., Oostra, V., Nijman, V., Cleef, A.M., and Kappelle, M., (2008). Tolerance of frugivorous birds to habitat disturbance in a tropical cloud forest. Biological Conservation 141: 860-871.

Gotwald, W.H.J., (1995). Army ants: the biology of social predation. Cornell University Press, New York.

Harvey, C.A., Villalobos, J.A.G., (2007). Agroforestry systems conserve species-rich but modified assemblages of tropical birds and bats. Biodiversity and Conservation 16: 22572292.

Horn, H.S., (1975). Ecology and evolution of communities. In Cody, M.L., and Diamond, J.M., (Eds.) Belknap Press, Cambridge, MA. pp. 196-211.

Jost, L., (2006). Entropy and diversity. Oikos 113: 363-375.

Kessler, M., Abrahamczyk, S., Bos, M., Buchori, D., Putra, D.D., et al., (2009). Alpha and beta diversity of plants and animals along a tropical land-use gradient. Ecological Applications 19: 2142-2156.

Legendre, P., and Gallagher, E.D., (2001). Ecologically meaningful transformations for ordination of species data. Oecologia 129: 271-280.

Lewis, O.T., (2009). Biodiversity change and ecosystem function in tropical forests. Basic and Applied Ecology 10: 97-102.

Lindenmayer, D.B., Fischer J., and Cunningham R.B., (2005). Native vegetation cover thresholds associated with species responses. Biological Conservation 124: 311-316.

Linder, J.M., and Palkovitz, R.E., (2016). The Threat of Industrial Oil Palm Expansion to Primates and Their Habitats. In Waller, M.T. (Ed.) Ethnoprimatology: primate conservation in the 21 st century. Springer, Berlin, Germany. pp. 21-45.

Lucey, J.M., and Hill, J.K., (2012). Spillover of insects from rain forest into adjacent oil palm plantations. Biotropica 44: 368-377. 
Luck, G.W., and Daily, G.C., (2003). Tropical countryside bird assemblages: richness, composition, and foraging differ by landscape context. Ecological Applications 13: 235247.

Maas, B., Putra, D.D., Waltert, M., Clough, Y., Tscharntke, T., and Schulze, C.H., (2009). Six years of habitat modification in a tropical rainforest margin of Indonesia do not affect bird diversity but endemic forest species. Biological Conservation 142: 2665-2671.

Marsden, S.J., Symes, C.T., and Mack, A.L. (2006). The response of a New Guinean avifauna to conversion of forest to small-scale agriculture. Ibis 148: 629-640.

Martensen, A.C., Ribeiro, M.C., Banks-Leite, C., Prado, P.I., and Metzger, J.P., (2012). Associations of forest cover, fragment area, and connectivity with Neotropical understorey bird species richness and abundance. Conservation Biology 26: 1100-1111.

Metzger, J.-P., Décamps, H., 1997. The structural connectivity threshold: an hypothesis in conservation biology at the landscape scale. Acta Oecol. 18, 1-12.

Milborrow, S., (2017). earth: Multivariate Adaptive Regression Splines. Derived from mda:mars by Trevor Hastie and Rob Tibshirani. Uses Alan Miller's Fortran utilities with Thomas Lumley's leaps wrapper. version 4.5.1. http://CRAN.Rproject.org/package=earth/ (assessed 02.08.2017).

Moran, C., Catterall, C.P., 2014. Responses of Seed-Dispersing Birds to Amount of Rainforest in Landscape around Fragments. Conserv. Biol. 28, 551:560.

Morante-Filho, J.C., Faria, D., Mariano-Neto, E., and Rhodes, J., (2015). Birds in anthropogenic landscapes: the responses of ecological groups to forest loss in the Brazilian Atlantic forest. PLoS ONE 10: e0128923.

Newbold, T., Scharlemann, J.P.W., Butchart, S.H.M., Şekercioğlu, Ç.H., Alkemade, R., Booth, H., and Purves, D.W., (2013). Ecological traits affect the response of tropical forest bird species to land-use intensity. Proceedings of the Royal Society London, Biology 280: 20122131.

Oates, J.F., Bergl, R.A., and Linder, J.M., (2004). Africa's Gulf of Guinea forests: Biodiversity patterns and conservation priorities. Center for Applied Biodiversity Science, Conservation International.

Ochoa-Quintero, J.M., Gardner, T.A., Rosa, I., Barros Ferraz, S.F., and Sutherland, W.J., (2015). Thresholds of species loss in Amazonian deforestation frontier landscapes. Conservation Biology 29: 440-451.

Oksanen, J., Guillaume Blanchet, F., Friendly, M., Kindt, R., Legendre, P., et al., (2017). vegan: Community Ecology Package. version 2.4-3. http://CRAN.R-project.org/package=vegan (assessed 05.07.2017). 
Pardini, R., de Arruda Bueno, A., Gardner, T.A., Prado, P.I., and Metzger, J.P., (2010). Beyond the Fragmentation Threshold Hypothesis: Regime Shifts in Biodiversity Across Fragmented Landscapes. PLoS ONE 5: e13666.

Peters, M.K., Likare, S., and Kraemer, M., (2008). Effects of habitat fragmentation and degradation on flocks of African ant-following birds. Ecological Applications 18: 847858.

Peters, M.K., and Okalo, B., (2009). Severe declines of ant-following birds in African rainforest fragments are facilitated by a subtle change in army ant communities. Biological Conservation 142: 2050-2058.

R Core Team (2017). R: A language and environment for statistical computing. Version 3.4.1. R Foundation for Statistical Computing, Vienna, Austria. https://www.R-project.org/ (assessed 01.07.2017).

Radford, J.Q., Bennett, A.F., and Cheers, G.J. (2005). Landscape level thresholds of habitat cover for woodland-dependent birds. Biological Conservation 124: 317-337.

Ralph, C.J., Droege, S., and Sauer, J.R., (1995). Managing and monitoring birds using point counts: standards and applications. In: Ralph, C.J., Droege, S., Sauer, J.R. (Eds.) Monitoring bird populations by point counts, General Technical Report PSW-GTR-149, USDA Forest Service, Albany. pp. 161-169.

Reunanen, P., Mönkkönen, M., Nikula, A., Hurme, E., and Nivala, V., (2004). Assessing landscape thresholds for the Siberian flying squirrel. Ecological Bulletin 51: 277-286.

Rodewald, P.G., Dejaifve, P.-A., and Green, A.A., (1994). The birds of Korup National Park and Korup Project Area, Southwest Province, Cameroon. Bird Conservation International 4: $1-68$.

Schmidt, B.C., and Roland, J., (2006). Moth Diversity in a Fragmented Habitat: Importance of Functional Groups and Landscape Scale in the Boreal Forest. Annals of the Entomological Society of America 99: 1110-1120.

Schulze, C.H., Waltert, M., Kessler, P.J., Pitopang, R., Veddeler, D., et al., (2004). Biodiversity indicator groups of tropical land-use systems: comparing plants, birds and insects. Ecological Applications 14: 1321-1333.

Şekercioğlu, Ç.H., Daily, G.C., and Ehrlich, P.R., (2004). Ecosystem consequences of bird declines. Proceedings of the National Academy of Sciences of the United States of America 101: 18042-18047.

Şekercioğlu, Ç.H., (2012). Bird functional diversity and ecosystem services in tropical forests, agroforests and agricultural areas. Journal of Ornithology 153: 153-161. 
Senior, M.J.M., Hamer, K.C., Bottrell, S., Edwards, D.P., Fayle, T.M., et al., (2013). Traitdependent declines of species following conversion of rain forest to oil palm plantations. Biodiversity and Conservation 22: 253-268.

Tóthmérész, B., (1995). Comparison of different methods for diversity ordering. Journal of Vegetation Science 6: 283-290.

Tscharntke, T., Şekercioğlu, Ç.H., Dietsch, T.V., Sodhi, N.S., Hoehn, P., and Tylianakis, J.M., (2008). Landscape constraints on functional diversity of birds and insects in tropical agroecosystems. Ecology 89: 944-951.

Tscharntke, T., Tylianakis, J.M., Rand, T.A., Didham, R.K., Fahrig, L., et al., (2012). Landscape moderation of biodiversity patterns and processes - eight hypotheses. Biological Reviews 87: 661-685.

Turner, I., (1996). Species loss in fragments of tropical rain forest: a review of the evidence. Journal of Applied Ecology 33: 200-209.

Uezo, A., Beyer, D.D., and Metzger, J.P., (2008). Can agroforest woodlots work as stepping stones for birds in the Atlantic forest region? Biodiversity and Conservation 17: 19071922.

Veech, J.A., Summerville, K.S., Crist, T.O., and Gering, J.C., (2002). The additive partitioning of species diversity: recent revival of an old idea. Oikos 99: 3-9.

Villard, M.-A., Trzcinski, M.K., and Merriam, G., (1999). Fragmentation effects on forest birds: Relative influence of woodland cover and configuration on landscape occupancy. Conservation Biology 13: 774-783.

Waltert, M., Bobo, K.S., Sainge, N.M., Fermon, H., and Mühlenberg, M., (2005). From forest to farmland: habitat effects on Afrotropical forest bird diversity. Ecological Application 15: $1351-1366$.

Waltert, M., Mardiastuti, A., and Mühlenberg, M., (2004). Effects of land use on bird species richness in Sulawesi, Indonesia. Conservation Biology 18: 1339-1346.

Willis, E.O., (1985). East African Turdidae as safari ant-followers. Institut royal des sciences naturelles de Belgique. Le Gerfaut 75: 140-153.

Yoccoz, N.G., Nichols, J.D., and Boulinier, T., (2001). Monitoring of biological diversity in space and time. Trends in Ecology and Evolution 16: 446-453. 


\subsection{Supplement}

Table S3.1 - Moran's I autocorrelation tests on earth model residuals for all bird guilds (gamma richness).

\begin{tabular}{|c|c|c|c|}
\hline Model & Moran's I & SD & $p$ \\
\hline Total community & -0.101 & -2.048 & 0.999 \\
\hline Forest specialist & -0.093 & -1.845 & 0.990 \\
\hline Habitat generalist & -0.043 & -0.495 & 0.663 \\
\hline Open-land species & -0.059 & -1.008 & 0.849 \\
\hline Carnivore & -0.047 & -0.648 & 0.718 \\
\hline Frugivore & -0.026 & -0.121 & 0.500 \\
\hline Granivore & -0.036 & -0.325 & 0.571 \\
\hline Insectivore & -0.090 & -1.781 & 0.988 \\
\hline Nectarivore & -0.012 & 0.297 & 0.351 \\
\hline Omnivore & -0.010 & 0.342 & 0.321 \\
\hline Sallyier & -0.055 & -0.846 & 0.797 \\
\hline Arboreal foliage gleaner & -0.053 & -0.806 & 0.783 \\
\hline Miscalleneous insectivore & -0.074 & -1.352 & 0.941 \\
\hline Bark gleaner & 0.075 & 2.579 & 0.021 \\
\hline Sallyier foliage gleaner & -0.099 & -2.072 & 0.999 \\
\hline Terrestrial insectivore & -0.022 & 0.014 & 0.447 \\
\hline Ant-follower & -0.109 & -2.285 & 0.999 \\
\hline Large arboreal foliage gleaner & 0.069 & 2.326 & 0.028 \\
\hline Medium-sized arboreal foliage gleaner & -0.077 & -1.439 & 0.956 \\
\hline Small arboreal foliage gleaner & -0.006 & 0.431 & 0.285 \\
\hline Large canopy bird & -0.027 & -0.134 & 0.496 \\
\hline Ground-nester & -0.042 & -0.505 & 0.662 \\
\hline Shrub-nester & -0.054 & -0.843 & 0.798 \\
\hline Bush-nester & -0.086 & -1.698 & 0.991 \\
\hline Tree-nester & -0.092 & -1.821 & 0.993 \\
\hline Biome-restricted & -0.096 & -1.956 & 0.998 \\
\hline Non-biome-restricted & -0.026 & -0.045 & 0.478 \\
\hline Tropical African range & -0.081 & -1.510 & 0.969 \\
\hline Sub-Saharan range & -0.051 & -0.732 & 0.748 \\
\hline African range & -0.018 & 0.179 & 0.379 \\
\hline
\end{tabular}


Table S3.2 - Performance of earth models (gamma species richness against forest cover) with and without elevation and landscape as covariates as well as single response variable models (elevation and landscape)

\begin{tabular}{lll}
\hline Model & Generalized $\mathbf{R}^{2}$ & Observation \\
\hline Forest Cover & 0.5862338 & main model \\
Forest Cover * Elevation & 0.5862338 & elevation unused \\
Forest Cover * Landscape & 0.5777616 & landscape unused \\
Forest Cover * Elevation * Landscape & 0.5777616 & landscape and elevation unused \\
Elevation & 0.1774103 & - \\
Landscape & 0.4498074 & - \\
\hline
\end{tabular}


Table S3.3 - Bird species recorded during the survey sorted by family with information on the total records, their feeding and foraging guilds, size of arboreal foliage gleaners as well as nest and habitat affiliation. Habitat preference: $\mathbf{F}$ - forest species, $\mathbf{G}$ - generalist, $\mathbf{O}$ - open-land species; Feeding guild: C - carnivore, F - frugivore, G - granivore, I - insectivore, $\mathrm{O}$ - omnivore; Foraging guild: AFG - arboreal foliage gleaner, BG - bark gleaner, MISC - miscellaneous insectivore,

SA - sallyier, SFG - sallyier foliage gleaner, T - terrestrial insectivore; AFG size group: L - large, M - medium, S - small; Nest site: B - bush, G - ground, O - others, S - shrub, T - tree; Geographical range: A - Africa, BR - biome-restricted (Guineo-Congolian endemic), COS - cosmopolitan, OW - Old World, SUB - sub-Saharan Africa, TRA - tropical Africa; Others: Ant - Ant-follower, LCB - large canopy bird.

\begin{tabular}{|c|c|c|c|c|c|c|c|c|c|}
\hline Scientific Name & English Name & Records & Feeding & Foraging & AFG Size & Habitat & Nesting & Range & Others \\
\hline \multicolumn{10}{|l|}{ Accipitridae } \\
\hline Accipiter melanoleucus & Black Sparrowhawk & 1 & $\mathrm{C}$ & - & - & G & $\mathrm{T}$ & TRA & - \\
\hline Accipiter tachiro & African Goshawk & 2 & $\mathrm{C}$ & - & - & $\mathrm{F}$ & $\mathrm{T}$ & SUB & - \\
\hline Dryotriorchis spectabilis & Congo Serpent Eagle & 5 & C & - & - & $\mathrm{F}$ & - & $\mathrm{BR}$ & - \\
\hline Gypohierax angolensis & Palmnut Vulture & 3 & $\mathrm{O}$ & - & - & $\mathrm{F}$ & $\mathrm{T}$ & SUB & - \\
\hline Kaupifalco monogrammicus & Lizard Buzzard & 1 & $\mathrm{C}$ & - & - & $\mathrm{F}$ & - & TRA & - \\
\hline Lophaetus occipitalis & Long-crested Eagle & 1 & C & - & - & G & $\mathrm{T}$ & SUB & - \\
\hline Milvus migrans & Black Kite & 2 & C & - & - & $\mathrm{O}$ & $\mathrm{T}$ & ow & - \\
\hline Polyboroides typus & African Harrier Hawk & 16 & $\mathrm{C}$ & - & - & G & $\mathrm{T}$ & SUB & - \\
\hline Stephanoaetus coronatus & Crowned Eagle & 1 & $\mathrm{C}$ & - & - & $\mathrm{F}$ & $\mathrm{T}$ & TRA & - \\
\hline Urotriorchis macrourus & Long-tailed Hawk & 4 & C & - & - & $\mathrm{F}$ & $\mathrm{T}$ & $\mathrm{BR}$ & - \\
\hline \multicolumn{10}{|l|}{ Alcedinidae } \\
\hline Alcedo cristata & Malachite Kingfisher & 2 & $\mathrm{C}$ & - & - & $\mathrm{F}$ & G & SUB & - \\
\hline Alcedo quadribrachys & Shining-blue Kingfisher & 16 & C & - & - & $\mathrm{F}$ & $\mathrm{O}$ & TRA & - \\
\hline Ceyx picta & African Pygmy Kingfisher & 14 & 1 & MISC & - & G & $\mathrm{O}$ & TRA & - \\
\hline Halcyon badia & Chocolate-backed Kingfisher & 13 & 1 & MISC & - & $\mathrm{F}$ & $S$ & $\mathrm{BR}$ & Ant \\
\hline Halcyon malimbica & Blue-breasted Kingfisher & 20 & I & MISC & - & $\mathrm{F}$ & $S$ & TRA & - \\
\hline \multicolumn{10}{|l|}{ Apodidae } \\
\hline Apus affinis & Little Swift & 5 & 1 & SA & - & G & $\mathrm{O}$ & OW & - \\
\hline Cypsiurus parvus & African Palm Swift & 4 & 1 & SA & - & G & $\mathrm{O}$ & SUB & - \\
\hline Neafrapus cassini & Cassin's Spinetail & 5 & 1 & SA & - & $\mathrm{F}$ & - & $\mathrm{BR}$ & - \\
\hline Rhaphidura sabini & Sabine's Spinetail & 3 & I & SA & - & $\mathrm{F}$ & $\mathrm{T}$ & $\mathrm{BR}$ & - \\
\hline
\end{tabular}




\begin{tabular}{|c|c|c|c|c|c|c|c|c|c|}
\hline \multicolumn{10}{|l|}{ Ardeidae } \\
\hline Ardea melanocephala & Black-headed Heron & 2 & $\mathrm{O}$ & - & - & $\mathrm{O}$ & $\mathrm{T}$ & SUB & - \\
\hline \multicolumn{10}{|l|}{ Bucerotidae } \\
\hline Bycanistes albotibialis & White-thighed Hornbill & 34 & $\mathrm{~F}$ & - & - & $\mathrm{F}$ & $\mathrm{T}$ & $\mathrm{BR}$ & LCB \\
\hline Bycanistes fistulator & Piping Hornbill & 43 & $\mathrm{~F}$ & - & - & $\mathrm{F}$ & $\mathrm{T}$ & $\mathrm{BR}$ & $\mathrm{LCB}$ \\
\hline Ceratogymna atrata & Black-casqued Hornbill & 32 & $\mathrm{~F}$ & - & - & $\mathrm{F}$ & $\mathrm{T}$ & $\mathrm{BR}$ & LCB \\
\hline Ceratogymna elata & Yellow-casqued Hornbill & 101 & $\mathrm{~F}$ & - & - & $\mathrm{F}$ & $\mathrm{T}$ & $\mathrm{BR}$ & LCB \\
\hline Horizocerus albocristatus & White-crested Hornbill & 8 & 1 & SFG & - & $\mathrm{F}$ & $\mathrm{T}$ & $\mathrm{BR}$ & LCB, Ant \\
\hline Tockus camurus & Red-billed Dwarf Hornbill & 17 & 1 & SFG & - & $\mathrm{F}$ & $\mathrm{T}$ & $\mathrm{BR}$ & $\mathrm{LCB}$, Ant \\
\hline Tockus fasciatus & African Pied Hornbill & 36 & $\mathrm{O}$ & - & - & $\mathrm{F}$ & $\mathrm{T}$ & $\mathrm{BR}$ & LCB \\
\hline \multicolumn{10}{|l|}{ Campephagidae } \\
\hline Campephaga quiscalina & Purple-throated Cuckoo-shrike & 1 & I & AFG & $\mathrm{L}$ & $\mathrm{F}$ & $\mathrm{T}$ & TRA & - \\
\hline Coracina azurea & Blue Cuckoo-shrike & 41 & 1 & AFG & $\mathrm{L}$ & $\mathrm{F}$ & $\mathrm{T}$ & $\mathrm{BR}$ & - \\
\hline \multicolumn{10}{|l|}{ Capitonidae } \\
\hline Buccanodon duchaillui & Yellow-spotted Barbet & 203 & $\mathrm{~F}$ & - & - & $\mathrm{F}$ & $\mathrm{T}$ & $\mathrm{BR}$ & - \\
\hline Gymnobucco bonapartei & Grey-throated Barbet & 16 & $\mathrm{~F}$ & - & - & $\mathrm{F}$ & $\mathrm{T}$ & TRA & - \\
\hline Gymnobucco calvus & Naked-faced Barbet & 13 & $\mathrm{~F}$ & - & - & G & $\mathrm{T}$ & $\mathrm{BR}$ & - \\
\hline Gymnobucco peli & Bristle-nosed Barbet & 30 & $\mathrm{~F}$ & - & - & $\mathrm{F}$ & $\mathrm{T}$ & $\mathrm{BR}$ & - \\
\hline Pogoniulus atroflavus & Red-rumped Tinkerbird & 54 & $\mathrm{~F}$ & - & - & G & $\mathrm{T}$ & $\mathrm{BR}$ & - \\
\hline Pogoniulus bilineatus & Yellow-rumped Tinkerbird & 12 & $\mathrm{~F}$ & - & - & G & $\mathrm{T}$ & TRA & - \\
\hline Pogoniulus scolopaceus & Speckled Tinkerbird & 39 & $\mathrm{~F}$ & - & - & $\mathrm{F}$ & $\mathrm{T}$ & $\mathrm{BR}$ & - \\
\hline Pogoniulus subsulphureus & Yellow-throated Tinkerbird & 250 & $\mathrm{~F}$ & - & - & $\mathrm{F}$ & $\mathrm{S}$ & $\mathrm{BR}$ & - \\
\hline Trachylaemus purpuratus & Yellow-billed Barbet & 48 & $\mathrm{~F}$ & - & - & $\mathrm{F}$ & $\mathrm{S}$ & $\mathrm{BR}$ & - \\
\hline Tricholaema hirsuta & Hairy-breasted Barbet & 56 & $\mathrm{~F}$ & - & - & $\mathrm{F}$ & $\mathrm{T}$ & $\mathrm{BR}$ & - \\
\hline \multicolumn{10}{|l|}{ Caprimulgidae } \\
\hline Veles binotatus & Brown Nightjar & 1 & I & SA & - & $\mathrm{F}$ & $\mathrm{S}$ & $\mathrm{BR}$ & - \\
\hline \multicolumn{10}{|l|}{ Cisticolidae } \\
\hline Cisticola anonymus & Chattering Cisticola & 72 & I & MISC & - & $\mathrm{O}$ & G & $\mathrm{BR}$ & - \\
\hline
\end{tabular}




\begin{tabular}{|c|c|c|c|c|c|c|c|c|c|}
\hline Prinia bairdii & Banded Prinia & 1 & 1 & AFG & $\mathrm{S}$ & $\mathrm{F}$ & G & TRA & - \\
\hline Prinia leucopogon & White-chinned Prinia & 1 & I & AFG & M & $\mathrm{F}$ & B & TRA & - \\
\hline \multicolumn{10}{|l|}{ Columbidae } \\
\hline Streptopelia semitorquata & Red-eyed Dove & 49 & G & - & - & $\mathrm{F}$ & $\mathrm{T}$ & SUB & - \\
\hline Treron calvus & African Green Pigeon & 50 & $\mathrm{~F}$ & - & - & G & $\mathrm{T}$ & TRA & - \\
\hline Turtur afer & Blue-spotted Wood Dove & 73 & G & - & - & $\mathrm{F}$ & B & TRA & - \\
\hline Turtur brehmeri & Blue-headed Wood Dove & 241 & G & - & - & $\mathrm{F}$ & $\mathrm{S}$ & $\mathrm{BR}$ & - \\
\hline Turtur tympanistria & Tambourine Dove & 76 & G & - & - & $\mathrm{F}$ & $\mathrm{S}$ & TRA & - \\
\hline \multicolumn{10}{|l|}{ Coraciidae } \\
\hline Eurystomus gularis & Blue-throated Roller & 7 & 1 & SA & - & $\mathrm{F}$ & $\mathrm{T}$ & $\mathrm{BR}$ & - \\
\hline \multicolumn{10}{|l|}{ Corvidae } \\
\hline Corvus albus & Pied Crow & 28 & $\mathrm{O}$ & - & - & $\mathrm{O}$ & $\mathrm{T}$ & SUB & - \\
\hline \multicolumn{10}{|l|}{ Cuculidae } \\
\hline Centropus leucogaster & Black-throated Coucal & 52 & 1 & $\mathrm{~T}$ & - & $\mathrm{F}$ & G & $\mathrm{BR}$ & - \\
\hline Centropus monachus & Blue-headed Coucal & 20 & 1 & $\mathrm{~T}$ & - & $\mathrm{F}$ & B & TRA & - \\
\hline Centropus senegalensis & Senegal Coucal & 29 & 1 & $\mathrm{~T}$ & - & $\mathrm{O}$ & $\mathrm{S}$ & A & - \\
\hline Cercococcyx olivinus & Olive Long-tailed Cuckoo & 8 & 1 & AFG & L & $\mathrm{F}$ & G & BR & - \\
\hline Ceuthmochares aereus & Yellowbill & 60 & 1 & AFG & L & $\mathrm{F}$ & $\mathrm{S}$ & TRA & - \\
\hline Chrysococcyx cupreus & African Emerald Cuckoo & 16 & 1 & AFG & M & G & $\mathrm{S}$ & TRA & - \\
\hline Chrysococcyx klaas & Klaas's Cuckoo & 9 & 1 & AFG & M & G & $\mathrm{S}$ & SUB & - \\
\hline Clamator levaillantii & Levaillant's Cuckoo & 2 & 1 & AFG & L & $\mathrm{F}$ & - & SUB & - \\
\hline Cuculus clamosus & Black Cuckoo & 29 & 1 & AFG & L & $F$ & $S$ & SUB & - \\
\hline Cuculus solitarius & Red-chested Cuckoo & 43 & 1 & AFG & L & G & $\mathrm{S}$ & SUB & - \\
\hline \multicolumn{10}{|l|}{ Dicruridae } \\
\hline Dicrurus atripennis & Shining Drongo & 67 & $\mathrm{I}$ & SFG & - & $\mathrm{F}$ & $\mathrm{T}$ & $\mathrm{BR}$ & Ant \\
\hline Dicrurus modestus & Velvet-mantled Drongo & 4 & 1 & SFG & - & G & $\mathrm{T}$ & TRA & - \\
\hline \multicolumn{10}{|l|}{ Estrildidae } \\
\hline Estrilda melpoda & Orange-cheeked Waxbill & 21 & $\mathrm{G}$ & - & - & 0 & $\mathrm{G}$ & TRA & - \\
\hline
\end{tabular}




\begin{tabular}{|c|c|c|c|c|c|c|c|c|c|}
\hline Lonchura bicolor & Black-and-White Mannikin & 38 & G & - & - & $\mathrm{O}$ & $\mathrm{T}$ & TRA & - \\
\hline Nigrita bicolor & Chestnut-breasted Negrofinch & 25 & I & AFG & $\mathrm{S}$ & G & $\mathrm{T}$ & $\mathrm{BR}$ & - \\
\hline Nigrita canicapillus & Grey-headed Negrofinch & 14 & । & AFG & $\mathrm{S}$ & G & $\mathrm{T}$ & TRA & - \\
\hline Nigrita fusconota & White-breasted Negrofinch & 29 & । & AFG & $\mathrm{S}$ & $\mathrm{F}$ & $\mathrm{T}$ & $\mathrm{BR}$ & - \\
\hline Nigrita luteifrons & Pale-fronted Negrofinch & 22 & I & AFG & $\mathrm{S}$ & $\mathrm{F}$ & $\mathrm{S}$ & $\mathrm{BR}$ & - \\
\hline Parmoptila woodhousei & Woodhouse's Antpecker & 14 & । & AFG & $S$ & $\mathrm{~F}$ & $\mathrm{~T}$ & $\mathrm{BR}$ & - \\
\hline Pyrenestes ostrinus & Black-bellied Seedcracker & 1 & G & - & - & $\mathrm{F}$ & $\mathrm{T}$ & TRA & - \\
\hline Spermestes cucullata & Bronze Mannikin & 1 & G & - & - & $\mathrm{O}$ & $\mathrm{T}$ & SUB & - \\
\hline Spermophaga haematina & Western Bluebill & 20 & $\mathrm{O}$ & - & - & $\mathrm{F}$ & B & $\mathrm{BR}$ & - \\
\hline \multicolumn{10}{|l|}{ Eurylaimidae } \\
\hline Smithornis rufolateralis & Rufous-sided Broadbill & 14 & । & SA & - & $\mathrm{F}$ & B & $\mathrm{BR}$ & - \\
\hline \multicolumn{10}{|l|}{ Hirundinidae } \\
\hline Cecropis abyssinica & Lesser-striped Swallow & 3 & । & SA & - & $\mathrm{O}$ & $\mathrm{O}$ & SUB & - \\
\hline Cecropis daurica & Red-rumped Swallow & 7 & । & SA & - & $\mathrm{O}$ & $\mathrm{O}$ & OW & - \\
\hline Hirundo rustica & Barn Swallow & 3 & । & SA & - & $\mathrm{O}$ & $\mathrm{s}$ & $\cos$ & - \\
\hline Petrochelidon fuliginosa & Forest Swallow & 8 & । & SA & - & G & $\mathrm{T}$ & $\mathrm{BR}$ & - \\
\hline Psalidoprocne nitens & Square-tailed Saw-wing & 5 & । & SA & - & $\mathrm{F}$ & $\mathrm{O}$ & $\mathrm{BR}$ & - \\
\hline Psalidoprocne pristoptera & Black Saw-wing & 1 & I & SA & - & G & 0 & TRA & - \\
\hline Pseudhirundo griseopyga & Grey-rumped Swallow & 14 & । & SA & - & $\mathrm{O}$ & G & SUB & - \\
\hline \multicolumn{10}{|l|}{ Indicatoridae } \\
\hline Indicator conirostris & Thick-billed Honeyguide & 1 & I & SA & - & $\mathrm{F}$ & - & TRA & - \\
\hline Indicator exilis & Least Honeyguide & 8 & 1 & MISC & - & $\mathrm{F}$ & $\mathrm{s}$ & TRA & - \\
\hline Indicator maculatus & Spotted Honeyguide & 1 & I & MISC & - & G & - & $\mathrm{BR}$ & - \\
\hline Indicator minor & Lesser Honeyguide & 1 & । & MISC & - & $\mathrm{O}$ & - & SUB & - \\
\hline \multicolumn{10}{|l|}{ Jacanidae } \\
\hline Actophilornis africanus & African Jacana & 1 & I & MISC & - & 0 & 0 & SUB & - \\
\hline \multicolumn{10}{|l|}{ Malaconotidae } \\
\hline Chlorophoneus multicolor & Many-coloured Bush-shrike & 16 & । & AFG & $\mathrm{L}$ & $\mathrm{F}$ & $\mathrm{T}$ & TRA & - \\
\hline
\end{tabular}




\begin{tabular}{|c|c|c|c|c|c|c|c|c|c|}
\hline Dryoscopus senegalensis & Black-shouldered Puffback & 2 & 1 & AFG & $\mathrm{M}$ & $\mathrm{F}$ & $\mathrm{T}$ & $\mathrm{BR}$ & - \\
\hline Laniarius leucorhynchus & Sooty Boubou & 11 & 1 & AFG & $\mathrm{L}$ & $\mathrm{F}$ & B & $\mathrm{BR}$ & - \\
\hline Laniarius luehderi & Lühder's Bush-shrike & 4 & 1 & AFG & M & G & $\mathrm{B}$ & TRA & - \\
\hline \multicolumn{10}{|l|}{ Meropidae } \\
\hline Merops variegatus & Blue-breasted Bee-Eater & 1 & 1 & SA & - & $\mathrm{O}$ & $\mathrm{O}$ & TRA & - \\
\hline \multicolumn{10}{|l|}{ Monarchidae } \\
\hline Terpsiphone rufiventer & Red-bellied Paradise Flycatcher & 135 & 1 & SFG & - & $\mathrm{F}$ & $\mathrm{S}$ & $\mathrm{BR}$ & - \\
\hline Terpsiphone rufocinerea & Rufous-vented Paradise Flycatcher & 5 & 1 & SFG & - & $\mathrm{F}$ & $\mathrm{T}$ & $\mathrm{BR}$ & - \\
\hline Terpsiphone viridis & African Paradise Flycatcher & 20 & 1 & SFG & - & $\mathrm{O}$ & $\mathrm{S}$ & SUB & - \\
\hline Trochocercus nitens & Blue-headed Crested Flycatcher & 66 & 1 & AFG & $\mathrm{S}$ & $\mathrm{F}$ & $\mathrm{T}$ & $\mathrm{BR}$ & - \\
\hline \multicolumn{10}{|l|}{ Muscicapidae } \\
\hline Fraseria ocreata & Fraser's Forest Flycatcher & 4 & 1 & AFG & M & $\mathrm{F}$ & $\mathrm{T}$ & $\mathrm{BR}$ & - \\
\hline Muscicapa comitata & Dusky-blue Flycatcher & 1 & 1 & SFG & - & G & $\mathrm{S}$ & $\mathrm{BR}$ & - \\
\hline Muscicapa infuscata & Sooty Flycatcher & 1 & 1 & SA & - & $\mathrm{F}$ & $\mathrm{T}$ & $\mathrm{BR}$ & - \\
\hline Muscicapa sethsmithi & Yellow-footed Flycatcher & 17 & 1 & SA & - & $\mathrm{F}$ & $\mathrm{S}$ & $\mathrm{BR}$ & Ant \\
\hline Myioparus plumbeus & Grey Tit-flycatcher & 1 & 1 & AFG & $\mathrm{S}$ & G & $\mathrm{S}$ & SUB & - \\
\hline \multicolumn{10}{|l|}{ Musophagidae } \\
\hline Corythaeola cristata & Great Blue Turaco & 35 & $\mathrm{~F}$ & - & - & $\mathrm{F}$ & $\mathrm{T}$ & TRA & LCB \\
\hline Tauraco macrorhynchus & Yellow-billed Turaco & 169 & $\mathrm{~F}$ & - & - & $\mathrm{F}$ & $\mathrm{T}$ & $B R$ & $\mathrm{LCB}$ \\
\hline Tauraco persa & Green Turaco & 2 & $\mathrm{~F}$ & - & - & $\mathrm{F}$ & B & $B R$ & LCB \\
\hline \multicolumn{10}{|l|}{ Nectariniidae } \\
\hline Anthreptes rectirostris & Green Sunbird & 7 & $\mathrm{~N}$ & - & - & $\mathrm{F}$ & $\mathrm{T}$ & $\mathrm{BR}$ & - \\
\hline Chalcomitra rubescens & Green-throated Sunbird & 3 & $\mathrm{~N}$ & - & - & G & $\mathrm{T}$ & $\mathrm{BR}$ & - \\
\hline Cinnyris chloropygius & Olive-bellied Sunbird & 48 & $\mathrm{~N}$ & - & - & G & $\mathrm{S}$ & TRA & - \\
\hline Cinnyris superbus & Superb Sunbird & 24 & $\mathrm{~N}$ & - & - & $\mathrm{F}$ & $\mathrm{T}$ & $\mathrm{BR}$ & - \\
\hline Cyanomitra cyanolaema & Blue-throated Brown Sunbird & 135 & $\mathrm{~N}$ & - & - & G & $\mathrm{S}$ & $\mathrm{BR}$ & - \\
\hline Cyanomitra olivacea & Olive Sunbird & 250 & $\mathrm{~N}$ & - & - & G & $S$ & TRA & - \\
\hline Cyanomitra verticalis & Green-headed Sunbird & 7 & $\mathrm{~N}$ & - & - & G & $\mathrm{S}$ & TRA & - \\
\hline
\end{tabular}




\begin{tabular}{|c|c|c|c|c|c|c|c|c|c|}
\hline Deleornis fraseri & Fraser's Sunbird & 98 & 1 & AFG & $S$ & $\mathrm{~F}$ & $\mathrm{~T}$ & $\mathrm{BR}$ & - \\
\hline Hedydipna collaris & Collared Sunbird & 122 & $\mathrm{~N}$ & - & - & G & $\mathrm{S}$ & TRA & - \\
\hline \multicolumn{10}{|l|}{ Oriolidae } \\
\hline Oriolus brachyrhynchus & Western Black-headed Oriole & 109 & 1 & AFG & L & $\mathrm{F}$ & $\mathrm{T}$ & $\mathrm{BR}$ & - \\
\hline Oriolus nigripennis & Black-winged Oriole & 10 & 1 & AFG & L & G & $\mathrm{T}$ & $\mathrm{BR}$ & - \\
\hline \multicolumn{10}{|l|}{ Passeridae } \\
\hline Passer griseus & Northern Grey-headed Sparrow & 2 & G & - & - & $\mathrm{O}$ & $\mathrm{T}$ & SUB & - \\
\hline \multicolumn{10}{|l|}{ Phalacrocoracidae } \\
\hline Phalacrocorax africanus & Long-tailed Cormorant & 2 & $\mathrm{C}$ & - & - & G & G & SUB & - \\
\hline \multicolumn{10}{|l|}{ Phasianidae } \\
\hline Francolinus lathami & Latham's Forest Francolin & 1 & 1 & $\mathrm{~T}$ & - & $\mathrm{F}$ & G & $\mathrm{BR}$ & - \\
\hline Francolinus squamatus & Scaly Francolin & 4 & G & - & - & $\mathrm{F}$ & G & TRA & - \\
\hline \multicolumn{10}{|l|}{ Picidae } \\
\hline Campethera cailliautii & Little Spotted Woodpecker & 3 & 1 & BG & - & G & $\mathrm{T}$ & TRA & - \\
\hline Campethera caroli & Brown-eared Woodpecker & 2 & 1 & BG & - & $\mathrm{F}$ & $\mathrm{S}$ & $B R$ & - \\
\hline Campethera nivosa & Buff-spotted Woodpecker & 7 & 1 & BG & - & $\mathrm{F}$ & $\mathrm{T}$ & $\mathrm{BR}$ & - \\
\hline Dendropicos fuscescens & Cardinal Woodpecker & 4 & 1 & BG & - & G & $\mathrm{T}$ & SUB & - \\
\hline Dendropicos xantholophus & Yellow-crested Woodpecker & 7 & 1 & BG & - & $\mathrm{F}$ & $\mathrm{T}$ & $B R$ & - \\
\hline Sasia africana & African Piculet & 2 & 1 & BG & - & $\mathrm{F}$ & $\mathrm{S}$ & $\mathrm{BR}$ & - \\
\hline \multicolumn{10}{|l|}{ Platysteiridae } \\
\hline Batis occulta & West African Batis & 1 & 1 & AFG & S & $\mathrm{F}$ & $\mathrm{T}$ & $\mathrm{BR}$ & - \\
\hline Bias musicus & Black-and-White Flycatcher & 3 & 1 & SA & - & G & $\mathrm{T}$ & TRA & - \\
\hline Platysteira castanea & Chestnut Wattle-Eye & 36 & 1 & SA & - & $\mathrm{F}$ & $\mathrm{T}$ & $\mathrm{BR}$ & - \\
\hline Platysteira concreta & Yellow-bellied Wattle-Eye & 7 & 1 & AFG & $S$ & $\mathrm{~F}$ & B & TRA & - \\
\hline Platysteira cyanea & Common Wattle-Eye & 65 & 1 & SA & - & 0 & $\mathrm{~T}$ & TRA & - \\
\hline Platysteira tonsa & White-spotted Wattle-Eye & 23 & I & AFG & $S$ & $\mathrm{~F}$ & $\mathrm{~T}$ & $B R$ & - \\
\hline \multicolumn{10}{|l|}{ Ploceidae } \\
\hline Euplectes afer & Yellow-crowned Bishop & 1 & G & - & - & 0 & G & SUB & - \\
\hline
\end{tabular}




\begin{tabular}{|c|c|c|c|c|c|c|c|c|c|}
\hline Malimbus malimbicus & Crested Malimbe & 2 & 1 & AFG & $M$ & $\mathrm{~F}$ & $\mathrm{~T}$ & $\mathrm{BR}$ & - \\
\hline Malimbus nitens & Blue-billed Malimbe & 36 & 1 & AFG & $M$ & $\mathrm{~F}$ & B & BR & - \\
\hline Malimbus racheliae & Rachel's Malimbe & 4 & I & AFG & $M$ & $\mathrm{~F}$ & $\mathrm{~T}$ & BR & - \\
\hline Malimbus rubricollis & Red-headed Malimbe & 1 & I & AFG & M & $\mathrm{F}$ & $\mathrm{T}$ & BR & - \\
\hline Malimbus scutatus & Red-vented Malimbe & 14 & 1 & SFG & - & $\mathrm{F}$ & $\mathrm{T}$ & $B R$ & - \\
\hline Ploceus albinucha & Maxwell's Black Weaver & 1 & I & AFG & $M$ & $\mathrm{~F}$ & $\mathrm{~T}$ & $\mathrm{BR}$ & - \\
\hline Ploceus cucullatus & Village Weaver & 21 & G & - & - & $\mathrm{O}$ & $\mathrm{T}$ & SUB & - \\
\hline Ploceus nigerrimus & Vieillot's Black Weaver & 19 & I & MISC & - & $\mathrm{F}$ & B & $\mathrm{BR}$ & - \\
\hline Ploceus nigricollis & Black-necked Weaver & 4 & I & AFG & $M$ & $\mathrm{~F}$ & $\mathrm{~S}$ & TRA & - \\
\hline Ploceus ocularis & Spectacled Weaver & 42 & I & AFG & $M$ & G & $\mathrm{S}$ & TRA & - \\
\hline \multicolumn{10}{|l|}{ Psittacidae } \\
\hline Poicephalus gulielmi & Red-fronted Parrot & 16 & G & - & - & $\mathrm{F}$ & $\mathrm{T}$ & TRA & LCB \\
\hline Psittacus erithacus & Grey Parrot & 109 & $\mathrm{~F}$ & - & - & $\mathrm{F}$ & $\mathrm{T}$ & $\mathrm{BR}$ & LCB \\
\hline \multicolumn{10}{|l|}{ Pycnonotidae } \\
\hline Andropadus ansorgei & Ansorge's Greenbul & 37 & 1 & AFG & M & $\mathrm{F}$ & $\mathrm{T}$ & BR & - \\
\hline Andropadus curvirostris & Cameroon Sombre Greenbul & 2 & $\mathrm{O}$ & - & - & $\mathrm{F}$ & - & BR & - \\
\hline Andropadus gracilirostris & Slender-billed Greenbul & 44 & $\mathrm{O}$ & - & - & $\mathrm{F}$ & $\mathrm{T}$ & TRA & - \\
\hline Andropadus gracilis & Little Grey Greenbul & 7 & 1 & AFG & M & $\mathrm{F}$ & $\mathrm{T}$ & $\mathrm{BR}$ & - \\
\hline Andropadus latirostris & Yellow-whiskered Greenbul & 283 & $\mathrm{O}$ & - & - & G & B & TRA & Ant \\
\hline Andropadus virens & Little Greenbul & 355 & $\mathrm{O}$ & - & - & G & G & TRA & Ant \\
\hline Baeopogon clamans & Sjöstedt's Honeyguide Greenbul & 3 & I & AFG & $M$ & $\mathrm{~F}$ & $\mathrm{~T}$ & $\mathrm{BR}$ & - \\
\hline Baeopogon indicator & Honeyguide Greenbul & 28 & 0 & - & - & $\mathrm{F}$ & $\mathrm{T}$ & BR & Ant \\
\hline Bleda notata & Lesser Bristlebill & 85 & I & $\mathrm{T}$ & - & $\mathrm{F}$ & $\mathrm{S}$ & $B R$ & Ant \\
\hline Bleda syndactyla & Red-tailed Bristlebill & 93 & I & $\mathrm{T}$ & - & $\mathrm{F}$ & B & BR & Ant \\
\hline Calyptocichla serina & Golden Greenbul & 17 & $\mathrm{O}$ & - & - & $\mathrm{F}$ & $\mathrm{T}$ & BR & - \\
\hline Criniger calurus & Red-tailed Greenbul & 108 & I & AFG & M & $\mathrm{F}$ & $\mathrm{S}$ & $B R$ & Ant \\
\hline Criniger chloronotus & Eastern Bearded Greenbul & 84 & I & AFG & $\mathrm{L}$ & $\mathrm{F}$ & $\mathrm{S}$ & $\mathrm{BR}$ & Ant \\
\hline Criniger ndussumensis & White-bearded Greenbul & 5 & I & BG & - & $\mathrm{F}$ & - & $\mathrm{BR}$ & - \\
\hline
\end{tabular}




\begin{tabular}{|c|c|c|c|c|c|c|c|c|c|}
\hline Ixonotus guttatus & Spotted Greenbul & 90 & 0 & - & - & $\mathrm{F}$ & $\mathrm{T}$ & $\mathrm{BR}$ & - \\
\hline Nicator chloris & Western Nicator & 163 & 1 & AFG & $\mathrm{L}$ & $\mathrm{F}$ & B & $B R$ & - \\
\hline Nicator vireo & Yellow-throated Nicator & 6 & I & AFG & $M$ & $\mathrm{~F}$ & B & $B R$ & - \\
\hline Phyllastrephus icterinus & Icterine Greenbul & 33 & 1 & AFG & $M$ & $\mathrm{~F}$ & $\mathrm{~S}$ & BR & Ant \\
\hline Phyllastrephus xavieri & Xavier's Greenbul & 16 & I & AFG & $M$ & $\mathrm{~F}$ & B & $\mathrm{BR}$ & - \\
\hline Pycnonotus barbatus & Common Bulbul & 125 & 0 & - & - & G & $\mathrm{S}$ & $A$ & Ant \\
\hline Pyrrhurus scandens & Leaf-love & 23 & 1 & AFG & $\mathrm{L}$ & $\mathrm{F}$ & $\mathrm{T}$ & BR & - \\
\hline Thescelocichla leucopleura & Swamp Palm Bulbul & 4 & $\mathrm{O}$ & - & - & $\mathrm{F}$ & $\mathrm{S}$ & BR & Ant \\
\hline \multicolumn{10}{|l|}{ Rallidae } \\
\hline Amaurornis flavirostra & Black Crake & 4 & 0 & - & - & 0 & G & SUB & - \\
\hline Sarothrura pulchra & White-spotted Flufftail & 92 & 1 & $\mathrm{~T}$ & - & $\mathrm{F}$ & G & $\mathrm{BR}$ & - \\
\hline \multicolumn{10}{|l|}{ Strigidae } \\
\hline Bubo poensis & Fraser's Eagle Owl & 1 & $\mathrm{O}$ & - & - & $\mathrm{F}$ & G & BR & - \\
\hline Strix woodfordii & African Wood-owl & 1 & 0 & - & - & $\mathrm{F}$ & $\mathrm{T}$ & SUB & - \\
\hline \multicolumn{10}{|l|}{ Sturnidae } \\
\hline Hylopsar purpureiceps & Purple-headed Glossy Starling & 6 & $\mathrm{~F}$ & - & - & $\mathrm{F}$ & $\mathrm{T}$ & $\mathrm{BR}$ & - \\
\hline Lamprotornis splendidus & Splendid Glossy Starling & 2 & $\mathrm{~F}$ & - & - & $\mathrm{F}$ & $\mathrm{T}$ & TRA & - \\
\hline Onychognathus fulgidus & Chestnut-winged Starling & 2 & $\mathrm{~F}$ & - & - & $\mathrm{F}$ & $\mathrm{T}$ & $\mathrm{BR}$ & - \\
\hline \multicolumn{10}{|l|}{ Sylviidae } \\
\hline Apalis nigriceps & Black-capped Apalis & 56 & 1 & AFG & $\mathrm{s}$ & $\mathrm{F}$ & $\mathrm{T}$ & $\mathrm{BR}$ & - \\
\hline Apalis rufogularis & Buff-throated Apalis & 21 & 1 & AFG & $\mathrm{S}$ & $\mathrm{F}$ & $\mathrm{T}$ & $\mathrm{BR}$ & - \\
\hline Camaroptera brachyura & Grey-backed Camaroptera & 117 & 1 & MISC & - & G & B & SUB & - \\
\hline Camaroptera chloronota & Olive-green Camaroptera & 40 & 1 & AFG & $\mathrm{S}$ & $\mathrm{F}$ & G & $\mathrm{BR}$ & - \\
\hline Camaroptera superciliaris & Yellow-browed Camaroptera & 42 & I & AFG & $\mathrm{S}$ & $\mathrm{F}$ & $\mathrm{S}$ & BR & - \\
\hline Eremomela badiceps & Rufous-crowned Eremomela & 5 & I & AFG & $\mathrm{S}$ & $\mathrm{F}$ & - & BR & - \\
\hline Hylia prasina & Green Hylia & 143 & I & AFG & $\mathrm{S}$ & $\mathrm{F}$ & B & BR & - \\
\hline Hyliota violacea & Violet-backed Hyliota & 1 & I & AFG & $\mathrm{S}$ & $\mathrm{F}$ & - & BR & - \\
\hline Macrosphenus concolor & Grey Longbill & 62 & I & AFG & $\mathrm{s}$ & $\mathrm{F}$ & - & $\mathrm{BR}$ & - \\
\hline
\end{tabular}




\begin{tabular}{|c|c|c|c|c|c|c|c|c|c|}
\hline Macrosphenus flavicans & Yellow Longbill & 29 & 1 & AFG & $\mathrm{S}$ & $\mathrm{F}$ & - & $\mathrm{BR}$ & - \\
\hline Macrosphenus kempi & Kemp's Longbill & 1 & 1 & $\mathrm{~T}$ & - & $\mathrm{F}$ & - & $\mathrm{BR}$ & - \\
\hline Sylvietta denti & Lemon-bellied Crombec & 16 & I & AFG & $\mathrm{S}$ & $\mathrm{F}$ & $\mathrm{T}$ & $\mathrm{BR}$ & - \\
\hline Sylvietta virens & Green Crombec & 33 & 1 & AFG & $\mathrm{S}$ & $\mathrm{F}$ & B & $\mathrm{BR}$ & - \\
\hline \multicolumn{10}{|l|}{ Timaliidae } \\
\hline IIladopsis cleaveri & Black-capped Illadopsis & 7 & 1 & $\mathrm{~T}$ & - & $\mathrm{F}$ & G & $\mathrm{BR}$ & Ant \\
\hline Illadopsis fulvescens & Brown Illadopsis & 27 & 1 & AFG & $\mathrm{M}$ & $\mathrm{F}$ & B & $\mathrm{BR}$ & Ant \\
\hline Illadopsis rufipennis & Pale-breasted Illadopsis & 82 & 1 & $\mathrm{~T}$ & - & $\mathrm{F}$ & B & $\mathrm{BR}$ & Ant \\
\hline \multicolumn{10}{|l|}{ Trogonidae } \\
\hline Apaloderma aequatoriale & Bare-cheeked Trogon & 19 & 1 & SFG & - & $\mathrm{F}$ & $\mathrm{S}$ & $\mathrm{BR}$ & - \\
\hline \multicolumn{10}{|l|}{ Turdidae } \\
\hline Alethe diademata & Fire-crested Alethe & 79 & 1 & $\mathrm{~T}$ & - & $\mathrm{F}$ & $\mathrm{T}$ & $\mathrm{BR}$ & Ant \\
\hline Alethe poliocephala & Brown-chested Alethe & 31 & 1 & $\mathrm{~T}$ & - & $\mathrm{F}$ & $\mathrm{T}$ & TRA & Ant \\
\hline Cossypha cyanocampter & Blue-shouldered Robin-Chat & 1 & 1 & $\mathrm{~T}$ & - & $\mathrm{F}$ & $\mathrm{S}$ & $\mathrm{BR}$ & - \\
\hline Neocossyphus poensis & White-tailed Ant-thrush & 72 & 1 & $\mathrm{~T}$ & - & $\mathrm{F}$ & - & $\mathrm{BR}$ & Ant \\
\hline Neocossyphus rufus & Red-tailed Ant-thrush & 2 & 1 & $\mathrm{~T}$ & - & $\mathrm{F}$ & $\mathrm{T}$ & TRA & Ant \\
\hline Sheppardia cyornithopsis & Lowland Akalat & 3 & 1 & $\mathrm{~T}$ & - & $\mathrm{F}$ & $\mathrm{S}$ & $\mathrm{BR}$ & Ant \\
\hline Stiphrornis erythrothorax & Forest Robin & 118 & 1 & $\mathrm{~T}$ & - & $\mathrm{F}$ & B & $\mathrm{BR}$ & Ant \\
\hline Stizorhina fraseri & Rufous Flycatcher Thrush & 43 & 1 & SA & - & $\mathrm{F}$ & $\mathrm{T}$ & TRA & Ant \\
\hline Turdus pelios & African Thrush & 25 & 1 & $\mathrm{~T}$ & - & G & $\mathrm{T}$ & TRA & Ant \\
\hline \multicolumn{10}{|l|}{ Viduidae } \\
\hline Vidua macroura & Pin-tailed Whydah & 3 & G & - & - & 0 & G & SUB & - \\
\hline
\end{tabular}




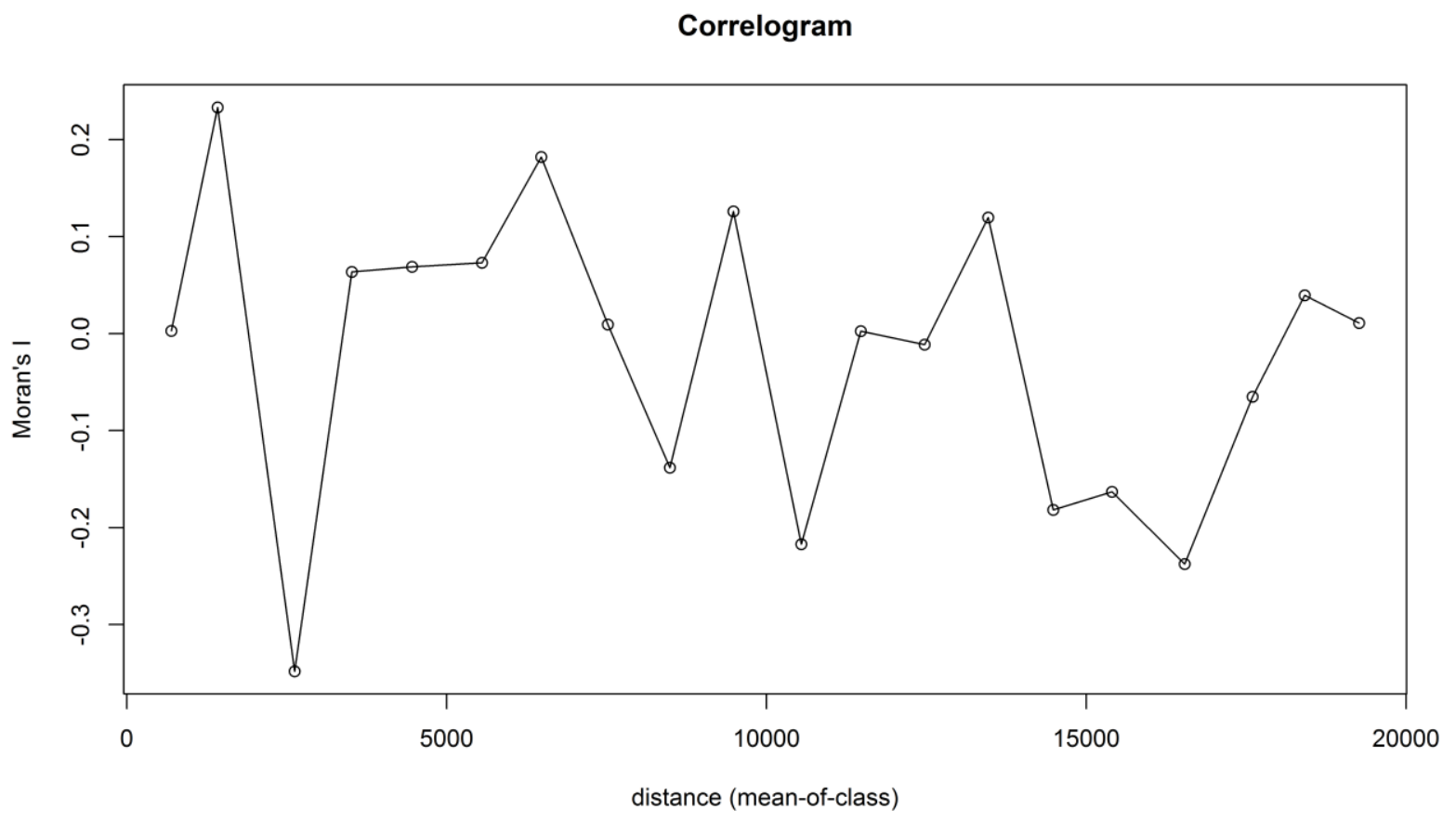

Figure S3.1 - Correlogram of the residuals of the earth model, which evaluated the response of the total bird community (gamma richness) to forest cover. The figure shows a random variation of residual correlation (all non-significant) as a function of distance between study points and, therefore, no spatial autocorrelation. 


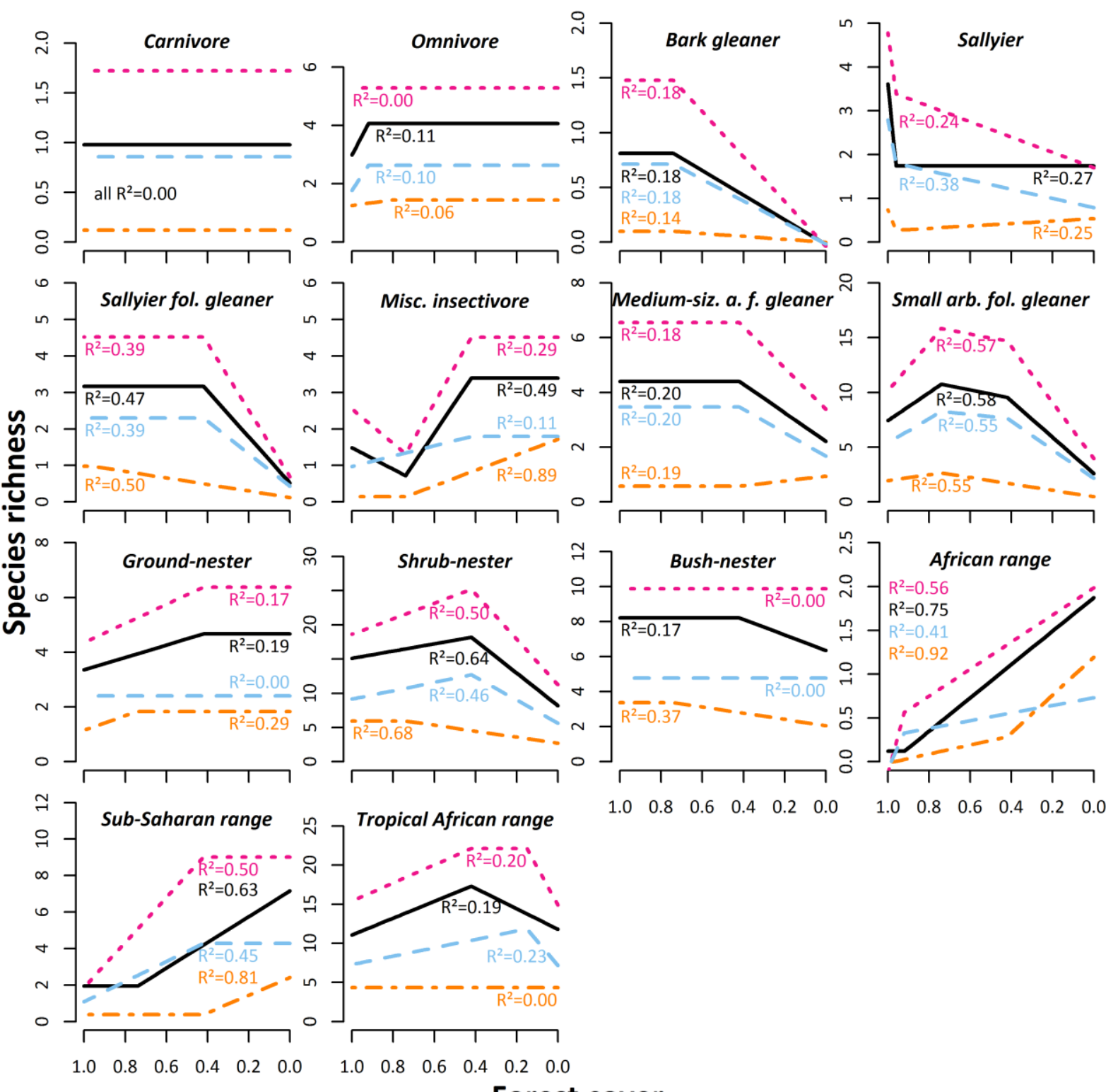

Forest cover

Figure S3.2 - Response patterns of within-microhabitat (alpha; orange dot-dashed line), between microhabitat (beta; skyblue dashed line), observed (black solid line) and estimated within-block (gamma; pink dotted line) species richness to changes in forest cover in some studied bird groups (see Fig. 3.2 for the remaining groups) corresponding to the best-fitting MARS models; richness estimates are based on the classical first-order Jackknife estimator. 

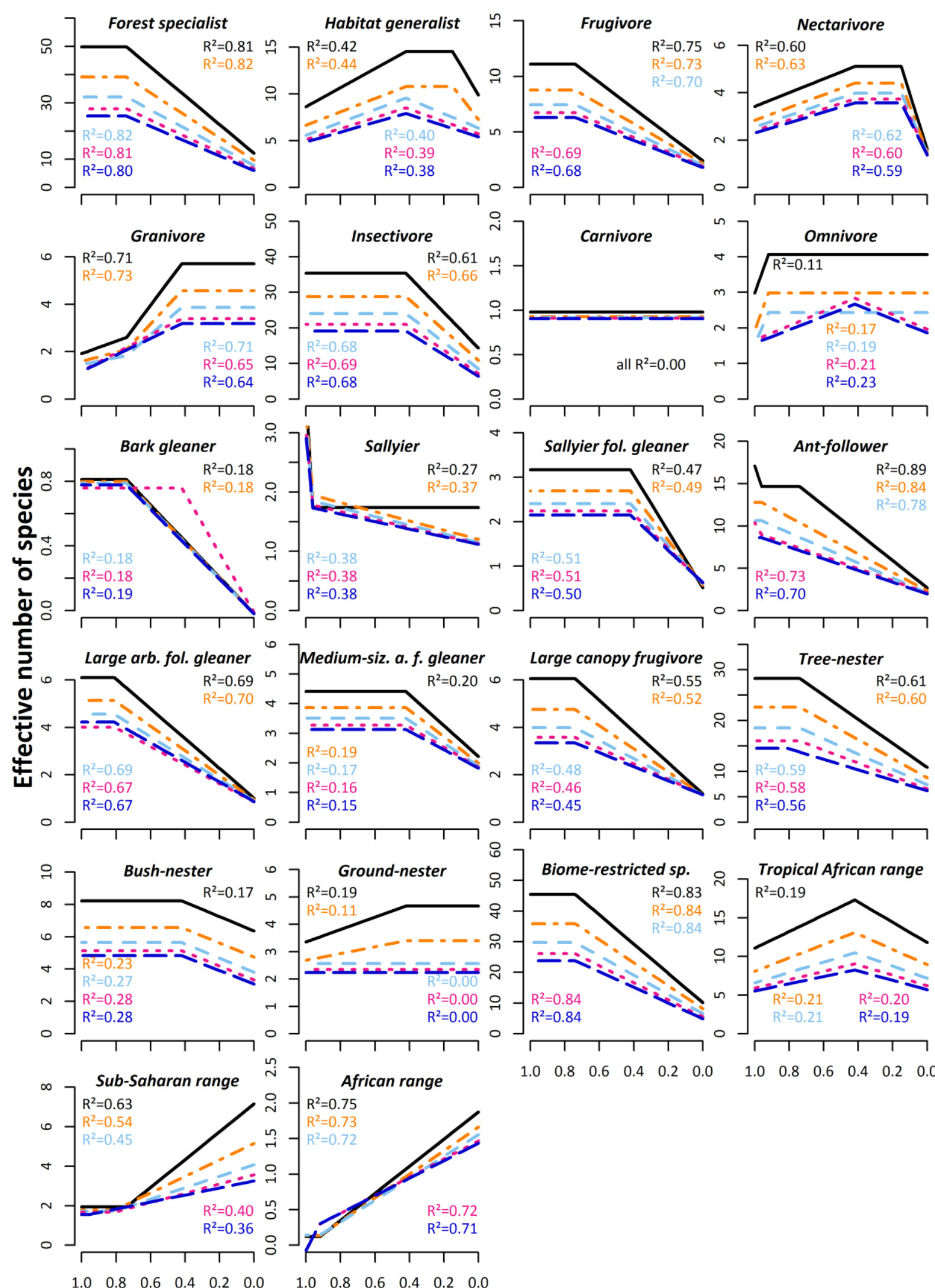

$\begin{array}{llllll}1.0 & 0.8 & 0.6 & 0.4 & 0.2 & 0.0\end{array}$

$\begin{array}{llllll}1.0 & 0.8 & 0.6 & 0.4 & 0.2 & 0.0\end{array}$

$\begin{array}{llllll}1.0 & 0.8 & 0.6 & 0.4 & 0.2 & 0.0\end{array}$

Forest cover

Figure S3.3 - Response patterns of observed within-block (gamma) species richness (black solid line), Shannon (orange dot-dashed line) as well as Rényi's second-order (skyblue dashed line), third-order (pink dotted line) and fourth-order entropy (blue coarse-dashed line) species richness to changes in forest cover in most studied bird groups (see Fig. 3.3 for the remaining groups) corresponding to the best-fitting MARS models; all diversity indices are expressed in effective numbers (see Jost 2006). 


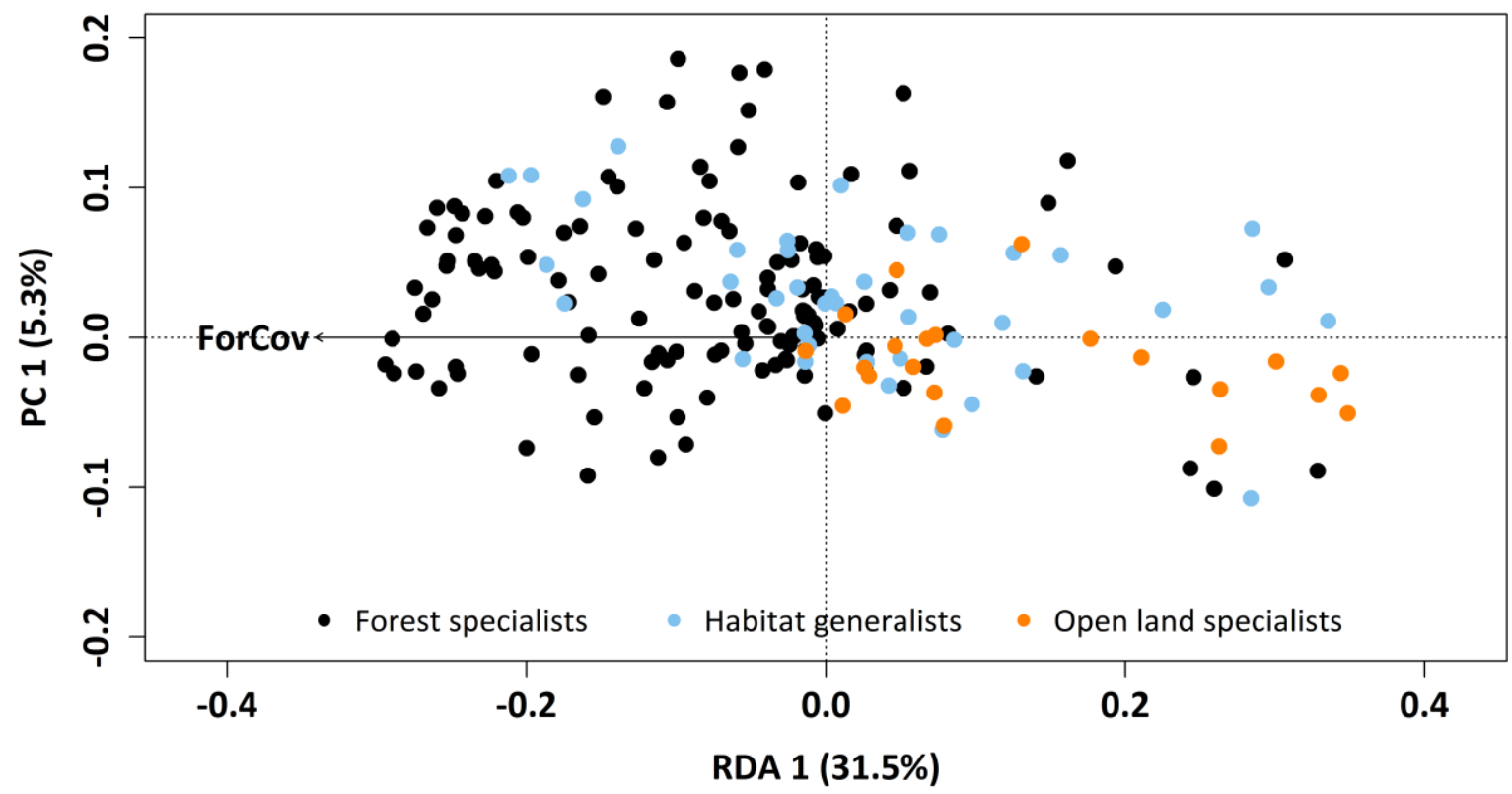

Figure S3.4 - RDA ordination plot of recorded bird species (points) with forest cover as constraining variable (vector ForCov); categorization by habitat preference.

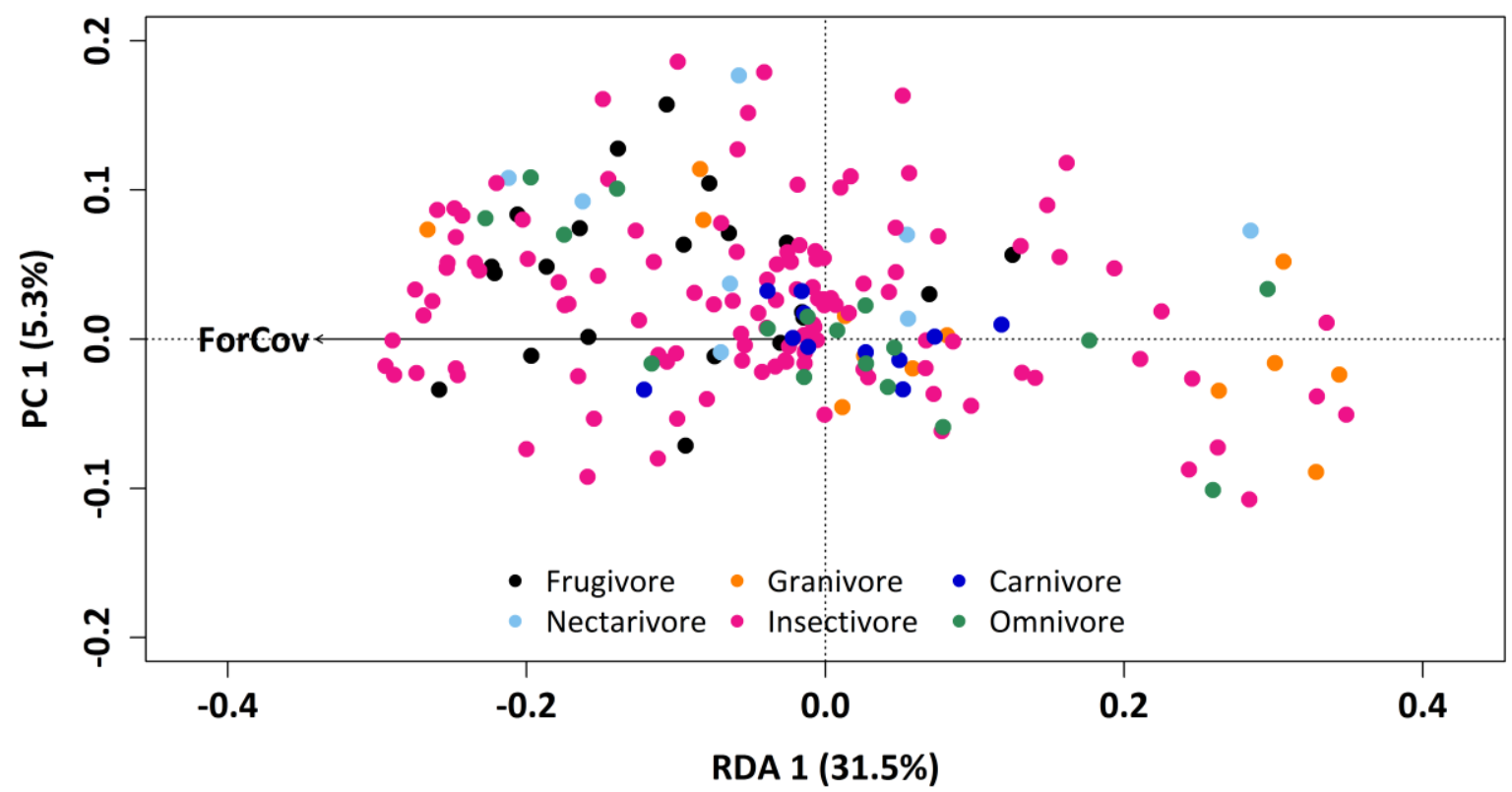

Figure S3.5 - RDA ordination plot of recorded bird species (points) with forest cover as constraining variable (vector ForCov); categorization by feeding guild. 


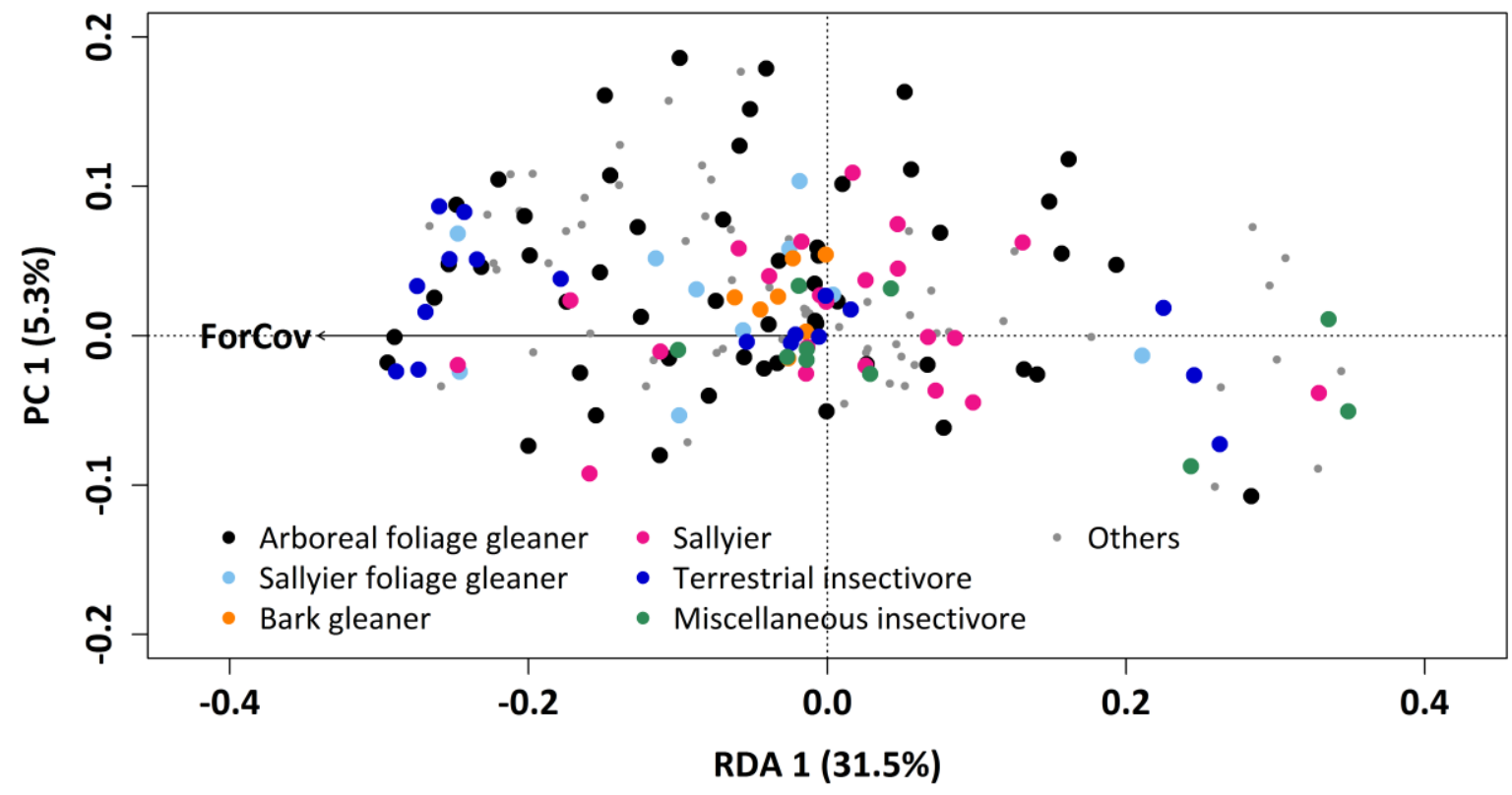

Figure S3.6 - RDA ordination plot of recorded bird species (points) with forest cover as constraining variable (vector ForCov); categorization by foraging habitats of insectivores and others.

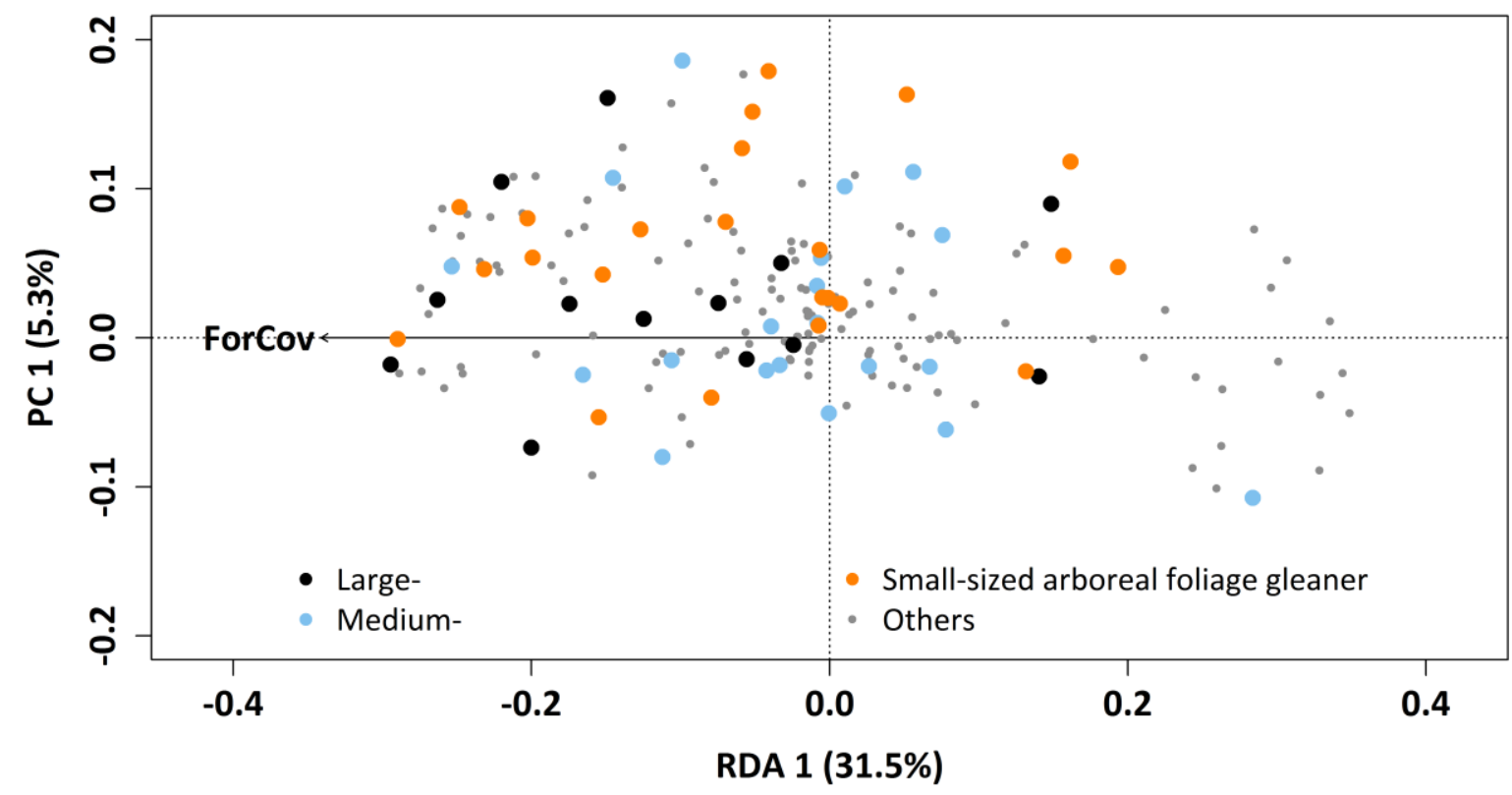

Figure S3.7 - RDA ordination plot of recorded bird species (points) with forest cover as constraining variable (vector ForCov); categorization by size classes of arboreal foliage gleaners and others. 


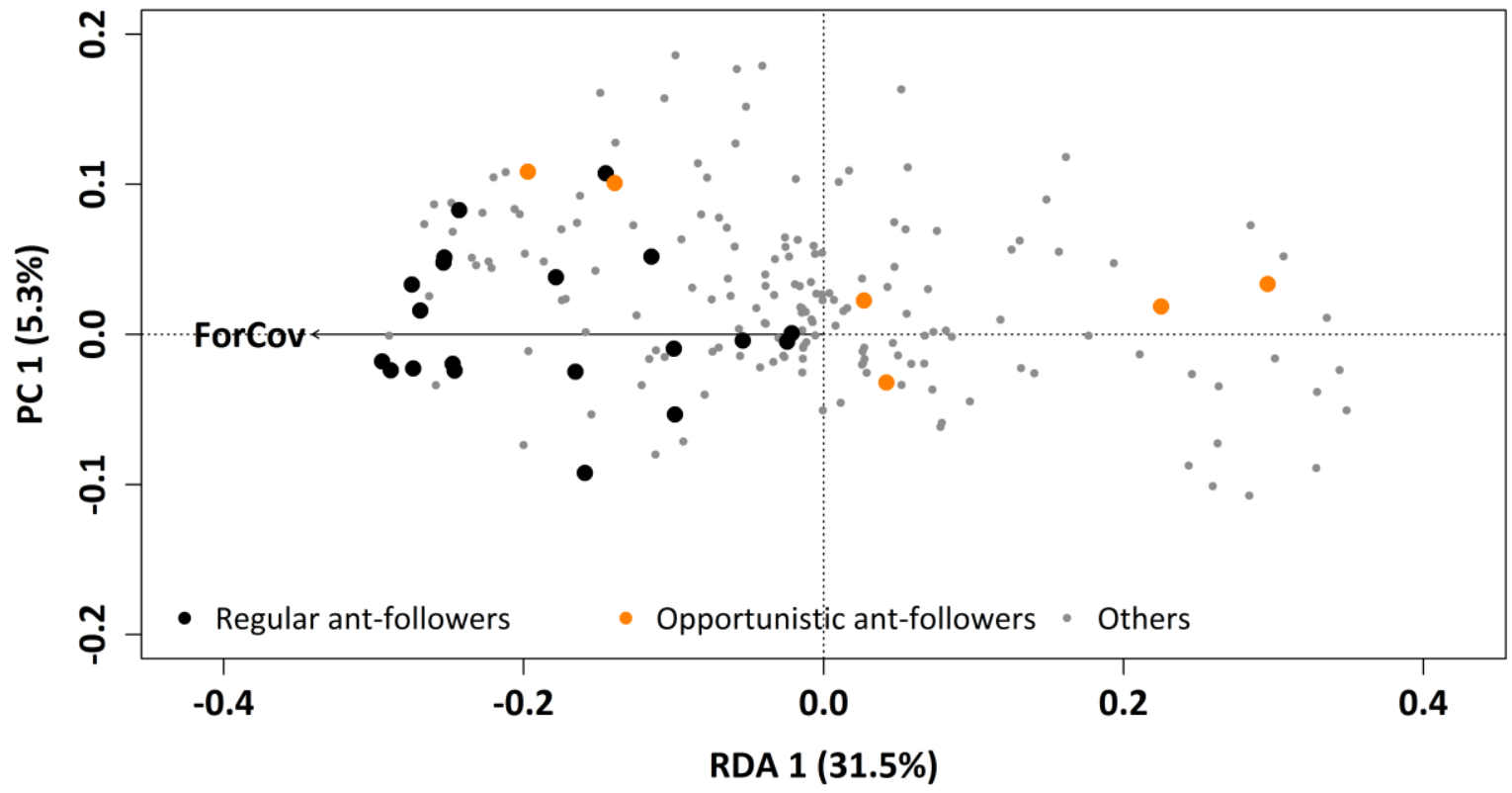

Figure S3.8 - RDA ordination plot of recorded bird species (points) with forest cover as constraining variable (vector ForCov); categorization by ant-followers and others.

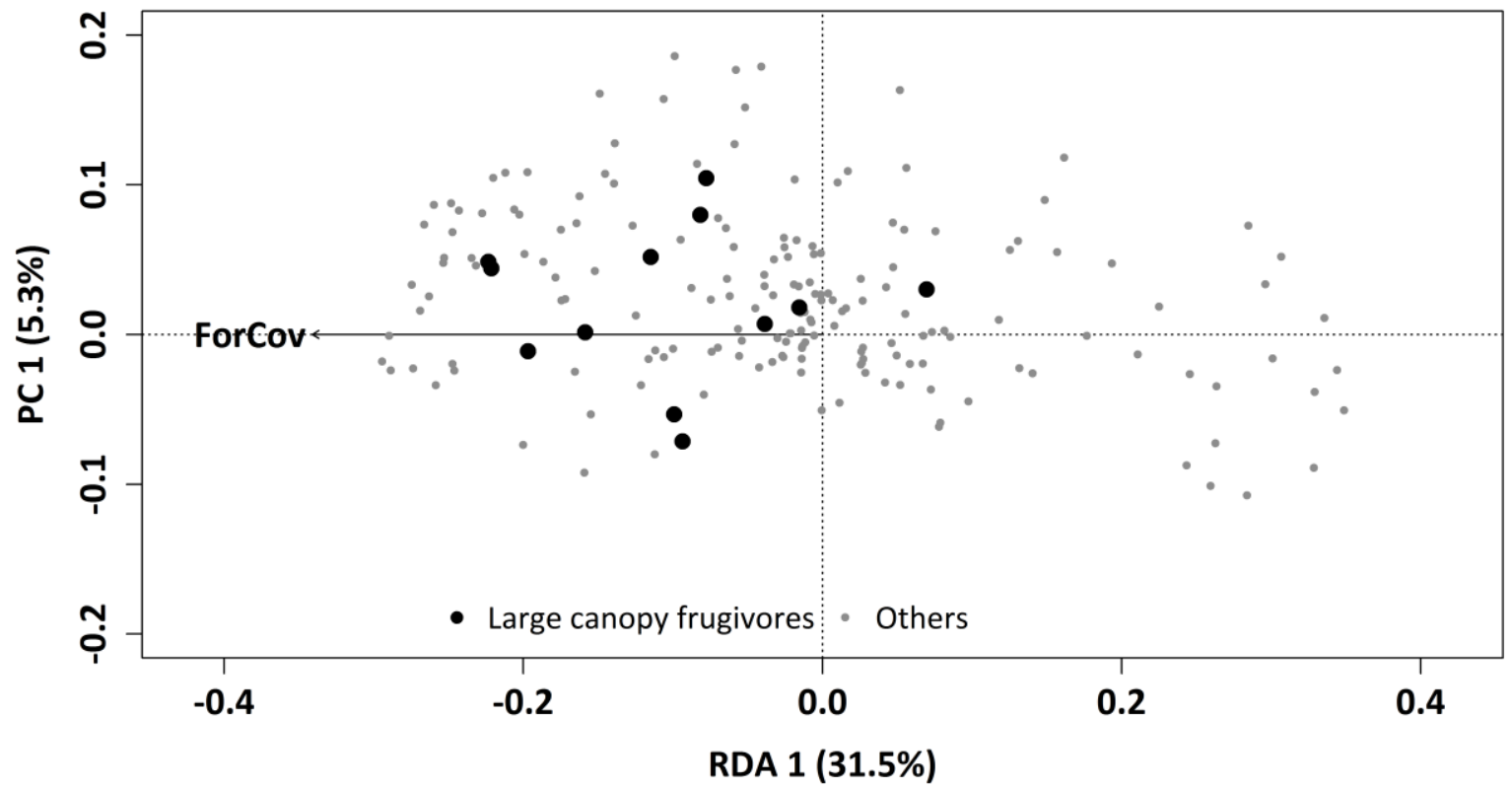

Figure S3.9 - RDA ordination plot of recorded bird species (points) with forest cover as constraining variable (vector ForCov); categorization by large canopy frugivores and others. 


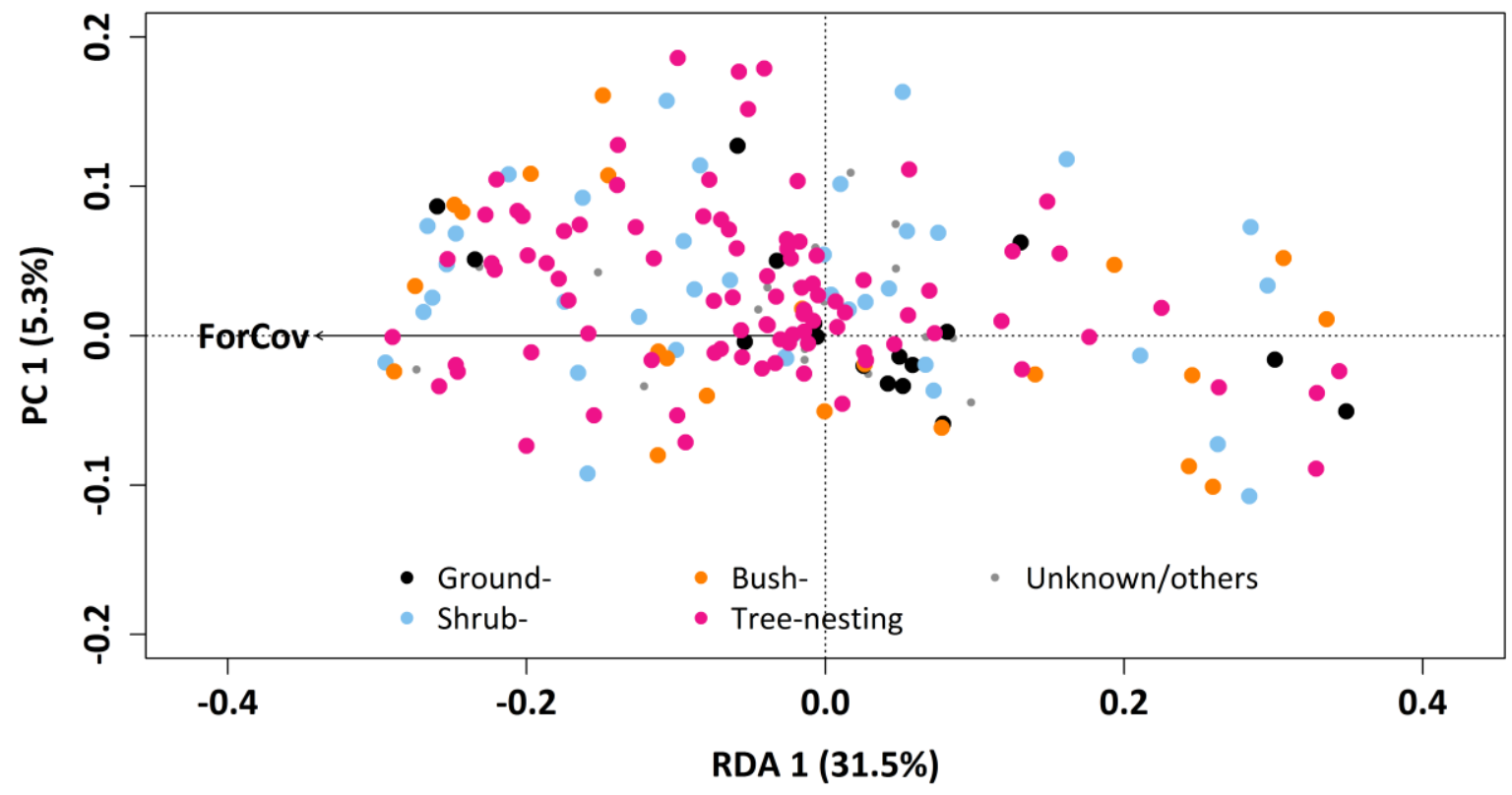

Figure S3.10 - RDA ordination plot of recorded bird species (points) with forest cover as constraining variable (vector ForCov); categorization by preferred nesting location.

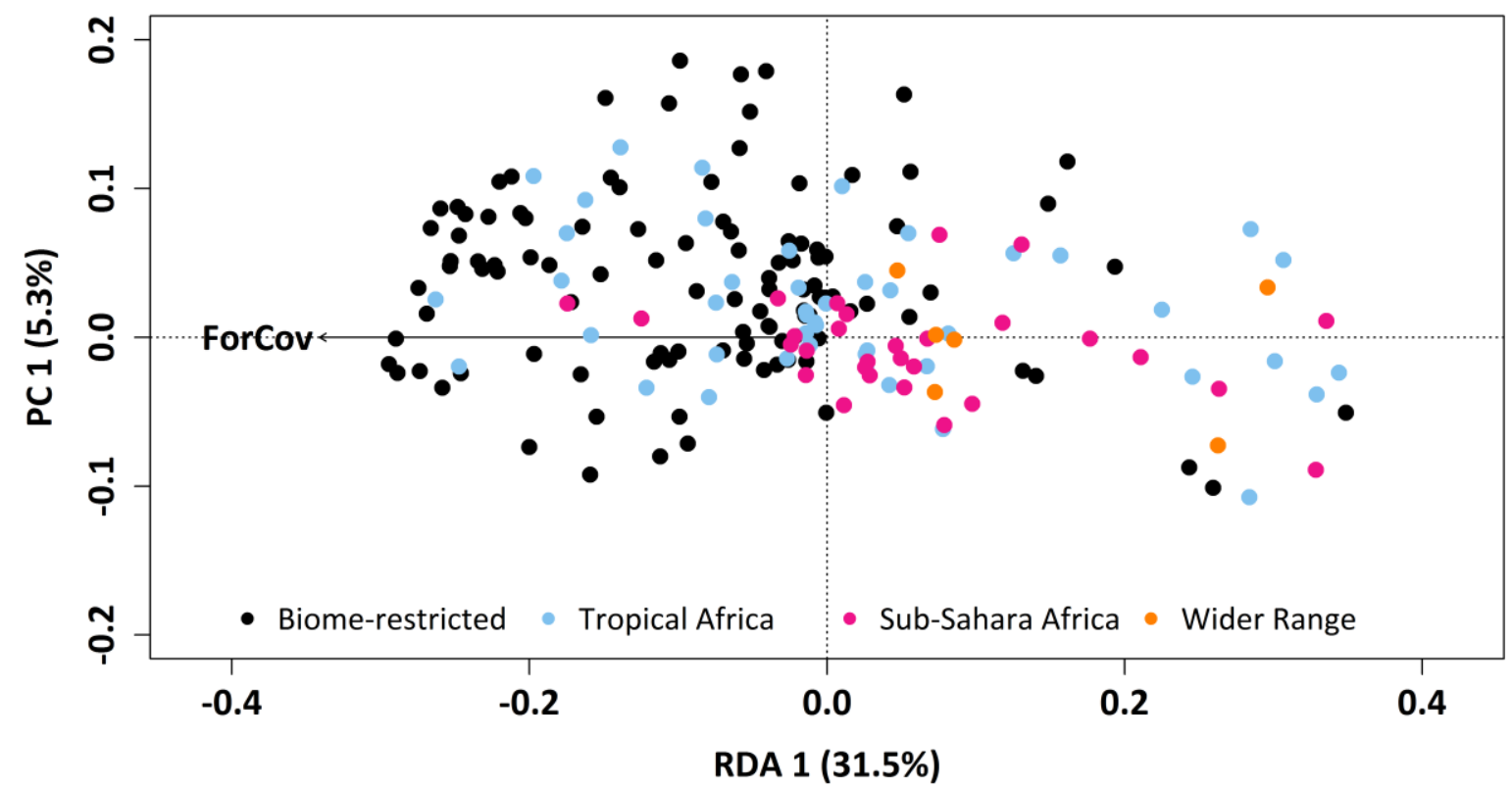

Figure S3.11 - RDA ordination plot of recorded bird species (points) with forest cover as constraining variable (vector ForCov); categorization by geographical range. 
CHAPTER 3 


\section{Chapter 4}

\section{Extinction thresholds and negative responses of Afrotropical ant-following birds to forest cover loss in oil palm and agroforestry landscapes}

\section{Publication}

Carolina Ocampo-Ariza, Denis Kupsch, Francis Njie Motombi, Kadiri Serge Bobo, Holger Kreft and Matthias Waltert, 2019, Basic and Applied Ecology 39: 26-37. https://doi.org/10.1016/j.baae.2019.06.008

\subsection{Abstract}

Afrotropical ant-following birds are vulnerable to forest loss and disturbance, but critical habitat thresholds regarding their abundance and species richness in human-dominated landscapes, including industrial oil palm plantations, have never been assessed. We measured forest cover through Landsat imagery and recorded species richness and relative abundance of 20 antfollowing birds in 48 plots of 1-km², covering three landscapes of Southwest Cameroon: Korup National Park, smallholder agroforestry areas (with farms embedded in forest), and an industrial oil palm plantation. We evaluated differences in encounter frequency and species richness among landscapes, and the presence of critical thresholds through enhanced adaptive regression through hinges. All species were detected in Korup National Park and the agroforestry landscape, which had similar forest cover (> 85\%). Only nine species were found in the oil palm plantation (forest cover $=10.3 \pm 3.3 \%$ ). At the $1-\mathrm{km}^{2}$ scale, the number of species and bird encounters were comparable in agroforests and the protected area: mean species richness ranged from $12.2 \pm 0.6$ in the park and $12.2 \pm 0.6$ in the agroforestry matrix to $1.0 \pm 0.4$ in the industrial oil palm plantation; whereas encounters decreased from $34.4 \pm 3.2$ to $26.1 \pm 2.9$ and $1.3 \pm 0.4$, respectively. Bird encounters decreased linearly with decreasing forest cover, down to an extinction threshold identified at $24 \%$ forest cover. Species richness declined linearly by ca. one species per $7.4 \%$ forest cover lost. We identified an extinction threshold at $52 \%$ forest cover for the most sensitive species (Criniger chloronotus, Dicrurus atripennis, and Neocossyphus poensis). Our results show that substantial proportions of forests are required to sustain complete ant-following bird assemblages in Afrotropical landscapes and confirm the high sensitivity of this bird guild to deforestation after industrial oil palm development. Securing both forest biodiversity and food production in an Afrotropical production landscape may be best attained through a combination of protected areas and wildlife-friendly agroforestry. 


\subsection{Introduction}

Agricultural expansion is the reason for deforestation and habitat loss in up to $96 \%$ of studied cases around the world (Geist and Lambin 2002) and is, consequently, the leading cause of ecosystem change and species extinctions (Brooks et al. 2002). In the case of birds, farming practices are the most important threat to endangered species, with a particularly high impact on the avifauna of developing countries (Green et al. 2005). The persistence of bird species in human-altered environments relies to a great extent on the amount of suitable habitat available in an area, as well as on other elements such as the mobility of the species and their ecological preferences. Whereas it may be easier for highly mobile and generalist species to find new suitable habitat, specialists are thought to be more prone to extinction due to the loss of adequate environmental conditions (e.g. Brook et al. 2003, Ferraz et al. 2007, Moran and Catterall 2014, Morante-Filho et al. 2015, Waltert et al. 2005). Understanding the response of the most vulnerable bird groups and species to habitat loss provides an insight into the minimum habitat requirements needed for their persistence in a given landscape.

Studies from diverse geographical locations have shown that species richness and abundance of bird communities may change either in a linear or in a non-linear way in response to habitat loss (e.g. Betts Forbes and Diamond 2007; Lindenmayer, Fischer and Cunningham 2005, Morante-Filho et al. 2015, Radford et al. 2005). Linear responses to habitat loss indicate a steady decline in the probability of survival of the target species. Conversely, non-linearities may indicate the presence of critical thresholds in the amount of suitable habitat. Small amounts of habitat loss below such thresholds are thought to result in abrupt changes in the probability of survival of species (Swift and Hannon 2010), by either resulting in extinction (henceforth extinction thresholds) or a considerable increase in the decline rate of the species (henceforth occurrence thresholds). These abrupt responses are thought to be related to a stronger effect of qualitative changes in the species' habitat (such as habitat connectivity, size and shape of habitat patches, among others) below the threshold (Fahrig 2001). The identification of critical thresholds is, therefore, valuable for the establishment of conservation targets and the effective design of landscapes with a focus on biodiversity conservation (Brown et al. 1999, Huggett 2005, Lindenmayer and Luck 2005).

Ant-following birds are insectivorous species from the tropics, whose foraging behavior includes, to variable extents, following swarms of carnivorous ants (either driver ants from the sub-family Dorylinae: Dorylini in tropical Africa; or army ants, Dorylinae: Ecitonini, in the Neotropics) to feed on insects that flee when the ants approach to avoid predation (Willis and Oniki 1978). Among the African passerine avifauna, ant-following birds are considered to be one of the groups most vulnerable to forest loss and fragmentation (Peters et al. 2008, Waltert et al. 2005). In fragmented forests of East Africa, species richness of ant-following birds has been related to the abundance of Dorylus wilverthi and D. molestus ant swarms whose activity 
varies with forest structure and humidity (Peters et al. 2009, Peters and Okalo 2009). Particularly in areas with intensive agriculture, specialized ant-followers are expected to become locally extinct as a consequence of the impacts that habitat disturbance has on such ants (Peters et al. 2008). However, information on ant-following birds in West and Central African forests remains limited, especially regarding the effects of deforestation and forest conversion.

Oil palm development has been rapidly increasing in forests of West Africa (Linder 2013). Coming from approx. 190,000 ha harvest area in 2010, Cameroon's Government showed a strong commitment to increase the amount of land dedicated to oil palm production: Already in 2012 several international companies tried to secure more than 1 million ha of land for palm oil production in the southern forested zone of Cameroon (Hoyle and Levang 2012). This urgently calls for an assessment of the responses of forest-dependent species to habitat loss and for information about the potential creation of sustainable production systems (Linder 2013).

We used direct observations of ant-following bird species in Southwest Cameroon to evaluate the responses of this bird guild to forest cover loss. The study covered an area of approximately $4,000 \mathrm{~km} 2$ in three landscapes with contrasting forest cover: Korup National Park (KNP), with largely undisturbed forest and some small farms near Park villages; a smallholder agroforestry matrix, consisting of a mosaic of farms embedded in native forest; and an industrial oil palm plantation, with small embedded remnant forest patches. Previous studies in the area provide evidence for a decline in species richness of ant-followers from forested to agricultural areas (Waltert et al. 2005). Our main research questions were: (1) are species richness and bird encounters significantly lower in human-intervened landscapes (agroforestry areas and industrial plantations) than in protected areas? (2) Can we identify a critical threshold of forest cover based on the response of the ant-following bird community to forest cover? And (3) are there detectable differences in the responses of individual ant-following bird species to forest cover change? Based on our results, we make recommendations for the design of wildlifefriendly farming systems in Afrotropical forest landscapes.

\subsection{Materials and methods}

Study area

The Guinean Forests of West Africa extend through eight countries from Guinea and Sierra Leone to the Sanaga River in Cameroon (Mittermeier et al. 2004). As a biodiversity hotspot, these humid evergreen rain forests hold a significant proportion of the biodiversity of tropical Africa, including approximately 9,000 vascular plant species as well as around 2,048 vertebrate animal species (Darwall et al. 2015). The avifauna is composed of approximately 917 bird 
species, which include $68 \%$ of all the African passerine birds and 48 species endemic to this hotspot (Darwall et al. 2015, Mittermeier et al. 2004).

The Lower Guinean subregion of the biodiversity hotspot includes some of the forests found in Equatorial Guinea, Cameroon and Sao Tomé (Mittermeier et al. 2004). The tropical forests of Southwest Cameroon are an important part of this subregion since they are still extensive (Darwall et al. 2015) and hold a significant proportion of the avifauna including many antfollowing species (del Hoyo et al. 2018, Waltert et al. 2005). However, forests are threatened by increasing agricultural activities, including the establishment of industrial oil palm plantations (Mbile et al. 2005).

Some of the protected areas in the region have human settlements inside. They are surrounded by traditional smallholder agroforests which are embedded in native forests and there are also some larger industrial plantations (MINEP and UNDP 1996). This landscape composition also holds true for our study area, located between $4^{\circ} 57^{\prime} \mathrm{N}$ to $5^{\circ} 10^{\prime} \mathrm{N}$ and $8^{\circ} 44^{\prime} \mathrm{E}$ to $9^{\circ} 7^{\prime} \mathrm{E}$ and between 56 and 768 m.a.s.l (Fig. 4.1). The area encompasses Korup National Park, which has a total size of 126,000 ha and five villages inside (Darwall et al. 2015, Mbile et al. 2005); adjacent agroforestry areas, which are located south-east from the park, and small to mediumsized (100 ha- 5,800 ha) industrial oil palm plantations found south-west from KNP. The area has a pseudo-equatorial climate, characterized by two seasons: A dry season between December and February and a humid one between March and November (Chuyong et al. 2004, Rodewald et al. 1994), with an average annual rainfall estimated at 5,272 $\mathrm{mm}$ (Chuyong et al. 2004). The mean annual temperature varies according to land cover: cooler mean annual temperatures of around $24.7{ }^{\circ} \mathrm{C}$ are found in forested areas; whereas deforested zones are much warmer, with average temperatures up to $32.6{ }^{\circ} \mathrm{C}$ (Rodewald et al. 1994).

These special climatic conditions, its geographic location and a considerable size of continuous forest make the region around $\mathrm{KNP}$ one of the most important areas for biodiversity conservation in Africa (Rodewald et al. 1994). Its avifauna represents around 53.4\% of the bird diversity found in the Guinean Forest of West Africa, including 12 endemic species of the montane areas of Southwest Cameroon and Nigeria and seven endemic species of lowlands and montane forests of Cameroon (Rodewald et al. 1994). 


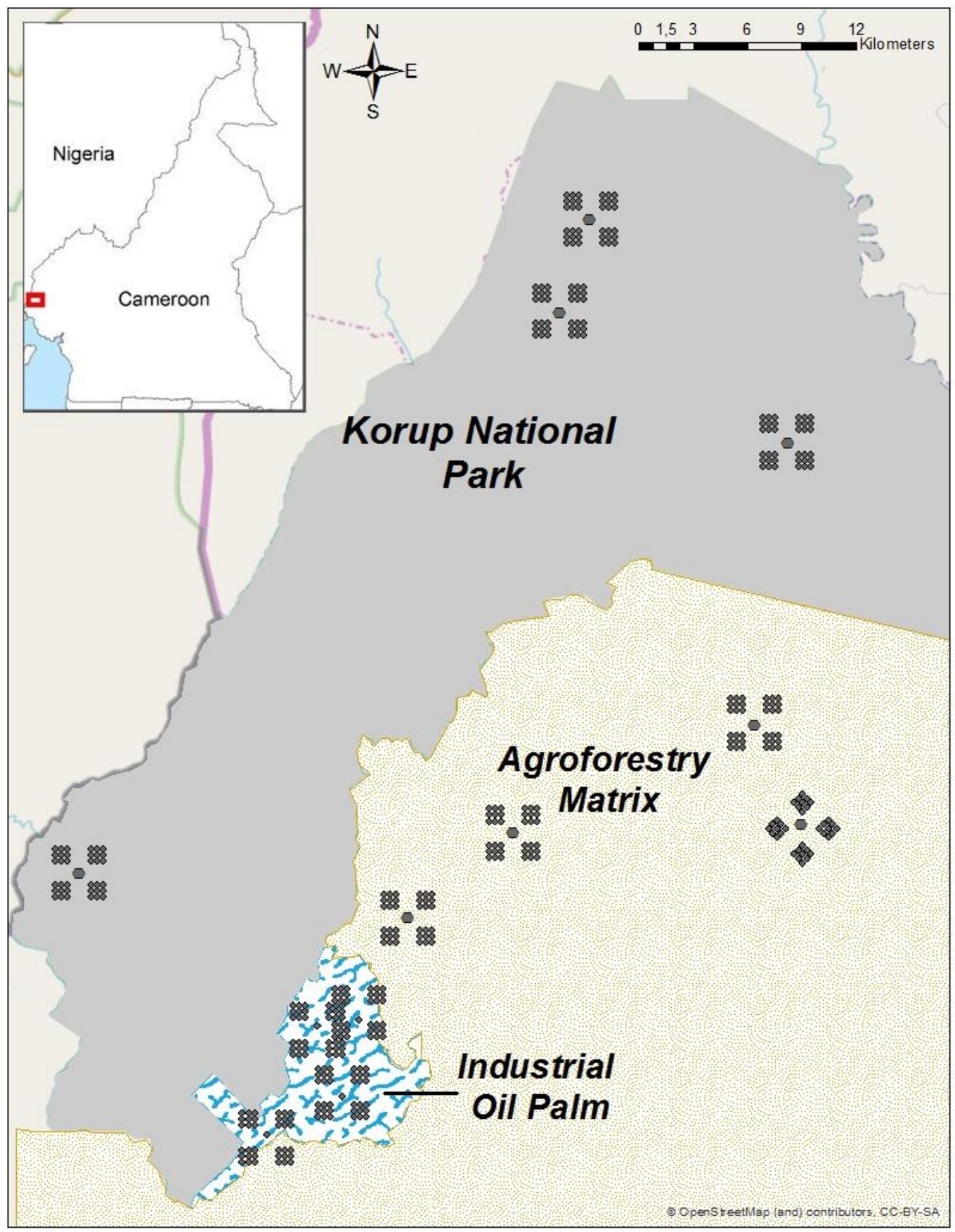

Figure 4.1 - Map of the study area around Korup National Park. Background colors indicate landscapes: Grey: Korup National Park; striped pattern: Oil palm plantations; dotted pattern: agroforestry matrix, which includes a mixture of native forests and smallholder farming systems. The grey dots indicate sampling points around each village: Large grey dots indicate villages (center), with four study plots, each composed of nine sampling points.

\section{Data collection}

We sampled ant-following birds through ten-minute unlimited distance point counts (Ralph et al. 1995) in three distinctive landscapes: (1) Protected forests inside Korup National Park, 
which are exposed to human presence and agricultural activities from the villages inside the park. (2) An agroforestry matrix in the area around KNP, consisting mainly of villages and smallholder crop farms that are usually small in size ( $<2 \mathrm{ha})$ and are still embedded in significant proportions of native primary and secondary forest. Such crop farms are mostly composed of small agroforestry systems (cacao, coffee or oil palm plantations, entrenched in native forest vegetation and fruit trees that serve as shade; and usually including a mixture of one main plus some secondary crops); but also other cash-crops such as cassava, yam, plantain and banana. (3) An industrial oil palm plantation from the company PAMOL located on the southern border of KNP, which consists of large palm plantations and villages bordering native forest and agroforests (see Table S4.3 for details on the vegetation structure of the selected landscapes).

We selected four villages per landscape ( 3 landscapes $\mathrm{x} 4$ villages $=12$ villages) and located four study plots of $1-\mathrm{km}^{2}$ per village (12 villages $\mathrm{x} 4$ study plots $=48$ study plots) at a distance of $1.5 \mathrm{~km}$ from the center of the village (Fig. 4.1). We assessed the percentage cover of forest on each $1-\mathrm{km}^{2}$ study plot by combining satellite image interpretation and ground truthing. We inspected LANDSAT imagery prior to the field survey and calculated the percentage cover of both near primary and secondary forest. Posteriorly, we confirmed our assessments through walks on each 1-km² plot between 2013 and 2014, to differentiate shaded farms from forest areas and detect the most recent changes due to farm opening (for more details, see Kupsch et al. 2019).

Field data were collected during the dry season in two stages: Six of the villages were sampled between June and July of 2013 and the remaining half was sampled between May and June, 2014. Each study plot of $1-\mathrm{km}^{2}$ was composed by a total of nine grid sells, with one sampling point in the center of each cell. Each sampling point was visited once either in the morning (between 6 and $11 \mathrm{am}$ ) or in the afternoon (between 3 and $6 \mathrm{pm}$ ) and all bird species seen or heard were registered only once per sampling point, excluding flyovers. Previous work in the same study region showed that $>90 \%$ of the bird records collected through point counts are acoustic observations and that there is no bias from differences in detection probability among habitat types (Waltert et al. 2005), except for some higher strata birds such as smaller, nectarivorous bird species which could be under-sampled in dense forests in comparison to secondary habitats.

We pooled the information collected at the nine sampling points of each study plot and considered the study plots as spatial units in our analysis. Consequently, a species' encounter frequency refers to the number of separate records of the species in each $1-\mathrm{km}^{2}$ study plot. Such frequency can have a maximum value of nine at the $1-\mathrm{km}^{2}$ scale (number of sampling points per plot). For the current study, we selected all bird species explicitly identified in the current literature as followers of Dorylus spp. ant swarms (del Hoyo et al. 2018, Peters et al. 2008, 
Waltert et al. 2005). We excluded five common species (Andropadus latirostris, Andropadus virens, Baeopogon indicator, Thescelocichla leucopleura and Turdus pelios), which have been reported to occasionally appear near ant swarms but which have a predominantly frugivorous diet (del Hoyo et al. 2018). We considered reports of these species in ant swarms as coincidences due to their relatively high abundance and/or opportunistic feeding behavior.

\section{Data analysis}

We evaluated whether the encounter frequency and species richness of ant-following birds, as well as forest cover, differed among landscapes using Mann-Whitney U-Tests. We also used this test to evaluate differences in the encounter frequency of individual species among the three landscapes. We assessed differences in the composition of ant-following bird communities in the three landscapes through a Permanova with the Vegan package (Oksanen et al. 2016) for R (R Core Team 2017). We ran the test with 1,000 permutations and using the Jaccard method to calculate pairwise distances (see Fig. S4.3 for results). Means are given with standard error if not mentioned otherwise.

We used Enhanced adaptive regression through hinges, implemented in the R package EARTH (Friedman 1991, Milborrow 2011), to model the response of ant-following birds to spatial changes in forest cover. EARTH uses hinge functions to identify breakpoints in the model and thus highlight possible non-linearities, in this case critical thresholds (Friedman 1991). EARTH models can be considered a type of multivariate piecewise regression, with an algorithm that searches for hinge position in an additive manner, across all combinations of variables and their interactions. As such, it automatically performs model and relevant variable selection (Friedman 1991, Milborrow 2014). The models were run including a generalized linear model (GLM) option and a Poisson distribution, using both the "backward" and "cross validation" methods. The model with the highest $\mathrm{GR}^{2}$ value was selected. $\mathrm{GR}^{2}$ is the model's estimate of generalization performance and indicates the predictability of the model (Milborrow 2014). We used EARTH models to evaluate critical thresholds for three response variables: ant-following bird encounter frequency, ant-following bird species richness and encounter frequency of each ant-following bird species recorded during the survey. To identify under-sampled species, we counted the number of study plots with encounters for each species and calculated their $95 \%$ confidence interval (CI). We considered the lower threshold of the $\mathrm{CI}$ as the minimum number of encounters required for the analysis. Species below this threshold were assumed to be undersampled and were rejected from the threshold analysis.

We tested for spatial autocorrelation in model residuals using spatial correlograms with the ncf packages for R and global Morans' I test for spatial autocorrelation in the ade4 package. Neither the EARTH model for bird encounter frequencies $(I=0.022 ; E I=-0.021 ; p=0.266)$, nor the one for bird species richness $(I=-0.047 ; E I=-0.021 ; p=0.514)$ were autocorrelated (see 
correlograms in Figs. S4.2, S4.1). At species level, only the model from the brown-chested alethe (Chamaetylas poliocephala) had significantly autocorrelated residuals. We focused our discussion on the non-autocorrelated models (Table S.4.2). All statistical analyses were performed using R v.3.4.0 (R Development Core Team 2017).

\subsection{Results}

We registered a total of 979 bird encounters of 20 ant-following bird species (Table S4.1). At the $1-\mathrm{km}^{2}$ scale, the community composition of ant-following birds was significantly different among the three landscapes $(F=28.20, p<0.001)$. A pair-wise comparison indicates that the composition of the bird community inside IOP is significantly different from that in either of the two remaining landscapes; whereas the KNP and AFM hold similarities (Fig. S4.3). All species were found in both Korup National Park and the agroforestry landscape but only nine ant-following bird species were encountered in the industrial oil palm plantation (Table 4.1). The most abundant species in the entire survey was the orange-breasted forest robin (Stiphrornis erythrothorax), while the species with the lowest encounter frequency overall was the red-tailed ant-thrush (Neocossyphus rufus).
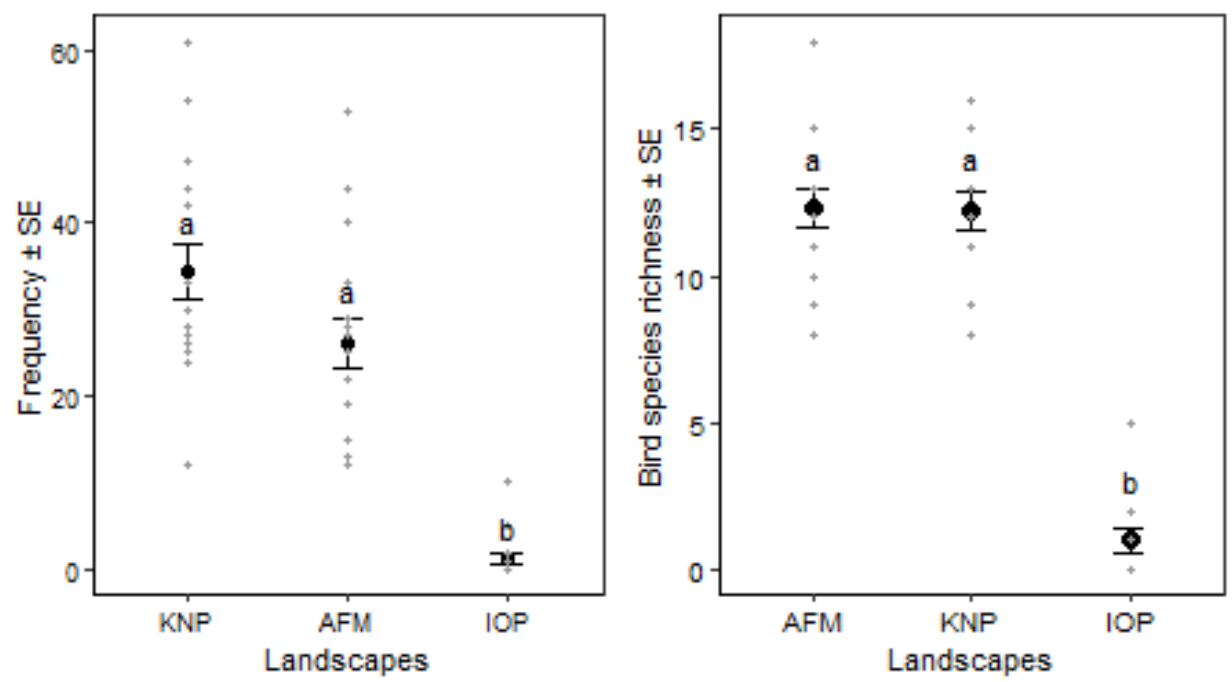

Figure 4.2 - Mean value and standard error (SE) bars of encounter frequency (bird records per study plot of $1-\mathrm{km}^{2}$, which can have a maximum value of nine per species) and species richness (bird species per study plot of $1-\mathrm{km}^{2}$ ) of ant-following birds inside the three landscapes found in the study area. KNP: Korup National Park; AFM: Agroforestry matrix; IOP: Industrial oil palm plantations. Different letters on top of error bars indicate a significant difference among landscapes (Mann-Whitney U-test with Bonferroni

Encounter frequency was marginally lower in the agroforestry matrix (26.06 \pm 2.94 encounters) than in Korup National Park (34.37 \pm 3.19 encounters; $W=178.5, p=0.059)$ and there were no significant differences in species richness between the two landscapes (KNP: $12.18 \pm 0.64$ bird species; AFM: $12.31 \pm 0.70$ bird species; $W=126, p=0.95)$. In contrast, there were 
significantly less ant-following bird encounters ( $1.31 \pm 0.36$ encounters $)$ and species richness ( $1 \pm 0.41$ species $)$ inside the industrial oil palm plantation than in either Korup National Park $(W=256, p<0.001)$ or the agroforestry matrix $(W=0, p<0.001$; Fig. 4.2). There were no significant differences in forest cover between plots inside Korup National Park (average forest cover $=88.37 \% \pm 3.54 \%$ ) and those inside the agroforestry matrix (average forest cover $=87 \%$ $\pm 2.82 \% ; W=150, p=0.41$ ). But plots in the palm plantation had significantly less forest cover (average forest cover $\left.=10.31 \% \pm 3.33 \% ; W_{K N P}=256, p<0.001 ; W_{A F M}=0, p>0.001\right)$.

Encounter frequency $\left(G R^{2}=0.69, R^{2}=0.72\right)$ as well as species richness $\left(G R^{2}=0.88, R^{2}=0.89\right)$ of ant-following birds decreased with forest cover loss at a rate of 4.67 records and 1.36 species per $10 \%$ of forest cover change, respectively (Fig. 4.3). We detected a clear extinction threshold of the ant-following bird community at $24 \%$ of forest cover (Fig. $4.3 \mathrm{~A}$ ), below which no ant following bird records were predicted by the model.
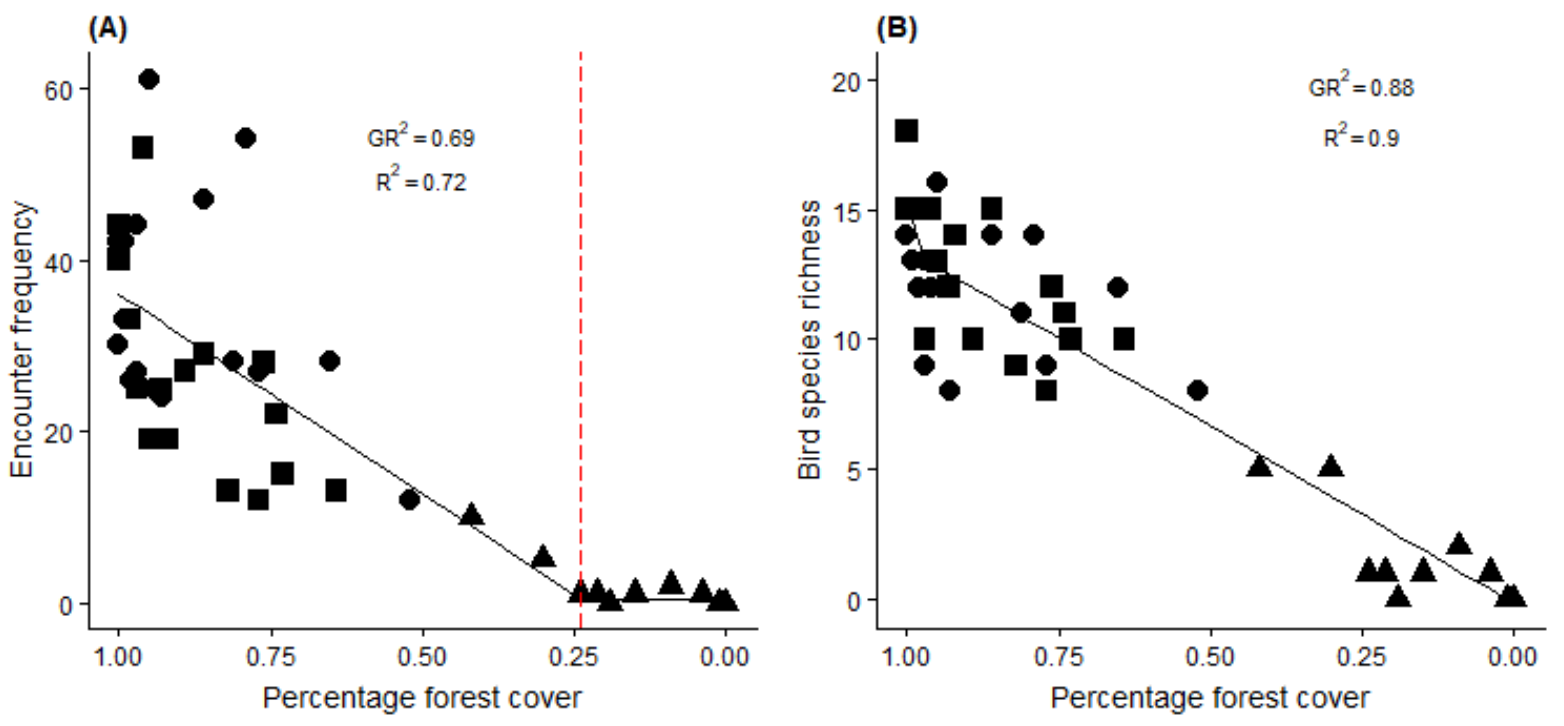

Figure 4.3 - Encounter frequency (A) and species richness (B) of ant-following birds in 1-km² study plots with different forest cover. Tendency line is the product of a multivariate additive regression spline and $\mathrm{GR}^{2}$ is a metric ranging from 0 to 1 , which indicates the predictability of the model. Dotted vertical line indicates an extinction threshold for the community. Dots represent values for each study plot inside the three landscapes: Circles = Korup National Park; triangles = Industrial oil palm plantations and squares

We rejected seven species from the single species threshold analyses, since we assumed they were under-sampled due to their low encounter rates (95\% CI [14.39 - 23.93 study plots with bird records], see Methods). All the analyzed species were encountered significantly less inside palm plantations than in KNP or AFM. Notably, bird encounters were also significantly lower in the agroforestry matrix than in KNP for the yellow-lored bristlebill (Bleda notatus), the white-tail ant-thrush (N. poensis) and the brown illadopsis (Illadopsis fulvescens; see Table A4.1). 
(A) Alethe castanea

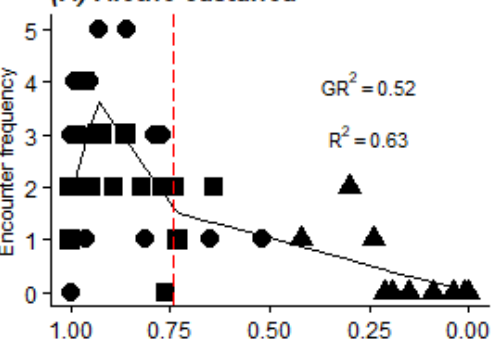

(D) Neocossyphus poensis

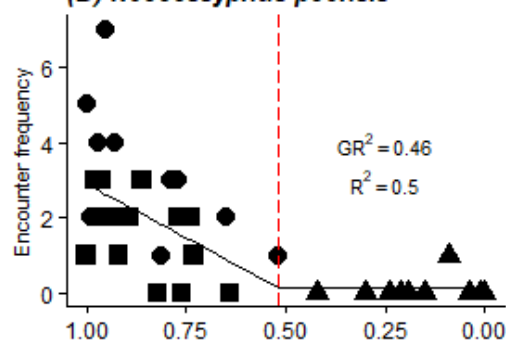

(G) Illadopsis rufipennis

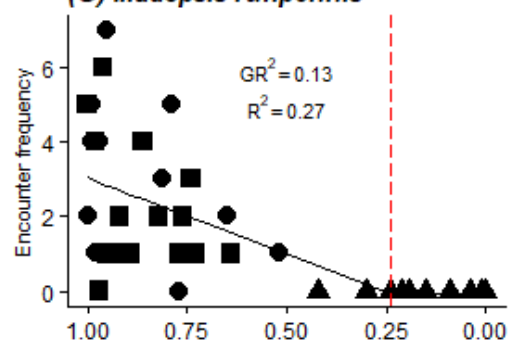

(J) Criniger calurus

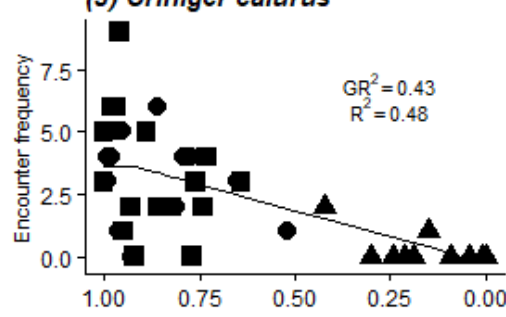

M. Stizorhina fraser

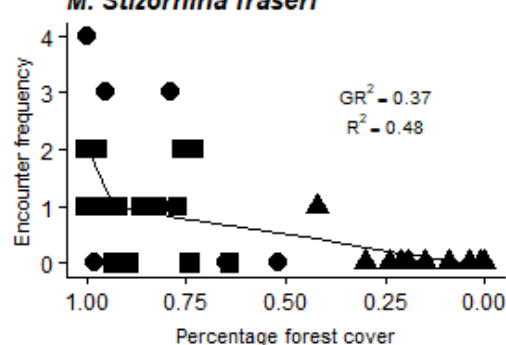

(B) Criniger chloronotus

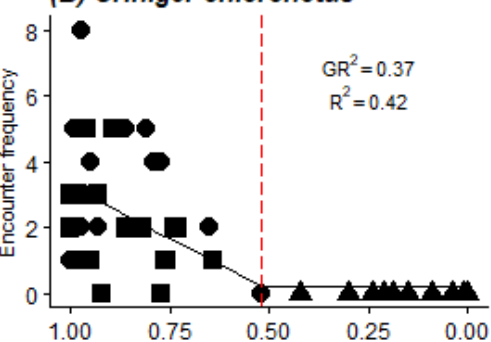

(E) Bleda notatus

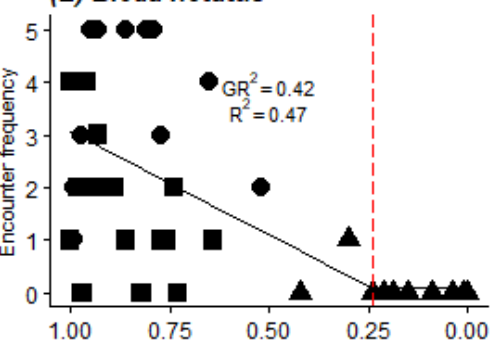

(H) Chamaetylas poliocephala

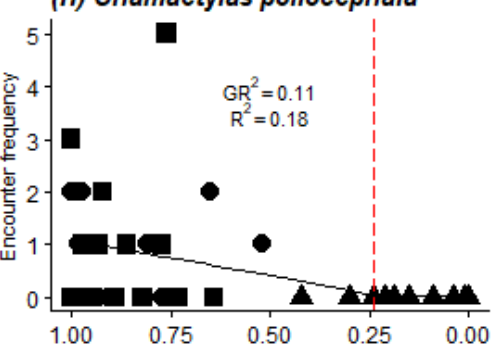

(K) Phyllastrephus icterinus

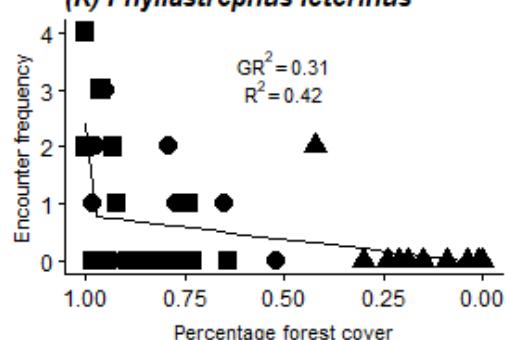

(C) Dicrurus atripennis

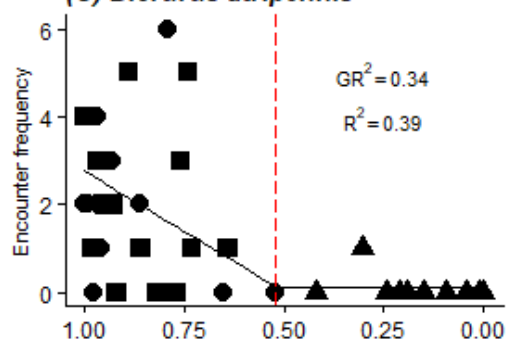

(F) Bleda syndactylus
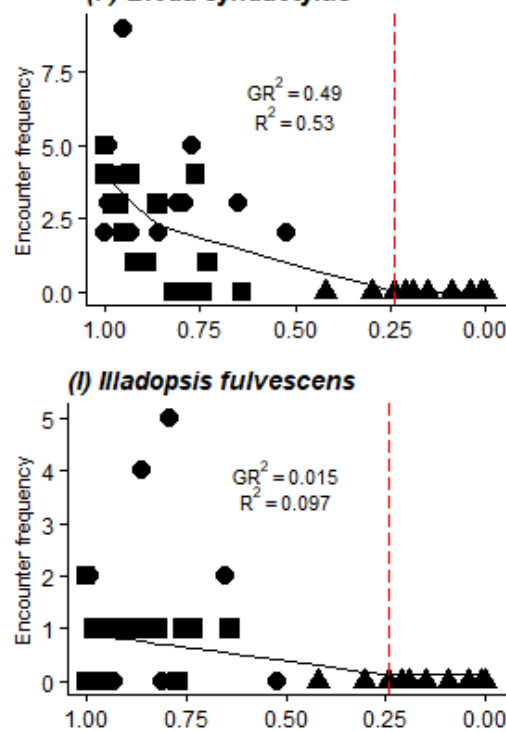

(L) Stiphrornis erythrothorax

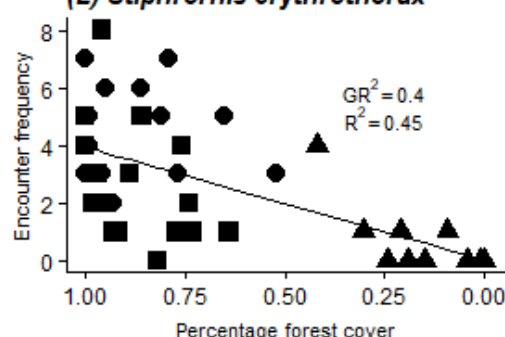

Figure 4.4 - Encounter frequencies of individual ant-following bird species in study areas of 1-km $\mathbf{w i t h}^{2}$ different proportions of forest cover. Tendency lines are the product of a multivariate additive regression spline. Dotted vertical lines indicates an extinction threshold and $G^{2}$ is a metric ranging from 0 to 1 , which indicates the predictability of the model Dots represent encounter frequency of the species in each of the study plots across the three landscapes: Circles = Korup National Park; triangles = Industrial oil palm plantations and squares = Agroforestry matrix 
The encounter frequency of all tested ant-following bird species was positively related to forest cover (Fig. 4.4). In the case of the eastern-bearded greenbul ( $C$. chloronotus), the shining drongo (D. atripennis) and the white-tailed ant-thrush ( $N$. poensis), we identified an extinction threshold at $52 \%$ forest cover. In other words, encounter frequency of these species declined linearly with forest loss in areas with $\geq 52 \%$ of forest cover and they were predicted to be absent in areas with less forest (Figs. 4.4B-D). In four cases (C. calurus, S. fraseri, P. icterinus, and $S$. erythrothorax), there was a linear decline in encounter frequency with forest loss and the species were absent in areas with no forest (Figs. 4.4J-M). An extinction threshold at $24 \%$ of forest cover was identified for both bristlebill species (B. notatus and B. syndactylus), as well as for the black-capped illadopsis (Illadopsis cleaveri), the pale-breasted illadopsis (I. rufipennis) and C. poliocephala (Figs. 4.4E-I). The model obtained for the fire-crested alethe (A. castanea) displays a peak in encounter rate at around $85 \%$ forest cover. However, there was a visible decline in the encounter rate of this species in areas with $\geq 75 \%$ of forest cover and the species was not recorded in areas with $>25 \%$ forest cover (Fig. 4.4A). Given that residuals of this model were found to be autocorrelated (see Table S4.2), we do not discuss these results further.

\subsection{Discussion}

This study constitutes the first assessment of the effect of deforestation on ant-following birds from the Guinean Forests of West Africa and the Guineo-Congolian forests as a whole. Species richness and encounter frequency of ant-followers were considerably affected by forest reduction, which resulted in a significantly different composition of the bird community in industrial oil palm plantations compared to that of forests and agroforests. Whereas Kupsch et al. (2019) identified extinction thresholds for many bird guilds in Cameroonian forests between $42 \%$ and $74 \%$, we show that ant-followers do not seem to follow the same pattern. In contrast, our data suggests a clear extinction threshold for the entire ant-following bird community at around $24 \%$ forest cover, at a scale of $1-\mathrm{km}^{2}$. However, species-specific analyses suggest the complete absence of three ant-following bird specialists in areas with less than $52 \%$ forest cover. This indicates that large proportions of forest cover, at least above 52\%, are necessary to conserve the complete ant following bird guild in mixed production landscapes.

The results of this study are consistent with previous evidence revealing negative impacts of deforestation on tropical bird communities, including a decrease in diversity (Sodhi et al. 2004) and alterations in species composition (Kofron and Chapman 1995, Martensen et al. 2015, Prabowo et al. 2016, Waltert et al. 2005, Waltert et al. 2011). The linear declines and extinction thresholds found for the ant-following bird species confirm the high sensitivity of this guild to forest loss and land-use change. Deforestation at any stage seems to have a negative effect on the community, with linear declines of species richness and encounter frequencies. This is in 
line with evidence found from ant-following bird flocks of Neotropical areas, which tend to become smaller in response to forest loss and fragmentation (Kumar and O'Donnell 2007). Local extinctions of specialized ant-following species and reduced occupancy have been documented with decreasing forest fragment size in the Brazilian Amazonia (Ferraz et al. 2007, Harper 1989). Similarly, a negative effect of land-use change and decreasing forest fragment size on the species richness of African ant-following birds has been reported elsewhere in Southwest Cameroon (Waltert et al. 2005) and Kenya (Peters et al. 2008).

The deforested areas within the industrial oil palm plantations in our study held a maximum of only $24 \%$ of the total species richness of ant-following birds present in the region and they had a lower abundance there than in either forests or agroforestry areas (Fig. 4.2). This limited bird diversity is most likely maintained by the large forest matrix in which the oil palm plantations are currently embedded. Adjacent forests provide both a source for bird colonization and for increased insect diversity in the plantations (Lucey and Hill 2012), which serve as attractants for insectivorous bird species. However, given the already impoverished bird community we found inside a plantation embedded in nearby forests, ongoing deforestation at larger spatial scales can be expected to result in further negative effects or even the complete disappearance of the ant-following bird community from industrial agricultural areas.

The use of forest cover as a central variable to predict the occurrence of species has been validated by comparisons of the impact that variables of either habitat configuration or quantity (Fahrig 2003) have on species occurrence. Generally, the amount of suitable habitat seems to be the primary driver of species occurrence, more than other landscape parameters such as habitat connectivity or the shape of habitat patches (Fahrig 2003). Moreover, forest cover may be a useful surrogate variable indirectly encompassing other limiting factors for the distribution of ant-following birds, such as food availability. The availability and foraging behavior of army ants, for example, seems to be strongly affected by humidity levels in the forest (Willis 1986). Consequently, driver ants are thought to remain inactive in open areas during the day if conditions are too dry (Peters and Okalo 2009), which in turn may reduce the probability of occurrence of ant-following bird species.

Our research provides strong evidence of the considerable effects that large agro-industrial plantations may have on the permanence of Afrotropical biota. This is in line with similar studies from various taxa in other tropical regions, including Thailand, Guatemala, Malaysia and Africa (Aratrakorn et al. 2006, Cajas-Castillo et al. 2015, Edwards et al. 2013, Linder 2013, Prabowo et al. 2016). Oil palm and rubber plantations in Thailand and Sumatra also harbored a significantly less rich bird community than forest areas, and there was a replacement of rare and endangered species by widely distributed ones and a reduced diversity of insectivorous birds (Aratrakorn et al. 2006, Prabowo et al. 2016). Similar to our study, Neotropical antfollowing bird flocks in forests of Panama displayed a decrease of around 50\% in the attendance 
of obligate ant-following birds to coffee plantations adjacent to forest, with some species even disappearing from distant plantations (Roberts et al. 2000). Even though there is little taxonomic overlap between Neotropical and Afrotropical ant-following bird communities (Powell et al. 2015), these mixed flocks share the basic behavior of following army ants of sister tribes in the subfamily Dorylinae and have similar compositions of understory insectivorous species, with obligate and opportunistic flock attendants (Willis and Oniki 1978). Studies in the Neotropical family Thamnophilidae indicate that specialization through ant-following behavior is phylogenetically conserved and ancient (Brumfield et al. 2007). Therefore, understanding the effects of industrial agricultural areas on individual ant-following bird species is pivotal to also assess its effect on the entire assembly of this guild.

In our study all ant-following bird species had significantly fewer encounters inside industrial oil palm plantations than in protected forests (Table S4.1). In contrast, all species were recorded in both protected forests and agroforests; only three species (N. poensis, B. notatus and I. fulvescens) appeared significantly less abundant inside the agroforestry matrix than in Korup National Park. We found no significant differences in species richness between nearly undisturbed forests and agroforestry areas, with fewer encounters inside the agroforestry matrix. Thus far, it appears that smallholder agricultural practices in forested systems have a limited negative effect on the ant-following bird guild.

The most sensitive species to forest cover loss appear to be $C$. chloronotus, $N$. poensis and D. atripennis. We document extinction thresholds for these three species at $52 \%$ of forest cover at a scale of $1-\mathrm{km}^{2}$. This confirms the disappearance and possible replacement of habitatspecialist tropical bird species in forest cover gradients (Banks-Leite et al. 2014, Kofron and Chapman 1995). The three mentioned species are specialized insectivores, considered to be restricted to forests and rarely occupy secondary habitats (del Hoyo et al. 2018). We found, however, that the bearded greenbul and the shining drongo have similar encounter frequencies in the agroforestry matrix than in protected forests, which highlights the value of smallholder agroforests for the conservation of forest-specialist bird species in the Guinean Forests of West Africa.

The vulnerability of forest-specialized birds to deforestation has been related to their low mobility and inability to cross habitat gaps (Martensen et al. 2012). Likewise, habitat specialists are also thought to have narrow niche widths and, therefore, depend on very specific resources (Edwards et al. 2013). Notably, the white-tailed ant-thrush is a particularly specialized groundforaging and ant-following species, known to engage in specific behaviors that allow other birds to adequately locate and follow ant swarms (Willis and Oniki 1978). We found that this species is significantly less frequent both in industrialized oil palm plantations and in agroforests, in comparison to the protected forests inside KNP. The absence of such specialized ant-following species is thought to have profound effects on the establishment and stability of ant-following 
bird flocks, since their calls are crucial for other bird species to locate ant swarms and assemble into mixed flocks (Maldonado-Coelho and Marini 2004, Peters et al. 2008). Moreover, the ability of facultative ant-followers to recognize the calls from obligate ant-following species is a learned behavior that disappears a few generations after the local extinction of the call emitters (Pollock et al. 2017). Consequently, it remains to be assessed how changes in the encounter frequency of obligate ant-following birds in agroforestry areas and industrialized plantations affect the stability and functionality of the guild.

Waltert et al. (2005) relate the absence of ground insectivorous birds in deforested areas of Cameroon to the alteration in prey availability as a result of continuous disturbance. Additionally, Willis and Okalo (2009) found that the decline in the abundance of specialized ant-followers in eastern Africa relates to declines in the daytime activity of the swarm ant Dorylus molestus as a result of habitat fragmentation. This indicates that food-limitation for ant-followers in deforested areas of tropical Africa can be related to the absence of the ants, rather than the non-existence of prey. Swarms of army ants and the animals that follow them are known to control the population size of abundant insects and thus increase the diversity of insect communities (Franks and Bossert 1983) while maintaining pest invasions under control. Consequently, the change in bird communities and the absence of strong ant-following bird flocks in large plantations and other deforested areas could have important effects on insect communities and the abundance of pests that are released from two groups of predators.

Forest conversion due to agricultural practices and its consequences for biodiversity opens the question on whether effective biodiversity conservation can be achieved through wildlifefriendly agricultural practices (land sharing), or rather through the sparing of natural ecosystems in protected areas whereas other land is dedicated exclusively to intensive agriculture (land sparing). While some authors favor exclusively land sparing (e.g. Green et al. 2005, Phalan et al. 2011) or land-sharing (e.g. Perfecto and Vandermeer 2012, Pywell et al. 2012) there has been an increasing tendency towards an integrated approach (e.g. Fischer et al. 2008, Tscharntke et al. 2012, Kremen and Merenlender 2018). Our research highlights the relevance of such an approach, which combines biodiversity conservation and functional ecosystem service provision within the so-called working lands conservation framework (Kremen and Merenlender 2018). The results of our study indicate that wildlife-friendly agricultural practices could help maintain the entire ant-following bird community of the region. The decline of certain specialists in agroforests, such as the white-tailed ant-thrush, highlights the relevance of spared land inside protected areas, which may serve as a source for the colonization of mixeduse landscapes (e.g. Lucey and Hill 2012). The agroforestry matrix we studied holds smallholder oil palm plantations and shows that production of palm oil can also be achieved in a heterogeneous agroforestry mosaic. An efficient planning for palm oil production in Cameroon and the Guineo-Congolian region should seek to maintain plantations embedded within large forest areas. Such a landscape may need to contain at least 52\% forest if the 
diversity of understory ant-following birds and the pest-predation services they offer are to be maintained.

\subsection{Conclusions}

This study provides the first quantitative measurements of the vulnerability of an ant-following bird community to deforestation within the Guineo-Congolian forest region. We found linear negative responses of the ant-following bird community and individual species to deforestation at the level of $1-\mathrm{km}^{2}$. The eastern-bearded greenbul, the white-tailed ant-thrush and the shining drongo were the most sensitive species, with extinction thresholds at $52 \%$ of forest cover. Based on these results of an indicator group sensitive to deforestation, we conclude that the conservation of forest dependent wildlife on the long term requires substantial forest cover in the matrix surrounding the protected areas of the region. The creation of large industrial plantations threatens the survival of the most forest-dependent bird species. Traditional agroforestry systems, which retain substantial forest cover, may therefore be essential for biodiversity conservation in this region while playing an important role for food security and rural livelihoods.

\subsection{References}

Aratrakorn, S., Thunhikorn, S., and Donald, P.F., (2006). Changes in bird communities following conversion of lowland forest to oil palm and rubber plantations in southern Thailand. Bird Conservation International 16: 71-82.

Banks-Leite, C., Pardini, R., Tambosi, L.R., Pearse, W.D., Bueno, A.A., et al. (2014). Using ecological thresholds to evaluate the costs and benefits of set-asides in a biodiversity hotspot. Science 345: 1041.

Betts, M.G., Forbes, G.J., and Diamond, A.W. (2007). Thresholds in songbird occurrence in relation to landscape structure. Conservation Biology 21: 1046-1058.

Brook, B.W., Sodhi, N.S., and Ng, P.K.L., (2003). Catastrophic extinctions follow deforestation in Singapore. Nature 424: 420-423.

Brooks, T.M., Mittermeier, R.A., Mittermeier, C.G., Da Fonseca, G.A., Rylands, A.B., et al. (2002). Habitat loss and extinction in the hotspots of biodiversity. Conservation Biology 16: 909-923.

Brown, J.R., Herrick, J., and Price, D., (1999). Managing low-output agroecosystems sustainably: the importance of ecological thresholds. Canadian Journal of Forest Research 29: 1112-1119. 
Brumfield, R.T., Tello, J.G., Cheviron, Z.A., Carling, M.D., Crochet, N., and Rosenberg, K.V. (2007). Phylogenetic conservatism and antiquity of a tropical specialization: Army-antfollowing in the typical antbirds (Thamnophilidae). Molecular Phylogenetics and Evolution 45: 1-13.

Cajas-Castillo, J. $\quad$ O., Cóbar-Carranza, A.J., Ávila-Santa Cruz, R.C., Kraker-Castañeda, C., and Quiñónez-Guzmán, J.M., (2015). Diversidad de aves de sotobosque en bosques tropicales, áreas de regeneración natural y cultivos de palma Africana en humedales del Lago de Izabal, Guatemala. Ornitología Neotropical 26: 1-12.

Chuyong, G.B., Condit, R., Kenfack, D., Losos, E.C., Moses, S.N., Songwe, N.C., and Thomas, D.W., (2004). Korup forest dynamics plot, Cameroon. In: Losos, E.C. and Leigh, E. Jr., (Eds.) Tropical forest diversity and dynamism: Findings from a large-scale plot network. University of Chicago Press. pp. 505-516.

Darwall, W., Polidoro, B., Smith, K., and Somda, J., (2015). Ecosystem Profile. Guinean Forests of West Africa Biodiversity Hotspot. Critical Ecosystem Partnership Fund Report.

del Hoyo, J., Elliott, A., Christie, D., and de Juana, E., (2018). HBW Alive: Handbook of the Birds of the World Alive. Lynx Edicions, Barcelona.

Edwards, D.P., Woodcock, P., Newton, R.J., Edwards, F.A., Andrews, D.J.R., et al. (2013). Trophic flexibility and the persistence of understory birds in intensively logged rainforest. Conservation Biology 27: 1079-1086.

Fahrig, L., (2001). How much habitat is enough? Biological Conservation 100: 65-74.

Fahrig, L., (2003). Effects of Habitat Fragmentation on Biodiversity. Annual Review of Ecology, Evolution, and Systematics 34: 487-515.

Ferraz, G., Nichols, J.D., Hines, J.E., Stouffer, P.C., Richard, O.B. Jr. Lovejoy, T.E., (2007). A large-scale deforestation experiment: effects of patch area and isolation on Amazon birds. Science 315: 238-241.

Fischer, J., Abson, D.J., Butsic, V., Chappell, M.J., Ekroos, J., et al. (2014). Land sparing versus land sharing: moving forward. Conservation Letters 7: 149-157.

Franks, N.R., and Bossert, W.H., (1983). The influence of swarm raiding army ants on the patchiness and diversity of a tropical leaf litter ant community. In Tropical Rain Forest: Ecology and Management. Special Publication of the British Ecological Society 2: 151163.

Friedman, J.H., (1991). Multivariate Adaptive Regression Splines. The Annals of Statistics 19: $1-67$. 
Geist, H.J., and Lambin, E.F., (2002). Proximate Causes and Underlying Driving Forces of Tropical Deforestation Tropical forests are disappearing as the result of many pressures, both local and regional, acting in various combinations in different geographical locations. BioScience, 52: 143-150.

Green, R.E., Cornell, S.J., Scharlemann, J.P., and Balmford, A., (2005). Farming and the fate of wild nature. Science 307: 550-555.

Harper, L. H., (1989). The persistence of ant-following birds in small Amazonian Forest fragments. Acta Amazonica 19: 249-263.

Hoyle, D., and Levang, P., (2012). Oil palm development in Cameroon. WWF and CIFOR. Yaoundé, Cameroon. http://assets.panda.org/downloads/palmoildevelopmentcameroon_english.pdf

Huggett, A.J., (2005). The concept and utility of "ecological thresholds" in biodiversity conservation. Biological Conservation 124: 301-310.

Kofron, C.P., and Chapman, A., (1995). Deforestation and bird species composition in Liberia, West Africa. Tropical Zoology 8: 239-256.

Kumar, A., and O‘Donnell, S., (2007). Fragmentation and elevation effects on bird-army ant interactions in Neotropical montane forest of Costa Rica. Journal of Tropical Ecology 23: 581-590.

Kupsch, D., Vendras, E., Ocampo-Ariza, C., Batáry, P., Motombi, F.N., Bobo, K.S., and Waltert, M., (2019). High critical forest habitat thresholds of native bird communities in Afrotropical agroforestry landscapes. Biological Conservation 230: 20-28.

Kremen, C., and Merenlender, A.M., (2018). Landscapes that work for biodiversity and people. Science 362: eaau6020.

Lindenmayer, D.B., Fischer, J., and Cunningham, R.B., (2005). Native vegetation cover thresholds associated with species responses. Biological Conservation 124: 311-316.

Lindenmayer, D.B., and Luck, G., (2005). Synthesis: Thresholds in conservation and management. Biological Conservation 124: 351-354.

Linder, J.M., (2013). African Primate Diversity Threatened by "New Wave" of Industrial Oil Palm Expansion. African Primates 8: 25-28.

Lucey, J.M., and Hill, J.K., (2012). Spillover of Insects from Rain Forest into Adjacent Oil Palm Plantations. Biotropica 44: 368-377.

Maldonado-Coelho, M., and Marini, M.Â., (2004). Mixed-species bird flocks from Brazilian Atlantic forest: The effects of forest fragmentation and seasonality on their size, richness and stability. Biological Conservation 116: 19-26. 
Martensen, A.C., Ribeiro, M.C., Banks-Leite, C., Prado, P.I., and Metzger, J.P., (2012). Associations of Forest Cover, Fragment Area, and Connectivity with Neotropical Understory Bird Species Richness and Abundance. Conservation Biology 26: 1100-1111.

Mbile, P., Vabi, M., Meboka, M., Okon, D., Arrey-Mbo, J., Nkongho, F., and Ebong, E., (2005). Linking management and livelihood in environmental conservation: Case of the Korup National Park Cameroon. Journal of Environmental Management 76: 1-13.

Milborrow, S., (2011). Earth. R package. Multivariate Adaptive Regression Splines. Derived from mda:mars by T. Hastie and R. Tibshirani.

Milborrow, S., (2014). Notes on the earth package. pp. 1-60.

MINEP and UNDP (1996). Plan national de gestion de l'environnement au Cameroun. http://adaptation-undp.org/sites/default/files/downloads/cameroon_national_plan_for_ environmental_management.pdf

Mittermeier, R.A., Robles-Gil, P., Hoffmann, M., Pilgrim, J.D., Brooks, T.B., Mittermeier, C.G., Lamoreux, J.L., and Fonseca, G.A.B., (2004). Hotspots Revisited: Earth's Biologically Richest and Most Endangered Ecoregions. CEMEX, Mexico City, Mexico.

Moran, C., and Catterall, C.P., (2014). Responses of seed-dispersing birds to amount of rainforest in the landscape around fragments. Conservation Biology 28: 551-560.

Morante-Filho, J.C., Faria, D., Mariano-Neto, E., and Rhodes, J., (2015). Birds in anthropogenic landscapes: The responses of ecological groups to forest loss in the Brazilian Atlantic forest. PLoS ONE 10: e0128923.

Oksanen, J., Blanchet, F.G., Kindt, R., Legendre, P., Minchin, P.R., et al. (2016). Vegan: community ecology package. R package, version $2.4-1$.

Perfecto, I., and Vandermeer, J., (2012). Separación o integración para la conservación de biodiversidad: la ideología detrás del debate "land-sharing" frente a "land-sparing". Revista Ecosistemas 21: 180-191.

Peters, M.K., Likare, S., and Kraemer, M., (2008). Effects of habitat fragmentation and degradation on flocks of African ant-following birds. Ecological Applications 18: 847858.

Peters, M.K., Fischer, G., Schaab, G., and Kraemer, M., (2009). Species compensation maintains abundance and raid rates of African swarm-raiding army ants in rainforest fragments. Biological Conservation 142: 668-675.

Peters, M.K., and Okalo, B., (2009). Severe declines of ant-following birds in African rainforest fragments are facilitated by a subtle change in army ant communities. Biological Conservation 142: 2050-2058. 
Phalan, B., Onial, M., Balmford, A., and Green, R.E., (2011). Reconciling food production and biodiversity conservation: land sharing and land sparing compared. Science 333: 12891291.

Pollock, H.S., Martínez, A.E., Kelley, J.P., Touchton, J.M., and Tarwater, C.E., (2017). Heterospecific eavesdropping in ant-following birds of the Neotropics is a learned behaviour. Proceedings of the Royal Society B: Biological Sciences 284: 20171785.

Powell, L.L., Cordeiro, N.J., and Stratford, J.A., (2015). Ecology and conservation of avian insectivores of the rainforest understory: A pantropical perspective. Biological Conservation 188: 1-10.

Prabowo, W.E., Darras, K., Clough, Y., Toledo-Hernandez, M., Arlettaz, R., Mulyani, Y.A., and Tscharntke, T., (2016). Bird responses to lowland rainforest conversion in Sumatran smallholder landscapes, Indonesia. PLoS ONE 11: e0154876.

Pywell, R.F., Heard, M.S., Woodcock, B.A., Hinsley, S., Ridding, L., Nowakowski, M., and Bullock, J.M., (2015). Wildlife-friendly farming increases crop yield: evidence for ecological intensification. Proceedings of the Royal Society B: Biological Sciences 282: 20151740.

R Development Core Team (2017). R: A Language and Environment for Statistical Computing. R Foundation for Statistical Computing, Vienna, Austria.

Radford, J.Q., Bennett, A.F., and Cheers, G.J., (2005). Landscape-level thresholds of habitat cover for woodland-dependent birds. Biological Conservation 124: 317-337.

Ralph, C.J., Droege, S., and Sauer, J.R., (1995). Managing and Monitoring Birds Using Point Counts: Standards and Applications. In: Ralph, C.J., Sauer, J.R., and Droege, S., (Techn. Eds.) Monitoring bird populations by point counts. Gen. Tech. Rep. PSW-GTR-149. U.S. Department of Agriculture, Forest Service, Pacific Southwest Research Station. Albany, CA. pp. 161-168.

Roberts, D.L., Cooper, R.J., and Petit, L.J., (2000). Flock characteristics of ant-following birds in premontane moist forest and coffee agroecosystems. Ecological Applications 10: $1414-1425$.

Rodewald, P.G., Dejaifve, P.A., and Green, A.A., (1994). The birds of Korup National Park and Korup Project Area, Southwest Province, Cameroon. Bird Conservation International 4: $1-68$.

Sodhi, N.S., Liow, L.H., and Bazzaz, F.A., (2004). From Tropical and Avian Extinctions Forests. Annual Review of Ecology, Evolution, and Systematics 35: 323-345.

Swift, T.L., and Hannon, S. J., (2010). Critical thresholds associated with habitat loss: A review of the concepts, evidence, and applications. Biological Reviews 85: 35-53. 
Tscharntke, T., Clough, Y., Wanger, T.C., Jackson, L., Motzke, I., et al. (2012). Global food security, biodiversity conservation and the future of agricultural intensification. Biological conservation 151: 53-59.

Waltert, M., Bobo, K.S., Sainge, N.M., Fermon, H., and Mühlenberg, M., (2005). From forest to farmland: Habitat effects on Afrotropical forest bird diversity. Ecological Applications 15: $1351-1366$.

Waltert, M., Bobo, K.S., Kaupa, S., Montoya, M.L., Nsanyi, M.S., and Fermon, H., (2011). Assessing conservation values: biodiversity and endemicity in tropical land use systems. PLoS ONE 6: e16238.

Willis, E.O., (1986). West African thrushes as safari ant followers. Le Gerfaut 76: 95-108.

Willis, E., and Oniki, Y., (1978). Birds and Army Ants. Annual Review of Ecology and Systematics 9: 243-263. 


\subsection{Supplement}

Table S4.1 - Encounter frequency of each species found in the survey inside the three landscapes of the study area $($ KNP $=$ Korup National Park; AFM = Agroforestry matrix; IOP $=$ Industrial oil palm plantation) and differences among landscapes Mann-Whitney U-tests (M-W). Taxonomic classification follows del Hoyo et al. (2016). ND= No significant differences; * $=0.05 \geq p \geq 0.01 ; * *=0.01>p \geq 0.001 ; * * *$ $=p \leq 0.001$.

\begin{tabular}{|c|c|c|c|c|c|c|c|}
\hline \multirow[b]{2}{*}{ Family and species } & \multicolumn{4}{|c|}{ Encounter frequency } & \multicolumn{3}{|c|}{ MW test } \\
\hline & Total & KNP & AFM & IOP & $\begin{array}{l}\text { KNP/ } \\
\text { AFM }\end{array}$ & $\begin{array}{c}\text { KNP/ } \\
\text { IOP }\end{array}$ & $\begin{array}{c}\text { AFM/ } \\
\text { IOP }\end{array}$ \\
\hline \multicolumn{8}{|l|}{ Bucerotidae } \\
\hline Lophoceros camurus & 17 & 6 & 11 & 0 & ND & $* * *$ & $* * *$ \\
\hline Horizocerus albocristatus & 8 & 5 & 3 & 0 & ND & ND & ND \\
\hline \multicolumn{8}{|l|}{ Alcedinidae } \\
\hline Halcyon badia & 13 & 4 & 8 & 1 & ND & ND & $* *$ \\
\hline \multicolumn{8}{|l|}{ Pycnonotidae } \\
\hline Phyllastrephus icterinus & 33 & 18 & 13 & 2 & ND & $* *$ & $*$ \\
\hline Bleda syndactylus & 92 & 58 & 34 & 0 & ND & $* * *$ & $* * *$ \\
\hline Bleda notatus & 85 & 58 & 26 & 1 & $* * *$ & $* * *$ & $* * *$ \\
\hline Criniger chloronotus & 83 & 50 & 33 & 0 & ND & $* * *$ & $* * *$ \\
\hline Criniger calurus & 110 & 54 & 53 & 3 & ND & $* * *$ & $* * *$ \\
\hline \multicolumn{8}{|l|}{ Turdidae } \\
\hline Stizorhina fraseri & 41 & 23 & 17 & 1 & ND & $* * *$ & $* * *$ \\
\hline Neocossyphus poensis & 73 & 46 & 26 & 1 & $* *$ & $* * *$ & $* * *$ \\
\hline Neocossyphus rufus & 2 & 1 & 1 & 0 & ND & ND & ND \\
\hline Chamaetylas poliocephala & 31 & 16 & 15 & 0 & ND & $* * *$ & $* * *$ \\
\hline Alethe castanea & 79 & 42 & 33 & 4 & ND & $* * *$ & $* * *$ \\
\hline Stiphrornis erythrothorax & 117 & 67 & 43 & 7 & ND & $* * *$ & $* * *$ \\
\hline Shepphardia cyornithopsis & 3 & 2 & 1 & 0 & ND & ND & ND \\
\hline \multicolumn{8}{|l|}{ Muscicapidae } \\
\hline Muscicapa sethsmithi & 17 & 10 & 7 & 0 & ND & $* *$ & $* *$ \\
\hline \multicolumn{8}{|l|}{ Timaliidae } \\
\hline Illadopsis cleaveri & 7 & 1 & 6 & 0 & ND & ND & ND \\
\hline Illadopsis rufipennis & 81 & 42 & 39 & 0 & ND & $* * *$ & $* * *$ \\
\hline Illadopsis fulvescens & 27 & 14 & 13 & 0 & ND & $* * *$ & $* * *$ \\
\hline \multicolumn{8}{|l|}{ Dicruridae } \\
\hline Dicrurus atripennis & 69 & 33 & 35 & 1 & ND & $* * *$ & $* * *$ \\
\hline
\end{tabular}




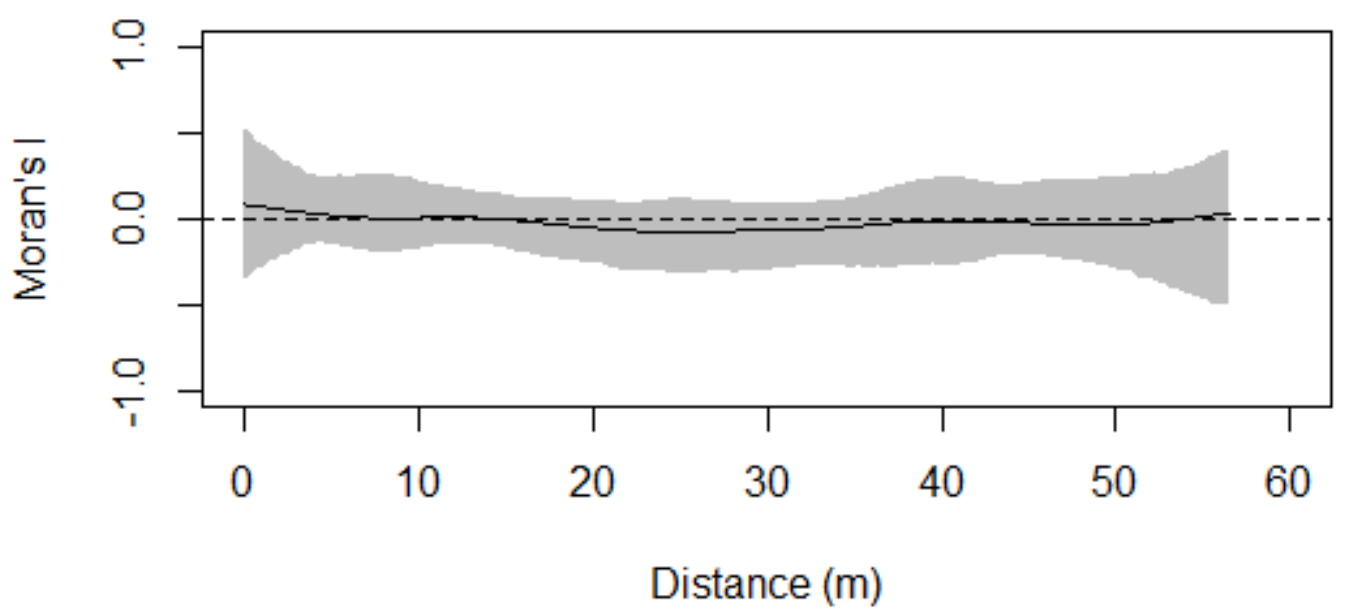

Figure S4.1 - Correlogram evaluating potential autocorrelation among residuals of the EARTH model, which tests the response of bird encounter frequency to forest cover. The grey area corresponds to the $95 \%$ confidence interval of 1,000 bootstrap iterations to calculate Moran's $I$, while the solid line represents the predicted autocorrelation values obtained from the bootstrap. The figure shows a random variation of residual correlation in function of distance between study points and, therefore, no spatial autocorrelation.

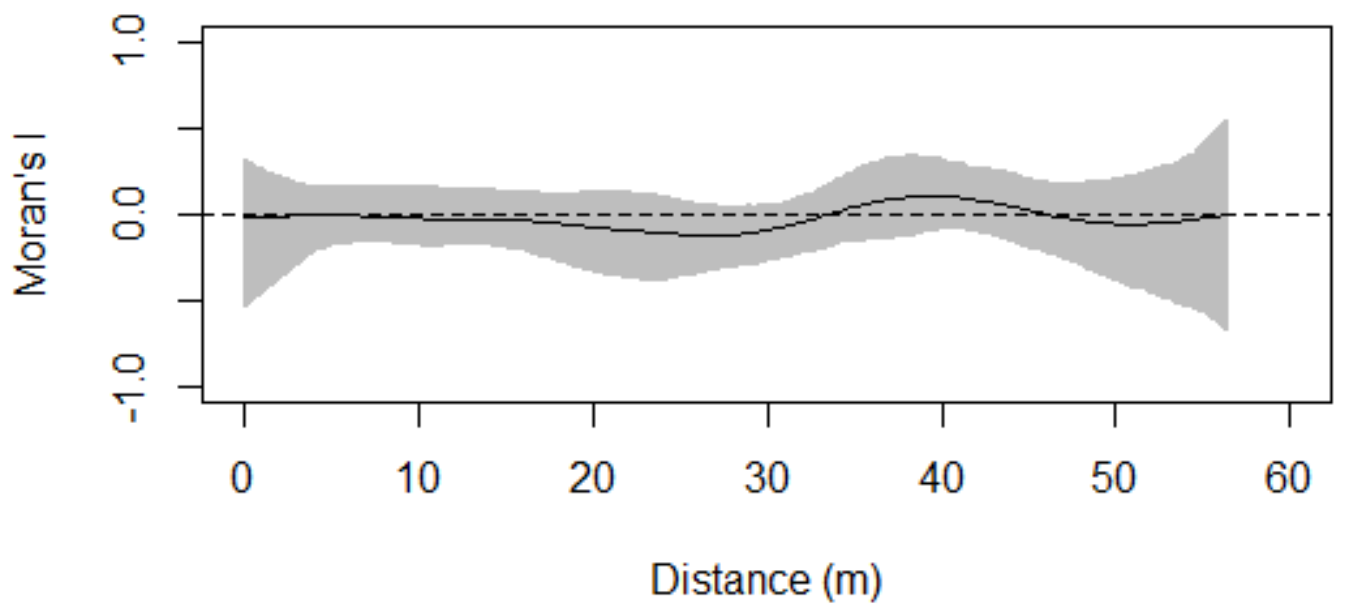

Figure S4.2 - Correlogram evaluating potential autocorrelation among residuals of the EARTH model, which tests the response of bird species richness to forest cover. The grey area corresponds to the $95 \%$ confidence interval of 1,000 bootstrap iterations to calculate Moran's $I$, while the solid line represents the predicted values obtained from the bootstrap. The figure shows a random variation of residual correlation in function of distance between study points and, therefore, no spatial autocorrelation. The large variation in the maximum distances is possibly an artifact due to the low amount of cases in our study design in which such high distances were reached. 
Table S4.2 - Moran's I autocorrelation tests for individual species' EARTH model residuals, for the antfollowing bird species included in Fig. 4.4. The expected value is calculated as $-1 /(n-1)$, where $n=48$ study plots. Stars next to p-values indicate significant spatial autocorrelation in model residuals under $\alpha<0.05$.

\begin{tabular}{lccr}
\hline Species & Moran's I & Expected I & $\boldsymbol{p}$ \\
\hline Alethe castanea & -0.028 & -0.021 & 0.763 \\
Criniger chloronotus & -0.050 & -0.021 & 0.938 \\
Dicrurus atripennis & -0.007 & -0.021 & 0.081 \\
Neocossyphus poensis & -0.040 & -0.021 & 0.887 \\
Bleda notatus & 0.060 & -0.021 & 0.969 \\
Bleda syndactylus & -0.044 & -0.021 & 0.924 \\
Illadopsis rufipennis & -0.014 & -0.021 & 0.400 \\
Chamaetylas poliocephala & -0.005 & -0.021 & $0.022 *$ \\
Illadopsis fulvescens & -0.011 & -0.021 & 0.234 \\
Criniger calurus & 0.086 & -0.021 & 0.0994 \\
Phyllastrephus icterinus & -0.011 & -0.021 & 0.307 \\
Styphrornis erythrothorax & 0.035 & -0.021 & 0.832 \\
Stizorhina fraseri & -0.023 & -0.021 & 0.641 \\
\hline
\end{tabular}

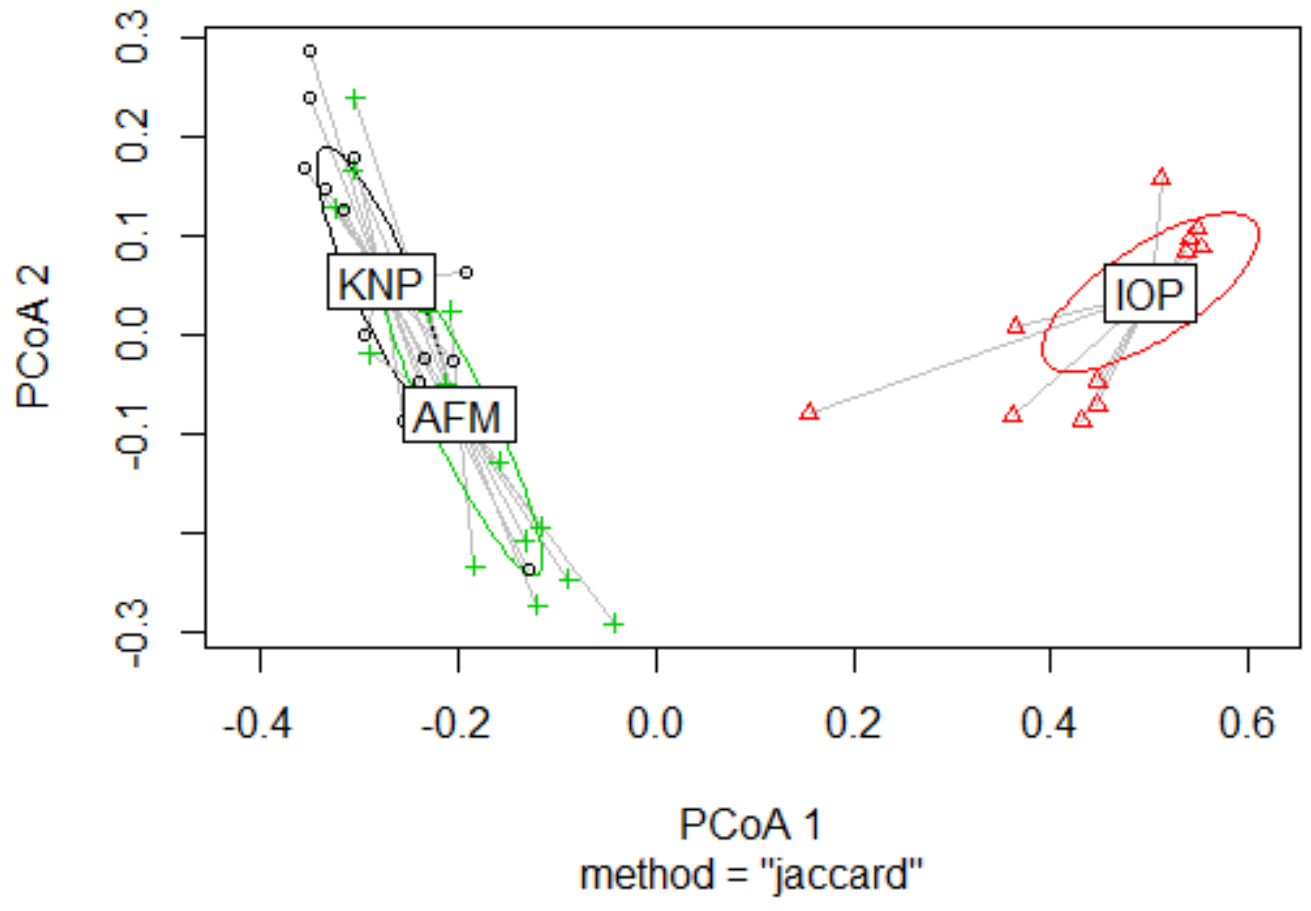

Figure S4.3 - Ordination of ant-following bird community composition inside the three study landscapes, as a result of a Permanova. KNP = Korup National Park, AFM = Unprotected Agroforestry, IOP = Industrial Oil Palm Plantations 


\section{CHAPTER 4}

Table S4.5 - Mean forest cover $( \pm \mathrm{SE})$ per $1-\mathrm{km}^{2}$ plot as well as mean vegetation cover $( \pm \mathrm{SE})$ at different forest strata at sampling points (estimated in a radius of $10 \mathrm{~m}$ around the point) inside each of the assessed landscapes. Each calculation is based on the 144 sampling points evaluated per landscape (36 points per settlement, see Materials and methods).

\begin{tabular}{|c|c|c|c|c|c|c|c|}
\hline \multirow{2}{*}{ Landscape } & \multirow{2}{*}{$\begin{array}{c}\text { Forest } \\
\text { cover (\%) }\end{array}$} & \multicolumn{5}{|c|}{ Vegetation cover at different forest strata (\%) } & \multirow{2}{*}{$\begin{array}{c}\text { Elevation } \\
\text { (m) }\end{array}$} \\
\hline & & $0-1 \mathrm{~m}$ & $1-5 m$ & $5-15 m$ & $15-25 m$ & $>25 \mathrm{~m}$ & \\
\hline KNP & $88.4 \pm 0.4$ & $48.6 \pm 1.5$ & $26.3 \pm 1.4$ & $20.42 \pm 1.1$ & $17.5 \pm 0.9$ & $16.1 \pm 1.1$ & $273 \pm 10.3$ \\
\hline AFM & $87.0 \pm 2.8$ & $55.4 \pm 2.0$ & $43.7 \pm 1.7$ & $33.7 \pm 1.9$ & $22.1 \pm 1.5$ & $8.4 \pm 0.8$ & $448 \pm 17.6$ \\
\hline IOP & $10.3 \pm 3.3$ & $69.3 \pm 1.6$ & $11.0 \pm 1.0$ & $22.5 \pm 1.3$ & $1.8 \pm 0.4$ & $0.3 \pm 0.2$ & $89 \pm 3.3$ \\
\hline
\end{tabular}




\section{Chapter 5 \\ Congo Grey Parrot Psittacus erithacus densities in oil palm plantation, agroforestry mosaic and protected forest in SW Cameroon}

\section{Publication}

Sascha Düker, Denis Kupsch, Kadiri Serge Bobo, Eckhard W. Heymann and Matthias Waltert, first view, Bird Conservation International.

https://doi.org/10.1017/S0959270919000194

\subsection{Abstract}

The Congo Grey Parrot has experienced a severe population breakdown in recent decades. The rainforests of the Korup region in Southwest Cameroon may harbour a large population of this species, but density and population estimates from this area remain controversial. Before the 2016 breeding season, we surveyed Grey Parrots along transects (621.1 km survey effort) in three adjacent landscape types: primary forest in Korup National Park (KNP), smallholder agroforestry matrix (AFM), and industrial oil palm plantation (OPP). We also collected information on the trees used for nesting, feeding and roosting. Using Distance analysis, we estimated relatively low densities of stationary flocks, ranging from $0.30 \mathrm{ind} . / \mathrm{km}^{2}$ in $\mathrm{KNP}$, over 0.82 ind. $/ \mathrm{km}^{2}$ in OPP to 2.70 ind. $/ \mathrm{km}^{2}$ in the AFM. Parrots were observed feeding or roosting in 17 tree species, of which 15 were located in AFM alone. Feeding was most often observed on cultivated Elaeis guineensis and Dacryodes edulis, but never in maize. The detected parrot densities probably reflect declines within the period 2008-2016, suggesting that the species' recent IUCN uplisting to Endangered and transfer to CITES Appendix I was indeed justified. Our results also suggest that traditional smallholder agroforestry may play a role in habitat conservation strategies, since these forms of cultivation may maintain important breeding and feeding opportunities for Congo Grey Parrots.

\subsection{Introduction}

Parrots of the genus Psittacus are found mainly in moist forests but also mangroves and wooded savannah across tropical Africa (Naurois 1981, BirdLife International 2017a,b). Phenotypic differentiation suggests that the genus comprises two species: the Congo Grey Parrot Psittacus erithacus and the Timneh Grey Parrot Psittacus timneh (Collar 2013). Distribution ranges are estimated at 4,490,000 km² for Psittacus erithacus and at 541,000 km2 for Psittacus timneh although recent assessments are lacking (BirdLife International 2017a,b). Grey parrots were still 'common to abundant' in parts of their range in the early 1980s (Green et al. 2007, 
Tamungang and Cheke 2012, see also Martin et al. 2014a). Recently, an estimated population decline of 50-79\% within three generations has been suggested (47 years, BirdLife International 2017a). In Ghana, it has been estimated that 90-99\% of the population has been lost since 1992 accompanied by regional extinctions (Annorbah et al. 2016). Consequently, Congo Grey Parrots are categorized as Endangered by the IUCN (BirdLife International 2017a) and listed under the CITES Appendix I (CITES 2016).

Due to their world-wide popularity as pets, Grey Parrots are among the most frequently traded parrots. (Chupezi et al. 2006, Martin et al. 2014a, Martin 2018a). Since 1975 net exports of more than 1.22 million wild Grey Parrots have been reported in international trade by CITES parties (Martin 2018b). Until 2016, national export quota were 5,000 and 3,000 for the Democratic Republic of Congo and Cameroon, respectively (CITES 2016, Martin 2018). Given high mortality (40-60\%) during trapping and transport (Fotso 1998a,b, McGowan 2001) as well as additional illegal export, the real yearly harvest was likely considerably higher than the stated quotas (BirdLife International 2017a). In Cameroon alone, some 100,000 birds per year were probably being captured during the late 1990s and early 2000s (BirdLife International 2017a).

Furthermore, Grey Parrots may also be impacted by forest loss and degradation, such as reduced availability of large nesting trees as a consequence of logging (Martin et al. 2014a). In Africa, high-value timber species such as Terminalia superba are commonly used as breeding trees by Grey Parrots (Annorbah et al. 2016). There is some evidence on the occasional use of Grey Parrots as bush meat, for ceremonies or medicinal purposes (Fotso 1998a, McGowan 2001, Clemmons 2003, Fa et al. 2006, Eniang et al. 2008, own unpubl. information), though its impacts on wild populations remains unclear.

The rainforests of the Korup region in SW Cameroon are still largely unfragmented (Kupsch et al. 2019) and should therefore be an important stronghold of the species. Based on survey data from 2008 to 2010, Tamungang et al. (2013) provided an population estimate for Southwest Cameroon as well as a more detailed assessment on habitat preferences in three landscape types (Tamungang et al. 2016), however, Martin et al. (2014b) criticized both their field and analysis methodology as deficient and prone to biases.

In order to update information from the same three landscape types, we collected data during the pre-breeding season 2016, approx. seven years after the surveys of Tamungang et al. (2016). We also report incidental observations on the trees used for feeding, breeding and roosting in order to inform assessments of habitat quality for the species. We assumed that habitat quality and parrot abundance would vary with the availability of these resources. Based on Tamungang et al. (2016), we expected to estimate higher parrot densities in a traditional smallholder agroforestry landscape compared to undisturbed primary forests or industrial oil palm plantations. 


\subsection{Materials and methods}

\section{Study area}

The study was conducted in and around Korup National Park (KNP) in SW Cameroon (Fig. 5.1) congruent with the study area of the surveys of 2008-2010 by Tamungang et al. (2016). Surveys were done between 23 March and 4 June 2016 during pre-breeding season (pers. obs.). With approx. 26,000 $\mathrm{km}^{2}$, the forest block of SE Nigeria/SW Cameroon is the largest relatively intact remaining continuous rainforest of the biodiversity hotspot "Guinean Forests of West Africa", which holds at least 416 mammal and 917 bird species (Mittermeier et al. 2004). The biggest urban area close to the park is the capital of Ndian division, Mundemba, with 5,000-6,000 inhabitants.

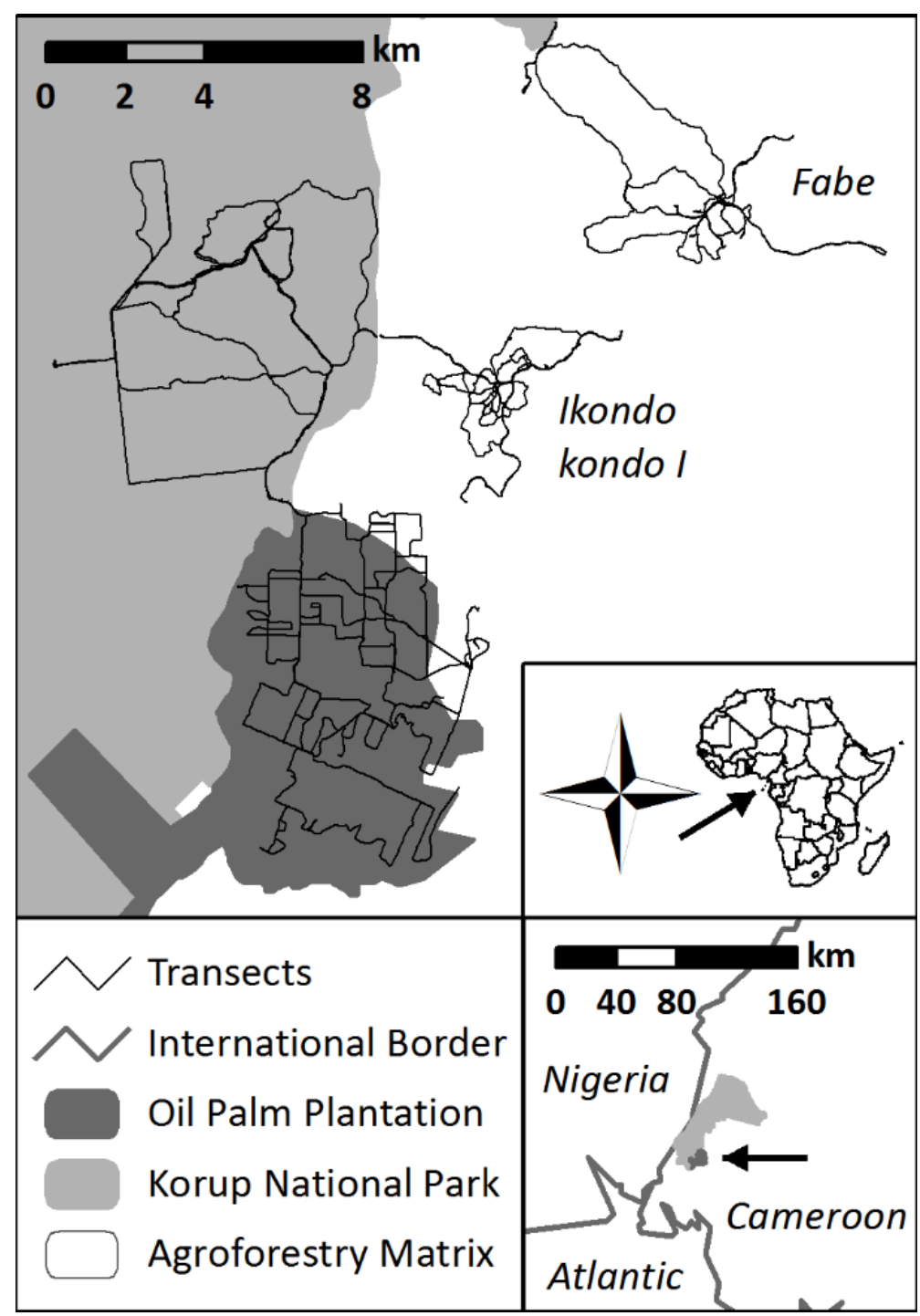

Figure 5.5 - Study area in and around Korup National Park in Southwest Cameroon. 
We collected data in three different adjacent landscape types: (i) the primary forests of the southern sector of KNP, (ii) the agroforestry matrix landscape shaped by traditional smallholder activities (AFM) in the eastern surroundings of the park, and (iii) in an industrial oil palm plantation (OPP) at the southern border of the park.

(i) Korup National Park

KNP is approx. $1,260 \mathrm{~km}^{2}$ in size and was created in 1986 with its western border adjacent to Nigeria (Fig. 5.1). It is characterized as primary forest, classified as Oubangia alata (Scytopetalaceae) coastal forest with an annual rainfall of more than 4,000 $\mathrm{mm}$ (Thomas 1996). KNP harbours 419 bird species (Bobo et al. 2005). The field-work was based at Chimpanzee Camp $\left(5.069^{\circ} \mathrm{N}, 8.860^{\circ} \mathrm{E}\right)$, which is located in $10 \mathrm{~km}$ distance from the national park entrance, Mana footbridge. The closest settlements were the villages Ikondo kondo 1, Erat, and the workers camps of the PAMOL oil palm plantation. The area is intersected by small to medium sized creeks and rivers during the wet season.

(ii) Agroforestry matrices

Data were collected in an area containing two rural villages close to the park, both of them with around 150 inhabitants. These were Ikondo kondo 1 and Fabe, which are located ca. $7.5 \mathrm{~km}$ and $15 \mathrm{~km}$ northeast of Mundemba, respectively (Fig. 5.1). These villages are mainly inhabited by traditional smallholder families, who plant a mixture of subsistence and cash crops in and around their villages within a landscape dominated by remaining primary and secondary forests (Kupsch et al. 2019). Fire is often used to clear small areas inside forest, often in the shade of old trees, e.g. for cacao Theobroma cacao. Around these villages, forest patches are relatively undisturbed and used for hunting. Therefore and because of minimal application of pesticides, the current smallholders' impact on the forest environment is minor.

(iii) Oil palm plantations

The OPP in the west of Mundemba is an estate of PAMOL Plantations Plc. The plantation area covers $58.04 \mathrm{~km}^{2}$ and is systematically partitioned in monocultural fields of Elaeis guineensis. It borders KNP and holds some remnants of forest along two large streams and steep slopes.

\section{Data collection}

Following procedures employed by Legault et al. (2013) and Marsden et al. (2015), we collected data from transects, and report both encounter rates and densities for stationary parrot 
flocks. These walks follow paths of least resistance through dense habitat (Walsh and White 1999). We used a GPS device to record the paths walked and measured perpendicular distances from the transect line to Grey Parrot flocks with a range finder. To increase accuracy and discernment, all transects were walked at least once by two observers (Legault et al. 2013). Transects were walked directly after dawn between $06 \mathrm{~h} 00$ and 10h00, and before dusk between $16 \mathrm{~h} 00$ and $19 \mathrm{~h} 00$, when parrot activity was highest. We did not survey under strong wind or rain, as this might strongly affect detectability (Lee \& Marsden 2012).

\section{Data analysis}

To estimate density we modelled detection probability using the Conventional Distance Sampling engine (Buckland et al. 2001) of Distance 6.0, release 2 (Thomas et al. 2010). Since fast flying parrots are violating assumptions of Distance methodology, potentially inflating density estimates, we ignored overflies in calculations of density (Buckland et al. 2001). Most studies follow this convention (including Tamungang et al. 2013, 2016). Different truncation distances were used to model data from each of the landscape types, as well as for data from all three landscape types combined. Different key functions (uniform, half-normal and hazard-rate) in combinations of series adjustments (cosine, simple polynomial and hermite polynomial) were fitted to the data. Finally, visual examination, Chi-Square Goodness of fit tests, and eventually the Akaike's Information Criterion (AIC) was used to evaluate model fit (Buckland et al. 2001, Thomas et al. 2010). AIC values from stratified data were compared to those from a global detection function, to assess the reliability of a global detection probability estimate. Since the sum of AIC values from stratified data was higher than the AIC value from a global detection function $\left(\mathrm{AIC}_{\text {global }}=170.17, \sum \mathrm{AIC}_{\text {stratified }}=171.80\right)$, densities were estimated based on a global detection probability function for data truncated to a strip width of $w=127 \mathrm{~m}$. The half-normal/cosine detection function was found to be most reliable to assess detection probability $\mathrm{P}$. The chosen function had eight intervals and detection probability was estimated at $P=0.55$ (12.56\% CV, Fig. S5.1a). For density calculations in each stratum, we used a global estimate of expected flock size $E(s)$ based on the size-biased regression method, regressing $\ln$ (flock size) against estimated detection probability $\mathrm{g}(\mathrm{x})$. We used a global estimate of flock size since records of stationary flocks in Korup National Park were only $n=5$. Size-biased regression suggested that smaller flocks were underrepresented at larger distances from transects to some extent: expected flock size was estimated at 2.40 individuals per flock (95\% C.I.: 1.88-3.08) whereas average flock size was estimated at 3.32 individuals per flock (95\% C.I.: 2.17-5.07). Density estimates in the three different landscape types were compared using a $Z$-test with a two-tailed $p$-value, and using the Delta method. 
Field observations on feeding, breeding and roosting sites

When encountering a stationary flock of Grey Parrots during surveys, observations on feeding, breeding and roosting trees were made following Reuleaux et al. (2014a, b). In addition, we noted the number of individuals, which aggregated for resting or sleeping. We recorded the location of feeding, breeding and roosting with a GPS. We also took pictures from the trees utilised for later analysis. Leaves, seeds and fruits falling to the ground were collected and identified later with the help of a local botanist. Moreover, the number of individual parrots was noted, activity was described as breeding, roosting, feeding or sitting, and the height of the respective tree measured using the range finder.

As repeated use of successful nests is very common among many cavity-nesters (Sedgwick 1997), particularly parrots (Gnam 1991, Pinho and Nogueira 2003), we asked local farmers to show us known breeding sites, i.e. areas where they observed either eggs, chicks or adult birds in and around a cavity for an extended period, and showing characteristic behaviour, such as inspections of the cavity or sentinel behaviour (see Marsden et al., 2001 classification for 'active' nests).

\subsection{Results}

\section{Parrot encounter metrics and density estimation}

In total we walked 68 transects and $621.1 \mathrm{~km}$ across the three different landscapes (Table 5.1), of which most $(k=28, L=286.8 \mathrm{~km}$ ) were allocated to KNP. However, here we also recorded the lowest numbers of flocks of Grey Parrots (20 overflying and five stationary flocks). After truncation to $w=127 \mathrm{~m}$, encounter rates of stationary flocks were lower in KNP (flocks $n / L=0.02$ ind. $/ \mathrm{km})$ and OPP $(n / L=0.05$ ind. $/ \mathrm{km})$ than in $\operatorname{AFM~}(n / L=0.16$ ind. $/ \mathrm{km}$; Table 5.2). Whereas both overflying and stationary flocks in AFM and OPP consisted of less than three individuals on average, they were much larger in $\mathrm{KNP}\left(E(s)_{\text {overfly }}=4.20 ; E(s)_{\text {stationary }}=9.40\right)$ (Table 5.1). Using the expected flock size estimate from data pooled across landscapes (see methods), density estimates ranged from 0.30 ind. $/ \mathrm{km}^{2}$ in $\mathrm{KNP}$, over 0.82 ind. $/ \mathrm{km}^{2}$ in OPP to 2.70 ind. $/ \mathrm{km}^{2}$ in the AFM. Consequently, estimated density for the AFM was nine times higher than that for KNP (albeit non-significantly; $\Delta Z=0.15, p=0.88$ ) and three times higher than that for the OPP $(\triangle Z=-2.53, p=0.01)$, respectively. Estimated parrot densities for the OPP did not differ significantly from that for $\operatorname{KNP}(\Delta Z=-0.71, p=0.48)$. 
Table 5.6 - Total transect length $L[\mathrm{~km}]$, number of transects $\mathrm{k}$ and flocks $\mathrm{n}$ observed, as well as numbers of individuals Ind, and mean flock sizes $E(s)$ including confidence interval (95\% C.I.) of Congo Grey Parrots from surveys in three different landscapes (KNP - Korup National Park, AFM - agroforestry matrix, OPP - oil palm plantation), as well as totals, in the Korup region, Cameroon, in 2016. Mean flock sizes were calculated for data truncated to $127 \mathrm{~m}$.

\begin{tabular}{lllllll}
\hline & $\boldsymbol{L}$ & $\boldsymbol{k}$ & Adjustments & $\boldsymbol{n}$ & Ind. & $\boldsymbol{E}(\boldsymbol{s})$ (95\% C.I.) \\
\hline KNP & 286.8 & 26 & all flocks & 25 & 105 & $4.20(2.42-7.30)$ \\
& & & only stationary & 5 & 47 & $9.40(2.15-41.13)$ \\
AFM & \multirow{2}{*}{209.2} & \multirow{2}{*}{31} & all flocks & 188 & 532 & $2.81(2.26-3.49)$ \\
& & & only stationary & 42 & 116 & $2.64(1.97-3.53)$ \\
OPP & \multirow{2}{*}{125.1} & \multirow{2}{*}{11} & all flocks & 57 & 147 & $2.61(2.12-3.22)$ \\
& & & only stationary & 9 & 18 & $2.00(1.26-3.19)$ \\
\hline Totals & \multirow{2}{*}{621.1} & \multirow{2}{*}{68} & all flocks & 270 & 784 & $2.90(2.45-3.44)$ \\
& & & only stationary & 56 & 181 & $3.32(2.17-5.07)$ \\
\hline
\end{tabular}

Table 5.7 - Survey effort L, number of flock encounters n, encounter rate $\mathbf{n} / \mathbf{L}$, estimated density $D$ with 95\% confidence interval C.I. for the Congo Grey Parrot Psittacus erithacus in three different landscape types (KNP - Korup National park, AFM - agroforestry matrix, OPP - oil palm plantation) in SW Cameroon. Numbers result from using data from stationary flocks (only perched flocks included, see Legault et al. (2013) and Marsden et al. (2015)). D and $N$ estimated using the model half-normal (cosine) from a distance data subset truncated to $w=127 \mathrm{~m}$ and estimated detection probability of $P=0.55$. Densities were calculated using a global estimate of expected flock size $E(s)=2.40$ (95\% C.I.: 1.88-3.08).

\begin{tabular}{|c|c|c|c|}
\hline & KNP & AFM & OPP \\
\hline$L$ & $286.8 \mathrm{~km}$ & $209.2 \mathrm{~km}$ & $125.1 \mathrm{~km}$ \\
\hline$n$ untruncated & 5 & 42 & 9 \\
\hline$n$ truncated & 5 & 33 & 6 \\
\hline$n / L(95 \%$ C.I.) untruncated & $0.02(0.01-0.04)$ & $0.20(0.14-0.29)$ & $0.07(0.02-0.27)$ \\
\hline$n / L$ (95\% C.I.) truncated & $0.02(0.01-0.04)$ & $0.16(0.10-0.24)$ & $0.05(0.02-0.15)$ \\
\hline$D(95 \%$ C.I.) & $0.30(0.13-0.69)$ & $2.70(1.57-4.63)$ & $0.82(0.26-2.62)$ \\
\hline
\end{tabular}

\section{Tree species used}

During transect surveys, we recorded the utilization of 16 tree species in 48 occasions, in which we observed feeding, roosting or nesting (Table 5.3). There were significant differences in tree use in regard to the three landscape types. Whereas in KNP and in OPP parrots were only seen in one tree species each, Lecomtedoxa klaineana (Sapotaceae) and Elaeis guineensis (Arecaceae), respectively, in the AFM the parrots were seen on a variety of different tree species.

In KNP, Grey Parrots were sighted ten times perching in L. klaineana. We did not detect signs of feeding, breeding or roosting at this tree species. In the OPP, we had ten parrot encounters in E. guineensis perching, but also feeding on palm nuts. In the AFM, a frequently used tree (six observations) was Terminalia superba (Combretaceae). In one of these, on 2 June 2016, Grey Parrots were inspecting a tree hollow. The second most used tree species with five observations was the bush plum Dacryodes edulis (Burseraceae). Parrots fed on its fruits on three occasions. Two observations each were from Desbordesia glaucescens (Irvingiaceae), 
Distemonanthus benthamianus and Piptadeniastrum africanum (both Leguminosae). On these three trees, parrots were only sighted perching. The family Leguminosae served five times as a host for the parrots in the AFM. Parrots were also found on undetermined dead trees where they showed social and sentinel behaviour, benefiting from open vegetation structures. Generally, parrots were always observed in canopy trees, with Elaeis guineensis and Dacryodes edulis being the lowest. While the latter only reach a height of ca. $20 \mathrm{~m}$, other forest trees can reach up to 50-60 m. Parrots were never seen on or close to the ground.

Table 5.8 - Tree species and their numbers used by Psittacus erithacus in incidental flock observations ( ntotal $=48$ ) in Korup National Park (KNP), the oil palm plantation (OPP) and the agroforestry matrix (AFM).

\begin{tabular}{llcc}
\hline & Family & \multicolumn{2}{c}{ No. of used trees per landscape type } \\
\cline { 2 - 3 } Tree species & Sapotaceae & AFM & OPP \\
\hline Lecomtedoxa klaineana & Arecaceae & 10 & 10 \\
Elaeis guineensis & Combretaceae & 6 & \\
Terminalia superba & Burseraceae & 5 \\
Dacryodes edulis & Irvingiaceae & 2 \\
Distemonanthus benthamianus & Leguminosae & 2 \\
Piptadeniastrum africanum & Leguminosae & 2 \\
dead tree & - & 2 \\
Angylocalyx oligophyllus & Leguminosae & 1 \\
Baillonella toxisperma & Sapotaceae & 1 \\
Ceiba pentandra & Malvaceae & 1 \\
Leptaulus daphnoides & Cardiopteridaceae & 1 \\
Lophira alata & Ochnaceae & 1 \\
Morinda lucida & Rubiaceae & 1 \\
spp. & Burseaceae & 1 \\
spp. & Euphorbiaceae & 1 \\
spp. & Icacinaceae & 1 \\
\hline
\end{tabular}

\subsection{Discussion}

\section{Spatial and temporal variation in parrot density estimates}

Our survey results indicate that daytime population densities of Grey Parrots in the Korup region (i) are much lower now than suggested by earlier surveys, (ii) and strongly vary between the three different landscapes. We also found (iii) that human modified landscapes potentially provide a high resource density, even compared to the primary forests of Korup National Park.

Compared to available density estimates for the period 2008-2010 (Tamungang et al. 2016), our estimates from the same study area and season in 2016 were much lower, comprising only $2.7 \%, 7.5 \%$ and $5.5 \%$ of these earlier estimates for KNP (density $D_{2009}=11 \mathrm{ind} . / \mathrm{km}^{2}$, $D_{2016}=0.3$ ind. $\left./ \mathrm{km}^{2}\right)$, AFM $\left(D_{2009}=36\right.$ ind. $/ \mathrm{km}^{2}, D_{2016}=2.7$ ind. $\left./ \mathrm{km}^{2}\right)$ and OPP $\left(D_{2009}=15\right.$ ind. $/ \mathrm{km}^{2}, D_{2016}=0.82$ ind. $\left./ \mathrm{km}^{2}\right)$, respectively. However, Distance sampling methods are sensitive to biases and, therefore, highly depend on accurate data collection and analysis as well as detailed information on the methods used and assumptions made in order to increase 
comparability. For the very same reasons absolute density estimates provided by Tamungang et al. (2013, 2016) have been criticized for potentially being biased (Martin et al. 2014). Thus, a strong conclusion on the Grey Parrot population trend in the study area cannot be made.

Nevertheless, a comparison of own unpublished data from line transect surveys in 2002 and 2016 just north of the current study area (for details see Waltert et al. 2002) also suggest strong declines. In two ca. $16 \mathrm{~km}^{2}$ study areas (around the villages Mgbegati and Bajo), encounter rates declined by $>85 \%$, from 3.55 flocks per $\mathrm{km}$ in $2002\left(n_{\text {records }}=455, L=128 \mathrm{~km}\right)$ to 0.50 flocks per $\mathrm{km}$ in 2016 ( $n_{\text {records }}=68, L=164 \mathrm{~km}$, own unpublished information). Such a severe population decline within a short time period indicates that wildlife depletion in and around KNP, which has been documented for other species (Linder and Oates 2011), is likely affecting Grey Parrots. This is especially remarkable, since there has been considerable and continuous conservation funding for the Korup region (the Korup Project 1986-2002, Programme of Sustainable Management of Natural Resources PSMNR-SWR since 2006, see also MINFOF 2017). Using similar data collection and analysis methods, Marsden et al. (2015) estimated much higher parrot population densities at other Cameroonian sites, such as Campo Ma' an $\left(D_{2013}=10.9\right.$ ind.$\left./ \mathrm{km}^{2}\right)$ or Lobeke $\left(D_{2013}=29.6\right.$ ind. $\left./ \mathrm{km}^{2}\right)$. Though this variability in parrot density estimates might have ecological as well as methodological reasons, Marsden et al. (2015) also suggested that good protected area management may play a role in this.

Our encounter rates and density estimates differed between the three landscapes studied. That KNP produced the lowest density estimate may be unexpected because primary lowland rainforest is supposed to represent the natural habitat of the Grey Parrot (Martin et al. 2014a, Birdlife International 2017a). Conclusions on habitat suitability and equilibrium densities are, however, difficult since high mobility of birds may require analyses at even larger spatial and temporal scales than those we present here (more than several hundred hectares in the three different landscapes). Indeed, Grey Parrots were often seen flying from the park during the morning in direction towards the oil palm plantation and back during the evening, suggesting a daily routine. The few flocks we observed inside the park were mostly seen perching close to the Mana River, which is also next to the park border, always in the canopy of mature Lecomtedoxa klaineana trees. Therefore, the differences in density estimates between the park and the surrounding agroforestry landscape may be at least partially a result of the high mobility and long feeding periods in oil palms and farmland.

We observed parrots feeding on fruits of Elaeis guineensis and these may indeed be among those favoured by Grey Parrots (as also suggested by others, e.g. Naurois 1981, Tamungang et al. 2016), providing highly valuable energy. Naurois (1981) reported that Grey Parrots used holes formed in the top of rotten oil palm trunks for nesting on Formosa Island. However, this has not been reported from other sites and it remains open if the homogeneous structure of an industrial oil palm plantation could provide such breeding opportunities. Given the ongoing 
expansion of oil palm plantations in the Afrotropical forest region (Linder and Palkovitz 2016), it seems reasonably to further investigate their ecological role for Grey Parrots aside from being permanent feeding habitats.

Interestingly, in the traditional smallholder agroforestry landscape, we estimated much higher densities than in either industrial oil palm or Korup National Park. Overall, the agroforestry landscape in the Korup region seems to be most diverse in regard to structure and resource availability: there, parrots may find a variety of nutritious crops (Amuno et al. 2007, Tamungang et al. 2016), and many high trees, either remnants of the original forest, regenerating pioneer trees or those planted decades ago. These may also provide safe lookouts and some of them also breeding cavities. As such, a mixed landscape composed of forest, farmland and fallows may provide high habitat quality, as it had also been discussed for Grey Parrots in Uganda (Dranzoa 1995, Amuno et al. 2007).

Tamungang et al. (2016) reported that the abundance of parrots in the primary forest of KNP may be lower than in the AFM constantly across seasons. On the island of Príncipe, Valle et al. (2017) found higher parrot densities in landscapes dominated by agricultural estates and secondary forest patches only during post-breeding when food availability was high. However, since these human-dominated landscapes presumably did not provide sufficient breeding opportunities, parrot distribution evened out between pristine and secondary forest areas during pre-breeding. In contrast, we estimated a higher density in the AFM compared to KNP during pre-breeding, which may support the idea that the traditional smallholder farming practice in the Korup region may create an important breeding habitat. In line with that, Marsden et al. (2015) estimated similar levels of Grey Parrot densities $\left(\mathrm{D}=4.1 \mathrm{ind} . / \mathrm{km}^{2}\right)$ in comparable agricultural areas with remnant forest patches near Yaoundé.

\section{Tree species used and other observations}

Though the tree canopy in the southern sector of KNP is dominated by Oubanguia alata (Lecythidaceae) and various Fabaceae species (Gartlan et al. 1986, Chuyong et al. 2004), we did not observe any parrots in those trees. Instead, we recorded parrots only at Lecomtedoxa klaineana (Sapotaceae), however, without determining their activity within these trees. The absence of feeding observations in tree species that have been reported elsewhere, might be due to the limited number of parrot encounters in KNP or reflect methodological limitations of observing parrot behaviour in the high and dense canopy from the ground. On the other hand, it might also be a result of low seasonal availability of food in these trees compared with the adjacent landscapes outside the park.

In contrast, inside the AFM, parrots were seen on a variety of different tree species as well as leafless dead trees. The most frequented tree was Terminalia superba. This species provides 
cavities and is known to be a major breeding tree for $P$. erithacus in the study area (Tamungang et al. 2013, 2016, Annorbah et al. 2016, this study). Annorbah et al. (2016) list Ceiba pentandra as possible nesting tree. While we recorded parrots at this tree species in the AFM, we did not find signs of breeding. However, local farmers also identified Ceiba pentandra (Oroko dialect: 'booma') and Terminalia superba ('white-afara') as breeding trees. One farmer in Fabe showed us two T. superba trees around his cacao farm, whose tree holes (at $8 \mathrm{~m}, 9.5 \mathrm{~m}$ and $19 \mathrm{~m}$ ) were supposedly used for parrot breeding.

According to observations from former years, the main parrot breeding season in the study area is July to September. Farmers claimed a link between the initiation of parrot breeding and the main ripening of fruits starting in June, especially of the bush plum Dacryodes edulis, a tree frequently visited by parrots. In contrast to other reports (see Perrin 2012), we neither observed nor received any reports on parrots feeding on maize in the AFM, even during the start of the harvest season in May, which might be attributed to high hunting pressure in the study area.

\subsection{Conclusion}

Although difficult to estimate declines accurately, our results may suggest that Grey Parrot populations in Cameroon's Korup area have decreased dramatically between 2008 and 2016. Given that forest cover remains high in the region it seems likely that these declines have been driven mainly by trapping for the trade, suggesting the transfer of the species to Appendix I of CITES (CITES 2016) potentially decreasing commercial export of this species was a prudent conservation action. We also found that daytime parrot density estimates differ between landscape types being highest in heterogeneous agroforestry mosaics. This suggests that Grey Parrots are at least to some extent able to adapt to substantial habitat alterations, if large trees are maintained as breeding and roosting sites. Our study highlights the urgent need for a stronger prioritization of Grey Parrots within conservation programmes and the development of multi-facetted conservation strategies containing: (i) effective eco-guard patrolling schemes in the Korup region (Astaras et al. 2017), (ii) a consequent inhibition of illegal pet trade routes and markets in the entire region of SW Cameroon/SE Nigeria, and (iii) the promotion of traditional agroforestry practices in preference to monocultural agriculture (Kupsch et al. 2019). Such steps along with the implementation of CITES will help prevent further over-exploitation and future declines of wild populations in the region.

\subsection{References}

Amuno, J.B., Massa, R., and Dranzoa, C., (2007). Abundance, movements and habitat use by African Grey Parrots (Psittacus erithacus) in Budongo and Mabira forest reserves, Uganda. Ostrich 78: 225-231. 
Annorbah, N.N.D., Collar, N.J., and Marsden, S.J., (2016). Trade and habitat change virtually eliminate the Grey Parrot Psittacus erithacus from Ghana. Ibis 158: 82-91.

Astaras, C., Linder, J.M., Wrege, P., Orume, R.D., and Macdonald, D.W., (2017). Passive acoustic monitoring as a law enforcement tool for afro-tropical rainforests. Frontiers in Ecology and the Environment 15: 233-234.

Bächler, E., and Liechti, F., (2007). On the importance of $g(0)$ for estimating bird population densities with standard distance-sampling: implications from a telemetry study and a literature review. Ibis 149: 693-700.

BirdLife International (2017a). Species factsheet: Psittacus erithacus. http://www.birdlife.org. Assessed on 04 September 2017.

BirdLife International (2017b). Species factsheet: Psittacus timneh. http://www.birdlife.org. Assessed on 04 September 2017.

BirdLife International (2017c). Species factsheet: Cacatua haematuropygia. http://www.birdlife.org. Assessed on 22 February 2017.

Bobo, K.S., Waltert, M., Fichtler, M., and Mühlenberg, M., (2005). New bird records for the Korup project area, Southwest Cameroon. Malimbus 27: 13-18.

Brush, T., (1983). Cavity use by secondary cavity nesting birds and response to manipulations. Condor 85: 461-466.

Buckland, S.T., Anderson, D.R., Burnham, K.P., Laake, J.L., Borchers, D.L., and Thomas, L., (2001). Introduction to distance sampling: estimating abundance of biological populations. Oxford, UK. Oxford University Press.

Buckland, S.T., Marsden, S.J., and Green, R.E., (2008). Estimating bird abundance: making methods work. Bird Conservation International 18: 91-108.

Casagrande, D.G., and Beissinger, S.R., (1997). Evaluation of four methods for estimating parrot population size. Condor 99: 445-457.

Chupezi, T.J., Ndoye, O., and Mpele, T.O., (2006). Commodity-Chain Analysis for the capture and trade in the African grey parrots (Psittacus erithacus erithacus) in Cameroon. Yaoundé, Cameroon: Center for International Forestry Research (CIFOR).

Chuyong, G.B., Condit, R., Kenfack, D., Losos, E.C., Moses, S.N., Songwe, N.C., and Thomas, D.W., (2004). Korup forest dynamics plot, Cameroon. In Losos, E.C. and Leigh Jr., E.G. (Eds.) Tropical forest diversity and dynamism. 506-516. Chicago, Illinois. University of Chicago Press. 
CITES (2016). Section 6.2. Consideration Proposals for Amendment of Appendices I and II. Transfer from Appendix II to Appendix I of Psittacus erithacus in accordance with Resolution Conf. 9.24. https://cites.org/. Accessed on 4 September 2017.

Clemmons J.R., (2003). Status survey of the African Grey Parrot (Psittacus erithacus timneh) and development of a management program in Guinea and Guinea-Bissau. Geneva, Switzerland: Unpublished report to the CITES Secretariat.

Collar, N.J., (2013). Timneh parrot and Grey Parrot represent two species. http://stuartmarsden.blogspot.co.uk/2013/12/timneh-parrot-and-grey-parrotrepresent.html. Accessed on 4 September 2017.

Dranzoa, C., (1995). Bird populations of primary and logged forests in Kibale Forest National Park, Uganda. Ph.D. dissertation, Makerere University, Uganda.

Eniang, E.E., Akpan, C.E., and Eniang, M.E., (2008). A survey of African Grey parrots (Psittacus erithacus) trade and trafficking in Ekonganaku area of Ikpan forest block, Nigeria. Ethiopian Journal of Environmental Studies and Management 1: 68-73.

Fa, J.E., Seymour, S., Dupain, J., Amin, R., Albrechtsen, L., and Macdonald, D., (2006). Getting to grips with the magnitude of exploitation: bushmeat in the Cross-Sanaga rivers region, Nigeria and Cameroon. Biological Conservation 129: 497-510.

Fotso, R., (1998a). Survey status of the distribution and utilization of the Grey Parrot (Psittacus erithacus) in Cameroon. Geneva, Switzerland: CITES.

Fotso, R.. (1998b). Etude sur l'état, la répartition géographique et l'utilisation du perroquet gris (Psittacus erithacus) dans la République démocratique du Congo. Geneva, Switzerland: CITES.

Gartlan, J.S., Newbery, D.M., Thomas, D.W., and Waterman, P.G., (1986). The influence of topography and soil phosphorus on the vegetation of Korup Forest Reserve, Cameroun. Vegetatio 65: 131-148.

Gnam, R.S., (1991). Nesting behaviour of the Bahama Parrot (Amazona leucocephala bahamensis) on Abaco Island, Bahamas. Proceedings of the International Ornithological Congress 20: 673-680.

Green A.A., Hall P., and Leventis A.P., (2007). Avifauna of Omo Forest Reserve, SW Nigeria. Malimbus 29: 16-30.

Ingold, D.J., (1991). Nest-site fidelity in Red-headed and Red-bellied Woodpeckers. Wilson Bulletin 103: 118-122. 
Kupsch, D., Vendras, E., Ocampo-Ariza, C., Batáry, P., Motombi, F.N., Bobo, K.S., and Waltert, M., (2019). High critical forest habitat thresholds of native bird communities in Afrotropical agroforestry landscapes. Biological Conservation 230: 20-28.

Lee, A.T., and Marsden, S.J., (2012). The influence of habitat, season, and detectability on abundance estimates across an Amazonian parrot assemblage. Biotropica 44: 537-544.

Legault, A., Theuerkauf, J., Baby, E., Moutin, L., Rouys, S., Saoumoé, M., Verfaille, L., Barré N., Chartendrault, V., and Gula, R., (2013). Standardising distance sampling surveys of parrots in New Caledonia. Journal of Ornithology 154: 19-33.

Linder, J.M., and Oates, J.F., (2011). Differential impact of bushmeat hunting on monkey species and implications for primate conservation in Korup National Park, Cameroon. Biological Conservation 144: 738-745.

Linder, J.M., and Palkovitz, R.E., (2016). The threat of industrial oil palm expansion to primates and their habitats. In: Waller M.T. (Ed.) Ethnoprimatology: Primate Conservation in the 21st Century. Springer, Berlin, Germany. pp. 21-45.

Marsden, S.J., Pilgrim, J.D., and Wilkinson, R., (2001). Status, abundance and habitat use of blue-eyed cockatoo Cacatua ophthalmica on New Britain, Papua New Guinea. Bird Conservation International 11: 151-160.

Marsden, S.J., Loqueh, E., Takuo, J.M., Hart, J.A., Abani, R., Ahon, D.B., Annorbah, N.N.D., Johnson, R., and Valle, S., (2015). Using encounter rates as surrogates for density estimates makes monitoring of heavily-traded grey parrots achievable across Africa. Oryx 50: 617-625.

Marsden, S.J., and Royle, K., (2015). Abundance and abundance change in the world's parrots. Ibis 157: 219-229.

Martin, R.O., Perrin, M.R., Boyes, R.S., Abebe, Y.D., Annorbah, N.N.D., et al., (2014a). Research and conservation of the larger parrots of Africa and Madagascar: a review of knowledge gaps and opportunities. Ostrich 85: 205-233.

Martin, R.O., Gilardi, J., Johnson, R., Ndang'ang'a, P.K., Fotso, R., Drori, O., and Perrin, M., (2014b). Grey parrot Psittacus harvesting for conservation must have a robust scientific basis: Commentary on Tamungang et al. (2013). International Journal of Biodiversity and Conservation 6: 750-753.

Martin, R. O., (2018a). The wild bird trade and African parrots: past, present and future challenges. Ostrich 89: 139-143.

Martin, R. O., (2018b). Grey areas: temporal and geographical dynamics of international trade of Grey and Timneh Parrots (Psittacus erithacus and P. timneh) under CITES. Emu 118: 113-125. 
McGowan, P., (2001). Status, management and conservation of the African Grey Parrot Psittacus erithacus in Nigeria. Geneva, Switzerland: Unpublished report to CITES.

MINFOF (2017). The Management Plan for Korup National Park and its peripheral zone 20172021. Buea, Cameroon: Regional Delegation of the Ministry of Forestry and Wildlife.

Mittermeier, R.A., Robles-Gil, P., Hoffmann, M., Pilgrim, J.D., Brooks, T.B., Mittermeier, C.G., Lamoreux, J.L., and Fonseca, G.A.B., (2004). Hotspots Revisited: Earth's Biologically Richest and Most Endangered Ecoregions. Mexico City, Mexico: CEMEX.

Naurois, R. de (1981) La distribution géographique du perroquet gris Psittacus erythacus timneh. Malimbus 3: 59-61.

Oates, J.F., Bergl, R.A., and Linder, J.M., (2004). Africa's Gulf of Guinea Forests: Biodiversity Patterns and Conservation Priorities. Advances in Applied Biodiversity Science 6. Washington D.C.: Conservation International.

Perrin, M., (2012). Parrots of Africa, Madagascar and the Mascarene Islands: biology, ecology and conservation. Johannesburg, South Africa: Wits University Press.

Pinho, J.B., and Nogueira, F.M.B., (2003). Hyacinth Macaw (Anodorhynchus hyacinthinus) reproduction in the Northern Pantanal, Mato Grosso, Brazil. Ornitologia Neotropica 14: 29-38.

Reuleaux, A., Bunbury, N., Villard, P., and Waltert, M., (2013). Status, distribution and recommendations for monitoring of the Seychelles black parrot Coracopsis (nigra) barklyi. Oryx 47: 561-568.

Reuleaux, A., Richards, H., Payet, T., Villard, P., Waltert, M., and Bunbury, N., (2014 a) Breeding ecology of the Seychelles black parrot Coracopsis barklyi. Ostrich 85: 255-265.

Reuleaux, A., Richards, H., Payet, T., Villard, P., Waltert, M., and Bunbury, N., (2014 b). Insights into the feeding ecology of the Seychelles Black Parrot Coracopsis barklyi using two monitoring approaches. Ostrich 85: 245-253.

Sedgwick, J. A., (1997) Sequential cavity use in a cottonwood bottomland. Condor 99: 880887.

Tamungang S.A., and Cheke R.A., (2012). Population status and management plan of the African Grey Parrot (SC62 Inf. 14). Report prepared by the Ministry of Forestry and Wildlife, Cameroon. Geneva, Switzerland: CITES Secretariat.

Tamungang, S.A., Cheke, R.A., Kougoum, G.P., and Ntiri, E.S., (2013). Linking population size to conservation needs of the Grey Parrot in Cameroon. International Journal of Biodiversity and Conservation 5: 478-485. 
Tamungang, S.A., Onabid, M.A., Awa, T., and Balinga, V.S. (2016). Habitat preferences of the Grey Parrot in heterogeneous vegetation landscapes and their conservation implications. International Journal of Biodiversity 2016: 7287563.

Thomas, D.W. (1996). Botanical Survey of the Rumpi Hills and Nta Ali. Report to the GTZ, Germany, and to the Korup Project, Mundemba, Cameroon.

Thomas, L., Buckland, S.T., Rexstad, E.A., Laake, J.L., Strindberg, S., et al., (2010). Distance software: design and analysis of distance sampling surveys for estimating population size. Journal of Applied Ecology 47: 5-14.

Valle, S., Collar, N.J., Harris, W.E., and Marsden, S.J., (2017). Spatial and seasonal variation in abundance within an insular grey parrot population. African Journal of Ecology 55: 433-442.

Walsh, P.D., and White, L.J., (1999). What it will take to monitor forest elephant populations. Conservation Biology 13: 1194-1202.

Waltert, M., Lien, Faber, K., and Mühlenberg, M., (2002). Further declines of threatened primates in the Korup Project Area, south-west Cameroon. Oryx 36: 257-265. 


\subsection{Supplement}
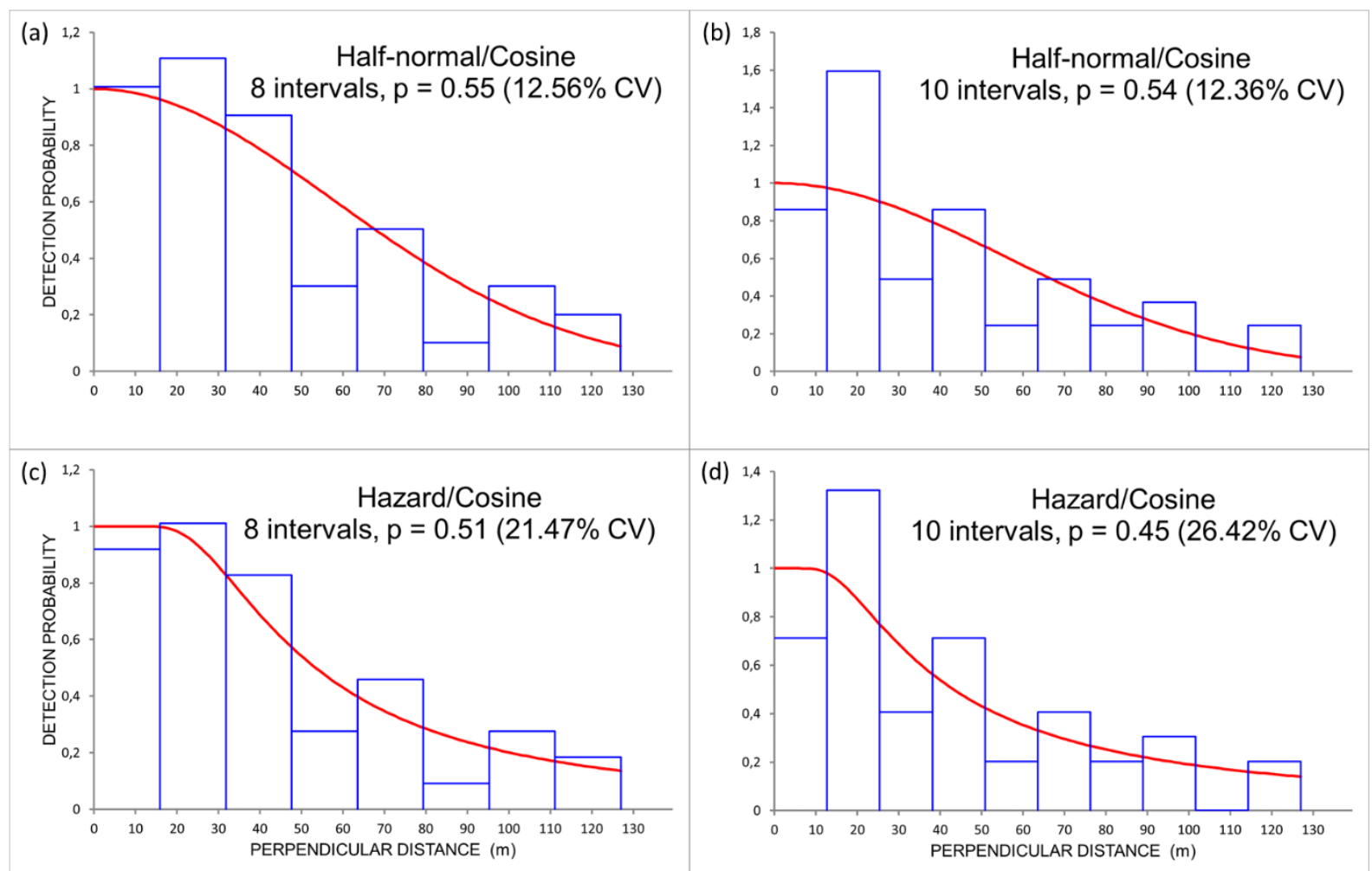

Figure S6.1 - Global detection functions (a-d) for $P$. erithacus distance data $(n=44$ stationary clusters, data truncated to strip width $w=127 \mathrm{~m}$ ) from three landscapes in SW Cameroon. Data were fitted using two different models (half-normal/cosine and hazard/cosine) and two different grouping approaches (eight and ten intervals). Also given are estimates of detection probability $P$. 
CHAPTER 5 


\section{PART IV}

DIRECT AND INDIRECT EFFECTS OF AGRICULTURAL

INTENSIFICATION ON RURAL LIVELIHOODS IN SOUTHWEST

CAMEROON 



\section{Chapter 6 \\ Income generation and expenditures of rural households in Afrotropical agroforestry systems and oil palm plantations}

\subsection{Abstract}

Livelihoods in rural West and Central Africa are often characterized by social and ecological complexities. Changing conditions in forest-dominated landscapes through agricultural intensification might, therefore, profoundly effect socio-economic realities, which calls for a deeper understanding of household structures of rural communities. In Southwest Cameroon, we interviewed 118 households in 12 settlements in Korup National Park (KNP), its surrounding agroforestry matrix (AFM) and an adjacent industrial oil palm plantation (OPP) using standardized questionnaires to collect household data on income generation and expenditures. We found little differences in income and expenditure between the park and the surrounding villages, though higher income from forest products was generated in KNP compared to AFM, whereas self-employment and wage labour were more important in AFM. Total income in plantation households was lower than in KNP, but slightly higher than in AFM. However, respondents in OPP had to spent 2.1 hours to generate 1,000 FCFA compared to 1.2 and 1.3 hours in KNP and AFM, respectively. Although OPP households were nearly $40 \%$ smaller than those in AFM and KNP, expenditures were much higher in OPP, nearly twice as high alone for food. Our results highlight that heterogeneous agroforestry matrices in West Africa can assure more diversified and sufficient livelihoods than wage labour in industrial oil palm plantations and might, thus, represent a more sustainable future for rural households.

\subsection{Introduction}

The economic development of palm oil business in the beginning of the twenty-first century is a success story for investors (e.g. Koh and Wilcove 2008), but up to date less so for the forestdependent communities in the wet tropics. There have been numerous reports, mainly from Southeast Asia, about land-grabbing tactics, disinformation campaigning, illegal environmental pollution and other violations of social rights (e.g. Marti 2008, Rist et al. 2010, Sinaga 2013, Li 2014). In recent years, investment activities of the oil palm industry were increasing in West and Central African countries (Feintrenie 2014), at a time, in which most of the region is already facing a severe transformation process from forest-dominated landscapes with rural agroforestry to more intensified forestry and agricultural cultivation (Norris et al. 2010). Since forest-related livelihoods in Southwest Cameroon are characterized by social and ecological complexities (Mbile et al. 2005, Vega et al. 2013), effects on rural communities due to largescale land use change might be profound. It has been suggested that in some regions in West 
and Central Africa forest resources can contribute up to 50\% to rural household income (Mbile et al. 2005, Wright and Priston 2010, Endamana et al. 2019). However, knowledge on the extent and role of monetary as well as non-monetary values of forest resources in the context of land use change in tropical Africa remains - particularly in the presence of an emerging oil palm wave - incredibly poor (Dislich et al. 2016). This study aims to address this research gap by providing a first systematic and straightforward assessment of rural livelihood in a rural multiland use landscape in Southwest Cameroon. In particular, we want to identify and describe differences in income generation as well as expenditure patterns between households in a protected area, its surroundings dominated by traditional agroforestry and an industrial oil palm plantation.

\subsection{Material and methods}

\section{Study area}

This research took place in Ndian Division, Southwest Cameroon, around its divisional capital Mundemba. The study area is (Fig. 6.1) located between $4^{\circ} 57^{\prime} \mathrm{N}$ to $5^{\circ} 10^{\prime} \mathrm{N}$ and $8^{\circ} 44^{\prime} \mathrm{E}$ to $9^{\circ} 7^{\prime} \mathrm{E}$ and between 50 and $800 \mathrm{~m}$ a.s.l. The climate is generally humid with annual rainfall averaging above 5,000 $\mathrm{mm}$ and characterized by distinct dry and rainy seasons, peaking from December to February and June to September, respectively (Chuyong et al. 2004). The study area, which is dominated by an intact and diverse lowland rainforest and reputedly one of the oldest and richest rainforest in Africa, is located within the biodiversity hotspot of the Gulf of Guinea forests (Oates et al. 2004, Darwall et al. 2015). The area encompasses Korup National Park (KNP), which has a total size of 126,000 ha and contains five villages (Mbile et al. 2005, Darwall et al. 2015), of which one, the northeastern Bareka Batanga, has been recently abandoned. The area around the park is dominated by rural smallholder agroforestry. This agroforestry matrix (AFM) contains large sections of primary and secondary forests at different stages as well as farmland, which is characterized by small-scale shifting cultivation for annual food crops or perennial cash crops, mainly cocoa. Besides farming, inhabitants of the villages in KNP and AFM rely on fishing, hunting, trapping and gathering NTFPs (Mbile et al. 2005). Many inhabitants of Korup area are culturally, socially and economically connected to their neighbours in Nigeria (MINEF 2002). Most settlements are remote and rather hard to access. In and around KNP hundreds of kilometers of food paths can be found, linking villages inside and outside the park.

In the southeast of KNP in the proximity of Mundemba, a number of small to medium-sized (100 ha- 5,800 ha) oil palm estates can be found, of which the largest is represented by the industrial plantation of PAMOL Plantations Plc. (OPP). The public sector company PAMOL Plantations Plc. is partly owned by the state after establishment in 1960 (Konings 1986). Besides Ndian estate, PAMOL produces palm oil products in Lobe and Ekondo Nene, both 
located in the Southwest Region, for sale on the local and export markets. PAMOL employs a mix of permanent and casual workers, totaling 2,683 in Ndian estate in 2014. In addition to monthly salaries, PAMOL uses an incentive-based reward system (PAMOL 2014), which allows encouraged workers to earn above minimum wages, especially during peak harvest season. PAMOL Ndian estate contains eight settlements, in which mainly migrated workers and their families live. Housing, electricity, primary school access as well as basic health care is provided free by the company.

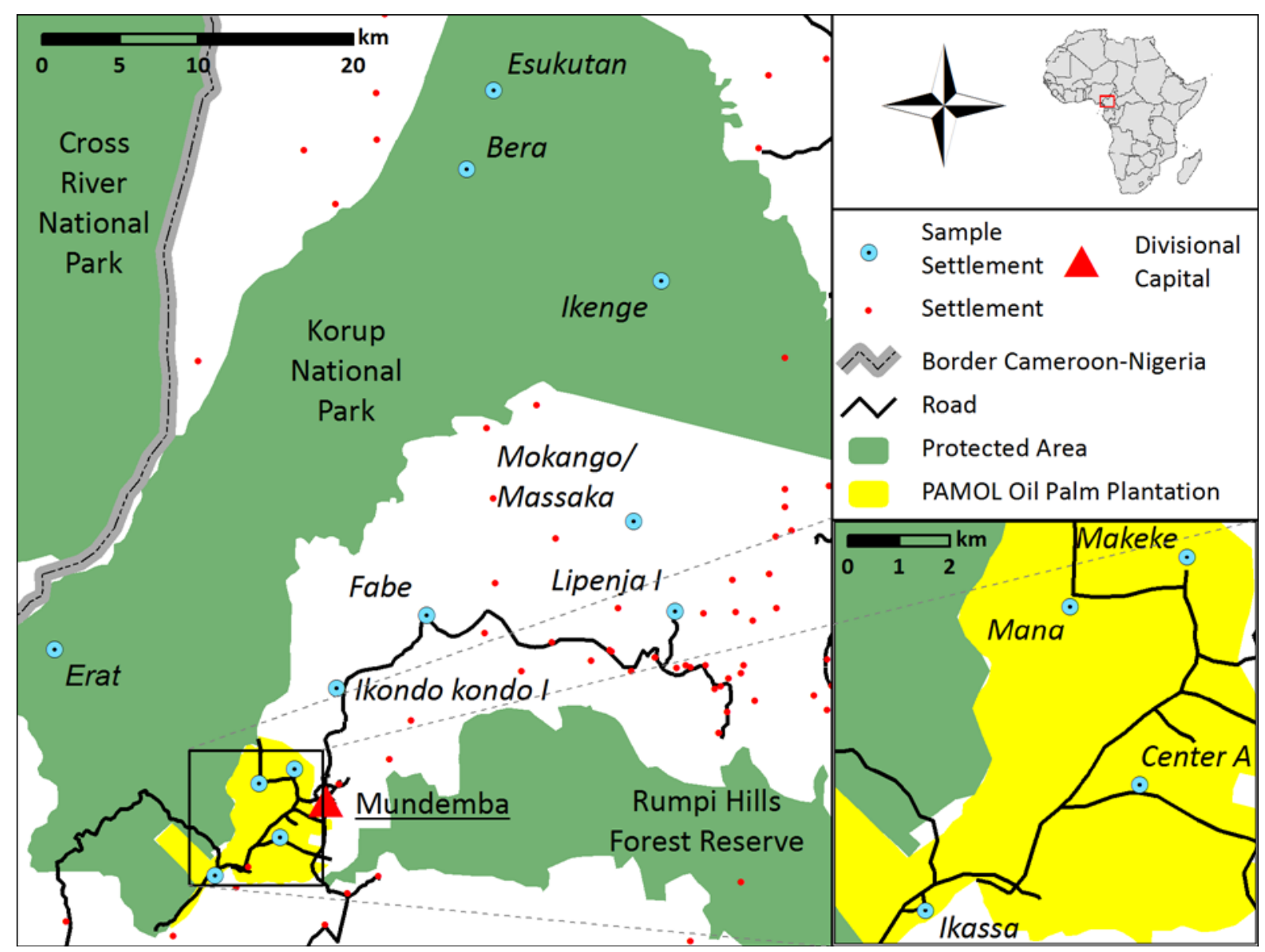

Figure 6.1 - Study area and sampled settlements in three landscape types in Southwest Cameroon.

\section{Definitions and categories}

Smallholders

There are several characteristics of small farms or smallholders e.g. total farm size $(<2$ ha, C'saki and de Haan 2003), production orientation (mainly in-kind staple food, Hazell et al. 2007) or limited resources of land capital, skills and labour (Dixon et al. 2003). However, since this study focused on income structures, we use the term 'smallholder' for those rural households making their living mainly from subsistence and cash-crop farming, forestry and fishery activities, while these activities can be complemented with non-farm activities. 


\section{Households}

We use households as our sampling units, which might either be a single economically independent person or a group making common provision for food or other essentials for living, in which intense social and economic interdependencies occur (Ellis 2000). It differs from the term 'family' which refers to any kind of kinship relation and sometimes spreading over different households. At the same time, a household may also include non-family members.

Income

We focus our study on household income flows, since their composition represents the main visible product of livelihood status and structure (Ellis 2000). Since households in rural Southwest Cameroon highly depend on forest products and stable farming for self-consumption (Mbile et al. 2005), our total income measure comprises both cash and in-kind components. We valued self-consumption according to the amount of cash income that could have been generated through selling the same good at the local market. We consider a set of income generating activities: farming, rearing, gathering NTFPs, fishing, hunting and trapping, employment including self-employment and other income sources including any kind of support from outside (e.g. monetary donations or food provided by relatives). Total annual net income is composed of gross cash or in-kind income from an activity minus particular input expenses, such as fertilizer, wage labor, transportation of goods for farming, nets, hooks and lines for fishing or guns, batteries, bullets for hunting and building material for keeping cattle.

\section{Expenditure}

Since income as a measure alone cannot reflect the ability of households to buffer their standards of living through saving and borrowing (C'saki and de Haan 2003), we also collected data on household expenditure as a measure of well-being. In addition, detailed expenditure data gives us an impression on the social and economic needs of households in its particular environment. We collected expenditure data within different categories: food, consumer goods, clothing, luxury goods, housing, education, health, transportation and other (including any contributions to church, village or relatives). In addition, for food and consumer goods, we differentiated between basic (indispensable for living), diversified (not essential, e.g. food that is not grown in the region) and dispensable items (not common, usually processed and expensive). 


\section{Data collection}

We conducted fieldwork from March to April 2015 in twelve different villages in three landscape types of the Korup region, namely Bera, Erat, Ikenge and Esukutan in KNP, Fabe, Ikondo kondo I, Lipenja I and Mokango/Massaka in AFM, and Center A, Ikassa, Makeke and Mana Camps in OPP. We also performed a preliminary interview survey in a village south of Mundemba to test the methodology and questionnaire for final modifications. We conducted ten household interviews in each of the settlements, except for Bera, where the village household number was only eight in total, summing up to $n_{\text {total }}=118$ households. Several days before the interviews started the community chiefs and camp officials were informed about the project to obtain their consent and give time for them to prepare full household lists. The day of arrival at a study location, households were randomly drawn from that list and appointments for interviews made with household heads and, if applicable their spouses. Since in women and men in rural households usually do not contribute to the total income in the same way (Ruiz et al. 2002), the survey team consisted of a women and a men group with each one researcher and local assistant, enabling us to gather income data gender-related and pool them afterwards. Interviews took between 1 and 2 hours and were conducted in the houses of the respondents in English, and - with the help of the local assistants - in Pidgin English, as well as occasionally in Korup and Oroko languages.

During interviews we used a standardized questionnaire (fully provided in the supplement), which included four sections: general household characteristics, household income from income generating activities, personal time budget and household expenditures. To determine who counts as a household member, a minimum of 3 months of continuous presence before the interview was set. Income and expenditure data were collected for the last twelve months. For all income types, we requested the quantity of all harvested crops, gathered NTFPs, caught fish and trapped or hunted animals, as well as the proportion of self-consumed and sold quantities. Data of income and expenditures were recorded in CFA-Franc (FCFA, Franc de la Coopération Financière en Afrique Centrale). We requested a detailed overview on time spent for the daily activities for each day of a week, in addition, we asked for changes in the personal time budget during the course of a year. Since women spend more time for reproductive activities than men (Fonjong 2004), we also asked for activities such as housework (i.e. cooking, washing and cleaning). During interviews, we used checklists of income types, farm and forest products and expenditure items to enhance interviews and ensure completeness.

We reviewed all gathered interview sheets during the survey and revisited households if data were unclear, inaccurate or incomplete. We revised or eliminated interview sheets when the total cash income exceeded $150 \%$ of total expenditures and vice versa, or the interviewee did obviously withhold information, such as income from poaching activities. If so, we randomly drew another household from the list provided by village authorities. However, since we already 
built a trustful cooperation in all villages during field research stays in previous years, those cases were seldom.

\subsection{Results}

Though the number of respondents as well as household gender structures were similar between surveyed landscapes, we found significant differences in household size (Table 6.1). Whereas villages in KNP and AFM averaged around five household members, households in the plantation settlement mainly support two to four persons. Respondents in PAMOL were often migrants from other parts of Anglophone Cameroon or Nigeria, and held higher educational degrees than people in the AFM and KNP (Tables S6.3 and S6.4).

Table 6.1 - Overview on selected structure parameters of interviewed households.

\begin{tabular}{|c|c|c|c|c|c|c|c|c|}
\hline \multirow{2}{*}{$\begin{array}{r}\text { Landscape } \\
\text { Location }\end{array}$} & \multirow{2}{*}{$\begin{array}{l}\text { No. } \\
\text { interv. }\end{array}$} & \multirow{2}{*}{$\begin{array}{l}\text { No. } \pm \text { SE HH } \\
\text { members }\end{array}$} & \multicolumn{5}{|c|}{ Household gender structure } & \multirow{2}{*}{$\begin{array}{c}\text { No. respon. } \\
(M / F)\end{array}$} \\
\hline & & & $\mathbf{F}$ & M & MF & MFF & $\mathbf{F F}$ & \\
\hline Park villages & 38 & $4.7 \pm 0.4$ & $4(11 \%)$ & $8(21 \%)$ & $23(64 \%)$ & $2(5 \%)$ & - & $64(34 / 30)$ \\
\hline Bera & 8 & $3.1 \pm 1.1$ & 1 & 4 & 3 & - & - & $11(7 / 4)$ \\
\hline Erat & 10 & $5.5 \pm 0.7$ & 2 & 2 & 5 & - & - & $15(8 / 7)$ \\
\hline Esukutan & 10 & $4.5 \pm 0.8$ & - & 2 & 6 & 2 & - & $19(10 / 9)$ \\
\hline Ikenge & 10 & $5.5 \pm 0.6$ & 1 & - & 9 & - & - & $19(9 / 10)$ \\
\hline Non-park villages & 40 & $5.1 \pm 0.4$ & $12(30 \%)$ & $5(13 \%)$ & $20(50 \%)$ & $2(5 \%)$ & $1(3 \%)$ & $64(27 / 37)$ \\
\hline Ikondo k. I & 10 & $4.3 \pm 0.7$ & 4 & 1 & 5 & - & - & $15(6 / 9)$ \\
\hline Fabe & 10 & $3.5 \pm 0.5$ & 4 & 3 & 3 & - & - & $13(6 / 7)$ \\
\hline Lipenja I & 10 & $6.7 \pm 0.8$ & 3 & - & 5 & 1 & 1 & $17(6 / 11)$ \\
\hline Mok./Mas. & 10 & $6.0 \pm 0.7$ & 1 & 1 & 7 & 1 & - & $19(9 / 10)$ \\
\hline Plantation settl. & 40 & $3.1 \pm 0.4$ & $8(20 \%)$ & $12(30 \%)$ & $17(43 \%)$ & $3(8 \%)$ & - & $60(32 / 28)$ \\
\hline Center A & 10 & $2.1 \pm 0.5$ & 4 & 4 & 2 & - & - & $12(6 / 6)$ \\
\hline Ikassa & 10 & $2.5 \pm 0.8$ & 2 & 4 & 3 & 1 & - & $14(8 / 6)$ \\
\hline Makeke & 10 & $4.2 \pm 1.1$ & 3 & - & 7 & - & - & $17(10 / 7)$ \\
\hline Mana & 10 & $3.7 \pm 0.9$ & 2 & 1 & 5 & 2 & - & $17(8 / 9)$ \\
\hline
\end{tabular}

Mean total annual household income was highest in KNP villages and lowest in AFM (Table 6.2). Whereas households in KNP and AFM spent between 70 and 80 minutes to generate 1,000 FCFA, households in OPP need more than two hours for the same money. Due to the dominant proportion of salaries from wage labour in PAMOL (Table S6.5), total cash income was highest and in-kind income was lowest, compared to KNP and AFM. (Self-)employment was also more important in AFM than in KNP (Table S6.10). The most important income type in KNP and AFM was farming (Table S6.5), though income from hunting and poaching was nearly as high as farming in KNP, which is mainly attributed to extraordinary high hunting activities in Ikenge. Consequently, the total share of all forest related income types strongly 
increased from OPP over AFM to KNP. The least importance of all income activities in all landscape types was livestock rearing. The most important food crops were banana, plantain and cassava (Tables S6.6 and S6.7). Moreover, nearly half of the income generated from the latter was in cash. Cocoa was the most important cash crop in all landscape types. Whereas most households in AFM and KNP were engaged in red oil processing, only plantation households sold considerable amounts of palm oil or their raw bunches. We found that nearly all households in AFM and KNP as well as 70\% of the households in OPP were engaged in NTFP gathering. Whereas the latter occasionally collected snails for consumption within the plantation area, bush mango (Irvingia spp.) and njangsa (Ricinodendron heudelotii) in particular contributed strongly to AFM and KNP households (Table S6.11).

Tabelle 6.2 - Selected household income and expenditure parameters in twelve settlements and three landscape types in $2015(1,000$ FCFA $=1.52 €)$.

\begin{tabular}{|c|c|c|c|c|c|c|}
\hline \multirow{2}{*}{$\begin{array}{c}\text { Landscape } \\
\text { Location }\end{array}$} & \multicolumn{3}{|c|}{ Mean annual income $\pm S E$} & \multirow{2}{*}{$\begin{array}{c}\text { Hours / 1,000 } \\
\text { FCFA } \pm \text { SE }\end{array}$} & \multicolumn{2}{|c|}{ Mean annual expend. $\pm S E$} \\
\hline & Total HH & In-kind only & Forest prod.* & & Total HH & Food \\
\hline Park village & $1,651 \pm 132$ & $530 \pm 45$ & $893 \pm 111$ & $1.2 \pm 0.1$ & $1,072 \pm 96$ & $198 \pm 20$ \\
\hline Bera & $1,343 \pm 318$ & $411 \pm 113$ & $531 \pm 192$ & $1.5 \pm 0.3$ & $890 \pm 223$ & $170 \pm 38$ \\
\hline Erat & $1,288 \pm 170$ & $400 \pm 50$ & $761 \pm 217$ & $1.3 \pm 0.2$ & $907 \pm 154$ & $245 \pm 50$ \\
\hline Esukutan & $1,486 \pm 184$ & $569 \pm 86$ & $678 \pm 115$ & $1.1 \pm 0.1$ & $932 \pm 134$ & $120 \pm 25$ \\
\hline Ikenge & $2,488 \pm 206$ & $739 \pm 74$ & $1,600 \pm 183$ & $1.0 \pm 0.2$ & $1,559 \pm 191$ & $256 \pm 32$ \\
\hline Non-park village & $1,373 \pm 113$ & $457 \pm 31$ & $443 \pm 70$ & $1.3 \pm 0.1$ & $994 \pm 113$ & $237 \pm 16$ \\
\hline Ikondo k. I & $1,069 \pm 114$ & $520 \pm 55$ & $492 \pm 114$ & $1.4 \pm 0.1$ & $587 \pm 52$ & $179 \pm 21$ \\
\hline Fabe & $1,550 \pm 229$ & $522 \pm 62$ & $452 \pm 141$ & $1.3 \pm 0.2$ & $1,020 \pm 167$ & $261 \pm 30$ \\
\hline Lipenja I & $1,532 \pm 300$ & $307 \pm 36$ & $268 \pm 62$ & $1.5 \pm 0.2$ & $1,393 \pm 355$ & $321 \pm 37$ \\
\hline Mok./Mas. & $1,340 \pm 223$ & $478 \pm 70$ & $558 \pm 207$ & $1.1 \pm 0.2$ & $975 \pm 167$ & $188 \pm 23$ \\
\hline Plantation settl. & $1,420 \pm 126$ & $172 \pm 26$ & $134 \pm 43$ & $2.1 \pm 0.2$ & $1,335 \pm 93$ & $403 \pm 21$ \\
\hline Center A & $1,413 \pm 208$ & $196 \pm 42$ & $143 \pm 62$ & $2.4 \pm 0.5$ & $1,344 \pm 162$ & $349 \pm 37$ \\
\hline Ikassa & $1,389 \pm 394$ & $130 \pm 61$ & $101 \pm 92$ & $2.4 \pm 0.5$ & $1,400 \pm 262$ & $414 \pm 53$ \\
\hline Makeke & $1,418 \pm 206$ & $119 \pm 31$ & $59 \pm 32$ & $1.8 \pm 0.4$ & $1,355 \pm 195$ & $428 \pm 40$ \\
\hline Mana & $1,462 \pm 188$ & $244 \pm 67$ & $232 \pm 130$ & $1.6 \pm 0.2$ & $1,242 \pm 130$ & $421 \pm 40$ \\
\hline
\end{tabular}

*this figure of forest products includes all non-farm, non-employment and non-rearing income types (NTPFs, hunting, fishing)

Total mean annual expenditures were highest in plantation settlements and lowest in the AFM (Table 6.2). Herein, the proportion of food expenditures decreased strongly from OPP to AFM and KNP. Households in OPP spent more money on diverse and dispensable food and consumption goods than households in AFM and KNP (Table S6.14). Moreover, there was a significantly higher alcohol consumption in OPP but also KNP compared to AFM. Overall transport expenses were similar between landscape types, but households in AFM undertook mainly short and regular trips compared to OPP and KNP. Expenditures for education, health 
and other purposes, such as the support of relatives, did not differ between sites. Since many households along the main road were engaged in building new structures, expenditures on housing were highest in AFM.

\subsection{Discussion}

In accordance with previous research (Mbile et al. 2005, Wright and Priston 2010, Endamana et al. 2019), our results highlight the importance of forest products in rural communities in West African forest-dominated landscapes: the contribution of forest products to total household income in KNP and AFM amounted up to 54\% and 33\%. Certainly, revenues from hunting represent a considerable proportion of these numbers. When subtracting those, we still yield $31 \%$ and $22 \%$ of forest-related components in total incomes in KNP and AFM, respectively. However, zero hunting in traditional hunting communities as those in the Korup region is no realistic scenario. Conservation management should rather aim to promote sustainable hunting schemes (Bennett et al. 2007), which could allow a limited offtake of smaller and faster producing species, such as blue duiker, greater cane rat and porcupine. Already in our sample the proportion of these species in total hunting income made up more than $50 \%$ in the AFM.

In the plantation settlements of PAMOL, forest resources played a minor role $(<10 \%)$, although hunting still occurred, mainly in the adjacent forests of KNP. The same accounts for the in-kind component of total household income. Though more than $90 \%$ of the households in OPP were engaged in farming, most of the food crops were grown in small plots inside the workers camp and, thus, yielded very limited income. Unsurprisingly, the greatest share of the total household income in PAMOL came from employment and contract work. However, our findings demonstrate that, on the one hand, the total household income in OPP is still smaller compared to KNP and, on the other hand, the cash component can hardly cover the total household expenditures. The latter is mainly due to the fact that compared to households in KNP and AFM, plantation workers had to buy most of their food items instead of growing them. As a result, plantation households spent twice as much on food items as KNP households, which where even $50 \%$ larger in size. As already observed in Southeast Asia, this might lead to social insecurity and indebtedness (Rist et al. 2010, Li 2014).

Households with access to roads have a greater potential to increase their income through selfemployment, particularly by small-business activities (Warr 2008, Hine et al. 2014). We found that income from trading was 50\% higher in AFM households, which profited from road access, compared to those in KNP. Particularly women seemed to benefit from opening up minor businesses and selling food in their villages; their total income was $25 \%$ higher in AFM than in KNP and OPP (Table S6.12). However, although PAMOL is located in the direct proximity to the divisional capital Mundemba and its > 5,000 inhabitants, the plantation households generated even less income through trading than households in KNP. This might result from 
differences in household time budgets. Compared to village household in AFM and KNP, plantation households spent significantly more time for income generation activities, mainly wage labour.

What remains is the good predictability of monthly incoming salaries in plantation households versus the strong seasonality of cocoa, the main cash crop in AFM and KNP. A number of respondents in households that depend on farming complained about lacking funds to cover the input expenses (mainly for fungicides) in the beginning of the planting season. However, our results suggest that this is less of a problem stemming from low income in AFM and KNP than a matter of household budget management over the course of the year. We believe this could be addressed by trainings provided by development projects, such as the Programme for the Sustainable Management of Natural Resources in the Southwest Region.

Our findings also suggest negative indirect ecological effects through the employment practices of PAMOL. A large number of persons working in in the plantation were coming from other regions of Cameroon and Nigeria. We observed that many migrants held higher school degrees than locals and were often recruited for leading positions with higher salaries. As it has already been suggested for forest concessions (Poulsen et al. 2009, Lescuyer et al. 2012), this increases the pressure on adjacent forests from poaching - in our case Korup National Park - because higher salaries may create a higher demand for bushmeat. In addition, we observed that workers, which migrated from larger towns or cities, such as Bamenda, without traditional rights on village land, used their income surplusses to invest in land for private oil palm cultivation, which might increase forest conversion around Mundemba and along the roads to Toko and Ekondo titi. The fact that PAMOL buys in oil palm bunches to utilize the capacities of their central mill enhances this development.

We have to admit that our research represents a regional case study and generalizations should, thus, made with caution. However, to our knowledge this study was the first attempt to compare livelihoods in plantation and agroforestry systems in West Africa. Our results suggest that compared to village households in AFM and KNP, plantation households pay a considerably high prize for the benefit of receiving monthly salaries through employment. To put it simply, compared to AFM and KNP, households in OPP work longer for similar or even lower total incomes, while spending more money on living. According to these conclusions, it seems unlikely that industrial plantations may serve as a sustainable land use model for the benefit of the people in Central and West Africa. 


\subsection{References}

Bennett, E.L., Blencowe, E., Brandon, K., Brown, D., Burn, R.W., et al., (2007). Hunting for consensus: reconciling bushmeat harvest, conservation, and development policy in West and Central Africa. Conservation Biology 21: 884-887.

Chuyong, G.B., Condit, R., Kenfack, D., Losos, E.C., Moses, S.N., Songwe, N.C., and Thomas, D.W., (2004). Korup forest dynamics plot, Cameroon. In: Losos, E.C., Leigh Jr.E.G., (Eds.), Tropical Forest Diversity and Dynamism: Findings From a Large-Scale Plot Network. University of Chicago Press, Illinois, pp. 506-516.

C'saki, C., and de Haan, C., (2003). Reaching the Rural Poor: A Renewed Strategy for Rural Development. World Bank Publications, Washington DC, USA.

Darwall, W., Polidoro, B., Smith, K., and Somda, J., (2015). Ecosystem Profile. Guinean Forests of West Africa Biodiversity Hotspot. Critical Ecosystem Partnership Fund Report.

Dislich, C. Keyel, A.C., Salecker, J., Kisel, Y., Meyer, K.M., et al., (2016). A review of the ecosystem functions in oil palm plantations, using forests as a reference system. Biological Reviews 92: 1539-1569.

Dixon, J., Taniguchi, K., and Wattenbach, H., (Eds., 2003). Approaches to assessing the impact of globalization on African smallholders: Household and village economy modeling. Proceedings of a working session on Globalization and the African Smallholder Study. FAO (Agricultural Support Systems Division [AGS] and Agricultural and Development Economics Division [ESA]) and the World Bank. Rome, Italy.

Ellis, F., (2000). Rural Livelihoods and Diversity in Developing Countries. Oxford University Press, Oxford, UK.

Endamana, D., Shepherd, G., Neba, G.A., Angu, K.A., Bonito, C.N., and Ako, C.E., (2019). Rapid Assessment of the Value of Forest Income for People in Central Africa. Journal of Sustainable Forestry 38: 343-368.

Feintrenie, L., (2014). Agro-industrial plantations in Central Africa, risks and opportunities. Biodiversity and Conservation 23:1577-1589.

Fonjong, L.N., (2004). Challenges and Coping Strategies of Women Food Crops Entrepreneurs in Fako Division, Cameroon. Journal of International Women's Studies 5:1.

Hazell, P., Poulton, C., Wiggins, S., and Dorward, A., (2007). The Future of small farms for poverty reduction and growth. International Food Policy Research Institute (IFPRI) 2020. Discussion Paper 42. 
Hine, J., Abedin, M., Stevens, R., Airey, T., and Anderson, T., (2014). Does the Extension of the Rural Road Network Have a Positive Impact on Poverty Reduction and Resilience for the Rural Areas Served? If so How, and if Not Why Not? EPPI-Centre, Social Science Research Unit, Institute of Education, University of London. London, UK.

Koh, L.P., and Wilcove, D.S., (2009). Oil palm: disinformation enables deforestation. Trends in Ecology and Evolution 24: 67-68.

Konings, P., (1986). L'état, l'agro-industrie et la paysannerie au Cameroun. Politique Africaine 22: $120-137$.

Lescuyer, G., Mvondo, S.A., Essoungou, J.N., Toison, V., Trébuchon, J.-F., and Fauvet, N., (2012). Logging concessions and local livelihoods in Cameroon: from indifference to alliance? Ecology and Society 17: 7.

Marti, S., (2008). Losing ground: the human rights impacts of oil palm plantation expansion in Indonesia. LifeMosaic, Sawit Watch Indonesia and Friends of the Earth.

Mbile, P., Vabi, M., Meboka, M., Okon, D., Arrey-Mbo, J., Nkongho, F., and Ebong, E., (2005). Linking management and livelihood in environmental conservation: Case of the Korup National Park Cameroon. Journal of Environmental Management 76: 1-13.

MINEF (2002). A Management Plan for Korup National Park and Its Peripheral Zone 20022007. Buea, Cameroon.

Norris, K., Asase, A., Collen, B., Gockowski, J., Mason, J., Phalan, B., and Wade, A., (2010). Biodiversity in a forest-agriculture mosaic - The changing face of West African rainforests. Biological Conservation 143: 2341-2350.

Oates, J.F., Bergl, R.A., and Linder, J.M., (2004). Africa's Gulf of Guinea Forests: Biodiversity Patterns and Conservation Priorities. Center for Applied Biodiversity Science, Conservation International.

PAMOL (2014). 2014 Review. Pamol Plantations Plc., Lobe, Cameroon.

Poulsen, J.R., Clark, C.J., Mavah, G., and Elkan, P.W., (2009). Bushmeat supply and consumption in a tropical logging concession in northern Congo. Conservation Biology 23: $1597-1608$.

Rist, L., Feintrenie, L., and Levang, P., (2010). The livelihood impacts of oil palm: smallholders in Indonesia. Biodiversity and Conservation 19: 1009-1024.

Ruiz Perez, M., NDoye, O., Eyebe, A., and Ngono, D. L., (2002). A Gender Analysis of Forest Product Markets in Cameroon. Africa Today. 49: 97-126. 
Sinaga, H., (2013). Employment and income of workers on Indonesian oil palm plantations. Food crisis at the micro level. Future of Food. Journal on Food, Agriculture and Society 1: 64-78.

Vega, M.G., Carpinetti, B., Duarte, J., and Fa, J.E., (2013). Contrasts in livelihoods and protein intake between commercial and subsistence bushmeat hunters in two villages on Bioko Island, Equatorial Guinea. Conservation Biology 27: 576-587.

Warr, P., (2008). How Road Improvement Reduces Poverty: The Case of Laos. Agricultural Economics 39: 269-279.

Wright, J.H., and Priston, N.E.C., (2010). Hunting and Trapping in Lebialem Division, Cameroon: Bushmeat Harvesting Practices and Human Reliance. Endangered Species Research 11: 1-12. 


\subsection{Supplement}

Questionnaire used for household interviews

\section{Household questionnaire}

Project title: Land-use related patterns in rural livelihood in the agroforestry landscapes of Southwest Cameroon

Researchers: Denis Kupsch, Luisa Knobloch

Georg-August-Universität Göttingen, Germany

\section{Introduction}

We, Luiso and Denis, are students from Göttingen University in Germany. [In villages: You may already now me/Mr. Denis, who came here lost year [accounts for Bera, Esukutan, Ikenge, Massaka, Mokangol/in 2013 [accounts for Ekundukundu, Erat, Fabe, Lipenja] to study trees and insects around your villoge. However, this time] we are interested in the way forest/camp communities making their living. So we came to your villoge/camp to learn more about how you [and your spouse] are generating income and what you spent your money on. All information that we take will be kept confidential and will be used for acodemic purposes only. Although the park/PAMOL management is aware of our research, none of the information gathered will be given to them. We do not even note down your name.

To focilitate our communication during the interview, I asked Daniel from Ekundukundu/[mention Name of female assistant] to assist, since he is used to this kind of work and speoks country talk. [In case of a two-gender HH: Today I came here to speak to you, then, tomorrow Luisa/Denis would like to make a similar interview with your spouse.] We usually spent ane to one-and-a-half hours on the questions we have. And of course, if there is anything you would like to know, feel free to ask. So, before we start, I would like to ask, if everything I soid is clear and if you would like to make such an interview with me.

\section{Household identification}

Village:

Date \& Time:

Interviewer:
Household code:

Gender:

Ethnic group:

\section{Household structure}

Table 1 - Household structure

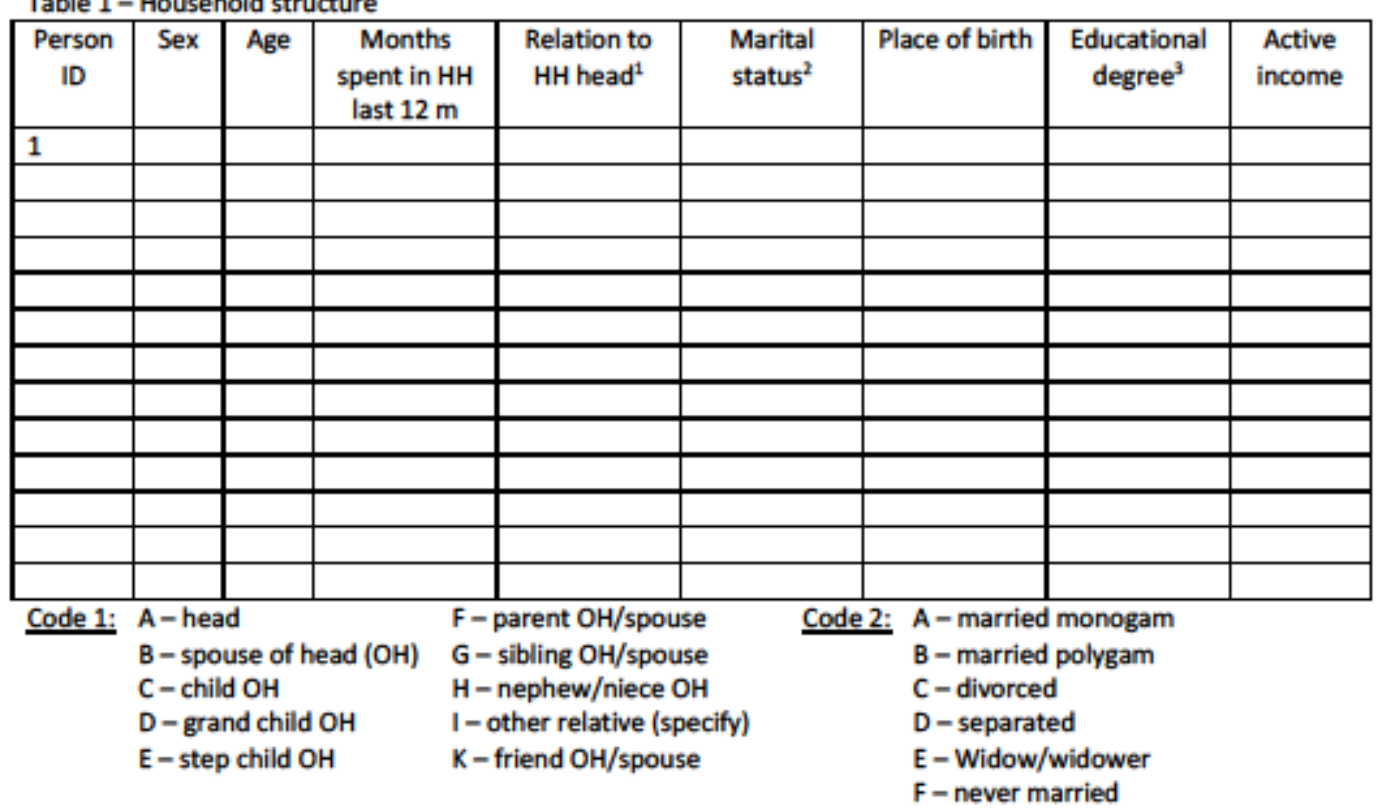

Code 3: A-primary school

B - secondary school - All level

C - secondary school - Advanced level
D - Professional school degree

E- University Bachelor degree

F- University Master degree 
3. Income

3.1 Farming

Table 2 - Farming, Plots incl. house gardens

\begin{tabular}{|c|c|c|c|}
\hline Plot no. & Cultivated area (in ha) & Occupiers (IDs) & Ownership status \\
\hline & & & \\
\hline & & & \\
\hline & & & \\
\hline & & & \\
\hline & & & \\
\hline
\end{tabular}

We would like to make a sketch of the location and size of your plots.

Table 3-Farming, Output and Input

\begin{tabular}{|c|c|c|c|c|c|c|c|c|c|}
\hline \multirow[b]{2}{*}{ Plot } & \multirow{2}{*}{$\begin{array}{l}\text { Crop } \\
\text { types }\end{array}$} & \multicolumn{2}{|c|}{ Output } & \multicolumn{6}{|c|}{ Input } \\
\hline & & $\begin{array}{c}\text { Yield last } \\
1 \mathrm{~m} / \mathrm{y}^{1}\end{array}$ & $\begin{array}{l}\mathrm{g} / \mathrm{b} / \mathrm{a} \\
\text { yield? }\end{array}$ & $\begin{array}{l}\text { Seeds / } \\
\text { plants }\end{array}$ & Chemical & $\begin{array}{l}\text { Process } \\
\text { (mill...) }\end{array}$ & Transp & Labour & Others \\
\hline & & & & & & & & & \\
\hline & & & & & & & & & \\
\hline & & & & & & & & & \\
\hline & & & & & & & & & \\
\hline & & & & & & & & & \\
\hline & & & & & & & & & \\
\hline & & & & & & & & & \\
\hline & & & & & & & & & \\
\hline & & & & & & & & & \\
\hline & & & & & & & & & \\
\hline & & & & & & & & & \\
\hline & & & & & & & & & \\
\hline & & & & & & & & & \\
\hline & & & & & & & & & \\
\hline & & & & & & & & & \\
\hline & & & & & & & & & \\
\hline & & & & & & & & & \\
\hline
\end{tabular}

Specification 1: Use predefined units for each crop type! Check separate information leaflet! 
Can you give me an estimate of income you generate with your cash crops per year?

Can you give me an estimate of income you generate with your subsistence crops per month?

Table 4 - Farming, Consumption and Marketing

\begin{tabular}{|c|c|c|c|c|c|c|}
\hline $\begin{array}{l}\text { Crop type } \\
\text { (con/sold as... })^{1}\end{array}$ & Total yield $^{2}$ & $\begin{array}{l}\text { Support HH } \\
\text { memb (ID) }\end{array}$ & $\begin{array}{l}\text { Quantity loss } \\
\text { after yield }\end{array}$ & $\begin{array}{l}\text { Quantity self- } \\
\text { consumed }\end{array}$ & Quantity sold ${ }^{3}$ & $\begin{array}{l}\text { Price per unit } \\
\text { sold }\end{array}$ \\
\hline & & & & & & \\
\hline & & & & & & \\
\hline & & & & & & \\
\hline & & & & & & \\
\hline & & & & & & \\
\hline & & & & & & \\
\hline & & & & & & \\
\hline & & & & & & \\
\hline & & & & & & \\
\hline & & & & & & \\
\hline & & & & & & \\
\hline & & & & & & \\
\hline
\end{tabular}

Seccification 1: For crop types respondents also process before selling (such as cassava or corn), note down the crop type only if they sell them as unprocessed product. For others add the product (e.g. gari, fufu) in brackets. Specification 2: Note down calculated figure and ask back the farmer if this is correct! If not, find out why! Specification 3: Give a figure for each selling event! Separate them with a backslash!

\subsection{Forest products}

Can you give me an estimate of income you generate with forest products per year?

Table 5-Forest products, Output

\begin{tabular}{|l|l|l|l|l|l|l|l|l|}
\hline Product & $\begin{array}{l}\text { Yield in } \\
\text { last 1 mo / } \\
\mathrm{y}^{1}\end{array}$ & $\begin{array}{l}\text { How was } \\
\text { the yield? }\end{array}$ & $\begin{array}{l}\text { Support } \\
\mathrm{HH} \text { memb } \\
\text { (ID) }\end{array}$ & $\begin{array}{l}\text { Quantity } \\
\text { loss after } \\
\text { yield }\end{array}$ & $\begin{array}{l}\text { Quantity } \\
\text { self } \\
\text { consum }\end{array}$ & $\begin{array}{l}\text { No. of } \\
\text { selling } \\
\text { events }\end{array}$ & $\begin{array}{l}\text { Quantity } \\
\text { sold }\end{array}$ & $\begin{array}{l}\text { Price per } \\
\text { unit sold }\end{array}$ \\
\hline & & & & & & & & \\
\hline & & & & & & & & \\
\hline & & & & & & & & \\
\hline & & & & & & & & \\
\hline & & & & & & & & \\
\hline
\end{tabular}

Specification 1: Use predefined units for each product! Check separate information leaflet!

Specification 2: Give a figure for each selling event! Separate them with a backslash!

Money spent on baskets/bags within 12 months:

\subsection{Fishing}

Can you give me an estimate of income you generate with fishing per month?

Table 6 - Fishing, Output

\begin{tabular}{|l|l|l|l|l|l|l|}
\hline Fish type & $\begin{array}{l}\text { Amount in } \\
\text { last } 1 \mathrm{mo} / \mathrm{y}^{1}\end{array}$ & $\begin{array}{l}\text { Support HH } \\
\text { memb (ID) }\end{array}$ & $\begin{array}{l}\text { Quantity self- } \\
\text { consumed }\end{array}$ & $\begin{array}{l}\text { Number of } \\
\text { selling events }\end{array}$ & Quantity sold & $\begin{array}{l}\text { Price per } \\
\text { unit sold }^{2}\end{array}$ \\
\hline Cray fish & & & & & & \\
\hline Fish (big) & & & & & & \\
\hline Fish (small) & & & & & & \\
\hline Tortoise & & & & & & \\
\hline (Dwarf) Croco & & & & & & \\
\hline
\end{tabular}

Specification 1: Use predefined units for each fish type! Check separate information leaflet!

Specification 2: Give a figure for each selling event! Separate them with a backslash! 
Table 7 - Fishing, Input

\begin{tabular}{|l|l|l|l|l|l|}
\hline \multirow{2}{*}{ Fish type } & Expenses for ... in last 12 mo & Hooks & Lines & Others \\
\cline { 2 - 6 } & Nets & Mopito & & & \\
\hline Cray fish & & & & & \\
\hline Fish & & & & \\
\hline
\end{tabular}

\subsection{Rearing}

Can you give me an estimate of income you generate with your liverstock per year?

Table 8-Rearing, Output

\begin{tabular}{|l|l|l|l|l|}
\hline Livestock type & $\begin{array}{l}\text { Support HH } \\
\text { members (ID) }\end{array}$ & Consumed last 12 mo & Sold last 12 mo & Price per unit sold \\
\hline Chicken & & & & \\
\hline Chicken (egg) & & & & \\
\hline Goat & & & & \\
\hline Swine & & & & \\
\hline Dog & & & & \\
\hline$\ldots$ & & & & \\
\hline
\end{tabular}

Table 9-Rearing, Input

\begin{tabular}{|l|l|l|l|}
\hline Livestock type & Bought units in last 12 mo & $\begin{array}{l}\text { Bought feed in last 1 } \\
\text { month / year }\end{array}$ & $\begin{array}{l}\text { Building material on last } \\
12 \text { mo }\end{array}$ \\
\hline Chicken & & & \\
\hline Goat & & & \\
\hline Swine & & & \\
\hline Dog & & & \\
\hline ... & & & \\
\hline
\end{tabular}

\subsection{Labour}

Table 10 - Employment

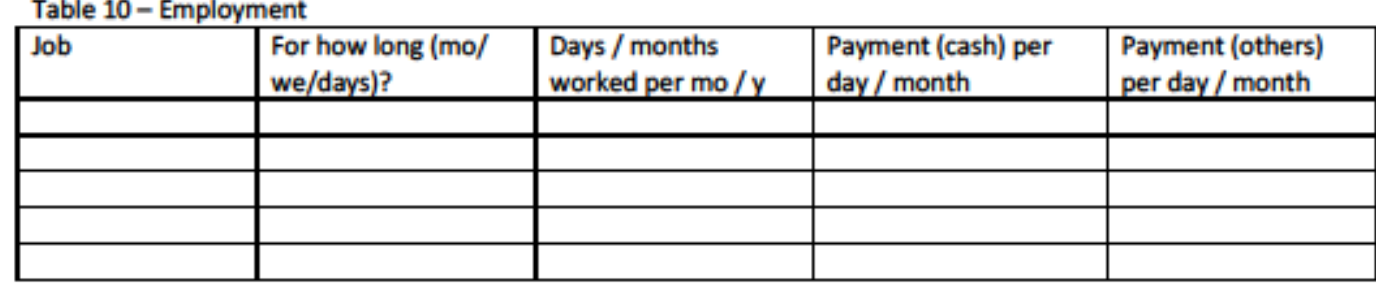

Table 11 - Self-employment

\begin{tabular}{|l|l|l|l|l|}
\hline Job & $\begin{array}{l}\text { For how long (mo/ } \\
\text { we/days)? }\end{array}$ & $\begin{array}{l}\text { Days / months } \\
\text { worked per mo/y }\end{array}$ & $\begin{array}{l}\text { Estimated income } \\
\text { (cash) per d/mo }\end{array}$ & $\begin{array}{l}\text { Other income } \\
\text { types per d/mo }\end{array}$ \\
\hline salesperson & & & & \\
\hline driver & & & & \\
\hline processing trader & & & & \\
\hline craftsman & & & & \\
\hline constr. worker & & & & \\
\hline landlord & & & & \\
\hline.. & & & & \\
\hline
\end{tabular}

\subsection{Trapping and hunting}

Can you give me an estimate of income you generate with your trapping activities per year? 
Table12 - Hunting, Output

\begin{tabular}{|c|c|c|c|c|c|c|}
\hline Animal & $\begin{array}{l}\text { Amount in } \\
\text { last } 1 \text { month / } \\
\text { year }^{1}\end{array}$ & $\begin{array}{l}\text { Who } \\
\text { processes the } \\
\text { meat? }\end{array}$ & $\begin{array}{l}\text { Number self- } \\
\text { consumed }\end{array}$ & $\begin{array}{l}\text { Number of } \\
\text { selling } \\
\text { events }\end{array}$ & Number sold ${ }^{3}$ & $\begin{array}{l}\text { Price per } \\
\text { unit sold }\end{array}$ \\
\hline & & & & & & \\
\hline & & & & & & \\
\hline & & & & & & \\
\hline & & & & & & \\
\hline & & & & & & \\
\hline & & & & & & \\
\hline & & & & & & \\
\hline & & & & & & \\
\hline & & & & & & \\
\hline & & & & & & \\
\hline & & & & & & \\
\hline & & & & & & \\
\hline & & & & & & \\
\hline & & & & & & \\
\hline & & & & & & \\
\hline & & & & & & \\
\hline & & & & & & \\
\hline & & & & & & \\
\hline & & & & & & \\
\hline & & & & & & \\
\hline & & & & & & \\
\hline
\end{tabular}

Specification 1: Use predefined units for each species! Check separate information leaflet!

Code 2: A-woman of HH B-man of HH C-other members of $\mathrm{HH}$ (specify) D-person outside HH (specify) Specification 3: Give a figure for each selling event! Separate them with a backslash!

Money spent on gun within 12 months:

Money spent on dogs within 12 months:

Money spent on cartridges within 1 month / 12 months:

Money spent on wires within 1 month / 12 months:

Money spent on other item within 1 month / 12 months:

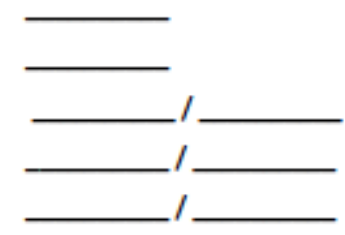

\subsection{Others}

Table 13 - Other income types

\begin{tabular}{|l|l|l|l|}
\hline $\begin{array}{l}\text { Item (cash, food, consum, } \\
\text { assets) gained }{ }^{1}\end{array}$ & Unit in last 1 month / year & Price per unit & Donor \\
\hline Cash & & & \\
\hline Food & & & \\
\hline Consumer goods & & & \\
\hline Assets & & & \\
\hline Other women, children & & & \\
\hline$\ldots$ & & & \\
\hline
\end{tabular}

Specification 1: Give also following examples - support from relatives/village, marriage, administration, NGO

How much of the income you generate by yourself is your personal and how much is household share? 


\section{Activity budget}

Have there been any special events in your house during the last week (travel, wedding etc.)?

$\rightarrow$ If yes, switch to the week before!

Table 14 - Week activity (incl participating Persons)

\begin{tabular}{|c|c|c|c|c|c|c|c|}
\hline Day time & Day 1 & Day 2 & Day 3 & Day 4 & Day 5 & Day 6 & Yesterday \\
\hline & 1 & & & & & & \\
\hline \multicolumn{8}{|l|}{6.00} \\
\hline \multicolumn{8}{|l|}{7.00} \\
\hline \multicolumn{8}{|l|}{$\ddot{8.00}$} \\
\hline \multicolumn{8}{|l|}{9.00} \\
\hline \multicolumn{8}{|l|}{10.00} \\
\hline \multicolumn{8}{|l|}{11.00} \\
\hline \multicolumn{8}{|l|}{12.00} \\
\hline \multicolumn{8}{|l|}{$13.00^{\circ}$} \\
\hline \multicolumn{8}{|l|}{$14.00^{71 .}$} \\
\hline \multicolumn{8}{|l|}{$15.00^{\circ}$} \\
\hline \multicolumn{8}{|l|}{16.00} \\
\hline \multicolumn{8}{|l|}{$17.00^{\circ}$} \\
\hline \multicolumn{8}{|l|}{$18.00^{\prime \prime}$} \\
\hline \multicolumn{8}{|l|}{19.00} \\
\hline \multicolumn{8}{|l|}{20.00} \\
\hline \multicolumn{8}{|l|}{21.00} \\
\hline \multicolumn{8}{|l|}{22.00} \\
\hline 23.00 & & & & & & & \\
\hline
\end{tabular}

Soecification 1: Fill in the actual days of the week! Start the table from the end (yesterday)!

Table 15 - Year activity (qualitative)

\begin{tabular}{|c|c|c|c|c|c|c|c|c|c|c|c|c|}
\hline Activity type & Jan & Feb & Mar & Apr & May & Jun & Jul & Aug & Sep & Oct & Nov & Dec \\
\hline Patming & & & & & & & & & & & & \\
\hline Farming' & & & & - & & -- & - & - & & & - & \\
\hline Farming' & & & & - & & & - & - & & & - & \\
\hline Farming & & & & 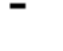 & & & $\cdot$ & 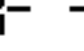 & & & - & \\
\hline Trap/Hunt & & & & - & & - & $\cdot$ & - & & & - & \\
\hline Labour & & & & - & & 7 & - & - & & & - & \\
\hline NTFP & & & & & & 1 & - & I & & & & \\
\hline Fishing & & & & - & & & 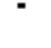 & - & & & - & \\
\hline Rearing & & & & - & & & 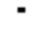 & - & & & 一 & \\
\hline Processing & & & & & & & - & & & & - & \\
\hline$\ldots$ & & & & - & & ᄀ & - & I- & & & - & \\
\hline$\ldots$ & & & & & & & & & & & & \\
\hline
\end{tabular}

Specification 1: Fill in the cultivated crop types! 


\section{Expenditures}

\subsection{Feeding (in two-gender HHs outside PAMOL: only women)}

How often you go to a market and when have you been there last time?

$\rightarrow$ Choose an appropriate time period according to the answer!

$\rightarrow$ Also, if there have been any special events during the last week, switch to the week before!

Can you give me an estimate of expenditures you have on food per month?

Table 16 - Feeding

\begin{tabular}{|l|l|l|}
\hline Food type & $\begin{array}{l}\text { Units bought in } \\
\text { last 7d }\end{array}$ & Price(s)/ unit \\
\hline Meat & & \\
\hline Fish & & \\
\hline Rice & & \\
\hline Spaghetti & & \\
\hline Irish & & \\
\hline Beans & & \\
\hline Bread & & \\
\hline Gari & & \\
\hline Water fufu & & \\
\hline Plantain & & \\
\hline Cocojam & & \\
\hline Corn & & \\
\hline Sweet jam & & \\
\hline Tomato & & \\
\hline Onion & & \\
\hline Banana & & \\
\hline Eggs & & \\
\hline Sugar & & \\
\hline Veggitable & & \\
\hline Sogit & & \\
\hline
\end{tabular}

\begin{tabular}{|l|l|l|}
\hline Food type & $\begin{array}{l}\text { Units bought } \\
\text { in last } 7 \mathrm{~d}^{1}\end{array}$ & Price(s)/ unit \\
\hline $\begin{array}{l}\text { Salt, Pepper, } \\
\text { Spic, GinGar }\end{array}$ & & \\
\hline Green bean & & \\
\hline Groundn oil & & \\
\hline Red oil & & \\
\hline Carrot & & \\
\hline Ocro & & \\
\hline Egussi & & \\
\hline Bush mango & & \\
\hline Maggi & & \\
\hline Coco nut & & \\
\hline Fruits & & \\
\hline Buiscuits & & \\
\hline Bonbon & & \\
\hline Tee & & \\
\hline Coffee & & \\
\hline Milk & & \\
\hline Sweet drink & & \\
\hline.- & & \\
\hline
\end{tabular}

Specification 1: Use predefined units for each item! Check separate information leaflet!

\subsection{Consumer goods}

Can you give me an estimate of expenditures you have on consumer goods per month?

Table 17 - Consumer goods

\begin{tabular}{|l|l|l|}
\hline Item & $\begin{array}{l}\text { Units bought } \\
\text { last mo }\end{array}$ & $\begin{array}{l}\text { Price(s) / } \\
\text { unit }\end{array}$ \\
\hline Alcohol & & \\
\hline Cigarettes & & \\
\hline Kerosine & & \\
\hline Petrol & & \\
\hline Savon & & \\
\hline Sponge & & \\
\hline Washing powd & & \\
\hline Toilet tissue & & \\
\hline Tooth paste & & \\
\hline Tooth brush & & \\
\hline Batteries & & \\
\hline Baby stuff & & \\
\hline Mobile & & \\
\hline... & & \\
\hline
\end{tabular}

\begin{tabular}{|l|l|l|}
\hline Item & $\begin{array}{l}\text { Units bought } \\
\text { last year }\end{array}$ & Price(s) / unit \\
\hline Mattress & & \\
\hline Mosquito net & & \\
\hline Shoes & & \\
\hline Clothing & & \\
\hline Blanket & & \\
\hline Cosmetics & & \\
\hline Hair style & & \\
\hline Kitchen utens & & \\
\hline Bush lamp & & \\
\hline Torch & & \\
\hline Bucket/canister & & \\
\hline Cutlers + Sharpener & & \\
\hline Mp3/film & & \\
\hline Mp3/film & & \\
\hline
\end{tabular}


5.3 Possessions

Table 18 - Assets

\begin{tabular}{|l|l|l|l|}
\hline Item & $\begin{array}{l}\text { Estimated } \\
\text { value }\end{array}$ & $\begin{array}{l}\text { Units } \\
\text { bought in } \\
\text { last 12 mo }\end{array}$ & $\begin{array}{l}\text { Price(s)/ } \\
\text { unit }\end{array}$ \\
\hline Moto bike & & & \\
\hline TV & & & \\
\hline Radio & & & \\
\hline Mobile & & & \\
\hline Furniture & & & \\
\hline
\end{tabular}

\begin{tabular}{|l|l|l|l|}
\hline Item & $\begin{array}{l}\text { Estimated } \\
\text { value }\end{array}$ & $\begin{array}{l}\text { Units } \\
\text { bought in } \\
\text { last 12 mo }\end{array}$ & $\begin{array}{l}\text { Price(s)/ } \\
\text { unit }\end{array}$ \\
\hline & & & \\
\hline & & & \\
\hline & & & \\
\hline & & & \\
\hline & & & \\
\hline
\end{tabular}

5.4 Housing (in two-gender HHs: only men)

Rent:

Building/fixing expenses:

Land or buildings bought:

\subsection{Education}

School fees:

School material + dress:

Accommodation:

Feeding:

5.6 Health

Drugs/bandages etc:

Treatments:

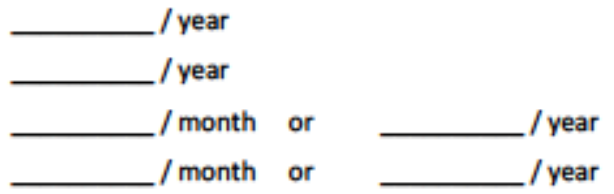

/ month

$/$ year

/ year

month or

/ year

/ year

\subsection{Transport}

Table 19- Transport

\begin{tabular}{|l|l|l|}
\hline Person ID & Travel expenses in last 12 mo & Expenses for porters last 12mo \\
\hline & & \\
\hline & & \\
\hline & & \\
\hline & & \\
\hline & & \\
\hline & & \\
\hline
\end{tabular}

\subsection{Others}

Table 20 - Support of relatives and community

\begin{tabular}{|l|l|l|l|}
\hline $\begin{array}{l}\text { Item (cash, food, consum, } \\
\text { assets) provided }\end{array}$ & Unit in last month / year & Price per unit & Recipient \\
\hline Cash & & & \\
\hline & & & \\
\hline & & & \\
\hline & & & \\
\hline & & & \\
\hline
\end{tabular}

Specification 1: Give following examples - marriage, support to relatives/village, birth, funerals, spiritual events 
Table S6.1 - Overview on important crops/fruits (with market units), forest products and household activities used for interviews

\begin{tabular}{|c|c|c|}
\hline \multicolumn{2}{|l|}{ Field crops } & Animals \\
\hline Cocoa & bag / kg & Bay Duiker (Sleeping deer) \\
\hline \multicolumn{2}{|c|}{ Oil palm bunch / gallon (100I) } & Blue duiker (Frutambo, inen) \\
\hline Cassava & basket & Buffalo \\
\hline Cassava (gari) & cup / rappon (sacksa) & Bushbuck (Antelope) \\
\hline Cassava (fufu) & lumps & Cane Rat (Cutting gras) \\
\hline Egussi & bag / cup & Chimpanzee \\
\hline Corn & basket / pile (5 pieces) & Civet (Bush dog) \\
\hline Cocoyam & basket & Crowned Monkey (Mboma) \\
\hline Plantain & bunch & Drill (Sombo) \\
\hline Banana & bunch & Dwarf crocodile (Dwarf) \\
\hline Okro & basket / quantity $(50,100$ frs $)$ & Elephant \\
\hline Cabbage & piece & Galago \\
\hline Veggitable & bunch & Genet (Mba, bush baby, bush pussy, enok) \\
\hline Groundnut & basket / quantity $(50,100$ frs) & Giant Rat (Rat mole) \\
\hline \multirow{2}{*}{\multicolumn{2}{|c|}{ bucket / rappon (sacksa) }} & Guineafowl / Francolin (Bush fow) \\
\hline & & Mona Monkey (Chop banana) \\
\hline \multirow{2}{*}{\multicolumn{2}{|c|}{ Trees and fruits }} & Mongoose (Company beef, family beef, imbiet) \\
\hline & & Nile monitor (Giant lizard, iguana, ngombe, uran) \\
\hline Orange & tree / pile & Ogilby's duiker (Red deer, enum) \\
\hline Pear & tree / pile & Otter \\
\hline Ananas & piece & Palm Civet / Genet (Mba, bush baby / pussy, enok) \\
\hline Powpow & piece & Pangolin (Cutter beef, iang) \\
\hline Plum & pile & Porcupine (Chuku chuku) \\
\hline Lime & pile & Potto \\
\hline Lemon & pile & Preuss' guenon (Njanda) \\
\hline Coconut & piece & Putty-nosed Monkey (White nose) \\
\hline Palm wine & gallon $(5 \mathrm{l}, 10 \mathrm{l})$ & Red Colobus \\
\hline Bitter cola & bucket / rappon (sacksa) & Red River Hog (Bush pig) \\
\hline Cola & bucket / pieces & Red-capped Mangabey (Mbi) \\
\hline Njansa & rappon (sacksa) & Red-eared Monkey (Red tail) \\
\hline \multirow{2}{*}{\multicolumn{2}{|c|}{ Atama $\quad$ quantity $(50,100 \mathrm{frs})$}} & Snake \\
\hline & & Squirrel \\
\hline \multirow{2}{*}{\multicolumn{2}{|c|}{ Activities }} & Tortoise (Trokey, ellima, kun) \\
\hline & & Tree Hyrax \\
\hline \multicolumn{2}{|l|}{ Farm work } & Water Chevrotain (Water beef) \\
\hline \multicolumn{2}{|l|}{ Cooking } & Yellow-backed Duiker (Bush cow) \\
\hline \multicolumn{3}{|c|}{ Washing } \\
\hline \multicolumn{2}{|c|}{ Processing farm products } & Forest products \\
\hline \multicolumn{3}{|c|}{ Resting } \\
\hline \multicolumn{2}{|l|}{ Travel } & Fire wood \\
\hline \multicolumn{2}{|l|}{ Fishing } & Bush mango \\
\hline \multicolumn{2}{|c|}{ Rearing (swine) } & Snails \\
\hline \multicolumn{2}{|c|}{ Hunting/trapping } & Medicinal plants \\
\hline \multicolumn{2}{|c|}{ Basket production } & Eru \\
\hline \multicolumn{2}{|c|}{ Mats production } & Country onion \\
\hline \multicolumn{2}{|c|}{ Community work } & Raffia (for mats) \\
\hline \multicolumn{2}{|c|}{ Palm wine tapping } & Cane rope \\
\hline \multirow{2}{*}{\multicolumn{2}{|c|}{ Other work activity }} & Bitter cola \\
\hline & & Cola \\
\hline \multirow{2}{*}{\multicolumn{2}{|c|}{ Birds }} & Timber \\
\hline & & Bambus \\
\hline Hornbill, Turac & & Wooden sticks (for sale) \\
\hline Eagle, Parrot & & \\
\hline
\end{tabular}




\section{CHAPTER 6}

Table S6.2 - Farm calendar for common crops and fruit trees used for interviews.

\begin{tabular}{|c|c|c|c|c|c|c|c|c|c|c|c|c|}
\hline Crop type & Jan & Feb & Mar & Apr & May & Jun & Jul & Aug & Sep & Oct & Nov & Dec \\
\hline Coco & & pre & pre & pre & pre & pre & $\mathrm{pl}$ & $\mathrm{pl}$ & & & & \\
\hline \multicolumn{13}{|l|}{ Oil palm } \\
\hline \multicolumn{13}{|l|}{ Cassava } \\
\hline Egussi & & $\mathrm{pl}$ & pre & pre & pre & & & & & & & \\
\hline Corn & & $\mathrm{pl}$ & pre & pre & pre & & & & & & & \\
\hline Cocoyam & $\mathrm{pl}$ & $\mathrm{pl}$ & pre & pre & pre & & & & & & & \\
\hline Plantain & $\mathrm{pl}$ & $\mathrm{pl}$ & $\mathrm{pl}$ & & & & & & & & $\mathrm{pl}$ & $\mathrm{pl}$ \\
\hline \multicolumn{13}{|l|}{ Banana } \\
\hline Occro & $\mathrm{pl}$ & & & $\mathrm{pl}$ & $\mathrm{pl}$ & & & & & & & $\mathrm{pl}$ \\
\hline \multicolumn{13}{|l|}{ Veggitable } \\
\hline Groundnut & $\mathrm{pl}$ & $\mathrm{pl}$ & $\mathrm{pl}$ & & & & & & & & & \\
\hline \multicolumn{13}{|l|}{ Ginger } \\
\hline Pepper & $\mathrm{pl}$ & $\mathrm{pl}$ & & & & & & & & & & $\mathrm{pl}$ \\
\hline Beans & $\mathrm{pl}$ & $\mathrm{pl}$ & $\mathrm{pl}$ & & & & & & & & & \\
\hline Cucumber & $\mathrm{pl}$ & $\mathrm{pl}$ & & & & & & & & & & $\mathrm{pl}$ \\
\hline \multicolumn{13}{|l|}{ Orange } \\
\hline \multicolumn{13}{|l|}{ Apple } \\
\hline \multicolumn{13}{|l|}{ Mango } \\
\hline \multicolumn{13}{|l|}{ Pear } \\
\hline \multicolumn{13}{|l|}{ Pineapple } \\
\hline Powpow & & & & $\mathrm{pl}$ & & & & & & & & \\
\hline \multicolumn{13}{|l|}{ Plum } \\
\hline \multicolumn{13}{|l|}{ Lime } \\
\hline \multicolumn{13}{|l|}{ Lemon } \\
\hline \multicolumn{13}{|l|}{ Coconut } \\
\hline \multicolumn{13}{|l|}{ Palm wine } \\
\hline \multicolumn{13}{|l|}{ Bitter cola } \\
\hline \multicolumn{13}{|l|}{ Cola } \\
\hline \multicolumn{13}{|l|}{ Njansa } \\
\hline \multicolumn{13}{|l|}{ Atama } \\
\hline \multicolumn{13}{|l|}{ Bush mango } \\
\hline \multicolumn{13}{|l|}{ Eru } \\
\hline Country onion & & & & & & & & & & & & \\
\hline
\end{tabular}


Table S6.3 - Ethnic groups of interviewed households.

\begin{tabular}{ll}
\hline $\begin{array}{l}\text { Landscape type } \\
\text { Location }\end{array}$ & Ethnic group \\
Bera & Bakoko \\
Erat & Korup \\
Esekutan & Bakoko, Ejagham \\
Ikenge & Batanga \\
& \\
Non-park villages & \\
Ikondo kondo I & Korup \\
Fabe & Bima \\
Lipenja I & Batanga \\
Mokango \& Massaka & Bima \\
& \\
Plantation settlements & \\
Center A & Oche, Mauko, Oko, Ngolo, Babanki, Bakundu, Bagberi, Ngenbe \\
Ikassa Camp & Ngolo, Oko, Ibo, Nani, Ngo, Tikari, Bekom \\
Makeke Camp & Oko, Kom, Babenki, Bima, Menkaf \\
Mana Camp & Ngolo, Oko, Korup, Babenki, Balundu \\
\hline
\end{tabular}

Table S6.4 - Education level of men and women in three landscape types; FSLC - First School Leaving Certificate (6 years of primary school), GCE - General Certificate of Education, O' level - Ordinary (five years of secondary school), A' level - Advanced (additional 2 years of sec. school).

\begin{tabular}{|c|c|c|c|c|c|c|}
\hline & \multirow{2}{*}{ Gender } & \multicolumn{5}{|c|}{ Proportion of education level (\%) } \\
\hline & & FSLC & GCE O’ level & GCE A' level & Above $A^{\prime}$ level & none \\
\hline \multirow[t]{2}{*}{ KNP } & M & 62 & 9 & 6 & - & 23 \\
\hline & $\mathrm{F}$ & 60 & - & - & - & 40 \\
\hline \multirow[t]{2}{*}{ AFM } & M & 70 & - & - & - & 30 \\
\hline & $\mathrm{F}$ & 57 & 3 & - & 5 & 35 \\
\hline \multirow[t]{2}{*}{ OPP } & M & 66 & - & 12 & - & 22 \\
\hline & $\mathrm{F}$ & 64 & 25 & 4 & - & 7 \\
\hline
\end{tabular}


Table S6.5 - Mean total net income of income activities in three landscape types in 1,000 FCFA.

\begin{tabular}{|c|c|c|c|c|c|c|c|c|c|c|c|c|}
\hline \multirow{2}{*}{$\begin{array}{l}\text { Income } \\
\text { type }\end{array}$} & \multicolumn{3}{|c|}{ KNP } & \multicolumn{3}{|c|}{ AFM } & \multicolumn{3}{|c|}{ OPP } & \multicolumn{3}{|c|}{ Total } \\
\hline & $\begin{array}{c}\text { prop. } \\
{[\%]}\end{array}$ & mean & SE & $\begin{array}{c}\text { prop. } \\
{[\%]}\end{array}$ & mean & SE & $\begin{array}{c}\text { prop. } \\
{[\%]}\end{array}$ & mean & SE & $\begin{array}{c}\text { prop. } \\
{[\%]}\end{array}$ & mean & SE \\
\hline Farming & 34 & 605 & 63 & 39 & 550 & 43 & 17 & 266 & 68 & 30 & 471 & 37 \\
\hline Rearing & 2 & 34 & 10 & 4 & 54 & 15 & 0 & 6 & 2 & 2 & 31 & 6 \\
\hline NTFP & 11 & 197 & 25 & 11 & 158 & 18 & 3 & 48 & 15 & 9 & 133 & 13 \\
\hline Hunting \& trapping & 31 & 548 & 96 & 14 & 200 & 57 & 3 & 53 & 32 & 17 & 262 & 42 \\
\hline Fishing & 8 & 150 & 25 & 5 & 73 & 20 & 2 & 32 & 15 & 5 & 84 & 12 \\
\hline (Self-)employment & 10 & 181 & 57 & 21 & 292 & 84 & 72 & 1102 & 84 & 34 & 531 & 58 \\
\hline Other & 3 & 55 & 13 & 6 & 77 & 13 & 2 & 28 & 7 & 3 & 53 & 7 \\
\hline
\end{tabular}

Table S6.6 - Mean total net farm income and proportion of engaged households for each crop in three landscape types in 1,000 FCFA.

\begin{tabular}{|c|c|c|c|c|c|c|c|c|c|c|c|c|}
\hline \multirow{2}{*}{$\begin{array}{l}\text { Crop } \\
\text { type }\end{array}$} & \multicolumn{3}{|c|}{ KNP } & \multicolumn{3}{|c|}{ AFM } & \multicolumn{3}{|c|}{ OPP } & \multicolumn{3}{|c|}{ Total } \\
\hline & $\begin{array}{l}\mathrm{HH} \\
{[\%]}\end{array}$ & mean & SE & $\begin{array}{l}\mathrm{HH} \\
{[\%]}\end{array}$ & mean & SE & $\begin{array}{l}\mathrm{HH} \\
{[\%]}\end{array}$ & mean & SE & $\begin{array}{l}\mathrm{HH} \\
{[\%]}\end{array}$ & mean & SE \\
\hline Agbana & 39 & 9 & 2 & 58 & 14 & 3 & 8 & 4 & 2 & 35 & 9 & 1 \\
\hline Avocado & 66 & 2 & 0 & 53 & 3 & 1 & 13 & 0 & 0 & 43 & 2 & 0 \\
\hline Banana & 97 & 56 & 7 & 100 & 73 & 9 & 50 & 13 & 4 & 82 & 47 & 4 \\
\hline Beans & 45 & 3 & 1 & 25 & 6 & 2 & 3 & 1 & 1 & 24 & 3 & 1 \\
\hline Cashew & 0 & 0 & 0 & 5 & 0 & 0 & 5 & 1 & 1 & 3 & 0 & 0 \\
\hline Cassava & 87 & 92 & 23 & 90 & 95 & 23 & 60 & 32 & 12 & 79 & 72 & 13 \\
\hline Cocoa & 63 & 203 & 42 & 65 & 139 & 37 & 13 & 29 & 24 & 47 & 122 & 21 \\
\hline Coconut & 50 & 3 & 1 & 30 & 1 & 0 & 10 & 0 & 0 & 30 & 1 & 1 \\
\hline Cocoyam & 68 & 16 & 4 & 83 & 28 & 5 & 58 & 9 & 3 & 69 & 18 & 2 \\
\hline Corn & 89 & 13 & 2 & 88 & 19 & 3 & 78 & 13 & 2 & 85 & 15 & 1 \\
\hline Egusi & 79 & 18 & 4 & 73 & 19 & 4 & 55 & 8 & 2 & 69 & 15 & 2 \\
\hline Greens & 76 & 13 & 2 & 83 & 15 & 3 & 83 & 14 & 2 & 81 & 14 & 1 \\
\hline Groundnut & 55 & 6 & 2 & 50 & 10 & 3 & 30 & 2 & 1 & 45 & 6 & 0 \\
\hline Mango & 53 & 3 & 1 & 45 & 3 & 1 & 13 & 1 & 0 & 36 & 2 & 0 \\
\hline Okra & 68 & 6 & 1 & 73 & 9 & 2 & 48 & 3 & 1 & 63 & 6 & 1 \\
\hline Orange & 76 & 3 & 1 & 38 & 2 & 1 & 10 & 1 & 0 & 41 & 2 & 0 \\
\hline Other & 42 & 4 & 1 & 33 & 12 & 8 & 20 & 4 & 2 & 31 & 7 & 1 \\
\hline Palm oil & 66 & 28 & 6 & 50 & -14 & 18 & 15 & 99 & 56 & 43 & 38 & 4 \\
\hline Palm wine & 58 & 39 & 8 & 35 & 25 & 8 & 0 & 0 & 0 & 4 & 21 & 5 \\
\hline Papaya & 42 & 1 & 0 & 40 & 2 & 0 & 20 & 1 & 0 & 34 & 1 & 0 \\
\hline Pepper & 63 & 7 & 2 & 73 & 13 & 3 & 25 & 2 & 1 & 53 & 7 & 1 \\
\hline Pineapple & 34 & 1 & 0 & 25 & 1 & 0 & 10 & 1 & 1 & 23 & 1 & 0 \\
\hline Plantain & 97 & 79 & 9 & 100 & 70 & 6 & 53 & 26 & 7 & 83 & 58 & 5 \\
\hline Plum & 87 & 4 & 1 & 75 & 5 & 1 & 18 & 1 & 0 & 59 & 3 & 0 \\
\hline Sweet potato & 8 & 2 & 2 & 20 & 2 & 1 & 3 & 0 & 0 & 10 & 1 & 1 \\
\hline Sweet yam & 53 & 7 & 2 & 50 & 11 & 4 & 18 & 3 & 1 & 40 & 7 & 1 \\
\hline Water yam & 21 & 3 & 1 & 33 & 11 & 7 & 0 & 0 & 0 & 18 & 5 & 1 \\
\hline TOTAL & 97 & 605 & 63 & 100 & 550 & 43 & 93 & 266 & 68 & 97 & 471 & 37 \\
\hline
\end{tabular}


Table S6.7 - Mean cash and in-kind components of the three most sold food and two most sold cash crop types in three landscape types in FCFA.

\begin{tabular}{|c|c|c|c|c|c|c|c|c|c|}
\hline \multirow{2}{*}{ Crop type } & \multirow{2}{*}{$\begin{array}{l}\text { Income } \\
\text { type }\end{array}$} & \multicolumn{2}{|c|}{ KNP } & \multicolumn{2}{|c|}{ AFM } & \multicolumn{2}{|c|}{ OPP } & \multicolumn{2}{|c|}{ Total } \\
\hline & & mean & SE & mean & SE & mean & SE & mean & SE \\
\hline \multicolumn{10}{|l|}{ Food crops } \\
\hline \multirow[t]{4}{*}{ Plantain } & in-kind & 63,392 & 6,704 & 56,018 & 5,890 & 17,874 & 5,771 & 45,462 & 3,959 \\
\hline & cash & 16,693 & 4,583 & 14,238 & 2,971 & 8,948 & 3,880 & 13,235 & 2,220 \\
\hline & input expenses & 974 & 801 & 175 & 175 & 1,015 & 951 & 717 & 415 \\
\hline & total net income & 79,112 & 8,640 & 70,080 & 6,457 & 25,806 & 6,981 & 57,981 & 4,740 \\
\hline \multirow[t]{4}{*}{ Banana } & in-kind & 50,911 & 6,680 & 65,348 & 7,972 & 10,318 & 3,240 & 42,044 & 4,197 \\
\hline & cash & 5,550 & 1,594 & 8,035 & 2,309 & 3,785 & 1,796 & 5,794 & 1,119 \\
\hline & input expenses & 315 & 316 & 825 & 708 & 625 & 512 & 593 & 311 \\
\hline & total net income & 56,145 & 6,681 & 72,558 & 8,838 & 13,478 & 4,012 & 47,245 & 4,535 \\
\hline \multirow[t]{4}{*}{ Cassava } & in-kind & 52,908 & 7,340 & 56,488 & 10,430 & 23,213 & 5,554 & 44,055 & 4,815 \\
\hline & cash & 52,553 & 10,547 & 49,700 & 8,126 & 15,050 & 5,040 & 38,873 & 4,915 \\
\hline & input expenses & 13,789 & 4,550 & 11,675 & 2,961 & 6,662 & 3,455 & 10,656 & 2,127 \\
\hline & total net income & 91,671 & 13,916 & 945,123 & 12,210 & 31,600 & 6,889 & 72,271 & 7,014 \\
\hline \multicolumn{10}{|l|}{ Cash crops } \\
\hline \multirow[t]{4}{*}{ Cocoa } & in-kind & - & & - & & - & & - & \\
\hline & cash & 194,838 & 60,607 & 56,450 & 35,670 & 285,138 & 55,282 & 177,006 & 30,674 \\
\hline & input expenses & 55,540 & 25,739 & 27,755 & 15,965 & 81,949 & 17,749 & 54,626 & 11,740 \\
\hline & total net income & 139,298 & 37,607 & 28,908 & 23,558 & 203,189 & 40,927 & 122,453 & 20,933 \\
\hline \multirow[t]{4}{*}{ Palm oil } & in-kind & 14,043 & 3,283 & 5,115 & 1,210 & 5,500 & 4,159 & 8,120 & 1,847 \\
\hline & cash & 17,079 & 4,327 & 5,623 & 2,580 & $1,182,238$ & 123,184 & 69,192 & 42,113 \\
\hline & input expenses & 3,526 & 1,797 & 24,725 & 18,302 & 88,383 & 69,567 & 39,477 & 24,377 \\
\hline & total net income & 27,596 & 6,119 & $-13,958$ & 18,774 & 99,355 & 55,672 & 37,835 & 20,275 \\
\hline
\end{tabular}


Table S6.8 - Mean total hunting income and proportion of engaged households for each wildlife species as well as total hunting input expenses in three landscape types in 1,000 FCFA.

\begin{tabular}{|c|c|c|c|c|c|c|c|c|c|c|c|c|}
\hline \multirow[b]{2}{*}{ Hunted species } & \multicolumn{3}{|c|}{ KNP } & \multicolumn{3}{|c|}{ AFM } & \multicolumn{3}{|c|}{ OPP } & \multicolumn{3}{|c|}{ Total } \\
\hline & $\begin{array}{l}\mathrm{HH} \\
\text { [\%] }\end{array}$ & mean & SE & $\begin{array}{l}\mathrm{HH} \\
\text { [\%] }\end{array}$ & mean & SE & $\begin{array}{l}\mathrm{HH} \\
\text { [\%] }\end{array}$ & mean & SE & $\begin{array}{l}\mathrm{HH} \\
\text { [\%] }\end{array}$ & mean & SE \\
\hline Brush-t. porcupine & 76 & 94 & 17 & 58 & 47 & 14 & 10 & 5 & 4 & 48 & 48 & 8 \\
\hline Blue duiker & 68 & 94 & 19 & 48 & 31 & 13 & 10 & 6 & 5 & 42 & 43 & 8 \\
\hline Ogilby's duiker & 61 & 76 & 18 & 38 & 18 & 6 & 10 & 13 & 11 & 36 & 35 & 8 \\
\hline Greater cane rat & 71 & 40 & 9 & 58 & 18 & 5 & 13 & 5 & 2 & 47 & 20 & 4 \\
\hline Pangolin & 40 & 27 & 10 & 33 & 8 & 4 & 5 & 1 & 1 & 78 & 12 & 3 \\
\hline Red river hog & 37 & 23 & 6 & 18 & 12 & 7 & 3 & 0 & 0 & 19 & 11 & 3 \\
\hline African palm civet & 47 & 16 & 4 & 48 & 13 & 4 & 13 & 2 & 1 & 36 & 11 & 2 \\
\hline Mona monkey & 45 & 20 & 5 & 20 & 8 & 4 & 5 & 0 & 0 & 23 & 9 & 2 \\
\hline Putty-nosed monkey & 42 & 19 & 6 & 20 & 7 & 4 & 5 & 1 & 1 & 22 & 9 & 2 \\
\hline Red-eared monkey & 37 & 19 & 7 & 20 & 4 & 2 & 5 & 1 & 1 & 21 & 8 & 2 \\
\hline Giant rat & 68 & 11 & 2 & 55 & 8 & 3 & 13 & 1 & 0 & 45 & 6 & 1 \\
\hline Drill & 18 & 18 & 8 & - & & & 3 & 3 & 3 & 7 & 7 & 3 \\
\hline Nile monitor & 42 & 5 & 1 & 35 & 8 & 4 & 15 & 4 & 3 & 31 & 6 & 2 \\
\hline Red-cap. mangabey & 29 & 15 & 5 & 8 & 1 & 0 & - & & & 12 & 5 & 2 \\
\hline Preuss' red colobus & 18 & 13 & 5 & - & & & 3 & 1 & 1 & 7 & 5 & 2 \\
\hline Bay duiker & 42 & 10 & 3 & 8 & 1 & 1 & 5 & 0 & 0 & 18 & 4 & 1 \\
\hline Snake & 13 & 2 & 1 & 25 & 5 & 3 & 15 & 2 & 1 & 18 & 3 & 1 \\
\hline Mongoose & 47 & 5 & 2 & 38 & 2 & 1 & 15 & 0 & 0 & 33 & 3 & 1 \\
\hline Crowned monkey & 34 & 7 & 2 & - & & & 5 & 0 & 0 & 13 & 3 & 1 \\
\hline Genet & 21 & 5 & 2 & 8 & 0 & 0 & 10 & 1 & 0 & 13 & 2 & 1 \\
\hline Dwarf crocodile & 3 & 1 & 1 & - & & & 8 & 3 & 2 & 4 & 2 & 1 \\
\hline Eagle & 3 & 5 & 3 & - & & & - & & & 1 & 2 & 1 \\
\hline Water chevrotain & 37 & 4 & 1 & - & & & 3 & 0 & 0 & 13 & 1 & 0 \\
\hline African grey parrot & 26 & 4 & 2 & - & & & - & & & 9 & 1 & 1 \\
\hline Hornbill & 32 & 3 & 1 & 3 & 0 & 0 & 3 & 0 & 0 & 13 & 1 & 0 \\
\hline Tree hyrax & - & & & 8 & 2 & 2 & 3 & 0 & 0 & 4 & 1 & 1 \\
\hline Squirrel & 26 & 1 & 0 & 40 & 1 & 0 & 8 & 0 & 0 & 25 & 1 & 0 \\
\hline Yellow-b. duiker & 5 & 2 & 1 & - & & & - & & & 2 & 1 & 0 \\
\hline Turaco & 24 & 1 & 0 & 3 & 0 & 0 & - & & & 9 & 0 & 0 \\
\hline Preuss's guenon & - & & & 5 & 1 & 1 & - & & & 2 & 0 & 0 \\
\hline Potto & 13 & 1 & 1 & 5 & 0 & 0 & 3 & 0 & 0 & 7 & 0 & 0 \\
\hline Otter & 13 & 0 & 0 & 3 & 0 & 0 & 5 & 0 & 0 & 7 & 0 & 0 \\
\hline Tortoise & 13 & 0 & 0 & 18 & 0 & 0 & 10 & 0 & 0 & 14 & 0 & 0 \\
\hline Galago & 18 & 0 & 0 & 13 & 0 & 0 & 3 & 0 & 0 & 11 & 0 & 0 \\
\hline Bushbuck & - & & & 3 & 0 & 0 & - & & & 1 & 0 & 0 \\
\hline Bush fow & 5 & 0 & 0 & 10 & 1 & 1 & 3 & 0 & 0 & 6 & 1 & 0 \\
\hline TOTAL & 79 & 548 & 96 & 58 & 200 & 57 & 20 & 53 & 32 & 52 & 262 & 42 \\
\hline
\end{tabular}


Table S6.9 - Mean cash and in-kind components of the three most sold wildlife species in three landscape types in FCFA.

\begin{tabular}{|c|c|c|c|c|c|c|c|c|c|}
\hline \multirow{2}{*}{ Species } & \multirow{2}{*}{$\begin{array}{l}\text { Income } \\
\text { type }\end{array}$} & \multirow{2}{*}{$\begin{array}{c}\text { KNP } \\
\text { mean }\end{array}$} & \multicolumn{3}{|c|}{ AFM } & \multirow{2}{*}{$\begin{array}{c}\text { OPP } \\
\text { mean }\end{array}$} & \multicolumn{3}{|c|}{ Total } \\
\hline & & & SE & mean & SE & & SE & mean & SE \\
\hline \multirow{2}{*}{ Porcupine } & in-kind & 22,771 & 4,860 & 5,275 & 2,371 & 837 & 489 & 9,405 & 3,430 \\
\hline & cash & 71,544 & 13,198 & 41,800 & 13,004 & 4,550 & 3,536 & 38,751 & 11,637 \\
\hline \multirow{2}{*}{ Blue duiker } & in-kind & 10,865 & 2,953 & 4,357 & 2,182 & 200 & 205 & 5,044 & 2,205 \\
\hline & cash & 82,663 & 17,215 & 26,987 & 11,608 & 5,500 & 5,134 & 37,633 & 13,237 \\
\hline \multirow{2}{*}{ Og.'s duiker } & in-kind & 526 & 526 & - & - & - & - & 169 & 299 \\
\hline & cash & 75,710 & 18,201 & 17,700 & 5,777 & 12,500 & 11,291 & 34,618 & 13,409 \\
\hline
\end{tabular}

Table S6.10 - Mean total wage net income and proportion of engaged households for each (self-)employment type in three landscape types in 1,000 FCFA.

\begin{tabular}{|c|c|c|c|c|c|c|c|c|c|c|c|c|}
\hline \multirow{2}{*}{ Income type } & \multicolumn{3}{|c|}{ KNP } & \multicolumn{3}{|c|}{ AFM } & \multicolumn{3}{|c|}{ OPP } & \multicolumn{3}{|c|}{ Total } \\
\hline & $\mathrm{HH}[\%]$ & mean & SE & $\mathrm{HH}[\%]$ & mean & SE & $\mathrm{HH}$ [\%] & mean & SE & $\mathrm{HH}[\%]$ & mean & SE \\
\hline PAMOL OPP & - & & & 3 & 3 & 3 & 100 & 972 & 79 & 34 & 330 & 88 \\
\hline Petty trader & 37 & 48 & 17 & 18 & 18 & 10 & 18 & 31 & 15 & 24 & 32 & 14 \\
\hline Trader & 13 & 32 & 24 & 5 & 33 & 32 & 3 & 3 & 3 & 23 & 22 & 23 \\
\hline Contract work & 18 & 5 & 2 & 15 & 3 & 1 & 35 & 43 & 18 & 23 & 17 & 11 \\
\hline Porter & 40 & 9 & 2 & 3 & 0 & 0 & - & & & 14 & 3 & 2 \\
\hline Food seller & 11 & 6 & 3 & 25 & 31 & 14 & - & & & 12 & 12 & 8 \\
\hline SGSOC oil palm nursery & - & & & 25 & 113 & 38 & - & & & 8 & 38 & 24 \\
\hline Driver & - & & & - & & & 10 & 41 & 23 & 7 & 14 & 14 \\
\hline Craftsman & 3 & 1 & 1 & 8 & 7 & 5 & 8 & 1 & 1 & 6 & 3 & 3 \\
\hline Teacher & 11 & 63 & 48 & 3 & 36 & 37 & - & & & 5 & 33 & 35 \\
\hline Research & 8 & 4 & 3 & 3 & 1 & 1 & - & & & 4 & 2 & 2 \\
\hline Hair dresser & 3 & 3 & 3 & - & & & 5 & 6 & 4 & 3 & 3 & 3 \\
\hline Health center & 3 & 9 & 9 & - & & & 3 & 0 & 0 & 2 & 3 & 5 \\
\hline Tailor & 3 & 0 & 0 & - & & & 3 & 0 & 0 & 2 & 0 & 0 \\
\hline Shop owner & - & & & 3 & 41 & 42 & - & & & 1 & 14 & 24 \\
\hline Bartender & - & & & - & & & 3 & 3 & 3 & 1 & 1 & 2 \\
\hline Landlord & - & & & 3 & 1 & 1 & - & & & 1 & 0 & 1 \\
\hline Village management & - & & & 3 & 1 & 1 & - & & & 1 & 0 & 0 \\
\hline TOTAL & 71 & 181 & 41 & 83 & 292 & 87 & 100 & 1,102 & 87 & 85 & 531 & 103 \\
\hline
\end{tabular}


Table S6.11 - Mean total NTFP income and proportion of engaged households for NTFP type as well as total NTFP input expenses in three landscape types in 1,000 FCFA.

\begin{tabular}{|c|c|c|c|c|c|c|c|c|c|c|c|c|}
\hline \multirow[b]{2}{*}{ NTFP } & \multicolumn{3}{|c|}{ KNP } & \multicolumn{3}{|c|}{ AFM } & \multicolumn{3}{|c|}{ OPP } & \multicolumn{3}{|c|}{ Total } \\
\hline & $\begin{array}{l}\mathrm{HH} \\
{[\%]}\end{array}$ & mean & SE & $\begin{array}{l}\mathrm{HH} \\
{[\%]}\end{array}$ & mean & SE & $\begin{array}{l}\mathrm{HH} \\
{[\%]}\end{array}$ & mean & SE & $\begin{array}{l}\mathrm{HH} \\
{[\%]}\end{array}$ & mean & SE \\
\hline Bush Mango & 95 & 91 & 11 & 78 & 61 & 9 & 20 & 9 & 5 & 64 & 53 & 6 \\
\hline Rattan & 84 & 8 & 2 & 78 & 8 & 2 & 16 & 1 & 1 & 59 & 5 & 1 \\
\hline Snails & 50 & 8 & 2 & 50 & 11 & 4 & 55 & 31 & 12 & 52 & 17 & 4 \\
\hline Njangsa & 58 & 27 & 6 & 65 & 31 & 6 & 5 & 0 & 0 & 43 & 19 & 3 \\
\hline Raffia & 63 & 6 & 1 & 58 & 5 & 1 & 5 & 0 & 0 & 42 & 3 & 1 \\
\hline Bitter kola & 47 & 13 & 3 & 48 & 13 & 4 & 13 & 4 & 2 & 36 & 10 & 2 \\
\hline Country onion & 26 & 8 & 3 & 20 & 19 & 11 & 5 & 1 & 1 & 17 & 9 & 4 \\
\hline Kola & 40 & 3 & 1 & 53 & 5 & 1 & 8 & 1 & 1 & 16 & 3 & 1 \\
\hline Bush pepper & 18 & 1 & 1 & 15 & 3 & 2 & 3 & 0 & 0 & 12 & 2 & 1 \\
\hline Bitter mango & 32 & 19 & 5 & 5 & 2 & 1 & - & & & 12 & 7 & 2 \\
\hline Various spices & 26 & 3 & 1 & 5 & 1 & 1 & - & & & 10 & 1 & 0 \\
\hline Eru & 24 & 5 & 3 & 3 & 0 & 0 & - & & & 9 & 2 & 1 \\
\hline Shea nut & 18 & 3 & 2 & 5 & 1 & 1 & - & & & 8 & 1 & 1 \\
\hline Njabe & 16 & 2 & 1 & 5 & 0 & 0 & - & & & 7 & 1 & 0 \\
\hline Bamboo & 5 & 1 & 1 & 3 & 0 & 0 & - & & & 3 & 0 & 0 \\
\hline TOTAL & 97 & 197 & 25 & 100 & 158 & 18 & 70 & 48 & 15 & 89 & 133 & 13 \\
\hline
\end{tabular}

$\begin{array}{lllllllllllll}\text { Input expenses } & 61 & 3 & 1 & 60 & 3 & 1 & 13 & 1 & 0 & 25 & 2 & 0\end{array}$

Table S6.12 - Mean cash and in-kind components of the three most sold NTFPs in three landscape types in FCFA.

\begin{tabular}{llrrrrrrrr}
\hline \multirow{2}{*}{ NTFP } & Income & \multicolumn{2}{c}{ KNP } & \multicolumn{2}{c}{ AFM } & \multicolumn{2}{c}{ OPP } & \multicolumn{3}{c}{ Total } \\
\cline { 3 - 10 } & type & mean & SE & mean & SE & mean & \multicolumn{1}{c}{ SE } & \multicolumn{1}{c}{ mean } & SE \\
\hline \multirow{2}{*}{ Bush mango } & in-kind & 9,900 & 2,578 & 7,725 & 1,592 & 1,120 & 694 & 6,186 & 1,066 \\
& cash & 81,008 & 9,289 & 53,438 & 8,320 & 8,175 & 4,743 & 46,973 & 5,179 \\
\multirow{2}{*}{ Njangsa } & in-kind & 4,513 & 1,182 & 6,375 & 1,258 & 100 & 100 & 3,648 & 618 \\
& cash & 22,671 & 5,546 & 24,325 & 5,868 & 100 & 100 & 15,581 & 2,842 \\
\multirow{3}{*}{ Snails } & in-kind & 6,829 & 1,603 & 6,388 & 1,262 & 21,908 & 7,408 & 11,791 & 2,663 \\
& cash & 1,184 & 873 & 4,700 & 3,406 & 9,273 & 4,705 & 5,118 & 1,996 \\
\hline
\end{tabular}

Table S6.13 - Mean annual income of men and women in three landscape types in FCFA.

\begin{tabular}{lrrrr}
\hline & KNP & AFM & OPP & \multicolumn{1}{c}{ Total } \\
\hline Annual income of men (FCFA) & & & & \\
mean & $1,336,638$ & 981,819 & $1,329,625$ & $1,222,503$ \\
$\mathrm{SE}$ & 107,018 & 188,951 & 130,654 & 100,905 \\
$\mathrm{n}$ & 34 & 27 & 32 & 93 \\
Annual income of women (FCFA) & & & & \\
mean & 623,047 & 829,728 & 662,514 & 712,713 \\
$\mathrm{SE}$ & 54,627 & 62,647 & 61,171 & 35,670 \\
$\mathrm{n}$ & 30 & 35 & 28 & 93 \\
\hline
\end{tabular}


Table S6.14 - Mean total household expenditure according to expenditure categories in three landscape types.

\begin{tabular}{|c|c|c|c|c|c|c|c|c|c|c|c|c|}
\hline & \multicolumn{3}{|c|}{ KNP } & \multicolumn{3}{|c|}{ AFM } & \multicolumn{3}{|c|}{ OPP } & \multicolumn{3}{|c|}{ Total } \\
\hline & \multirow{2}{*}{$\begin{array}{l}\mathrm{HH} \\
\text { [\%] }\end{array}$} & \multicolumn{2}{|c|}{ Expenditure } & \multirow{2}{*}{$\begin{array}{l}\mathrm{HH} \\
\text { [\%] }\end{array}$} & \multicolumn{2}{|c|}{ Expenditure } & \multirow{2}{*}{$\begin{array}{l}\mathrm{HH} \\
{[\%]}\end{array}$} & \multicolumn{2}{|c|}{ Expenditure } & \multirow{2}{*}{$\begin{array}{l}\mathrm{HH} \\
{[\%]}\end{array}$} & \multicolumn{2}{|c|}{ Expenditure } \\
\hline & & mean & SE & & mean & SE & & mean & SE & & mean & SE \\
\hline Food & 100 & 199 & 20 & 100 & 237 & 17 & 100 & 403 & 22 & 100 & 281 & 24 \\
\hline essential & 100 & 131 & 15 & 100 & 145 & 11 & 100 & 227 & 13 & 100 & 168 & 15 \\
\hline diversifying & 95 & 41 & 6 & 100 & 67 & 7 & 100 & 110 & 9 & 98 & 73 & 9 \\
\hline dispensable & 79 & 27 & 5 & 88 & 26 & 5 & 100 & 66 & 6 & 89 & 40 & 6 \\
\hline Consumer goods & 100 & 201 & 21 & 100 & 163 & 28 & 100 & 220 & 21 & 100 & 195 & 24 \\
\hline essential & 100 & 97 & 7 & 100 & 88 & 5 & 100 & 46 & 4 & 100 & 77 & 6 \\
\hline diversifying & 87 & 61 & 9 & 98 & 39 & 9 & 100 & 101 & 13 & 94 & 67 & 11 \\
\hline dispensable & 68 & 42 & 12 & 70 & 36 & 19 & 100 & 73 & 10 & 79 & 51 & 14 \\
\hline Education & 81 & 137 & 21 & 85 & 135 & 27 & 83 & 137 & 21 & 83 & 136 & 23 \\
\hline school fees & 79 & 56 & 10 & 80 & 75 & 21 & 83 & 71 & 12 & 83 & 68 & 15 \\
\hline equipment & 76 & 34 & 5 & 75 & 28 & 5 & 65 & 30 & 5 & 72 & 30 & 5 \\
\hline rent & 45 & 22 & 5 & 25 & 10 & 4 & 20 & 10 & 4 & 90 & 14 & 5 \\
\hline feeding & 45 & 25 & 6 & 43 & 23 & 6 & 48 & 26 & 6 & 45 & 24 & 6 \\
\hline Alcohol & 95 & 139 & 20 & 85 & 81 & 14 & 90 & 139 & 28 & 90 & 119 & 22 \\
\hline Cigarettes & 24 & 11 & 5 & 20 & 13 & 6 & 33 & 15 & 5 & 26 & 13 & 5 \\
\hline Transport & 92 & 105 & 21 & 95 & 76 & 11 & 98 & 97 & 12 & 95 & 93 & 15 \\
\hline irregular/long & 71 & 74 & 15 & 55 & 36 & 10 & 88 & 61 & 10 & 71 & 56 & 12 \\
\hline regular/short & 53 & 32 & 9 & 90 & 42 & 6 & 80 & 37 & 6 & 74 & 37 & 7 \\
\hline Luxury goods & 87 & 47 & 7 & 80 & 40 & 15 & 93 & 58 & 12 & 87 & 48 & 12 \\
\hline Health & 90 & 50 & 9 & 93 & 50 & 10 & 95 & 42 & 8 & 93 & 47 & 9 \\
\hline Housing & 63 & 17 & 4 & 45 & 64 & 21 & 40 & 28 & 11 & 49 & 37 & 14 \\
\hline rent & 8 & 2 & 1 & 5 & 1 & 1 & 3 & 1 & 1 & 5 & 1 & 1 \\
\hline building & 61 & 13 & 3 & 43 & 62 & 21 & 33 & 21 & 10 & 46 & 33 & 14 \\
\hline land & 3 & 1 & 1 & - & & & 10 & 6 & 4 & 4 & 2 & 2 \\
\hline Other & 100 & 108 & 22 & 98 & 68 & 17 & 100 & 140 & 20 & 99 & 105 & 20 \\
\hline village, family & 100 & 95 & 22 & 90 & 49 & 15 & 98 & 111 & 18 & 96 & 85 & 19 \\
\hline church & 79 & 5 & 1 & 85 & 9 & 1 & 83 & 9 & 2 & 82 & 8 & 1 \\
\hline other & 71 & 8 & 2 & 70 & 10 & 2 & 93 & 20 & 6 & 78 & 13 & 4 \\
\hline TOTAL & 100 & 1078 & 95 & 100 & 985 & 116 & 100 & 1335 & 109 & 100 & 1134 & 105 \\
\hline
\end{tabular}


CHAPTER 6 


\section{Chapter 7 \\ The effects of road access on income generation. Evidence from an integrated conservation and development project in Cameroon}

\section{Publication}

Ina-Kathrin Spey, Denis Kupsch, Kadiri Serge Bobo, Matthias Waltert and Stefan Schwarze, 2019, Sustainability 11: 3368 . https://doi.org/10.3390/su11123368

\subsection{Abstract}

Many integrated conservation and development projects use road construction to induce a shift in income activities, since road access can reduce both poverty and environmental degradation. There is, however, little empirical evidence on the effects of road access on income patterns. We contribute to existing literature by analyzing the effects of road access on income activity choice in Korup National Park, Cameroon using a difference-in-difference approach. Road access led to a rise in total household income by $38 \%$ due to higher household participation in self-employment and wage labor. We neither found an effect on income from crop farming nor on participation in hunting activities. The effects of road access can be diverse and unforeseeable. Road construction in protected areas should thus be carefully considered and planned and only be implemented when other options are not feasible.

\subsection{Introduction}

In accordance with the Sustainable Development Goals of the United Nations, the need for infrastructure in developing regions and its positive effect on poverty reduction has been widely accepted (Gibson and Rozelle 2002, Warr 2008, Warr 2010). Among others, roads enable access to public services and institutions, providing connection and simplifying transport (Hine et al. 2014). In the past, studies have focused on highlighting these positive effects of road access on poverty alleviation and livelihoods by reducing travel time and costs, as well as creating job opportunities and establishing better access to local markets, which in turn increase agricultural production and household income (Gibson and Rozelle 2002, Warr 2008, Warr 2010, Gockowski and Dury 1999, Porter 2014, Charlery et al. 2016a,b). Additionally, local communities profit from employment during construction and better access to public services, like hospitals and schools (Hine et al. 2014).

In Western Africa, where commercial bushmeat hunting remains one of the main conservation challenges (Lindsey et al. 2012), road access is also suggested to induce a shift in primary 
occupation from hunting to farming (Willcox and Nambu 2007). Indeed, others found hunting effort to be a negative function of farming effort and likely to decline if agricultural production increases (Shively 1997, Johannesen 2004). In West Africa, many integrated conservation and development projects (ICDP), which aim to promote conservation in a way that reduces poverty and use poverty reduction as a tool to enhance conservation (Roe and Elliott 2006), failed to substitute poaching as a very lucrative income source with alternatives, such as cash-crop farming or livestock keeping (Amadi 1993, Wicander and Coad 2014). Improving road access may serve as a key instrument in ICDPs, since it fosters agricultural production and in turn combats both poverty and wildlife decline. However, information on the effects of road access on income activity patterns as well as the effectiveness of ICDPs in general remains limited (Wicander and Coad 2014).

Here, we present a case study from Southwest Cameroon, where the construction of unpaved motorbike roads in the context of an ICDP has been used to facilitate the marketing of crops such as cocoa, plantain, and cassava and, therefore, promote crop farming and reduce hunting (Amadi 1993, Nana et al. 2014). Acknowledging that there are many other adverse effects of roads on biodiversity, such as deforestation (Barber et al. 2014), fragmentation (Newman et al. 2014), genetic degradation (Forman and Alexander 1998), and wildlife collisions (Bruinderink and Hazebroek 1996), we want to focus this study on the impact of road access on income patterns of rural communities, which indirectly affect biodiversity.

Taking the case of an ICDP in Southwest Cameroon, we aim to identify the causal effects of road access on income activities. We hypothesized that total household income will increase in response to road access due to higher crop sales and new job opportunities. In consequence, we expected a negative impact of road access on income from hunting. We further enrich these quantitative findings by the perceptions of rural households concerning the effects of improved road access on village life.

\subsection{Materials and methods}

Study area

Korup National Park (KNP), located in the Southwest Region of Cameroon ( $4^{\circ} 53^{\prime} \mathrm{N}$ to $5^{\circ} 27^{\prime} \mathrm{N}$ and $8^{\circ} 43^{\prime} \mathrm{E}$ to $9^{\circ} 15^{\prime} \mathrm{E}$ ), is part of the largest continuous forest block in West Africa, the CrossSanaga-Bioko coastal forests. Its $1,260 \mathrm{~km}^{2}$ range is dominated by an intact and diverse lowland rainforest and offsets of the Cameroonian mountain line (MINFOF 2017). KNP is part of the Gulf of Guinea Biodiversity Hotspot, harboring a rich fish, insect, bird, and herpetofaunal species pool (Oates et al. 2004). The Korup region is also home of more than 160 mammal species, many of which are endangered due to commercial hunting, such as the African forest elephant, Elliot's chimpanzee, and the Mainland drill. There are five isolated villages located 
within the park (Fig. 7.1), which are part of an ICDP, aiming, amongst others, to reduce hunting pressure using a variety of incentives and agreements. Out of these, one incentive entailed firsttime road access for the park villages Erat and Esukutan (in March 2015 and April 2015, respectively). The new motorbike roads are dirt roads constructed along former foot tracks with small-sized culverts for drainage, preventing the passage of cars. The motorbike roads allow transport of heavy cargo, while they reduce travelling time to the nearest regional markets from four to two hours for Mundemba and three to one hour for Babi (Oben et al. 2013, Fig. 7.1).

Ikenge village, which is situated within the same natural environment as the road villages, providing similar conditions for crop farming, hunting, and collecting forest products, served as a control site for this study. As it can only be reached by foot, spending at least three hours to get to the next neighboring village, we considered Ikenge as not affected by the road. The other two remaining villages in the park were excluded from the study because of their small size.

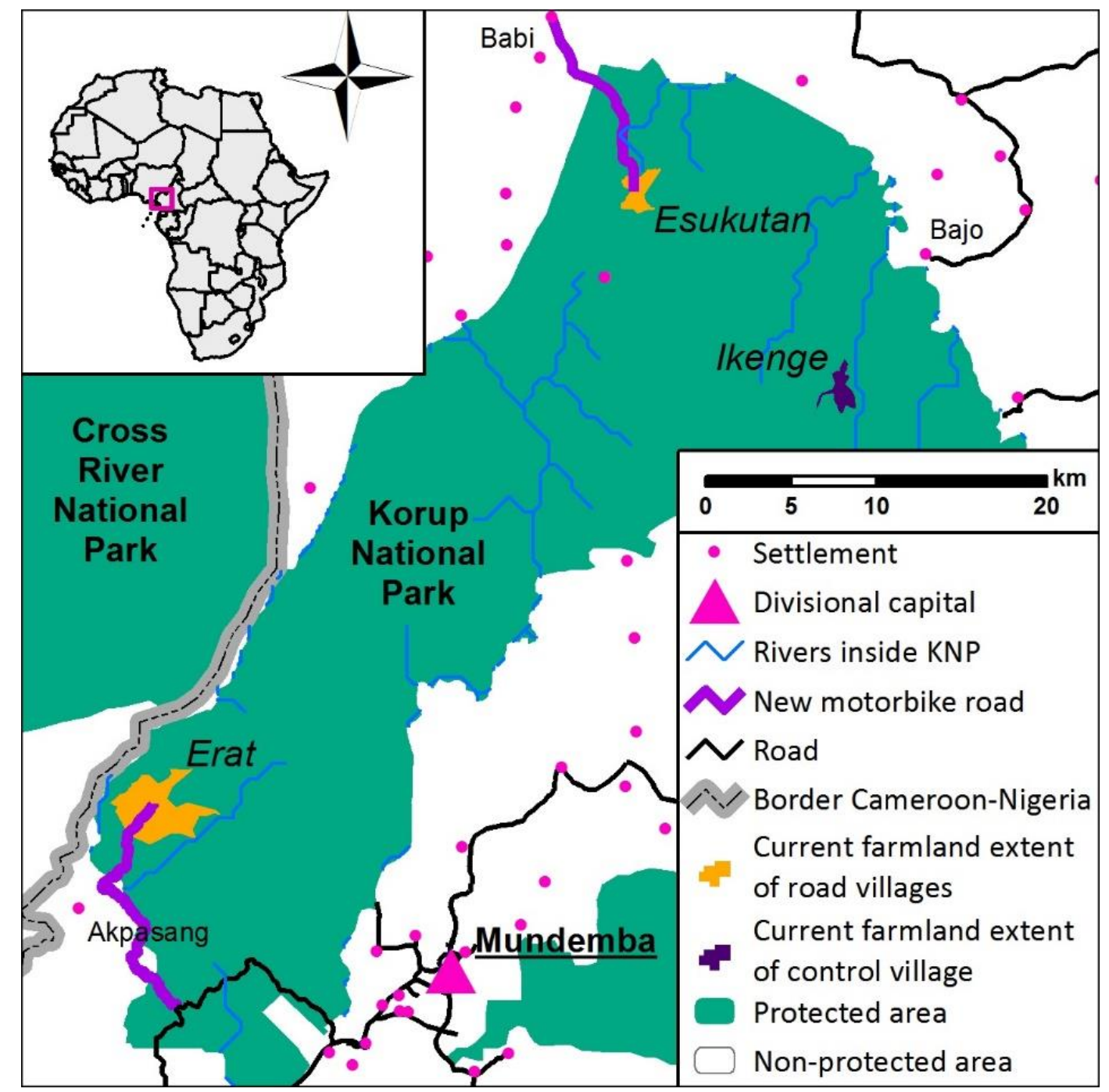

Figure 7.1 - Study area in Korup National Park, Cameroon with the road villages (Erat and Esukutan) and control village (Ikenge) and their farmland extent in 2016, as well as the new motorbike roads (thick purple lines) connecting to the road network. 


\section{Data collection}

We conducted structured interviews on quantitative household data in Erat, Esukutan, and Ikenge prior to (March and April 2015) and post-road construction (April and May 2016). Though the members of the survey team changed from 2015 to 2016, the local assistant and translator, the sampling protocol, and the questionnaire sheet remained the same. In 2016 only, we used a box questionnaire, open as well as with questions with item-specific response options in road villages to support and describe quantitative survey results. We organized box questionnaires to ascertain that the household selection for interviews was representative, as direct questions on sensitive topics, such as illegal activities (i.e., poaching), are likely to result in biased data (Tourangeau and Yan 2007, Tsuchiya et al. 2007, Nuno and John 2015). All inhabitants were invited to fill out a short anonymous questionnaire. Sheets were thrown into a cardboard box. Questionnaires were filled out prior to the actual interviews and generated 95 completed sheets in Erat and 92 in Esukutan. Similar income source distributions between face to face interviews and box questionnaires were found $\left(X^{2}=20, d f=16, p=0.2202\right.$; Table S7.1). In both years, sample households were drawn randomly based on census lists received from local authorities. Since income-generating activities of men and women differed in the study region and contribution to household income was not equal, the household head and his/her spouse were interviewed separately, and data pooled subsequently (Oben et al. 2013, Serges and Zachary 2013, Oben et al. 2014). All interviews were conducted face to face with only the respondent, interviewer, and translator present.

Each interview consisted of three sections and lasted between one and a half to two hours. Section one covered household demographics. Section two encompassed the main part of the survey. Here, we collected data about household income by requesting detailed information on inputs, outputs, and prices for different income sources as well as expenditures for the last 12 months. Income and expenses were recorded in local currency (CFA Franc CFAF). The third section of the survey only addressed households in road villages after road construction. It consisted of open-ended questions as well as questions with item-specific response options (Saris et al. 2010), regarding attitudes towards the new road, farming, and poaching.

All interview sheets were reviewed during the survey and households revisited if data were unclear, inaccurate or incomplete. We revised or eliminated interview sheets when either the sum of all income data exceeded $150 \%$ of total expenses and vice versa, or the interviewee did obviously withhold information, such as income from poaching activities. Accordingly, data from 30 households in $2015\left(n_{\text {road }}=20, n_{\text {control }}=10\right)$ and from 68 households in 2016 $\left(n_{\text {road }}=51, n_{\text {control }}=17\right)$ with similar household demographics (Table S7.2) was analyzed. 


\section{Data analysis}

We considered income as the sum of cash income plus the market value of produced but selfconsumed goods, minus all expenditures for inputs such as pesticides and hired labor. Labor provided by household members was hereby not considered (Angelsen and Lund 2011). We distinguished between six major income sources (Table 7.1). Income from self-employment and wage labor (SEW) was combined because engagement was often short-dated or undefined and could not be allocated to one or the other category (e.g., irregular paid work on farm, employed teacher with irregular payment). Changes in income between the survey years were tested in the road villages and control village, respectively, using Mann-Whitney U tests (MWU). For the econometric analyses, total income, crop income, NTFP income (income from non-timber forest products), and income from fishing were log transformed due to non-normal distributions (Mincer 1958, Mandelbrot and Hudson 2005). SEW income, hunting income, and income from livestock were zero inflated and therefore transformed to binary variables $(0,1)$. Statistical analysis was carried out in R version 3.3.2 (R Core Team 2015).

Table 7.1 - Description of income sources

\begin{tabular}{lll}
\hline Income Source & Description & Potential Inputs \\
\hline Crop income & Net income from cash and food crops & $\begin{array}{l}\text { Seeds, seedlings, chemicals, } \\
\text { processing, transport, and } \\
\text { hired labor }\end{array}$ \\
$\begin{array}{l}\text { Non-timber forest } \\
\text { product (NTFP) income }\end{array}$ & $\begin{array}{l}\text { Net income from plant material collected in the } \\
\text { forest excluding values for wooden goods such as } \\
\text { timber, firewood etc. }\end{array}$ & $\begin{array}{l}\text { Baskets and bags for } \\
\text { collection }\end{array}$ \\
Hunting income & $\begin{array}{l}\text { Net income from hunting and trapping including } \\
\text { revenues from bushmeat, skins, bones, and } \\
\text { feathers }\end{array}$ & Gun, dog, cartridges, wire \\
Self-employment and & $\begin{array}{l}\text { Net income from wage labor (e.g., teacher) and } \\
\text { from self-employment other than own farm work } \\
\text { income }\end{array}$ & Porter, transport, goods \\
(e.g., shop owner, motorbike driver) & $\begin{array}{l}\text { Net income from freshwater catch using fishing } \\
\text { baskets, crossing net, crossing hook, hooking or }\end{array}$ & Nets, hooks, lines \\
flying hook & $\begin{array}{l}\text { Net income from farm animals and their products } \\
\text { such as eggs }\end{array}$ & $\begin{array}{l}\text { Animals purchased, } \\
\text { material, feed }\end{array}$ \\
\hline Livestock income & $\begin{array}{l}\text { Net total household income calculated as the sum } \\
\text { of crop, NTFP, hunting, SEW, fishing and livestock } \\
\text { income }\end{array}$ & Sum of all inputs \\
\hline
\end{tabular}

We tested the effect of road access on total income and income composition using the difference-in-difference (DD) approach. It measures an impact by comparing a treatment and control group with respect to heterogeneity and changes over time. DD allows unobserved 
heterogeneity but assumes that this is time-invariant. By collecting data of a control and treatment group, before and after the treatment, this heterogeneity can be differenced out (Khandker et al. 2010). The underlying estimation equation (Eq. 7.1) for the outcome variable is (Meyer 1995):

Eq. (7.1) $\quad Y_{i t}^{j}=\alpha+\alpha_{1} d_{t}+\alpha^{1} d^{j}+\beta d_{t}^{j}+\epsilon_{i t}^{j}$

where $Y_{\mathrm{i} t}$ is the outcome variable for household $\mathrm{i}, d_{t}$ is a dummy variable for time $\left(d_{t}=1\right.$ for 2016 and zero for 2015), $d^{j}$ is a dummy variable for treatment status ( $d^{j}=1$ for all households living in villages with road access and zero otherwise), and $d_{t}^{j}$ is an interaction term between time and treatment. The coefficient $\beta$ captures the effect of the treatment on the outcome for the treatment group, while $\alpha^{1}$ controls for the difference within the control group before and after the treatment. $\epsilon^{j}$ is a vector of time-variant variables, which might have an impact on the outcome variable as well.

Applying DD estimation, the effect of road connection was tested on total income and all six major income sources (Table 7.1). As mentioned above, DD controls for time-invariant unobserved heterogeneity, i.e., that other covariates do not change across the years. If those variables, however, vary over time, they need to be controlled for in the regression model to get the net effect of improved road access on the outcome. We hence extended the regression model by including other covariates that may affect the outcome. The selection of covariates was based on a previous study (Charlery et al. 2016). Multicollinearity was identified using Spearman rank tests and the generalized variance inflation factors (GVIF; Fox and Monette 1992). GVIF was used because there were categorical and dummy variables in the model. We defined moderate correlations at $G V I F>5$ and strong correlations at $G V I F>10$ and $\rho>0.7$ (rhô, a measure of correlation strength; Fox and Monette 1992, O'brien 2007, Hair et al. 2014, Dormann et al. 2013). Since the interaction term of treated and time constitutes the heart of a DD analysis, it was kept despite a moderate GVIF value (Khandker et al. 2010). Model selection was based on selective stepwise backward regressions, impact of road connection (that is, the respective $p$-value) and ranked adjusted $\mathrm{R}$ square values (Khandker et al. 2010). Covariates of the final models can be found in Table 7.2.

Furthermore, we tested the effect of road access on total income of different wealth groups. Therefore, we divided the dataset into two income categories ( $\mathrm{I}$ = 'below median total income' and II = 'above median total income') using the median of total income as the threshold value and repeated DD estimations. 
Table 7.2 - Covariates used in difference-in-difference (DD) analysis, HH: Household, NTFP: Non-timber forest products, SEW: Self-employment and wage labor.

Income Sources

\begin{tabular}{|c|c|c|c|c|c|c|c|}
\hline Covariates & 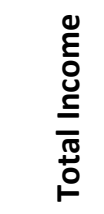 & 인 & 品 & 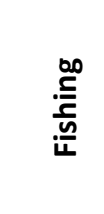 & 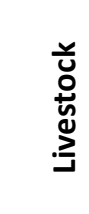 & 蛋 & 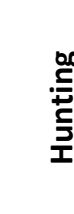 \\
\hline Age of HH head & $x$ & $x$ & $x$ & & $x$ & $x$ & \\
\hline $\mathrm{HH}$ head born in village & $x$ & $x$ & & $x$ & & & $x$ \\
\hline $\mathrm{HH}$ head is female & $x$ & $x$ & $x$ & $\mathrm{x}$ & & & $x$ \\
\hline $\mathrm{HH}$ head is married & $x$ & $x$ & $x$ & $x$ & & & \\
\hline No. of children in $\mathrm{HH}$ & $x$ & & $x$ & $x$ & $x$ & & \\
\hline No. of adult men in $\mathrm{HH}$ & $x$ & & $x$ & & $x$ & & $x$ \\
\hline No. of elders in $\mathrm{HH}$ & & & & $\mathrm{x}$ & $x$ & $x$ & $x$ \\
\hline No. of adult females in $\mathrm{HH}$ & & & & $x$ & $x$ & & \\
\hline Hunting carried out in $\mathrm{HH}$ & $x$ & & & & & & \\
\hline
\end{tabular}

Following the idea of the qualitative content analysis in Mayring (1991), responses from openended and focus group questions were first paraphrased, then generalized, and finally reduced to their central statements. All data on behavior change and attitude towards the road were analyzed using frequency analysis.

\subsection{Results}

Descriptive analysis of household incomes

The main income source in road villages was crop farming, followed by hunting, collection of NTFP, fishing, SEW, and livestock keeping (Fig. 7.2) before the road opening. With road access, income from crop farming (MWU, $U=321, p=0.015$ ) and SEW was significantly higher (MWU, $U=351, p=0.038$ ); the latter was even higher than income from fishing. In the control village, hunting income was the main income source in 2015 but significantly dropped in 2016 (MWU, $\mathrm{U}=136, p=0.001$ ). Further, income from livestock breeding (MWU, $U=140$, $p=0.005$ ) significantly decreased. Even though SEW increased significantly (MWU, $U=118$, $p=0.094$ ) total income decreased significantly (MWU, $U=124, p=0.052$ ). 


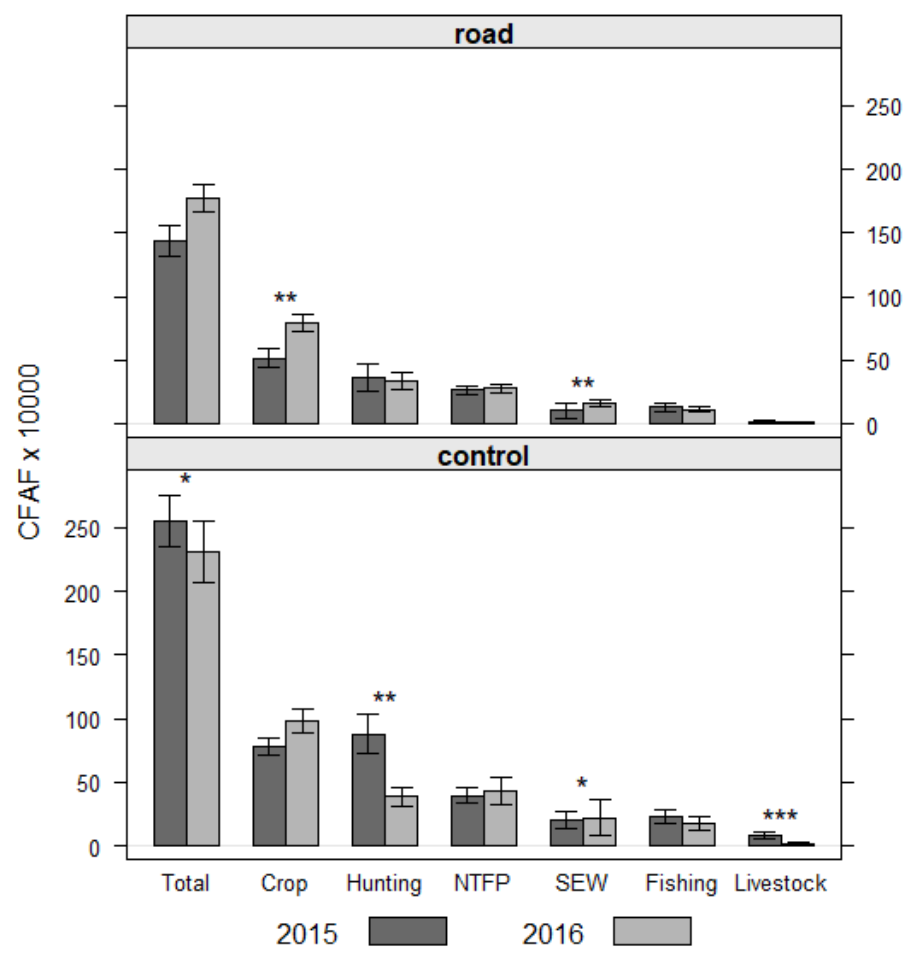

Figure 7.2 - Income (CFAF x 10000) before (2015) and after (2016) road access in road and control villages. NTFP: Non-timber forest products, SEW: Self-employment and wage labor. Significant Mann-Whitney U test results are presented as $* * * p<0.01$; ** $p<0.05$; $*<<0.1$.

\section{Impact analysis of road access on household incomes}

The results of the DD models indicate that road connectivity led to an increase in total income by 38\% (Table 7.3). When looking at the different income sources, we found that road access had a positive effect on the participation of households in self-employment and wage labor, which increased by $63 \%$ (Table 7.4). All other income activities were not affected (Tables 7.3, 7.4). Road connectivity lead to a significant increase in total income of 'above median income' households by $33 \%$ but had no significant impact on the income of 'below median income' households (Table 7.3). 
Table 7.3 - Impact of road access on logarithmized incomes. HH: Household, DD: Difference-in-difference, NTFP: Non-timber forest products, SEW: Self-employment and wage labor. Standard errors given in parentheses. *, **, and $* * *$ indicate significance at $10 \%, 5 \%$, and $1 \%$ levels, respectively.

\begin{tabular}{|c|c|c|c|c|c|c|c|}
\hline & \multicolumn{3}{|c|}{$\begin{array}{l}\text { Control Village } \\
{[1,000 \text { CFAF }]}\end{array}$} & \multicolumn{3}{|c|}{$\begin{array}{l}\text { Road Villages } \\
{[1,000 \text { CFAF }]}\end{array}$} & \multirow[t]{2}{*}{ DD results } \\
\hline & 2015 & 2016 & Diff & 2015 & 2016 & Diff & \\
\hline Crop income & $781(66)$ & $982(94)$ & 201 & $514(71)$ & 794 (64) & 280 & $0.222(0.365)$ \\
\hline NTFP income & $396(60)$ & 435 (105) & 38 & 264 (39) & $280(36)$ & 16 & $-0.652(1.187)$ \\
\hline Fishing income & $228(54)$ & $173(50)$ & -55 & $131(31)$ & $115(22)$ & -16 & $0.481(1.600)$ \\
\hline Tot. income all HH & $2,552(196)$ & $2,307(231)$ & -245 & $1,437(119)$ & $1,774(109)$ & 336 & $0.381^{* *}(0.178)$ \\
\hline $\begin{array}{l}\text { Tot. income below } \\
\text { median } \mathrm{HH}\end{array}$ & $835(-)$ & 1,610 (119) & 774 & $1,147(90)$ & $1,258(86)$ & 111 & $-0.224(0.401)$ \\
\hline $\begin{array}{l}\text { Tot. income above } \\
\text { median } \mathrm{HH}\end{array}$ & $2,743(89)$ & $2,597(297)$ & -145 & $2,116(88)$ & $2,454(164)$ & 338 & $0.330 * *(0.141)$ \\
\hline
\end{tabular}

Table 7.4 - Impact of road access on participation in self-employment and wage labor (SEW), hunting, and livestock keeping. Standard errors given in parentheses. *,**, and *** indicate significance at $10 \%, 5 \%$, and $1 \%$ levels, respectively.

\begin{tabular}{lrrrrrrrr}
\hline & \multicolumn{2}{c}{ Control village [\%] } & \multicolumn{2}{c}{ Road villages [\%] } & \multicolumn{2}{c}{ DD results (\%) } \\
& 2015 & $\mathbf{2 0 1 6}$ & Diff & 2015 & $\mathbf{2 0 1 6}$ & Diff & \\
\hline SEW participation & $100(0)$ & $59(12.3)$ & -41 & $50(11.5)$ & $75(6.2)$ & 25 & $63.4^{* * *}(21.0)$ \\
\hline Hunting participation & $80(13.3)$ & $82(9.5)$ & -2 & $80(9.2)$ & $75(6.2)$ & -15 & $-12.5(17.5)$ \\
Livestock participation & $100(0)$ & $82(9.5)$ & -18 & $80(9.2)$ & $57(7.0)$ & -23 & $24.7(22.5)$ \\
\hline
\end{tabular}

\section{Perception of road impacts}

In addition to the quantitative results concerning the income effects of improved road access presented above, we also asked the respondents in the road villages about their perceptions regarding the influence of improved road access. According to them, the road had positive effects on vending outside (48\%) and inside the village (59\%), of which the latter could be attributed particularly to an increased number of customers. The number of visitors (85\%) and vendors (75\%) also increased in the village. Bushmeat sales, on the other hand, decreased (37\%) or stayed the same (34\%) following road construction. Most respondents stated that their crop sales stayed the same (55\%), yet some also reported an increase (31\%). Respondents agreed that transport costs were higher after road opening (69\%). It appears that hunting quantity was reduced $(73 \%)$ mainly due to fear of consequences $(34 \%)$ and alternative income sources (24\%). According to respondents, road access led to an increase in agricultural production (55\%), which could be attributed to simplified sales (21\%) and less hunting (11\%). Most respondents stated that income was positively affected (47\%) largely due to improved sales (28\%), while respondents who reported that income had been affected negatively (29\%) explained this with reduced hunting effort (35\%; Table 7.5). 
Table 7.5 - Perceptions of respondents regarding road effects in road villages.

\begin{tabular}{|c|c|c|c|c|}
\hline & $\begin{array}{l}\text { Decreasing } \\
\text { (n/\%) }\end{array}$ & $\begin{array}{l}\text { Same } \\
\text { (n/\%) }\end{array}$ & $\begin{array}{l}\text { Increasing } \\
\text { (n/\%) }\end{array}$ & $\begin{array}{c}\text { No response } \\
(\mathrm{n} / \%)\end{array}$ \\
\hline \multicolumn{5}{|l|}{ Sales } \\
\hline Sale in the village & $7(7)$ & $24(24)$ & $60(59)$ & $10(10)$ \\
\hline Sale outside the village & $2(4)$ & $15(30)$ & $24(48)$ & $9(18)$ \\
\hline Bushmeat sale & $37(37)$ & $34(34)$ & $8(8)$ & $22(22)$ \\
\hline Crop sale & $12(12)$ & $56(55)$ & $31(31)$ & $2(2)$ \\
\hline Transport costs & $19(19)$ & $9(9)$ & $70(69)$ & $3(3)$ \\
\hline \multicolumn{5}{|l|}{ Income generation } \\
\hline Hunting quantity & $74(73)$ & 19 (19) & $5(5)$ & $3(3)$ \\
\hline Fear of consequences & $25(34)$ & & & \\
\hline Alternative income sources & $18(24)$ & & & \\
\hline Other & $3(4)$ & & & \\
\hline No response & $28(38)$ & & & \\
\hline Agricultural production & $11(11)$ & $32(32)$ & $56(55)$ & $2(2)$ \\
\hline Simplified sales & & & $12(21)$ & \\
\hline Less/no hunting & & & $6(11)$ & \\
\hline $\begin{array}{l}\text { Farmland increase } \\
\text { (not because of the road) }\end{array}$ & & & $4(7)$ & \\
\hline No response & & & $34(61)$ & \\
\hline Total income & $29(29)$ & $22(22)$ & $47(47)$ & $3(3)$ \\
\hline Less/no hunting & $10(35)$ & & & \\
\hline Expensive transport & $2(7)$ & & & \\
\hline Economics (exchange rate, bad price for cocoa) & $2(7)$ & & & \\
\hline No response & $15(52)$ & & $27(57)$ & \\
\hline Improved sales & & & $13(28)$ & \\
\hline Employment at road construction site & & & $4(9)$ & \\
\hline More ambition & & & $3(6)$ & \\
\hline \multicolumn{5}{|l|}{ Arrival frequency in the village } \\
\hline Visitors & $7(7)$ & $6(6)$ & $86(85)$ & $2(2)$ \\
\hline Vendors & $8(8)$ & $14(14)$ & $76(75)$ & $3(3)$ \\
\hline
\end{tabular}

Nearly half of the respondents (45\%, Fig. 7.3) perceived behavioral changes in the villages, including less conflicts and violence, lifestyle improvement, decreased alcohol consumption, tidiness of the village, and more civilized behavior. About $15 \%$ of the respondents mentioned that the village had developed and that traveling and transportation had increased. Personally, most respondents intended to improve their income situation (45\%), mainly with business (57\%) and crop farming (24\%). Hunting to improve income was mentioned by just $2 \%$ of the respondents. Other intended personal changes included improving the housing situation (16\%) and a lifestyle change (16\%). Respondents described the latter as investing more into education, dressing differently, and becoming a 'town person'. 


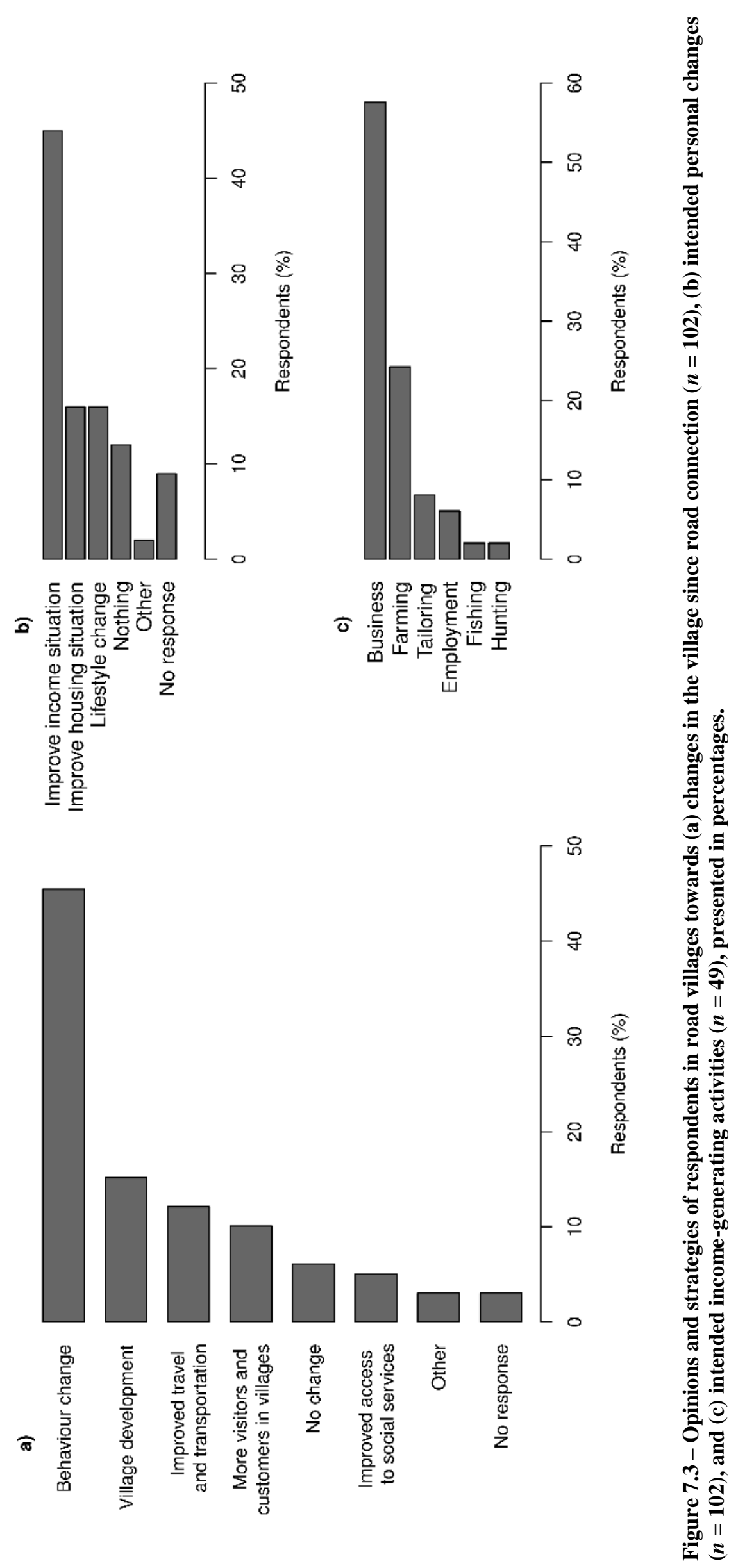




\subsection{Discussion}

In this study, we examined the effects of road access on the income structure of rural households and their perceptions concerning the effects on village life. Our results support the finding that livelihood of local people in KNP largely depends on crop farming, followed by hunting and income from NTFPs (Mbile et al. 2005, Wright and Priston 2010). Moreover, we found that total household income increased due to improved road access, which is in line with previous studies (Gibson and Rozelle 2002, Warr 2008, Warr 2010, Hine et al. 2014). However, 'below median income' households did not profit from road access. This could be due to lack of capital in combination with high transportation costs (Hettige 2006), preventing people from reacting on structural changes (i.e., road access) with an investment in their farms or opening of a business as well as gaining market access (Vasco and Sirén 2016). Even for nonbusiness travels, most households are now confronted with transportation costs, which were previously only paid when hiring porters. This is mainly because hiring a bike has become the modern way to travel, and people feel reluctant to walk.

We further found that the increase in total income can be attributed to a higher participation in household self-employment and wage labor. Our qualitative results suggest that the enhanced business activities are strongly related to a higher turnover rate in the village. Road access seems to establish new self-employment opportunities such as small shops. Traders, who buy products in neighboring Nigeria or nearby towns, are now using cheap transport to their villages, which creates higher profit margins. Furthermore, men with access to motorbikes offer transportation and delivery services. Women sell meals to visitors and vendors in the village. Many villagers declared their intentions to continue and extend such business activities. The qualitative results further suggest that wage employment has not improved. Overall, these findings show that the road not only opened new opportunities for villagers but also for people outside of KNP, which, on the downside, suggests growing human presence and activity in the protected area.

Crop income did not change in response to road access. This is not surprising, since the main cash crops in the area are tree crops, which need at least three years to reach maturity (Nalley et al. 2014). It seems to be beyond debate that road access can increase farming activities by enhancing access to fertilizers, speeding up transport of perishable products, and increasing transport capacities and better market access (Porter 2014, Laurance and Balmford 2013, Weng et al. 2013). Respondents confirmed that road access stimulated their farming activities to increase agricultural outputs and explained this trend with simplified sales. This is in line with findings of an earlier study in neighboring villages, which found a link between increased income and simplified product marketing and noted increased quantities of NTFP and agricultural products in response to primary road access (Nana et al. 2014). However, successful development of farming as an alternative income source to hunting will fail if wildlife-induced crop destruction re-increases hunting activities (Johannesen 2004, Barrett and Arcese 1998). 
Additional measures should thus include projects on mitigation of crop-raiding and human wildlife conflicts.

We also found that participation in hunting was not affected by road access. A reason for this result could be that giving up a major income source will only be manageable if alternative activities can yield similar income (Barrett and Arcese 1998). Many respondents mentioned that people who have mainly relied on hunting struggle to take up alternative activities due to a lack of necessary skills, tools, and capital. By ameliorating the income situation of only 'above median income' households, road access unfortunately seems to not reach this group. However, many respondents intended to decrease hunting output and effort as well as bushmeat sales, while only one respondent aimed at pursuing this activity, all of which point towards less hunting activities in the future. According to interview responses, this trend seems to primarily rely on enhanced law enforcement rather than alternative income sources. Apparently, the enhanced accessibility of eco guards reinforces the fear of legal consequences and thereby stalls hunting activities.

Nevertheless, in accordance with findings from Tanzania, our results suggest that reduced hunting efforts relate to an increase in agricultural production (Johannesen 2004). Moreover, several studies suggest a similar link to increased income from labor and self-employment (Vasco and Sirén 2016, Kümpel et al. 2010). An increased participation in self-employment activities within road villages may thus lead to reduced hunting in KNP (Knobloch 2016), which itself could be a consequence from time famine (Vasco and Sirén 2016). Fishing provides the main source of protein in Southern Cameroon, while bushmeat hunting serves primarily to generate income (Wright and Priston 2010). A decrease in hunting activities should thus not create a strong need for protein replacement, so fishing activities and livestock rearing are unlikely to be enhanced for this reason. Fishing, however, has the potential to become a lucrative business, as the fish can be caught and prepared in the village and sold for profit in town, while strenuous livestock production in the village cannot compete with mass-produced town meat. However, the short time span between road opening and data collection requires considering the results of this study as short-term effects, leaving the door open for consequences in the long-term.

Respondents' perceptions of changes in the village were primarily a reduction of conflicts and violence attributed to easier access of gendarmerie. Communities also reported a change in visitor fluctuation associated with a different presentation of the village and its inhabitants, including less alcohol consumption. Indeed, the road seems to provide possibilities for new and permanent constructions by facilitating transportation of large and heavy construction materials (such as cement). Respondents explained that access to hospitals stays limited, as transportation with motorbikes on dirt roads remains challenging for elderly and badly injured community members. Hence, many respondents suggested the construction of health centers inside the 
villages. Overall, road access appears to not only impact income distribution but also lifestyle and behavior of the forest communities and provides a stepping stone for village development.

\subsection{Conclusions}

Conflicts between local communities and national park management objectives often arise where villages are set within national park boundaries. This demands for solutions such as resettlements, compensations, alternative livelihood strategies or changed management approaches (Dudley 2008). In order to reduce negative anthropogenic effects on wildlife in the park, indigenous people in Korup National Park were successfully encouraged to leave the park through various measures, such as incentives, the implementation of new conservation policies or resettlements (Tiani and Diaw 2006, Siewe et al. 2017). However, experiences from resettling Ikondo Kondo I village, which was formerly situated inside Korup National Park, have shown that successful resettlements are difficult to realize since they require very careful planning and need to meet many prerequisites (Schmidt-Soltau 2003). Our results suggest that road access for villages in formerly remote areas, for which resettlement is not feasible, can lead to desired short-term shifts in income patterns in the framework of an ICDP. Connectivity provides new opportunities regarding income generation and village development and changes village life as well as individual behavior, especially for households with above median incomes. In KNP, road construction was the outcome of a long process included in a set of incentives to halt hunting activities (e.g., paid involvement in park activities, monetary incentives at community level, support of road maintenance), where a resettlement was not an option (MINFOF 2017, Linder 2008). Still, potential long-term consequences of road access, such as vehicle collisions (Bruinderink and Hazebroek 1996), fragmentation effects (Newman et al. 2014), increased pressure on wildlife, and open markets for species that were previously not hunted (Schmitt and Kramer 2010), also need to be taken into account in the decisionmaking process. Hence, we support other findings (Caro et al. 2014) that using road access as an incentive in biodiversity rich areas should be carefully considered and planned and only be implemented when other options (such as resettlements) are not feasible. We therefore conclude that road access can only approach sustainability of the desired effects if it (1) can meet the target group (below medium households, relying on hunting); (2) is embedded in a framework of good communication, support, education, alternative income sources, and incentives and (3) if possible adverse effects on wildlife are considered. 


\subsection{References}

Amadi, R.M., (1993). Harmony and conflict between NTFP use and conservation in Korup National Park. Rural Development Forestry Network. 15: 16-23.

Angelsen, A., and Lund, J.F., (2011). Designing the Household Questionnaire. In Measuring Livelihoods and Environmental Dependence: Methods for Research and Fieldwork. In: Larsen, H.O., Lund, J.F., Smith-Hall, C., and Wunder, S., (Eds.). CIFOR. Bogor, Indonesia. pp. 112-114.

Barber, C.P., Cochrane, M.A., Souza, C.M., and Laurance, W.F., (2014). Roads, Deforestation, and the Mitigating Effect of Protected Areas in the Amazon. Biological Conservation 177: 203-209.

Barrett, C.B., and Arcese, P., (1998). Wildlife Harvest in Integrated Conservation and Development Projects: Linking Harvest to Household Demand, Agricultural Production, and Environmental Shocks in the Serengeti. Land Economics 74: 449-465.

Bruinderink, G.W.T.A.G. and Hazebroek, E., (1996). Ungulate Traffic Collisions in Europe. Conservation Biology 10: 1059-1067.

Caro, T., Dobson, A., Marshall, A.J., and Peres. C.A., (2014). Compromise Solutions between Conservation and Road Building in the Tropics. Current Biology 24: 722-725.

Charlery, L.C., Nielsen, M.R., Meilby, H., and Smith-Hall, C., (2016). Effects of New Roads on Environmental Resource Use in the Central Himalaya. Sustainability 8: 363.

Charlery, L.C., Qaim, M., and Smith-Hall, C., (2016). Impact of Infrastructure on Rural Household Income and Inequality in Nepal. Journal of Development Efficiency 8: 266286.

Dormann, C.F., Elith, J., Bacher, S., Buchmann, C., Carl, G., et al., (2013). Collinearity: A Review of Methods to Deal with it and a Simulation Study Evaluating their Performance. Ecography 36: 27-46.

Dudley, N. (Ed., 2008). Guidelines for Applying Protected Area Management Categories. IUCN, Gland, Switzerland. pp. 16-17.

Forman, R.T.T., and Alexander, L.E., (1998). Roads and their Major Ecological Effects. Annual Review of Ecology and Systematics 29: 207-231.

Fox, J., and Monette, G. (1992). Generalized Collinearity Diagnostics. J. Am. Stat. Assoc. 87: $178-183$.

Gibson, J., and Rozelle, S., (2002). Poverty and Access to Infrastructure in Papua New Guinea. Working Paper. Department of Agriculture and Resource Economics, University of California: Davis, CA, USA. p. 2. 
Gockowski, J., and Dury, S., (1999). The Economics of Cocoa-Fruit Agroforests in Southern Cameroon. International Symposium Multi-strata Agroforestry Systems with Perennial Crops. pp. 239-241.

Hair, J.F., Black, W.C., Babin, B.J., and Anderson, R.E., (2014). Multivariate Data Analysis, 7th ed. Pearson Education, Upper Saddle River, NJ, USA. p. 200.

Hettige, H., (2006). When do Rural Roads Benefit the Poor and How? An In-Depth Analysis Based on Case Studies. Asian Development Bank, Hettige, Phillipines. pp. 30-51.

Hine, J., Abedin, M., Stevens, R., Airey, T., and Anderson, T., (2014). Does the Extension of the Rural Road Network Have a Positive Impact on Poverty Reduction and Resilience for the Rural Areas Served? If so How, and if Not Why Not? EPPI-Centre, Social Science Research Unit, Institute of Education, University of London. London, UK.

Johannesen, A.B., (2004). Wildlife Conservation Policies and Incentives to Hunt: An Empirical Analysis of Illegal Hunting in Western Serengeti, Tanzania. Environment and Development Economics 10: 271-292.

Khandker, S., Koolwal, G.B., and Samad, H., (2010). Handbook on Impact Evaluation: Quantitative Methods and Practices. World Bank Publications, Washington, DC, USA.

Knobloch, L., (2016). Gender, Livelihoods, and Employment in Industrial Oil Palm Plantations in Southwest Cameroon. Master thesis, Georg-August-Universität, Göttingen, Germany.

Kümpel, N.F., Milner-Gulland, E.J., Cowlishaw, G., and Rowcliffe, J.M., (2010). Incentives for Hunting: The Role of Bushmeat in the Household Economy in Rural Equatorial Guinea. Human Ecology 38: 251-264.

Laurance, W.F., and Balmford, A., (2013). A Global Map for Road Building. Nature 495: 308309.

Linder, J.M., (2008). The impact of hunting on primates in Korup National Park, Cameroon: Implications for Primate Conservation. Ph.D. thesis, The City University of New York, New York, USA.

Lindsey, P., Balme, G., Becker, M., Begg, C., Bento, C., et al. (2012). Illegal Hunting \& The Bushmeat Trade in Savanna Africa: Drivers, Impacts \& Solutions to Address the Problem. Wildlife Conservation Society Report. Panthera/Zoological Society of London, New York, NY, USA.

Mandelbrot, B., and Hudson, R.L., (2005). The Misbehavior of Markets: A Fractal View of Risk, Ruin and Reward. Basic Books, New York, NY, USA. pp. 155-167. 
Mayring, P., (1991). Qualitative Inhaltsanalyse. In Handbuch qualitative Forschung: Grundlagen, Konzepte, Methoden und Anwendungen. In: Flick, U., Kardoff, E.v., Keupp, H., Rosenstiel, L.v., and Wolff, S., (Eds.) Beltz- Psychologie Verl. Union, München, Germany. pp. 209-213.

Mbile, P., Vabi, M., Meboka, M., Okon, D., Arrey-Mbo, J., Nkongho, F., and Ebong, E., (2005). Linking Management and Livelihood in Environmental Conservation: Case of the Korup National Park Cameroon. Journal of Environmental Management 76: 1-13.

Meyer, B.D., (1995). Natural Quasi-Experiments in Economics. Journal of Business and Economic Statistics 13: 151-161.

Mincer, J., (1958). Investment in Human Capital and Personal Income Distribution. Journal of Political Economics 66: 281-302.

MINFOF (Ministry of Forestry and Wildlife, 2017). The Management Plan for Korup National Park and its Peripheral Zone 2017-2021. Ministry of Forestry and Wildlife, Buea, Cameroon.

Nalley, L.L., Dixon, B.L., and Popp, J.S., (2014). An Optimal Phased Replanting Approach for Cocoa Trees with Application to Ghana. Agricultural Economics 45. 291-302.

Nana, T., Cheumani, C., and Grandjean, L., (2014). Impact Assessment and Management of Motorbike Roads Inside National Parks and Around (Buffer Zone) in the South West Region of Cameroon. Eco Consult for GIZ, Deutsche Gesellschaft für Internationale Zusammenarbeit (GIZ) GmbH, Bonn, Germany.

Newman, M.E., McLaren, K.P., and Wilson, B.S., (2014). Assessing Deforestation and Fragmentation in a Tropical Moist Forest over 68 Years; The Impact of Roads and Legal Protection in the Cockpit Country, Jamaica. Forest Ecology and Management 315: 138152.

Nuno, A., and John, F.A.V.S., (2015). How to ask sensitive questions in conservation: A review of specialized questioning techniques. Biological Conservation 189: 5-15.

Oates, J.F., Bergl, R.A., and Linder, J.M., (2004). Africa's Gulf of Guinea Forests: Biodiversity Patterns and Conservation Priorities. In Advances in Applied Biodiversity Science. Conservation International, Washington, DC, USA. Number 6.

Oben, D., Zachary, I., and Edward, E., (2013). Korup National Park-Agro-Socio-Ecological Assessment Report for Esukutan. Ministry of Forestry and Wildlife, Buea, Cameroon.

Oben, D., Zachary, I., and Sumbede, S., (2014). Korup National Park-Agro-Socio-Ecological Assessment Report for Ikenge Village. Ministry of Forestry and Wildlife, Buea, Cameroon. 
O’brien, R.M., (2007). A Caution Regarding Rules of Thumb for Variance Inflation Factors. Quality and Quantity 41: 673-690.

Porter, G., (2014). Transport Services and their Impact on Poverty and Growth in Rural SubSaharan Africa: A Review of Recent Research and Future Research Needs. Transport Reviews 34: 25-45.

R Core Team (2015). R: A Language and Environment for Statistical Computing; R Foundation for Statistical Computing, Vienna, Austria.

Roe, D., and Elliott, J., (2006). Pro-poor Conservation: The Elusive Win-Win for Conservation and Poverty Reduction. Policy Matters 14: 53-63.

Saris, W., Revilla, M., Krosnick, J.A., and Shaeffer, E.M., (2010). Comparing Questions with Agree/Disagree Response Options to Questions with Item-Specific Response Options. Survey Research Methods 4: 61-79.

Schmidt-Soltau, K., (2003). Conservation-related Resettlement in Central Africa: Environmental and Social Risks. Development and Change 34: 525-551.

Schmitt, K.M., and Kramer, D.B., (2010). Road Development and Market Access on Nicaragua's Atlantic coast: Implications for Household Fishing and Farming Practices. Environmental Conservation 36: 289-300.

Serges, M.D., and Zachary, I., (2013). Korup National Park-Agro-Socio-Ecological Assessment Report for Erat. Ministry of Forestry and Wildlife, Buea, Cameroon.

Shively, G.E., (1997). Poverty, Technology, and Wildlife Hunting in Palawan. Environmental Conservation 24: 57-63.

Siewe, S., Vadjunec, J., and Caniglia, B., (2017). The politics of land use in the Korup National Park. Land 6: 7.

Tiani, A.M., and Diaw, M.C., (2006). Does resettlement contribute to conservation? The case of the Ikundu-kundu, Korup National Park, Cameroon. Policy Matters 14: 113-127.

Tourangeau, R., and Yan, T., (2007). Sensitive Questions in Surveys. Psychol. Bull. 133: 859. Tsuchiya, T., Hirai, Y., and Shigeru, O., (2007). A Study of the Properties of the Item Count Technique. Public Opinion Quarterly 71: 253-272.

Vasco, C., and Sirén, A., (2016). Correlates of Wildlife Hunting in Indigenous Communities in the Pastaza Province, Ecuadorian Amazonia. Animal Conservation 19: 422-429.

Warr, P., (2008). How Road Improvement Reduces Poverty: The Case of Laos. Agricultural Economics 39: 269-279. 
Warr, P., (2010). Roads and poverty in rural Laos: An Econometric Analysis. Pacific Economic Review 15: 152-169.

Weng, L., Klintuni Boedhihartono, A., Dirks, P., Dixon, J., Lubis, M.I., and Sayer, J.A., (2013). Mineral Industries, Growth Corridors and Agricultural Development in Africa. Global Food Security 2: 195-202.

Wicander, S., and Coad, L., (2014). Learning Our Lessons: A Review of Alternative Livelihood Projects in Central Africa. ECI, Oxford, UK. IUCN, Gland, Switzerland. University of Oxford, Oxford, UK.

Willcox, A.S., and Nambu, D.M., (2007). Wildlife Hunting Practices and Bushmeat Dynamics of the Banyangi and Mbo People of Southwestern Cameroon. Biological Conservation 134: 251-261.

Wright, J.H., and Priston, N.E.C., (2010). Hunting and Trapping in Lebialem Division, Cameroon: Bushmeat Harvesting Practices and Human Reliance. Endangered Species Research 11: 1-12. 


\subsection{Supplement}

Table S7.1 - Box questionnaire $(n=187)$ and face to face interview results $(n=143)$ in road villages $(2016)$ regarding percentage of respondents conducting a certain income-generating activity in Korup National Park, Cameroon.

\begin{tabular}{llllll}
\hline \multicolumn{7}{l}{ Number $(\boldsymbol{n})$ and percentage (\%) of respondents active in: } \\
\hline & Crop farming & Fishing & Hunting & NTFP $^{\mathbf{1}}$ & SEW $^{\mathbf{2}}$ \\
\hline Box & $185(99)$ & $113(60)$ & $64(60)$ & $147(79)$ & $73(39)$ \\
Face to face & $92(93)$ & $71(77)$ & $42(72)$ & $76(60)$ & $59(42)$ \\
\hline
\end{tabular}

${ }^{1}$ collection of non-timber forest products

${ }^{2}$ self-employment and wage labor

Table S7.2 - Demographic data of respondents (household (HH) head and spouse) in road villages and the control village in Korup National Park, Cameroon.

\begin{tabular}{lllll}
\hline & Road Villages & & \multicolumn{2}{l}{ Control Village } \\
& $\mathbf{2 0 1 5}$ & $\mathbf{2 0 1 6}$ & $\mathbf{2 0 1 5}$ & $\mathbf{2 0 1 6}$ \\
\hline Sampled HH & $14.4 \%$ & $44.6 \%$ & $27.8 \%$ & $52.8 \%$ \\
Mean HH size & 5 & 5.6 & 5.5 & 5.9 \\
& Korup (50\%) & Korup (49\%) & Bakoko (100\%) & Bakoko (100\%) \\
Ethnic groups & Bakoko (45\%) & Bakoko (51\%) & & \\
& Ejagham (5\%) & & $81 \%$ \\
Only Primary school education & $47.4 \%$ & $60 \%$ & $80 \%$ & $11 \%$ \\
Only Secondary school education & $13.2 \%$ & $21 \%$ & $0 \%$ & $3 \%$ \\
Higher education & $0 \%$ & $4 \%$ & $0 \%$ & $100 \%$ \\
Engagement in at least one & $100 \%$ & $100 \%$ & $100 \%$ & 3.0 \\
income-generating activity & 2.1 & 1.8 & 2.0 & 20.1 m \\
No. plots/HH & na & 13.2 m & na & $23.5 \%$ \\
Mean farm size/HH & $27.7 \%$ & $19.6 \%$ & $44.4 \%$ & $58.8 \%$ \\
Age HH head male $<30$ & $27.7 \%$ & $60.8 \%$ & $44.4 \%$ & $17.6 \%$ \\
Age HH head male 30 to 50 & $44.4 \%$ & $21.6 \%$ & $11.1 \%$ & \\
Age HH head male $>50$ & & & & \\
\hline
\end{tabular}




\section{PART V \\ OVERALl CONCLUSION}





\section{Chapter 8}

Synopsis

The results of this dissertation project enable a better understanding of biodiversity patterns and conservation values in Afrotropical agroforestry landscapes. Our results demonstrate that despite the long-term engagement of international conservation agencies, there is a strong negative population trend for threatened large mammal species in Southwest Cameroons protected areas. This negative trend is clearly attributed to an unsustainable hunting pressure on wildlife communities. The results from our critical habitat threshold analysis of bird guilds show that habitat quality is not only high inside Korup National Park but also in its surrounding agroforestry landscapes. However, abundancies of most mammal species only increase in higher distances to human settlements. Moreover, some species tend to prefer areas with rough terrain, where we detected significantly less hunting signs. Thus, distribution patterns of threatened large mammals are probably strongly shaped by poaching activities.

If our estimation holds true, there might have been a chimpanzee population decline of more than ninety percent in Banyang Mbo Wildlife Reserve. Both Korup and Banyang Mbo now harbour probably isolated chimpanzee populations of less than one hundred individuals. The same accounts for Korup National Parks elephants, for which we could not detect any active migration corridors to neighbouring protected areas during our surveys. Since their numbers are already too low, we also failed to detect any trends for rare primate species such as drill and red colobus. If current levels of hunting cannot be counteracted in near future, there is the risk of further local extinctions around but also inside the protected areas of Southwest Cameroon.

The predominance of hunting activity in some parts of the Korup area is also demonstrated in our household data. Particularly the villages inside the park were still highly engaged in hunting. However, the results from households in villages outside the park show that the total household income does not necessarily depend on hunting and might be replaced through other income activities. This has been supported by the findings of our study on household responses to road establishment in Esukutan and Erat, where park villagers started to engage more in wage labour and business activities. However, as roads might function as door openers to increased hunting, permanent eco-guard posts should soon be established in Erat and Esukutan. The further outcome of road access should be monitored in repeated impact surveys at a later stage. If the positive trend holds true, park management might consider approaching Ikenge village to renegotiate conservation agreements and a potential motorbike road construction.

Whereas we yielded diverging results on the ecological performance of agroforestry landscapes, our conclusions on ecological responses to industrial oil palm cultivation in our study region is unsurprisingly clear. Bird diversity and composition was significantly lower inside than outside the plantation area. Only parrots seemed to benefit from the plantation to a 
certain extent due to year-round supply with palm nuts. However, we never observed parrots roosting in the plantation area, indicating that their activity is limited to an opportunistic foraging behavior.

On the other hand, we would have expected to see some positive outcomes on the socioeconomic situation in plantation households compared to forest-depending ones. However, except for salaries are being paid on a monthly regular basis, we could not find any other positive indicator. Plantation households do not have more income compared to forestdepending households, but instead have to spend a much greater share on food items. In addition, they need to spend more time to generate same amount of income compared to forestdependent household. Therefore, we need to conclude that industrial oil palm cultivation is neither an ecologically nor socio-economically sustainable model for future development in Southwest Cameroonian landscapes. 


\section{PART VI}

APPENDICES 



\section{Declaration: Authorship and contributions}

Chapters 2 to 7 of this dissertation are research chapters, written as manuscripts for publication. Of those, chapters 2 and 6 are not yet published. My detailed contributions to each chapter were as follows:

For chapter 2, I partly contributed to study design, funding acquisition and project administration. I solely prepared data sets, performed statistical analysis and wrote the manuscript.

For chapter 3, I developed study design, methodology, collected data during field work, prepared data sets, was responsible for funding acquisition and project administration, performed statistical analysis, wrote most of the texts for the manuscript and supervised two masters students from the University of Göttingen.

For chapter 4, I developed study design, methodology, collected data during fieldwork, was responsible for funding acquisition and project administration, contributed to data preparation, statistical analysis and writing of the manuscript. I also supervised one masters student from the University of Göttingen.

For chapter 5, I contributed to study design, methodology, funding acquisition, project administration, did a significant amount of writing as well as editing and supervised one masters student from the University of Göttingen.

For chapter 6, I developed study design, methodology, collected data during field work, prepared data sets, was responsible for funding acquisition and project administration, performed statistical analysis, wrote the manuscript, and supervised one masters student from the University of Göttingen.

For chapter 7, I substantially contributed to study design, methodology, data collection during field work, data preparation and writing of the manuscript. I was responsible for funding acquisition and project administration. I also supervised one masters student from the University of Göttingen.

Consequently, I am the first author of the manuscripts included as chapters 2, 3 and 6 and second author of the manuscripts included as chapters 4,5 and 7 . Chapters 4 and 7 were published with an authorship order following the 'sequence-determines-credit' approach (see also Tscharntke et al., 2007, PLoS Biol. 5: e18). 


\section{Acknowledgements}

This project was supported by a $\mathrm{PhD}$ scholarship from the Heinrich-Böll Foundation. Furthermore, WWF Germany, Greenpeace International, the Volkswagen Foundation, the Gesellschaft für Tropenornithologie e.V., and the Programme for the Sustainable Management of Natural Resources, South-West Region (PSMNR-SWR) provided funding for data collection in Cameroon.

The Ministry of Forestry and Wildlife, the Ministry of Research and Scientific Innovation, the management of Korup National Park and the management of PAMOL Plantations Plc. provided permissions to conduct field research.

I am grateful to Matthias Waltert, Gerhard Gerold, Eckhard Heymann and Ulrich Brose for commitment in my thesis advisory committee and their support to meet all requirements of the $\mathrm{PhD}$ programme.

I am greatly indebted to Daniel Awoh, Blessed Ngoe, Motale Trevor and Njie Francis for sharing their knowledge and experience during field work and village meetings in Cameroon. Without their dedicated and patient advice I would have been lost and only their enthusiastic support enabled me to accomplish this work. I would also like to thank Wilson Chokeni, Libalah Moses, Mambo Peter, Nganga Lionel and Betobe Nelson for their essential support and expertise in the field. I am grateful to the Korup Rainforest Conservation Society (KRCS) and its members, in particular Orume Robinson, Sumbede Anthoine and Mosaki Emmanuel, for providing indispensable logistic support and advice prior to and during each field period. I am also thankful for the hospitality of my landlady and landlord in Mundemba, Solice and Linus Arong.

I am grateful to Joshua Linder who significantly influenced my decision to start this project by sharing his enthusiasm for Korup forest, inviting me for a first field trip to Korup National Park and providing contacts as well as equipment in Cameroon. I also want to thank Oemar Idoe who helped me get along during my first stay in Mundemba and shared highly valuable insights into Cameroonian conservation and development politics. I am also obliged to Christos Astaras and Kadiri Serge Bobo for giving advice and sharing data.

I want to thank Kelly Boekee for many fruitful discussions on field research and conservation management, but also for providing logistic support whenever needed, including cold beer and kind of luxurious accommodation in Limbe.

I am sincerely grateful to the people of Mundemba and its surrounding area for the hospitality, optimism and cheerfulness they willingly shared with me during all these years. I am utterly glad to have met and made friends with so many interesting personalities in this small town in 
the forest. Also in future, I will do my utmost to be able to return to this place for regular visits and hopefully new projects.

My gratitude goes to the people of Ikondo kondo I, Fabe, Lipenja I, Mokango, Massaka, Ikenge, Esukutan, Bera, Mofako and Erat villages as well as the inhabitants of the PAMOL camps Mundemba, Ikassa, Center A and Mana for their welcoming attitude and cooperation during my field research.

I want to acknowledge the good cooperation, successful work and enjoyable company of all the master students during field work in Cameroon. My particular thanks go to Elleni Vendras and Luisa Knobloch for countless hours we spent together talking as well as enjoying life in the villages and in Mundemba.

I want to thank my colleagues at the conservation workgroup at the University of Göttingen for sharing coffee or beer when it was needed.

Lastly and most importantly, my greatest thanks go to my parents and brothers as well as my friends, Stefan Tiepner, Pia Gremmer, Tobias Wommelsdorf and Ulrike Bock, for their continuous support, understanding, motivation and patient endurance during the time that I have spent working on my dissertation. 


\section{Curriculum Vitae}

Denis Kupsch, born on 2 February 1984 in Magdeburg, Germany

\section{Professional experience}

Academic

2014-2018 Research and teaching assistant, Workgroup on Endangered Species, Georg-August-Universität, Göttingen (GAUG)

2017-2018

Research assistant, Department of Agricultural Economics and Rural Development, GAUG

2012-2013

Research assistant, Department of Conservation Biology, GAUG

2009-2010

Student assistant, Department of Earth Sciences, Friedrich-Schiller-

Universität, Jena

Non-academic

Since 2019 Executive director and coordinator of the Earth Charter Initiative in Germany, Ökumenische Initiative Eine Welt e.V., Diemelstadt-Wethen

Main trainer wildlife assessment and project management, WWF

Education for Nature Programme, consultancy for Korup Rainforest

Conservation Society (NGO), Southwest Cameroon

HCV assessment for UNIQUE forestry and land use GmbH, Freiburg im Breisgau, MIRO forestry concession Tonkolili Sierra Leone

2013-2014

Biodiversity assessment for WWF Germany and Greenpeace International, Herakles Farm oil palm concession Southwest Cameroon

2011-2012 GIS officer, Wette \& Gödecke Landscape Planning GbR, Göttingen

$2005 \& 2009$

2003 Internship, White Oryx Reintroduction Programme, Hai Bar Nature Reserve, Israel Internship, BUND Friends of the Earth head office, Magdeburg

\section{Education}

2013-2019

Doctoral studies in 'Biodiversity and Ecology', GAUG

2009-2011

Master of Science in 'Biodiversity and Ecology', GAUG

2003-2009

Diplom-Ingenieur (FH) in 'Nature Conservation and Landscape Planning', Anhalt University of Applied Sciences, Bernburg 


\section{Publications (peer-reviewed)}

Ocampo-Ariza C, Kupsch D, Motombi FN, Bobo KS, Kreft H \& Waltert M (2019). Extinction thresholds and negative responses of Afrotropical ant-following birds to forest cover loss in oil palm and agroforestry landscapes. Basic and Applied Ecology 39: $26-37$.

Heymann EW, Culot L, Knogge C, Smith AC, Herrera ERT, Müller, Stojan-Dolar M, Ferrer YL, Kubisch P, Kupsch D, Slana D, Koopmann ML, Ziegenhagen B, Bialozyt R, Mengel C, Hambuckers J \& Heer K (2019). Small Neotropical primates promote the natural regeneration of anthropogenically disturbed areas. Scientific Reports 9: 10356.

Düker S, Kupsch D, Bobo KS, Heymann EW \& Waltert M (2019). Congo Grey Parrot Psittacus erithacus densities in oil palm plantation, agroforestry mosaic and protected forest in Southwest Cameroon. online. Bird Conservation International.

Spey I-K, Kupsch D, Bobo KS, Waltert M \& Schwarze S (2019). The Effects of Road Access on Income Generation. Evidence from an integrated conservation and development project in Cameroon. Sustainability 11: 3368.

Kupsch D, Vendras E, Ocampo-Ariza C, Batáry P, Motombi FN, Bobo KS \& Waltert M (2019). High critical forest habitat thresholds of native bird communities in Afrotropical agroforestry landscapes. Biological Conservation 230: 20-28.

Kupsch D, Waltert M \& Heymann EW (2014). Forest type affects foraging of saddleback tamarins, Saguinus nigrifrons. Primates 55: 403-413.

\section{Contributions to conferences (selected)}

Kupsch D, Vendras E, Njie F, Bobo KS \& Waltert M (2017). Forest bird conservation in African agroforestry matrices: How much forest is necessary? Oral presentation. 28th International Congress for Conservation Biology (ICCB). Cartagena, July 23.-27.

Kupsch D, Bobo KS \& Waltert M (2015). Evaluating wildlife conservation strategies in West African rainforests. Oral presentation. 27th ICCB. Montpellier, August 2.-6.

Kupsch D, Waltert M \& Heymann EW (2013). Do secondary forests serve as suitable prey foraging habitats for saddleback tamarins (Saguinus nigrifrons)? Oral presentation. 43rd Annual meeting of the Ecological Society of Germany, Austria and Switzerland. Potsdam, September 09.-13.

Kupsch D, Bobo KS, Linder J \& Waltert M (2013). Oil palm development jeopardizes exceptional biodiversity and rural agroforestry systems in Southwest Cameroon. Oral presentation. Annual Conference of the Society for Tropical Ecology. Vienna, April 02.-05. 